\title{
A spectral line survey of Orion $K L$ in the bands 486-492 and 541-577 GHz with the Odin ${ }^{\star}$ satellite ${ }^{\star \star}$
}

\section{Data analysis}

\author{
C. M. Persson ${ }^{1}$, A. O. H. Olofsson ${ }^{1,2}$, N. Koning ${ }^{3}$, P. Bergman ${ }^{1,4}$, P. Bernath ${ }^{5,6,7}$, J. H. Black ${ }^{1}$, U. Frisk ${ }^{8}$,
}

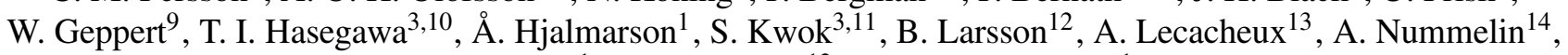
M. Olberg ${ }^{1}$, Aa. Sandqvist ${ }^{12}$, and E. S. Wirström ${ }^{1}$

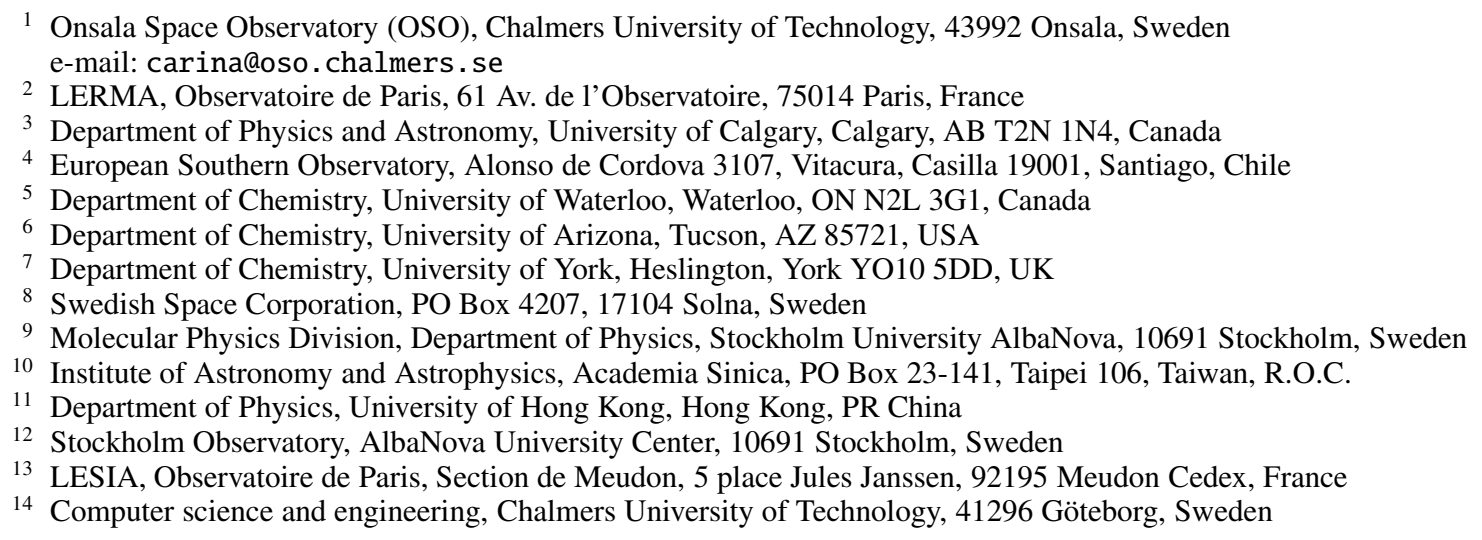

Received 2 February 2007 / Accepted 17 September 2007

\section{ABSTRACT}

\begin{abstract}
Aims. We investigate the physical and chemical conditions in a typical star forming region, including an unbiased search for new molecules in a spectral region previously unobserved.

Methods. Due to its proximity, the Orion KL region offers a unique laboratory of molecular astrophysics in a chemically rich, massive star forming region. Several ground-based spectral line surveys have been made, but due to the absorption by water and oxygen, the terrestrial atmosphere is completely opaque at frequencies around 487 and $557 \mathrm{GHz}$. To cover these frequencies we used the Odin satellite to perform a spectral line survey in the frequency ranges $486-492 \mathrm{GHz}$ and $541-577 \mathrm{GHz}$, filling the gaps between previous spectral scans. Odin's high main beam efficiency, $\eta_{\mathrm{mb}}=0.9$, and observations performed outside the atmosphere make our intensity scale very well determined.

Results. We observed 280 spectral lines from 38 molecules including isotopologues, and, in addition, 64 unidentified lines. A few $\mathrm{U}$-lines have interesting frequency coincidences such as $\mathrm{ND}$ and the anion $\mathrm{SH}^{-}$. The beam-averaged emission is dominated by $\mathrm{CO}$, $\mathrm{H}_{2} \mathrm{O}, \mathrm{SO}_{2}, \mathrm{SO},{ }^{13} \mathrm{CO}$ and $\mathrm{CH}_{3} \mathrm{OH}$. Species with the largest number of lines are $\mathrm{CH}_{3} \mathrm{OH},\left(\mathrm{CH}_{3}\right)_{2} \mathrm{O}, \mathrm{SO}_{2},{ }^{13} \mathrm{CH}_{3} \mathrm{OH}, \mathrm{CH}_{3} \mathrm{CN}$ and NO. Six water lines are detected including the ground state rotational transition $1_{1,0}-1_{0,1}$ of $o-\mathrm{H}_{2} \mathrm{O}$, its isotopologues $o-\mathrm{H}_{2}^{18} \mathrm{O}$ and $o-\mathrm{H}_{2}^{17} \mathrm{O}$, the Hot Core tracing $p-\mathrm{H}_{2} \mathrm{O}$ transition $6_{2,4}-7_{1,7}$, and the $2_{0,2}-1_{1,1}$ transition of HDO. Other lines of special interest are the $1_{0}-0_{0}$ transition of $\mathrm{NH}_{3}$ and its isotopologue ${ }^{15} \mathrm{NH}_{3}$. Isotopologue abundance ratios of $\mathrm{D} / \mathrm{H},{ }^{12} \mathrm{C} /{ }^{13} \mathrm{C},{ }^{32} \mathrm{~S} /{ }^{34} \mathrm{~S},{ }^{34} \mathrm{~S} /{ }^{33} \mathrm{~S}$, and ${ }^{18} \mathrm{O} /{ }^{17} \mathrm{O}$ are estimated. The temperatures, column densities and abundances in the various subregions are estimated, and we find very high gas-phase abundances of $\mathrm{H}_{2} \mathrm{O}, \mathrm{NH}_{3}, \mathrm{SO}_{2}, \mathrm{SO}, \mathrm{NO}$, and $\mathrm{CH}_{3} \mathrm{OH}$. A comparison with the ice inventory of ISO sheds new light on the origin of the abundant gas-phase molecules.
\end{abstract}

Key words. ISM: abundances - ISM: individual objects: Orion KL - ISM: molecules - line: formation - line: identification submillimeter

* Odin is a Swedish-led satellite project funded jointly by the Swedish National Space Board (SNSB), the Canadian Space Agency (CSA), the National Technology Agency of Finland (Tekes) and Centre National d'Etudes Spatiales (CNES). The Swedish Space Corporation was the prime contractor and also is responsible for the satellite operation.

$\star \star$ Section 10, Figs. 25-47 and Tables 5-35 are only available in electronic form at http://www. aanda.org

\section{Introduction}

To study the important ground-state rotational transition of water (including isotopologues), which traces shocks and heated star forming regions, is one of the main astronomy goals of the Odin satellite (Nordh et al. 2003, and subsequent papers in the A\&A "Special Letters Edition: First Science with the Odin satellite") and hence also of this spectral line survey towards the Orion KL region. The first observations of this water line were performed by SWAS in 1998 (NASA's Submillimeter Wave Astronomy 
Satellite; Melnick et al. 2000 and subsequent ApJ papers in that issue). The Odin satellite provides a smaller beam than SWAS $\left(2.1^{\prime}\right.$ vs. $\left.3.3^{\prime} \times 4.5^{\prime}\right)$, and our tunable SSB receivers enable a full line survey in this spectral window, including the water isotopologues $\left(\mathrm{H}_{2}^{16} \mathrm{O}, \mathrm{H}_{2}^{17} \mathrm{O}, \mathrm{H}_{2}^{18} \mathrm{O}\right.$ and $\left.\mathrm{HDO}\right)$, and a high energy $p-\mathrm{H}_{2} \mathrm{O}$ transition.

A spectral scan offers an unbiased search for new molecules. It also creates opportunities to observe multiple transitions of the same species as a uniformly calibrated data set, and this can be used to calculate rotation temperatures, column densities, abundances, source sizes, optical depths, and isotopic elemental abundance ratios of the observed gases. The latter are important constraints for models of the Galactic chemical evolution. These models predict the elemental abundance evolution as a function of star formation history, stellar nucleosynthesis, and the degree of mixing of the gas in the ISM (Wilson \& Rood 1994).

The Orion Molecular Cloud (OMC-1) is a well known massive star forming region (see Genzel \& Stutzki 1989, for a review), and an ideal target for spectral line surveys at millimetre and submillimetre wavelengths due to its chemical richness and proximity $(\sim 450 \mathrm{pc})$. The Kleinmann-Low nebula (Orion KL) is the brightest infrared region in the OMC- 1 and is situated about $1^{\prime} \mathrm{NW}$ of the Trapezium cluster. This region enables studies of the interaction between young massive stars and their parental molecular cloud. Powerful outflows, shocks and turbulence cause a very complex and chemically structured source, consisting of several distinct subsources.

There are five different components of radial velocity (e.g. Olofsson et al. 1981; Olofsson et al. 1982; Johansson et al. 1984; Friberg 1984; Genzel \& Stutzki 1989; Wright et al. 1996; Schilke et al. 2001; Beuther et al. 2005; Olofsson et al. 2007, hereafter Paper I) within the $\sim 126^{\prime \prime}$ Odin beam:

- The ambient medium/Extended Ridge (ER) with $v_{\mathrm{LSR}} \sim$ $8 \mathrm{~km} \mathrm{~s}^{-1}$ in the south and an abrupt velocity shift across the $\mathrm{KL}$ region to $v_{\mathrm{LSR}} \sim 10 \mathrm{~km} \mathrm{~s}^{-1}$ in the north. This extended emission is larger than our beam with quiescent, cool gas of narrow line widths of $\Delta v \sim 3-5 \mathrm{~km} \mathrm{~s}^{-1}$, a temperature of $\sim 20-60 \mathrm{~K}$, and densities of $10^{4}-10^{6} \mathrm{~cm}^{-3}$.

- The Plateau: the out-flowing gas, centred close to IRc2 contains two outflows (Greenhill et al. 1998). The bipolar High Velocity Flow (HVF) in the SE-NW direction at $v_{\text {LSR }} \sim 10 \mathrm{~km} \mathrm{~s}^{-1}$ reaches velocities of $150 \mathrm{~km} \mathrm{~s}^{-1}$ and covers 40-70". The second is a Low Velocity Flow (LVF) in the SW-NE direction at $v_{\mathrm{LSR}} \sim 5 \mathrm{~km} \mathrm{~s}^{-1}$, widths of $\sim 18 \mathrm{~km} \mathrm{~s}^{-1}$ ("the $18 \mathrm{~km} \mathrm{~s}^{-1}$ flow", Genzel et al. 1981), and a size of $15-30^{\prime \prime}$. The temperature and density are $100-150 \mathrm{~K}$ and $\sim 10^{5} \mathrm{~cm}^{-3}$, respectively.

- The Compact Ridge (CR): a compact warm clump in the northern tip of the southern ER was first discovered by Johansson et al. (1984), approximately 10-15" southwest of IRc2 with $v_{\text {LSR }} \sim 8 \mathrm{~km} \mathrm{~s}^{-1}$, and line widths of $\Delta v \sim 3 \mathrm{~km} \mathrm{~s}^{-1}$. It may be the result of an interaction between the LVF and the ER that compressed the gas to higher densities $\sim 10^{6} \mathrm{~cm}^{-3}$, temperatures of $100-150 \mathrm{~K}$, and to a small size of $6-15^{\prime \prime}$.

- The Hot Core (HC): a warm star forming region which is heated internally, probably by one (or more) young massive protostars. The total size is $\sim 5-10^{\prime \prime}$ (Hermsen et al. 1988a; Wilson et al. 2000) with smaller, very dense $\left(n \sim 10^{7} \mathrm{~cm}^{-3}\right)$ clumps (Beuther et al. 2005). It is centred only $2^{\prime \prime}$ from IRc2, at a projected distance of $10^{\prime \prime}$ from the CR. The velocity is centred on $v_{\text {LSR }} \sim 3-6 \mathrm{~km} \mathrm{~s}^{-1}$ with line widths of $\Delta v \sim 5-15 \mathrm{~km} \mathrm{~s}^{-1}$. The range of temperatures obtained from inversion transitions of $\mathrm{NH}_{3}$ is $165-400 \mathrm{~K}$ (Wilson et al. 2000).

- Photo Dissociation Region (PDR): the extended interface region between the molecular cloud and the foreground M42 HII region (Rodríguez-Franco et al. 1998, 2001; Wirström et al. 2006, and references therein) at velocities $8-10 \mathrm{~km} \mathrm{~s}^{-1}$.

The various cloud components have been displayed in Fig. 6 of Genzel \& Stutzki (1989), and Fig. 7 of Irvine et al. (1987). Figure 1 of Greenhill et al. (1998) shows a model of the bipolar High Velocity Flow and the Low Velocity Flow.

The Odin satellite has a large beam and covers high frequencies. This gives our survey the opportunity to simultaneously observe both the small, hot and dense regions, and the extended, cooler regions. Because of the complex source structure encompassed by our large antenna beam, we will compare our data with interferometric images for each species (see Paper I for an extensive list of spectral line survey references). In this way the origin and source sizes of our detected species can be checked.

The complete submm spectrum observed by Odin together with the proposed identification of each line can be found in Paper I. In the present paper we give a short description of our data in Sect. 2, and of the different analysis methods in Sect. 3. In Sect. 4 we present the results in tables and rotation diagrams together with spectra of typical or particularly important transitions. Tables of observed transitions can be found as electronic Tables in the online material (Tables 9 to 33). Tables 34 and 35 list our unidentified and tentatively identified lines. Section 4 also includes a short analysis for each molecule. The important water and CO lines are analysed in Sects. 5 and 6. An attempt to obtain molecular abundances in the different subregions of Orion KL and comparison with abundances in ice mantles of dust grains is found in Sect. 7. We end this paper with a discussion of source sizes and source structure in Sect. 8 , followed by a short summary.

\section{The line survey data}

The observational method is presented in Paper I, and the data is analysed in this paper. These data were obtained with the Odin satellite from spring 2004 to autumn 2005 during four different runs. The spectral scan covers frequencies between 486-492 and $541-577 \mathrm{GHz}$ and includes 280 spectral features from 38 species including isotopologues. The lines were identified using the Lovas SLAIM $\emptyset 3$ molecular line catalogue ${ }^{1}$ (Lovas 2003), the Cologne Database for Molecular Spectroscopy ${ }^{2}$ (CDMS, Müller et al. 2001) and the Jet Propulsion Laboratory ${ }^{3}$ database (JPL, Pickett et al. 1998). Identifications are based not only on frequency coincidence, but also expected abundance, line strength, width and velocity, upper state energy, and the presence of other expected transitions of the molecule.

Most lines in our survey (205 out of 280 identified lines) are due to $\mathrm{CH}_{3} \mathrm{OH},{ }^{13} \mathrm{CH}_{3} \mathrm{OH},\left(\mathrm{CH}_{3}\right)_{2} \mathrm{O}, \mathrm{SO}_{2}$, and $\mathrm{CH}_{3} \mathrm{CN}$ (Table 5, online material). A total of 64 lines (19\% of all lines) could not be uniquely identified, although from frequency coincidences we have suggestions for a few identifications such as ND, the interstellar anion $\mathrm{SH}^{-}, \mathrm{SO}^{+}, \mathrm{HNCO}$ and $\mathrm{CH}_{3} \mathrm{OCHO}$ (see Sect. 4 and Paper I). The spectroscopy still is sparse at higher frequencies

\footnotetext{
1 Not available online, but some of its content is maintained under http://physics.nist.gov/PhysRefData/

2 http://wwW.cdms.de

3 http://spec.jpl.nasa.gov/
} 
and a number of U-lines are likely to be poorly known transitions of the identified molecules and their isotopologues, including their vibrationally or torsionally excited states.

At $557 \mathrm{GHz}$ the Odin $1.1 \mathrm{~m}$ mirror has a circular beam with FWHM of $2 ! 1$. The main beam efficiency is $\eta_{\mathrm{mb}}=0.9$. This in addition to being outside the atmosphere makes our intensity calibration very accurate. The intensity scale is expressed in terms of antenna temperature $T_{\mathrm{A}}^{*}$. In all calculations of the column densities the main beam efficiency is properly taken into account. The reconstructed pointing uncertainty is $<15^{\prime \prime}$ during most of the time. The coordinates of Orion KL in our survey are RA $05^{\mathrm{h}} 35^{\mathrm{m}} 14^{\mathrm{s}} .36$, Dec $-05^{\circ} 22^{\prime} 29^{\prime \prime} 6$ (J2000), and the frequency scale is set in relation to a source LSR velocity of $+8 \mathrm{~km} \mathrm{~s}^{-1}$. The spectral resolution is $1 \mathrm{MHz}$, and the typical $\mathrm{rms}$ reached is $\sim 25 \mathrm{mK}$ per $1 \mathrm{MHz}$ channel.

\section{Data analysis methods - a simplified approach}

The observed line emission is not restricted to one single subregion in Orion KL, but may be a complicated blend from several subregions with a complex line profile. Thus, when we attempt to derive column densities and abundances, we have to separate the emission into its constituent parts. The most simple approach whenever several emission features are clearly present, is to use least-square fits of Gaussians to the line profiles to separate their relative contributions. This can give a first order input to modelling attempts including current and future knowledge of the source structure. The resulting parameters are found in the online tables and in fitted spectra (Sect. 4). This is based on the assumptions that either all emissions are optically thin or that the emission subregions do not overlap each other spatially, and also that the velocity distributions are Gaussian.

The formal errors obtained from the rotation diagram method and forward model are given in each subsection. The formal errors obtained from the single line analysis and from the Gaussian decomposition of the lines are mostly below $20 \%$, with weak lines having higher formal errors. We estimate the accuracy of our column densities results to be within a factor of $2-3$. The uncertainties in the derived abundances can be higher because the adopted $\mathrm{H}_{2}$ column density is also uncertain (see also Sect. 7). Details, definitions and additional uncertainties of the methods not discussed below are found in the online Sect. 10.

\subsection{Single line analysis}

With the assumption of optically thin emission, neglecting the background radiation, and assuming that the source fills the antenna main beam, the beam averaged upper state column density can be calculated as

$N_{\mathrm{u}}^{\mathrm{thin}}=\frac{8 \pi k v_{\mathrm{u} l}^{2}}{h c^{3}} \frac{1}{A_{\mathrm{u} l}} \int T_{\mathrm{mb}} \mathrm{d} v$,

where $k$ is the Boltzmann constant, $v_{\mathrm{u} l}$ is the frequency of the transition, $h$ is the Planck constant, $c$ is the speed of light, $A_{\mathrm{u} l}$ is the Einstein $A$-coefficient for the transition, and $T_{\mathrm{mb}}$ is the main beam brightness temperature. As customary the frequency $v$ has been converted to a Doppler velocity $v$.

For a Boltzmann distribution, and with corrections for opacity and beam-filling, the true total source-averaged column density can be calculated as

$N_{\mathrm{LTE}}=\frac{C_{\tau}}{\eta_{\mathrm{bf}}} \frac{8 \pi k v_{\mathrm{u} l}^{2}}{h c^{3}} \frac{1}{A_{\mathrm{u} l}} \frac{Q(T)}{g_{\mathrm{u}}} \mathrm{e}^{E_{\mathrm{u}} / k T_{\mathrm{ex}}} \int T_{\mathrm{mb}} \mathrm{d} v$, where $C_{\tau}$ and $\eta_{\mathrm{bf}}$ are the opacity and beam-filling correction factors, $Q(T)$ is the partition function, $g_{u}$ and $E_{u}$ are the statistical weight and energy of the upper state, respectively, and $T_{\mathrm{ex}}$ is the excitation temperature for the transition.

For molecules where one or few transitions are observed, the column density is calculated using Eq. (2). If no information about optical depth or source-size is available these corrections are not taken into account, thus producing a beam-averaged and not opacity corrected column density.

\subsection{Multiple line analysis}

\subsubsection{The rotation diagram method}

When we have observed a number of lines with a wide range of upper-state energies, the rotation diagram method can be used according to

$\ln \frac{N_{\mathrm{u}}^{\text {thin }}}{g_{\mathrm{u}}}=\ln \frac{N_{\mathrm{tot}}}{Q(T)}-\frac{E_{\mathrm{u}}}{k T_{\mathrm{ex}}}$.

To create a rotation diagram we plot $\ln \left(N_{\mathrm{u}}^{\text {thin }} / g_{\mathrm{u}}\right)$ as a function of the upper state energy $E_{\mathrm{u}}$ in a semi-log plot. A least squares fit to the data will then produce a straight line with slope $-1 / T_{\text {ROT. }}$. If we extrapolate the line to $E_{\mathrm{u}}=0 \mathrm{~K}$, we obtain the total column density from the intersection of the $y$-axis, $y_{0}$, and derive the total column density as

$N_{\mathrm{ROT}}=Q(T) \mathrm{e}^{y_{0}}$.

To correct for beam-filling, the right hand side of Eq. (4) is multiplied by $1 / \eta_{\text {bf }}$. Note that this constant does not change the rotation temperature. However, the optical depths can change the slope, and therefore the rotation temperature estimated from the rotation diagram.

The error bars shown in our rotation diagrams (Sect. 4) include $10 \%$ calibration error and the observed rms-noise.

\subsubsection{The forward model ( $\chi^{2}$-method)}

This model matches calculated opacity-corrected LTE integrated intensities and beam-filling in a $\chi^{2}$ sense, to observed intensities vs. $E_{\mathrm{u}}$ (Nummelin et al. 1998; Nummelin et al. 2000; Lampton et al. 1976; Bevington 1969). Equation (3) in this case is modified to include optical depth and beam-filling corrections

$\ln \frac{N_{\mathrm{u}}}{g_{\mathrm{u}}}+\ln C_{\tau}+\ln \frac{1}{\eta_{\mathrm{bf}}}=\ln \frac{N_{\mathrm{tot}}}{Q(T)}-\frac{E_{\mathrm{u}}}{k T_{\mathrm{ex}}}$.

The intensity of each transition can be calculated using Eq. (12), with a specific set of free parameters $\eta_{\text {bf }}, T_{\text {ROT }}$ and $N_{\text {tot }}$. The best fit to all the data, is obtained by finding the minimum of the reduced $\chi^{2}$, which is defined as

$\chi^{2}=\frac{1}{n-p} \sum_{i=1}^{n}\left(\frac{I_{i}^{\mathrm{obs}}-I_{i}^{\mathrm{calc}}}{\sigma_{i}^{\mathrm{obs}}}\right)^{2}$

Here $n$ is the number of data points, $p$ is the number of free parameters, $\sigma_{i}^{\text {obs }}$ is the $1 \sigma$ uncertainty of the observed line intensity, $I_{i}^{\text {obs }}$ and $I_{i}^{\text {calc }}$ are the observed and calculated integrated intensities.

Note that the column density obtained with this method will be somewhat lower than that calculated from a simple rotation 
diagram, since solutions producing $I_{i}^{\text {calc }}<I_{i}^{\text {obs }}$ are favoured compared to the opposite. This can be seen from the contribution to the $\chi^{2}$-value from each transition giving $\chi_{i}^{2}$.

$\chi_{i}^{2}=\left(\frac{I_{i}^{\mathrm{obs}}-I_{i}^{\mathrm{calc}}}{\sigma_{i}^{\mathrm{obs}}}\right)^{2} \rightarrow\left(\frac{I_{i}^{\mathrm{obs}}}{\sigma_{i}^{\mathrm{obs}}}\right)^{2}$

when $I_{i}^{\text {calc }} \rightarrow 0$. But if $I_{i}^{\text {calc }}>I_{i}^{\text {obs }}, \chi^{2}$ will be unlimited, and this favours the lower model intensities (Nummelin et al. 1998).

\section{Results}

A summary of the observed features for all the species is presented in the online Table 5; the number of observed lines, the range in upper state energy, and the total integrated intensity.

A mean line-to-continuum ratio of 0.2 is reported in Paper I. The largest emission comes from CO with approximately $45 \%$ of the total spectral line emission. The second strongest emitter is $\mathrm{H}_{2} \mathrm{O}(13 \%)$, followed by $\mathrm{SO}_{2}(10 \%), \mathrm{SO}(7 \%),{ }^{13} \mathrm{CO}(7 \%)$ and $\mathrm{CH}_{3} \mathrm{OH}(4 \%)$. The remaining species emit $\sim 14 \%$ of the total. However, these are beam-average values. Since the sizes of the $\mathrm{SO}_{2}$, SO and $\mathrm{CH}_{3} \mathrm{OH}$ emitting regions are much smaller than the extended $\mathrm{CO}$ emission, the relative amount of emission will change with a smaller beam, and will in addition not be the same for the different subregions.

The resulting column densities and rotation temperatures are shown in Tables 1 and 2, together with results from the groundbased submillimetre spectral scans by White et al. (2003, hereafter W03) from 455 to $507 \mathrm{GHz}$, Schilke et al. (2001, hereafter S01) from 607 to 725 GHZ, and Comito et al. (2005, hereafter C05) from 795 to $903 \mathrm{GHz}$. The number of lines used in our calculations are listed in parenthesis after the species in Table 1.

Differences may arise between the comparison surveys and ours due to the different beam-fillings. The comparison surveys W03 and S01 mostly use beam-averaged (with HPBW of $10^{\prime \prime}-12^{\prime \prime}$ ) and not opacity-corrected column densities, while our results are corrected for beam-filling and optical depth, when possible. A second source of discrepancy is our effort to separate the emissions from different subregions, while the column densities in the comparison surveys are calculated from the total integrated intensity. Most of our column densities have therefore been calculated using the total integrated intensity and a source size of the main emitting component as a first approximation and comparison to S01 and W03. The column densities for the different subregions, are also calculated when possible, and have been corrected for opacity (if known) and beam-filling. In C05 beam-filling and optical depth correction are taken into account as well as separation into different subregions.

The listed source sizes are either calculated with Eq. (12), the $\chi^{2}$-method, or taken from the literature. The size of the ER is assumed to be larger than our beam, although the East-West extent of the molecular ridge is rather limited (cf. Goldsmith et al. 1997). As excitation temperatures we use the population distribution temperatures $T_{\text {ROT }}$ obtained from rotation diagrams. These temperatures are also used for species with similar excitation conditions. If no similar species exist, the temperatures are assumed to have the typical value for the emitting region: $100 \mathrm{~K}$ for the LVF, HVF and PDR, $60 \mathrm{~K}$ for the ER, $115 \mathrm{~K}$ for the $\mathrm{CR}$, and $200 \mathrm{~K}$ for the $\mathrm{HC}$. The rotation diagram technique as well as the forward model have been applied to all species that have a broad upper state energy range and four lines or more; $\mathrm{SO}_{2},{ }^{34} \mathrm{SO}_{2}, \mathrm{SO}, \mathrm{CH}_{3} \mathrm{CN}, \mathrm{CH}_{3} \mathrm{OH},{ }^{13} \mathrm{CH}_{3} \mathrm{OH}$, $\mathrm{H}_{2} \mathrm{CS}$, and $\mathrm{CH}_{3} \mathrm{OCH}_{3}$; to calculate $N_{\mathrm{ROT}}$ and $N_{\chi^{2}}$. Only in the methanol case, the forward model directly leads to a beam-filling and hence a source size. For the other species it was impossible to discriminate between solutions for different beam size/optical depth combinations.

In the online Table 6 our estimated isotopologue abundance ratios are listed, as well as comparisons with several other studies.

\subsection{Outflow molecules}

Sulphur-bearing species are considered to be tracers of massive outflows from a newly formed star. The high temperatures caused by the intense radiation from the driving source, or by shocks, can enhance the production of $\mathrm{SO}_{2}, \mathrm{SO}$ and $\mathrm{SiO}$. The line profile of the outflow shows a characteristic triangular line shape with broad wings as seen in examples of SO in Fig. 27, $\mathrm{SiO}$ in Fig. 28, $\mathrm{SO}_{2}$ in Fig. 29, and in a comparison of $\mathrm{SO}_{2}$ and SO in Fig. 41 (online material). The Orion outflows are also traced by other molecules like $\mathrm{H}_{2} \mathrm{O}$ and $\mathrm{CO}$ : see Sects. 5 and 6, where also comparisons of $\mathrm{H}_{2}^{18} \mathrm{O}$, $\mathrm{SO}$ and $\mathrm{SO}_{2}$ are shown.

\subsubsection{Sulphur dioxide $\left(\mathrm{SO}_{2} /{ }^{34} \mathrm{SO}_{2}\right)$}

We have observed $42 \mathrm{SO}_{2}$, and five ${ }^{34} \mathrm{SO}_{2}$ transitions. Typical line profiles are shown in Fig. 29 (online material) with different upper state energies. As proposed by Johansson et al. (1984) the complicated $\mathrm{SO}_{2}$ and isotopologue line shapes suggest the presence of at least two velocity components, even though the emission primarily occurs in the outflow. Figure 1 shows a threecomponent Gaussian fit of a typical $\mathrm{SO}_{2}$ line with line widths of $\sim 5 \mathrm{~km} \mathrm{~s}^{-1}, 18 \mathrm{~km} \mathrm{~s}^{-1}$ and $35 \mathrm{~km} \mathrm{~s}^{-1}$ from the CR, LVF and HVF, respectively. This is very similar to the Gaussian components of $\mathrm{SO}$ (Fig. 2), $\mathrm{SiO}$ (Fig. 3), and $\mathrm{H}_{2}^{18} \mathrm{O}$ (Fig. 36).

Figure 42 (online material) shows the size of the $\mathrm{SO}_{2}$ emitting region vs. energy for each transition (Eq. (12)). The mean size is found to be $8^{\prime \prime}$, which is consistent with the aperture synthesis mapping of Wright et al. (1996). This size is used for beam-filling corrections.

The high line density and the broadness of the $\mathrm{SO}_{2}$ lines result in blends between the numerous transitions as well as with other species. There are $31 \mathrm{SO}_{2}$ transitions and four ${ }^{34} \mathrm{SO}_{2}$ transitions without blends, which are used in a rotation diagram shown in Fig. 43 (online material) producing $N_{\mathrm{ROT}}=(3.9 \pm$ $0.6) \times 10^{17} \mathrm{~cm}^{-2}, T_{\mathrm{ROT}}=(132 \pm 8) \mathrm{K}$ and $N_{\mathrm{ROT}}=(5.4 \pm 2.0) \times$ $10^{16} \mathrm{~cm}^{-2}, T_{\mathrm{ROT}}=125 \pm 30 \mathrm{~K}$ for $\mathrm{SO}_{2}$ and ${ }^{34} \mathrm{SO}_{2}$, respectively.

However, almost all of the $\mathrm{SO}_{2}$ transitions are optically thick which lowers the $\mathrm{SO}_{2}$ column density. The opacity is calculated using the same excitation temperature for all transitions and the column density obtained from the ${ }^{34} \mathrm{SO}_{2}$ rotation diagram (using an isotope ratio of 22.5, Table 6) and is found to be around 2-4 for most transitions. The opacity corrected rotation diagram is shown in Fig. 4 together with ${ }^{34} \mathrm{SO}_{2}$. The column density $N_{\text {ROT }}^{\tau \text {-corr }}$ increases to $(1.5 \pm 0.2) \times 10^{18} \mathrm{~cm}^{-2}$ and the temperature is lowered to $103 \pm 3 \mathrm{~K}$.

The isotopologue ${ }^{34} \mathrm{SO}_{2}$ is optically thin, hence no opacity correction is needed. But since the lines are weak and only four, the temperature from $\mathrm{SO}_{2}$ is applied to the rotation diagram, which increases the ${ }^{34} \mathrm{SO}_{2}$ column slightly to $6.5 \times 10^{16} \mathrm{~cm}^{-2}$.

As a consistency check we also use Eq. (2) together with the single optically thin $\mathrm{SO}_{2}$ line. This $16_{3,13}-16_{0,16}$ transition has an upper state energy of $148 \mathrm{~K}$, and $\tau \sim 0.2$. The column density $N_{\text {LTE }}$ obtained is $1.4 \times 10^{18} \mathrm{~cm}^{-2}$, in agreement with $N_{\text {ROT }}^{\tau-\text { corr }}$ and $N_{\text {ISO }}$ from ${ }^{34} \mathrm{SO}_{2}$. 
Table 1. Resulting column densities and rotation temperatures as well as comparison with W03, S01 and C05.

\begin{tabular}{|c|c|c|c|c|c|c|c|c|c|c|}
\hline \multirow[b]{2}{*}{ Species (No.) } & \multirow[b]{2}{*}{ Region } & \multirow[b]{2}{*}{$\begin{array}{l}N \\
{\left[\mathrm{~cm}^{-2}\right]}\end{array}$} & \multirow[b]{2}{*}{$\begin{array}{l}T_{\mathrm{ex}} \\
{[\mathrm{K}]}\end{array}$} & \multirow[b]{2}{*}{$\begin{array}{l}\operatorname{Size}^{a} \\
{\left[{ }^{\prime \prime}\right]}\end{array}$} & \multicolumn{2}{|c|}{${\mathrm{W} 03^{b, c}}^{b}$} & \multicolumn{2}{|c|}{$\mathrm{S} 01^{b, c}$} & \multicolumn{2}{|c|}{${\mathrm{C} 05^{d}}^{2}$} \\
\hline & & & & & $\begin{array}{l}N \\
{\left[\mathrm{~cm}^{-2}\right]}\end{array}$ & $\begin{array}{l}T_{\mathrm{ex}} \\
{[\mathrm{K}]}\end{array}$ & $\begin{array}{l}N \\
{\left[\mathrm{~cm}^{-2}\right]}\end{array}$ & $\begin{array}{l}T_{\mathrm{ex}} \\
{[\mathrm{K}]}\end{array}$ & $\begin{array}{l}N \\
{\left[\mathrm{~cm}^{-2}\right]}\end{array}$ & $\begin{array}{l}T_{\mathrm{ex}} \\
{[\mathrm{K}]}\end{array}$ \\
\hline \multirow[t]{4}{*}{$\mathrm{SO}_{2}(31)$} & Total $^{c}$ & $1.5 \times 10^{18 e}$ & $103^{e}$ & $8^{f}$ & $1 \times 10^{17}$ & 136 & $6 \times 10^{16}$ & 187 & $9 \times 10^{16}$ & 130 \\
\hline & $\mathrm{CR}^{g}$ & $2.0 \times 10^{17 h}$ & $(115)^{i}$ & $5^{f}$ & & & & & & \\
\hline & $\mathrm{LVF}^{g}$ & $6.0 \times 10^{17 h}$ & $103^{j}$ & $8^{f}$ & & & & & & \\
\hline & $\mathrm{HVF}^{g}$ & $9.0 \times 10^{17 h}$ & $103^{j}$ & $8^{f}$ & & & & & & \\
\hline${ }^{34} \mathrm{SO}_{2}(4)$ & $\operatorname{Total}^{c}$ (outflow) & $6.5 \times 10^{16 k}$ & $103^{j}$ & $8^{l}$ & $8 \times 10^{15}$ & 156 & $8 \times 10^{15}$ & 192 & & \\
\hline \multirow[t]{4}{*}{$\mathrm{SO}(5)$} & $\operatorname{Total}^{c}$ & $1.6 \times 10^{17 e}$ & $132^{e}$ & $18^{f}$ & $3 \times 10^{17}$ & $(72)^{i}$ & $2 \times 10^{17}$ & 64 & $5 \times 10^{16}$ & 150 \\
\hline & $\mathrm{CR}^{g}$ & $1.7 \times 10^{16 h}$ & $(115)^{i}$ & $6^{f}$ & & & & & & \\
\hline & $\mathrm{LVF}^{g}$ & $9.3 \times 10^{16 h}$ & $132^{m}$ & $11^{n}$ & & & & & & \\
\hline & $\mathrm{HVF}^{g}$ & $8.5 \times 10^{16 h}$ & $(100)^{i}$ & $18^{n}$ & & & & & & \\
\hline${ }^{33} \mathrm{SO}(3)$ & $\operatorname{Total}^{c}$ (outflow) & $1.7 \times 10^{15 o}$ & $132^{m}$ & $18^{p}$ & & & & & & \\
\hline${ }^{34} \mathrm{SO}(2)$ & $\operatorname{Total}^{c}$ (outflow) & $8.4 \times 10^{15 o}$ & $132^{m}$ & $18^{p}$ & $1 \times 10^{16}$ & 89 & & & & \\
\hline \multirow[t]{3}{*}{$\mathrm{SiO}(1)$} & $\operatorname{Total}^{c}$ & $4.0 \times 10^{15 q}$ & $(100)^{i}$ & $14^{f}$ & & & $5 \times 10^{14}$ & 110 & $1 \times 10^{15}$ & $(150)^{i}$ \\
\hline & $\mathrm{LVF}^{g}$ & $3.3 \times 10^{15 h}$ & $(100)^{i}$ & $10^{n}$ & & & & & & \\
\hline & $\mathrm{HVF}^{g}$ & $1.8 \times 10^{15 h}$ & $(100)^{i}$ & $14^{r}$ & & & & & & \\
\hline${ }^{29} \mathrm{SiO}(1)$ & $\operatorname{Total}^{c}$ (outflow) & $2.0 \times 10^{14 o}$ & $(100)^{i}$ & $14^{r}$ & & & & & & \\
\hline \multirow[t]{2}{*}{$\mathrm{H}_{2} \mathrm{~S}(1)$} & $\mathrm{LVF}^{g}$ & $4.5 \times 10^{16 o}$ & $(100)^{i}$ & $(15)^{i}$ & & & $1 \times 10^{16}$ & 129 & $4 \times 10^{16}$ & 140 \\
\hline & $\mathrm{HC}^{g}$ & $2.7 \times 10^{16 o}$ & $(200)^{i}$ & $(10)^{i}$ & & & & & & \\
\hline $\mathrm{CH}_{3} \mathrm{CN}(9)$ & $\operatorname{Total}^{c}(\mathrm{HC})$ & $5.0 \times 10^{15 k}$ & $137^{k}$ & $(10)^{i}$ & $3 \times 10^{15}$ & 227 & & & $4 \times 10^{15}$ & 250 \\
\hline $\mathrm{HC}_{3} \mathrm{~N}(2)$ & $\operatorname{Total}^{c}(\mathrm{HC})$ & $1.8 \times 10^{15 o}$ & $(200)^{i}$ & $(10)^{i}$ & $1 \times 10^{15}$ & 164 & & & & \\
\hline OCS (3) & $\operatorname{Total}^{c}(\mathrm{HC})$ & $1.7 \times 10^{16 o}$ & $(200)^{i}$ & $(10)^{i}$ & $9 \times 10^{16}$ & 106 & & & & \\
\hline NO (1) & $\operatorname{Total}^{c}(\mathrm{HC})$ & $2.8 \times 10^{17 o}$ & $(200)^{i}$ & $(10)^{i}$ & & & $1 \times 10^{17}$ & 90 & $2 \times 10^{17}$ & 150 \\
\hline \multirow[t]{2}{*}{$\mathrm{NH}_{3}(1)$} & $\mathrm{CR}^{g}$ & $4.0 \times 10^{16 h}$ & $(115)^{i}$ & $17^{f}$ & & & & & & \\
\hline & $\mathrm{HC}^{g}$ & $1.6 \times 10^{18 q}$ & $(200)^{i}$ & $8^{f}$ & & & & & & \\
\hline${ }^{15} \mathrm{NH}_{3}(1)$ & $\operatorname{Total}^{c}(\mathrm{HC})$ & $3.5 \times 10^{15 o}$ & $(200)^{i}$ & $8^{s}$ & & & & & & \\
\hline \multirow[t]{3}{*}{$\mathrm{CH}_{3} \mathrm{OH}(50)$} & Total $^{c}$ & $3.4 \times 10^{18 e}$ & $116^{e}$ & $6^{f, t}$ & $9 \times 10^{16}$ & 599 & $5 \times 10^{16}$ & 303 & & \\
\hline & $\mathrm{HC}^{g}$ & $7.9 \times 10^{17 u}$ & $178^{u}$ & $6^{n}$ & & & & & $3 \times 10^{16}$ & 220 \\
\hline & $\mathrm{CR}^{g}$ & $2.4 \times 10^{18 u}$ & $98^{u}$ & $6^{f}$ & & & & & $5 \times 10^{16}$ & 160 \\
\hline${ }^{13} \mathrm{CH}_{3} \mathrm{OH}$ (14) & Total $^{c}(\mathrm{CR})$ & $5.9 \times 10^{16 k}$ & $115^{k}$ & $6^{v}$ & & & $1 \times 10^{16}$ & 229 & & \\
\hline$\left(\mathrm{CH}_{3}\right)_{2} \mathrm{O}(37)$ & $\operatorname{Total}^{c}(\mathrm{CR})$ & $1.3 \times 10^{17 k}$ & $112^{k}$ & $6^{v}$ & $1 \times 10^{16}$ & 157 & $3 \times 10^{16}$ & 360 & $2 \times 10^{16}$ & 160 \\
\hline $\mathrm{H}_{2} \mathrm{CS}(4)$ & $\operatorname{Total}^{c}(\mathrm{CR})$ & $1.3 \times 10^{15 k}$ & $93^{k}$ & $14^{x}$ & & & & & & \\
\hline \multirow[t]{2}{*}{$\mathrm{H}_{2} \mathrm{CO}(3)$} & $\mathrm{LVF}^{g}$ & $4.3 \times 10^{15 o}$ & $(100)^{i}$ & $(15)^{i}$ & $1 \times 10^{16}$ & $(166)^{i}$ & $3 \times 10^{15}$ & 190 & $2 \times 10^{15}$ & 155 \\
\hline & $\mathrm{CR}^{g}$ & $2.0 \times 10^{16 q}$ & $(115)^{i}$ & $14^{f}$ & & & & & & \\
\hline $\mathrm{H}_{2}^{13} \mathrm{CO}(1)$ & $\operatorname{Total}^{c}(\mathrm{CR})$ & $3.3 \times 10^{14 o}$ & $(115)^{i}$ & $14^{x}$ & $1 \times 10^{15}$ & $(166)^{i}$ & & & & \\
\hline HDCO (2) & $\operatorname{Total}^{c}(\mathrm{CR})$ & $2.7 \times 10^{14 o}$ & $(115)^{i}$ & $14^{x}$ & & & & & & \\
\hline \multirow[t]{4}{*}{ CS (1) } & $\mathrm{LVF}^{g}$ & $3.6 \times 10^{15 o}$ & $(100)^{i}$ & $(15)^{i}$ & & & $1 \times 10^{15}$ & 127 & $3 \times 10^{15}$ & 100 \\
\hline & $\mathrm{HC}^{g}$ & $2.9 \times 10^{15 o}$ & $(200)^{i}$ & $(10)^{i}$ & & & & & $1 \times 10^{16}$ & 190 \\
\hline & $\mathrm{N}$ as $\mathrm{CR}^{g}$ & $8.0 \times 10^{15 q}$ & $(115)^{i}$ & $20^{f}$ & & & & & & \\
\hline & $\mathrm{N}$ as $\mathrm{ER}^{g}$ & $4.2 \times 10^{14 q}$ & $(60)^{i}$ & $\ldots$ & & & & & & \\
\hline \multirow[t]{2}{*}{${ }^{13} \mathrm{CS}(1)$} & Total $^{c}$ as CR & $1.3 \times 10^{14 o}$ & $(115)^{i}$ & $20^{y}$ & $2 \times 10^{14}$ & $(120)^{i}$ & & & & \\
\hline & Total $^{c}$ as ER & $7.1 \times 10^{12 o}$ & $(60)^{i}$ & $\ldots$ & & & & & & \\
\hline \multirow[t]{3}{*}{ HNC (1) } & $\mathrm{LVF}^{g}$ & $3.6 \times 10^{14 o}$ & $(100)^{i}$ & $(15)^{i}$ & & & & & $5 \times 10^{14}$ & $(150)^{i}$ \\
\hline & $\mathrm{HC}^{g}$ & $4.4 \times 10^{14 o}$ & $(200)^{i}$ & $(10)^{i}$ & & & & & & \\
\hline & $\mathrm{ER}^{g}$ & $1.9 \times 10^{12 o}$ & $(60)^{i}$ & $\ldots$ & & & & & & \\
\hline \multirow[t]{2}{*}{$\mathrm{CN}(2)$} & $\mathrm{PDR} / \mathrm{ER}^{g}$ & $4.9 \times 10^{13 o}$ & $(100)^{i}$ & $\ldots$ & & & & & & \\
\hline & $\mathrm{HC}^{g}$ & $7.9 \times 10^{15 o}$ & $(200)^{i}$ & $(10)^{i}$ & & & & & & \\
\hline $\mathrm{N}_{2} \mathrm{H}^{+}(1)$ & $\operatorname{Total}^{c}(\mathrm{ER})$ & $1.0 \times 10^{12 o}$ & $(60)^{i}$ & $\ldots$ & & & & & & \\
\hline
\end{tabular}

${ }^{a}$ The column density is a source-average if a source size is given, else it is a beam-average. ${ }^{b} \mathrm{HPBW}$ is $10-12^{\prime \prime}$ in comparison surveys, and the column densities are beam-averaged and not corrected for opacity. ${ }^{c}$ From the total integrated intensity of the line(s). ${ }^{d}$ Beam-filling and opacity corrected, as well as separation into components. ${ }^{e}$ From an opacity-corrected rotation diagram. ${ }^{f}$ From optically thick line(s). ${ }^{g}$ From Gaussian decomposition. ${ }^{h} N_{\text {LTE }}$, opacity corrected. ${ }^{i}$ Not calculated by the authors. ${ }^{j}$ Temperature from $\mathrm{SO}_{2}$ opacity-corrected rotation diagram. ${ }^{k}$ From a non opacity-corrected rotation diagram. ${ }^{l}$ Size from $\mathrm{SO}_{2} .{ }^{m}$ Temperature from a SO opacity-corrected rotation diagram. ${ }^{n}$ Opacity corrected. ${ }^{o}$ $N_{\text {LTE. }}{ }^{p}$ Size from SO total integrated intensity. ${ }^{q} N_{\text {ISO }} .{ }^{r}$ Size from SiO total integrated intensity. ${ }^{s}$ Size from $\mathrm{NH}_{3} .{ }^{t}$ From the forward model. ${ }^{u}$ From an opacity corrected two-component rotation diagram. ${ }^{v}$ Size from $\mathrm{CH}_{3} \mathrm{OH} .{ }^{x}$ Using $\mathrm{H}_{2} \mathrm{CO}$ calculated source size. ${ }^{y}$ Using size from CS.

Our column densities of both isotopologues are much larger than in the comparison surveys. This can partly be caused by our beam-filling correction with a rather small size, and the noncorrection for opacity in W03 and S01. However, Johansson et al. (1984) and Serabyn \& Weisstein (1995) obtain a column density of about $1 \times 10^{18} \mathrm{~cm}^{-2}$ (corrected for our source size) in agreement with our value.

Column densities for each subregion are estimated from the Gaussian components shown in Fig. 1 (Table 1). The rarer isotopologues are too weak for a Gaussian decomposition so 
Table 2. Column density results for water, $\mathrm{C}, \mathrm{CO}$ and $\mathrm{H}_{2}$.

\begin{tabular}{|c|c|c|c|c|c|c|c|}
\hline Species & Region & $\begin{array}{l}T_{\mathrm{ex}} \\
{[\mathrm{K}]}\end{array}$ & $\begin{array}{l}N_{\mathrm{LTE}} \\
{\left[\mathrm{cm}^{-2}\right]}\end{array}$ & $\begin{array}{l}N_{\text {ISO }} \\
{\left[\mathrm{cm}^{-2}\right]}\end{array}$ & $\begin{array}{l}N_{\mathrm{H}_{2}} \\
{\left[\mathrm{~cm}^{-2}\right]}\end{array}$ & $\begin{array}{l}\operatorname{Size}^{a} \\
{\left[{ }^{\prime \prime}\right]}\end{array}$ & $\tau$ \\
\hline $\mathrm{C}$ & & 100 & $5.6 \times 10^{17}$ & & & $\ldots$ & \\
\hline \multirow{3}{*}{$\mathrm{CO}$} & $\mathrm{PDR}^{b}$ & 100 & $1.6 \times 10^{17}$ & $1.6 \times 10^{18 c}$ & $2.0 \times 10^{22}$ & $\ldots$ & \\
\hline & LVF & 100 & & $2.5 \times 10^{19 c} c$ & $3.2 \times 10^{23}$ & $(30)^{d}$ & \\
\hline & HVF & 100 & $1.2 \times 10^{18}$ & $3.1 \times 10^{18 e}$ & $3.9 \times 10^{22}$ & $70^{f}$ & \\
\hline \multirow[t]{3}{*}{${ }^{13} \mathrm{CO}$} & $\mathrm{PDR} / \mathrm{ER}^{b}$ & 100 & $5.7 \times 10^{16}$ & $5.4 \times 10^{16 c}$ & & $\ldots$ & \\
\hline & LVF & 100 & $3.9 \times 10^{17}$ & $4.2 \times 10^{17 c}$ & & 30 & \\
\hline & HVF & 100 & $5.2 \times 10^{16}$ & & & 70 & \\
\hline \multirow[t]{2}{*}{$\mathrm{C}^{17} \mathrm{O}$} & $\mathrm{PDR} / \mathrm{ER}^{b}$ & 100 & $2.5 \times 10^{15}$ & & & $\ldots$ & 0.07 \\
\hline & LVF & 100 & $2.0 \times 10^{16}$ & & & 30 & 0.1 \\
\hline \multirow[t]{2}{*}{$\mathrm{C}^{18} \mathrm{O}$} & $\mathrm{PDR} / \mathrm{ER}^{b}$ & 100 & $8.9 \times 10^{15}$ & $9.8 \times 10^{15 c}$ & & $\ldots$ & 0.3 \\
\hline & LVF & 100 & $6.7 \times 10^{16}$ & $7.7 \times 10^{16 c}$ & & 30 & 0.3 \\
\hline \multirow[t]{5}{*}{$\mathrm{H}_{2} \mathrm{O}$} & Total $^{g}$ & 72 & & $1.7 \times 10^{18 h}$ & & $(15)^{d}$ & $\sim 1100$ \\
\hline & CR & 115 & & $5.6 \times 10^{17 h}$ & & $(6)^{d}$ & $\sim 860$ \\
\hline & LVF & 72 & & $8.7 \times 10^{17 h}$ & & $(15)^{d}$ & $\sim 1900$ \\
\hline & HVF & 72 & $8.0 \times 10^{17 i}$ & $8.8 \times 10^{17 h}$ & & $70^{f}$ & $\sim 910$ \\
\hline & $\mathrm{HC}$ & 200 & $1.2 \times 10^{19 j}$ & & & 10 & $0.3^{k}$ \\
\hline \multirow[t]{4}{*}{$\mathrm{H}_{2}^{17} \mathrm{O}$} & Total $^{g}$ & 72 & $1.3 \times 10^{15 l}$ & & & 15 & 0.9 \\
\hline & CR & 115 & $4.4 \times 10^{14 l}$ & & & 6 & 0.7 \\
\hline & LVF & 72 & $6.7 \times 10^{14 l}$ & & & 15 & 1.5 \\
\hline & $\mathrm{HVF}$ & 72 & $6.8 \times 10^{14 l}$ & & & 15 & 0.7 \\
\hline \multirow[t]{4}{*}{$\mathrm{H}_{2}^{18} \mathrm{O}$} & Total $^{g}$ & 72 & $5.0 \times 10^{15 l}$ & $5.0 \times 10^{15 h}$ & & 15 & 3.4 \\
\hline & CR & 115 & $1.8 \times 10^{15 l}$ & $1.7 \times 10^{15 h}$ & & 6 & 2.6 \\
\hline & LVF & 72 & $2.7 \times 10^{15 l}$ & $2.6 \times 10^{15 h}$ & & 15 & 5.9 \\
\hline & HVF & 72 & $2.8 \times 10^{15 l}$ & $2.7 \times 10^{15 h}$ & & 15 & 2.8 \\
\hline \multirow[t]{4}{*}{$\mathrm{HDO}$} & Total $^{g}$ & 72 & $9.1 \times 10^{15}$ & & & 15 & $1.5^{k}$ \\
\hline & CR & 115 & $1.8 \times 10^{16}$ & & & 6 & $3^{k}$ \\
\hline & LVF & 72 & $4.5 \times 10^{15}$ & & & 15 & $0.3^{k}$ \\
\hline & $\mathrm{HC}$ & 200 & $1.5 \times 10^{16}$ & & & 10 & $0.5^{k}$ \\
\hline
\end{tabular}

${ }^{a}$ The column density is a source-average if a source size is given, else it is a beam-average. ${ }^{b}$ The narrow component from CO isotopologues contains emission from both PDR and ER, the CO narrow component only from the PDR, hence the PDR column density for CO here is divided by two as motivated in Sect. 5. ${ }^{c}$ Using $\mathrm{C}^{17} \mathrm{O}$ together with $\left[{ }^{18} \mathrm{O} /{ }^{17} \mathrm{O}\right]=3.9,\left[{ }^{16} \mathrm{O} /{ }^{18} \mathrm{O}\right]=330$, and $\left[{ }^{12} \mathrm{CO} /{ }^{13} \mathrm{CO}\right]=60 .{ }^{d}$ Indirect size estimated using isotopologues. The full size may be larger. ${ }^{e}$ Using ${ }^{13} \mathrm{CO}$ together with $\left[{ }^{12} \mathrm{CO} /{ }^{13} \mathrm{CO}\right]=60 .{ }^{f}$ Hjalmarson et al. $(2005) .{ }^{g}$ From the total integrated intensity of the line. ${ }^{h}$ Using opacity and beam-filling corrected $o-\mathrm{H}_{2}^{17} \mathrm{O}$ together with $\left[{ }^{18} \mathrm{O} /{ }^{17} \mathrm{O}\right]=3.9$ and $\left[{ }^{16} \mathrm{O} /{ }^{18} \mathrm{O}\right]=330 .{ }^{i}$ From $\mathrm{HVF}$ Gaussian fit of $o-\mathrm{H}_{2} \mathrm{O}$, opacity and beam-filling corrected. ${ }^{j}$ Using beam-filling corrected $p-\mathrm{H}_{2} \mathrm{O} .{ }^{k}$ Calculated with Eq. (15). ${ }^{l}$ Opacity and beam-filling corrected.

opacities cannot be calculated by comparison with isotopologues. Still, the components are likely to be optically thick and therefore the sizes of the emitting regions are calculated with $T=115 \mathrm{~K}$ for the CR, and $T=103 \mathrm{~K}$ for the LVF and HVF. The source sizes are found to be $5^{\prime \prime}$ for the CR and $8^{\prime \prime}$ for both the LVF and HVF. These sizes correspond to optical depths of about 2-3. The opacity-corrected column densities become $2 \times 10^{17} \mathrm{~cm}^{-2}, 6 \times 10^{17} \mathrm{~cm}^{-2}$, and $9 \times 10^{17} \mathrm{~cm}^{-2}$ for the $\mathrm{CR}$, LVF and HVF, respectively.

The elemental isotopic ratio of $\left[{ }^{32} \mathrm{~S} /{ }^{34} \mathrm{~S}\right]$ can be estimated from a comparison of the optically thin column densities. In this way we obtain an isotopic ratio of $23 \pm 7$, in agreement with most other comparison studies listed in Table 6.

As expected, no vibrationally excited lines were found. The $5_{5,1}-4_{4,0} v_{2}$ bending mode transition has the lowest upper state energy $(822 \mathrm{~K})$ of all $v_{2}$ lines in our spectral range. The calculated expected peak temperature of this line is $34 \mathrm{mK}$, with an expected line width of $23 \mathrm{~km} \mathrm{~s}^{-1}$. Such weak and broad lines are marginally below our detection limit.

\subsubsection{Sulphur monoxide $\left(\mathrm{SO} /{ }^{33} \mathrm{SO} /{ }^{34} \mathrm{SO}\right)$}

Typical line profiles are shown in Fig. 27 (online material). The line profiles of the high energy transitions show an even broader outflow emission, and with more pronounced high velocity line wings than does $\mathrm{SO}_{2}$ (comparison in Fig. 41 in the online material). As for $\mathrm{SO}_{2}$, the emission is primarily from the Plateau, and Friberg (1984) has shown the bipolar nature of the HVF component. The ratios of $\mathrm{SO}_{2}$ and $\mathrm{SO}$ emission lines vs. velocity, also show a high degree of similarity between the line profiles except in the high velocity regime between -30 to $-5 \mathrm{~km} \mathrm{~s}^{-1}$. At these velocities $\mathrm{SO}$ has stronger emission than $\mathrm{SO}_{2}$.

Figure 2 shows the $13_{12}-12_{11}$ transition with a threecomponent Gaussian fit. The broad HVF component has a FWHM width of $\sim 35 \mathrm{~km} \mathrm{~s}^{-1}$ at $v_{\text {LSR }} \sim 9 \mathrm{~km} \mathrm{~s}^{-1}$. The LVF component has widths of $18 \mathrm{~km} \mathrm{~s}^{-1}$ at $v_{\mathrm{LSR}} \sim 8 \mathrm{~km} \mathrm{~s}^{-1}$. In addition to the LVF and HVF components a third from the CR appears with a width of $5 \mathrm{~km} \mathrm{~s}^{-1}$ at $v_{\mathrm{LSR}} \sim 9-10 \mathrm{~km} \mathrm{~s}^{-1}$.

The most likely source size is $18^{\prime \prime}$, calculated using the three optically thick SO lines. This is in agreement with the aperture synthesis mapping by Beuther et al. (2005), and Wright et al. (1996), who find a larger source size for SO than for $\mathrm{SO}_{2}$. The source size $18^{\prime \prime}$ is used for beam-filling correction.

The rotation diagram in Fig. 5 (calculated with the total integrated intensity of the lines) displays our five SO lines. The rotation temperature without any corrections is $(59 \pm 2 \mathrm{~K})$ and the column density $N_{\text {ROT }}$ is $(1.5 \pm 0.2) \times 10^{17} \mathrm{~cm}^{-2}$. However, the three higher energy lines have optical depth of $\sim 3$, whereas 


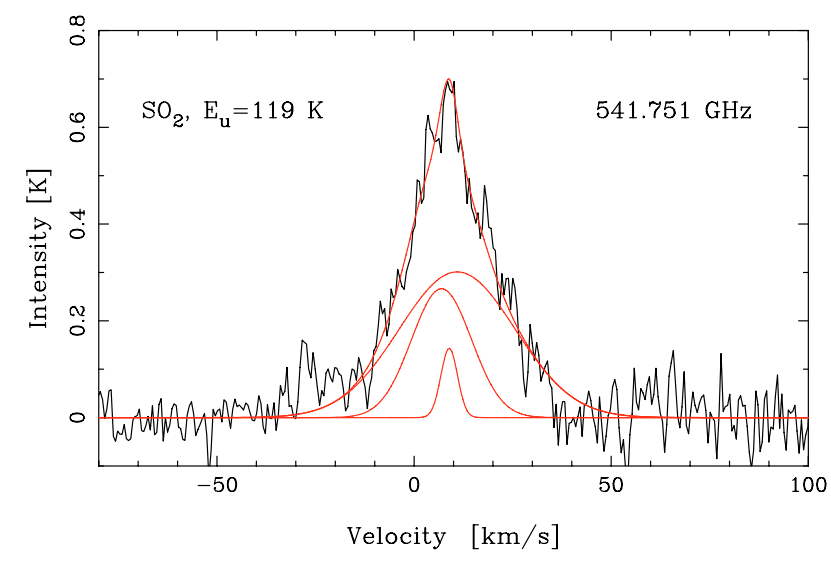

Fig. 1. The $14_{3,11}-13_{2,12} \quad \mathrm{SO}_{2}$ transition with a three-component Gaussian fit shown together with the individual Gaussians. The line widths are $5 \mathrm{~km} \mathrm{~s}^{-1}, 18 \mathrm{~km} \mathrm{~s}^{-1}$ and $35 \mathrm{~km} \mathrm{~s}^{-1}$ from the CR, LVF and HVF, respectively.

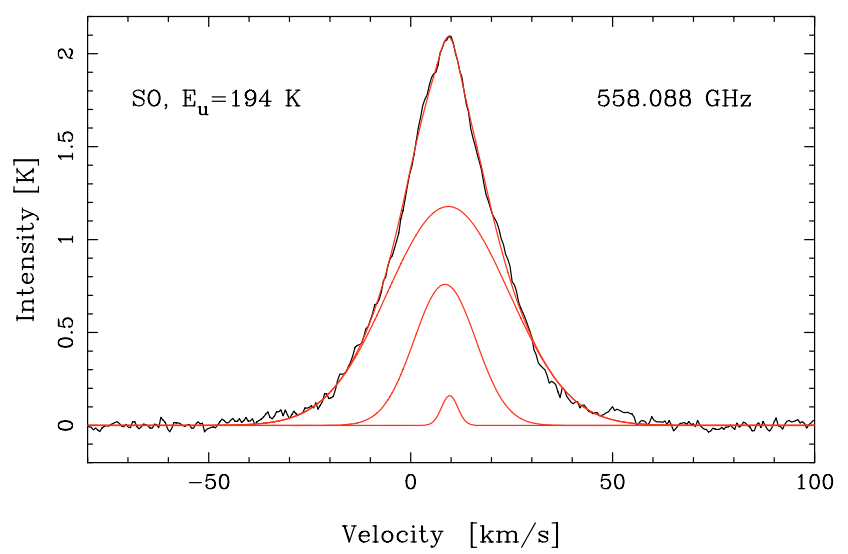

Fig. 2. The $13_{12}-12_{11}$ SO transition with a three-component Gaussian fit shown together with the individual Gaussians. The line widths are $5 \mathrm{~km} \mathrm{~s}^{-1}, 18 \mathrm{~km} \mathrm{~s}^{-1}$ and $35 \mathrm{~km} \mathrm{~s}^{-1}$ from the CR, LVF and HVF, respectively.

the two low energy transitions are optically thin with $\tau \sim 0.1$ (Eq. (15)). We make an optical depth correction for all five transitions and plot them again in Fig. 5 together with a new fit. Note that the correction is substantial for the high energy, optically thick lines (cf. Serabyn \& Weisstein 1995). The rotation temperature obtained is higher than without corrections, $132 \pm 22 \mathrm{~K}$, but the resulting column density is only slightly higher than that found without the corrections, $N_{\mathrm{ROT}}^{\tau \text {-corr }}=(1.6 \pm 0.5) \times 10^{17} \mathrm{~cm}^{-2}$. This is in agreement with the column density obtained from ${ }^{34} \mathrm{SO}, N_{\text {ISO }}=1.9 \times 10^{17} \mathrm{~cm}^{-2}$ (using 22.5 for $\left[{ }^{32} \mathrm{~S} /{ }^{34} \mathrm{~S}\right]$ ). The two optically thin SO transitions gives $N_{\mathrm{LTE}}=1.8 \times 10^{17} \mathrm{~cm}^{-2}$. The column densities for both isotopologues are calculated with the rotation temperature from SO.

The isotopologues, two ${ }^{33} \mathrm{SO}$ and three ${ }^{34} \mathrm{SO}$ transitions, are optically thin with opacities around 0.02 and 0.13 , respectively. These transitions are plotted in Fig. 5 with the integrated intensities multiplied by appropriate isotopic ratios $(5.5$ for $\left[{ }^{34} \mathrm{~S} /{ }^{33} \mathrm{~S}\right]$, Table 6). As seen in Fig. 5, the result of the isotopic ratio corrections is consistent with the optical depth corrected SO transitions.

As for $\mathrm{SO}_{2}$ the column densities for each SO subregion are estimated from the Gaussian components shown in Fig. 2. Opacities cannot be calculated by comparison with the rarer isotopologues since they are too weak for a Gaussian

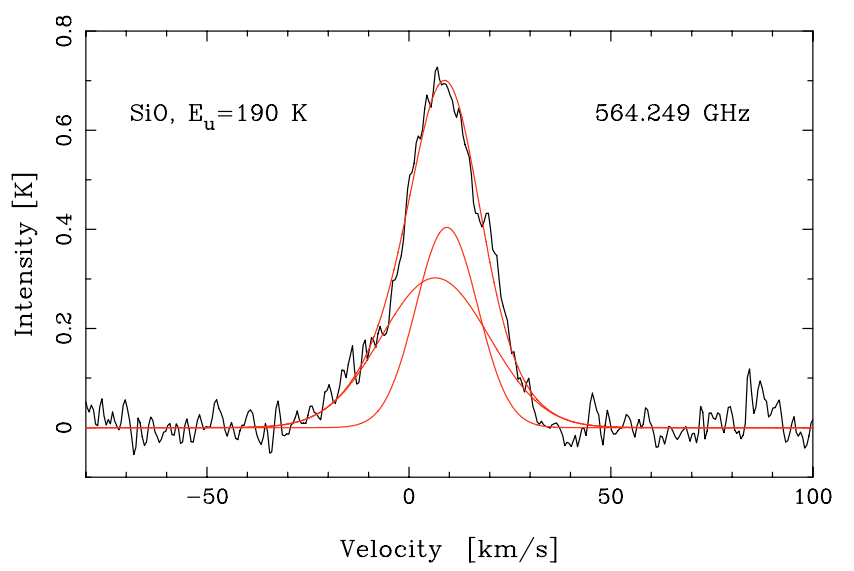

Fig. 3. The $J=13-12 \mathrm{SiO}$ transition with a two-component Gaussian fit shown together with the individual Gaussians. The line widths are $18 \mathrm{~km} \mathrm{~s}^{-1}$ and $31 \mathrm{~km} \mathrm{~s}^{-1}$ from the LVF and HVF, respectively.

decomposition. However, the components are likely to be optically thick and therefore the sizes of the emitting regions are calculated with $T=115 \mathrm{~K}$ for the CR, $T=132 \mathrm{~K}$ for the LVF, and $T=100 \mathrm{~K}$ for the HVF. The source sizes of the CR, LVF and HVF are found to be $6^{\prime \prime}, 10^{\prime \prime}$ and $14^{\prime \prime}$, respectively. These sizes may be larger if the opacities are low. Combining calculations of source size, optical depths, and column densities, the sizes for the LVF and HVF increase slightly to $11^{\prime \prime}$ and $18^{\prime \prime}$, respectively. These sizes correspond to optical depths of about 2.5 and 1.0 for respective region. The opacity-corrected column densities become $1.7 \times 10^{16} \mathrm{~cm}^{-2}, 9.3 \times 10^{16} \mathrm{~cm}^{-2}$, and $8.5 \times$ $10^{16} \mathrm{~cm}^{-2}$ for the CR, LVF and HVF, respectively.

The elemental isotopic ratio of $\left[{ }^{32} \mathrm{~S} /{ }^{34} \mathrm{~S}\right]$ and $\left[{ }^{34} \mathrm{~S} /{ }^{33} \mathrm{~S}\right]$ can be estimated from comparisons of the column densities of the isotopologues and the optically thin SO transitions. We obtain isotopic ratios of $21.0 \pm 6$ and 4.9, respectively in agreement with most other comparison studies listed in Table 6.

\subsubsection{Silicon monoxide $\left(\mathrm{SiO} /{ }^{29} \mathrm{SiO} /{ }^{30} \mathrm{SiO}\right)$}

We have observed the transition $J=13-12$ for each isotopologue, and we show the $\mathrm{SiO}$ and ${ }^{29} \mathrm{SiO}$ transitions in Fig. 28 (online material). As for $\mathrm{SO}_{2}$ and $\mathrm{SO}$, the complicated line profile of $\mathrm{SiO}$ suggests emission from both the LVF and the bipolar HVF (present in aperture synthesis maps of Wright et al. 1996), with widths of 18 and $31 \mathrm{~km} \mathrm{~s}^{-1}$ at $v_{\mathrm{LSR}}$ velocities of 9 and $7 \mathrm{~km} \mathrm{~s}^{-1}$, respectively. Figure 3 shows the two-component Gaussian fit to $\mathrm{SiO}$. The ${ }^{29} \mathrm{SiO}$ transition is located in the highvelocity wing of $o-\mathrm{H}_{2} \mathrm{O}$ (at $v_{\mathrm{LSR}} \sim-130 \mathrm{~km} \mathrm{~s}^{-1}$ ). The width is $21 \mathrm{~km} \mathrm{~s}^{-1}$ at a centre velocity of $\sim 9 \mathrm{~km} \mathrm{~s}^{-1}$. The ${ }^{30} \mathrm{SiO}$ transition is a questionable assignment due to its narrow line width of $7.5 \mathrm{~km} \mathrm{~s}^{-1}$.

Comparison of the peak antenna temperatures of $\mathrm{SiO}$ and ${ }^{29} \mathrm{SiO}$ shows that the $\mathrm{SiO}$ transition has an optical depth of $\sim 1.0$. The source size (Eq. (12)) is found to be 14". This is used as beam-filling correction. Using a LVF temperature of $100 \mathrm{~K}$ (about the same temperature as the $\mathrm{SO}_{2}$ rotation temperature), the total integrated intensity, and the simple LTE approximation, the opacity-corrected column density is found to be $4.0 \times$ $10^{15} \mathrm{~cm}^{-2}$ for $\mathrm{SiO}$.

The decomposition into subregions results in LVF and HVF source sizes of $8^{\prime \prime}$ and $7 "$ with temperatures of $100 \mathrm{~K}$ for both sources. The rather small values are most likely due to the low opacity in these components and are therefore only lower 


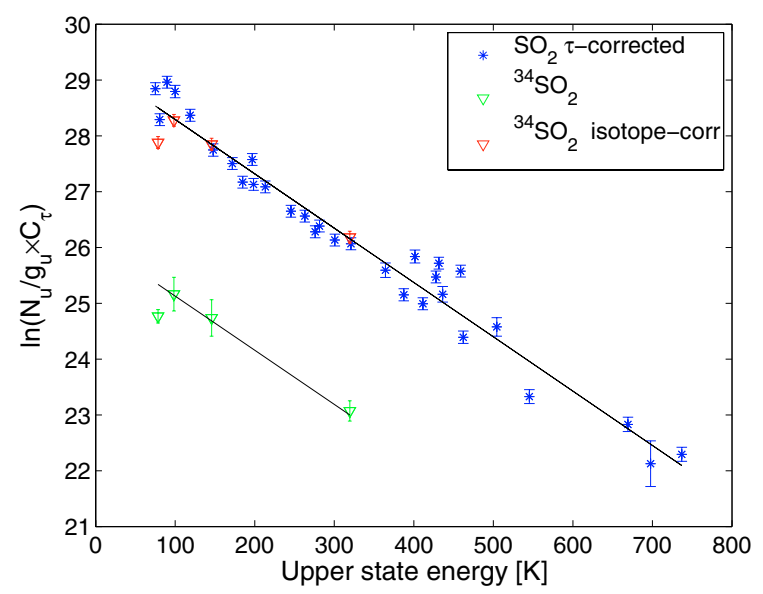

Fig. 4. Rotation diagram for $\mathrm{SO}_{2}$ produces $T_{\text {ROT }}=103 \mathrm{~K}$ (extended source). The ${ }^{34} \mathrm{SO}_{2}$ fit uses the $\mathrm{SO}_{2}$ rotation temperature.

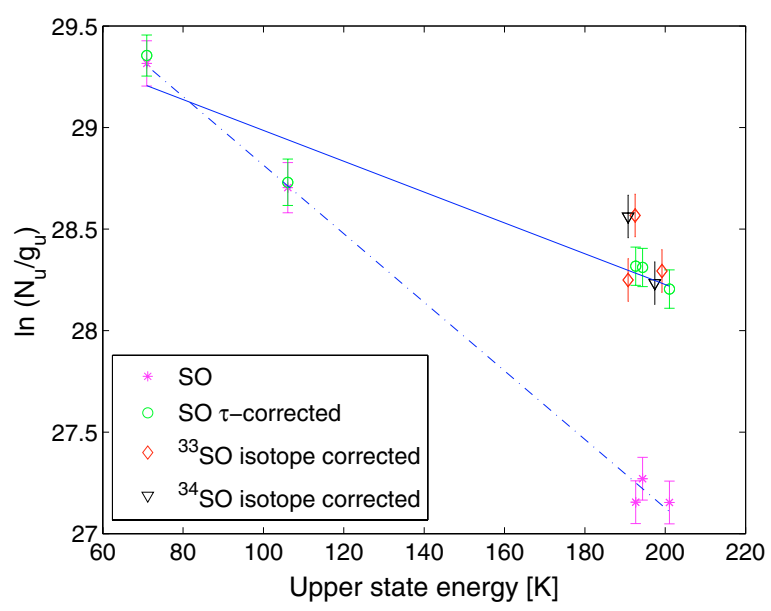

Fig. 5. Rotation diagram for $\mathrm{SO}$ and isotopologues (extended source). The isotopologues are plotted multiplied by respective isotopic ratio. Two fits are made: the first (dashed-dotted line) is not opacity corrected $\left(T_{\mathrm{ROT}}=59 \mathrm{~K}\right)$, while the second (solid line) is corrected for opacity $\left(T_{\mathrm{ROT}}=132 \mathrm{~K}\right)$.

limits. Assuming that the opacity in the LVF is about the same as for the total integrated emission, the LVF opacity-corrected source size increases to $10^{\prime \prime}$. The opacity in the HVF is most likely less than in the LVF. As an upper limit the size is assumed to be the same as for the total integrated emission, which results in an HVF opacity of about 0.4 . The sizes are consistent with Beuther et al. (2005). Note the similarity of the SO and $\mathrm{SiO}$ source sizes. In Sect. 6 the $\mathrm{H}_{2}^{18} \mathrm{O}$ sizes will also be shown to be similar. These source sizes are used to correct for beamfilling, and the resulting LVF and HVF opacity-corrected column densities are $3.3 \times 10^{15}$ and $1.8 \times 10^{15} \mathrm{~cm}^{-2}$, respectively.

\subsection{Outflow and Hot Core molecule}

The Hot Core is a collection of warm ( $\gtrsim 200 \mathrm{~K})$ and dense $\left(n \sim 10^{7} \mathrm{~cm}^{-3}\right)$ clumps of gas. The dominating species are oxygen-free, small, saturated nitrogen-bearing molecules such as $\mathrm{CH}_{3} \mathrm{CN}$ and $\mathrm{NH}_{3}$. Most $\mathrm{N}$-bearing molecules are strong in the $\mathrm{HC}$, while the oxygen-bearing molecules peak toward the $\mathrm{CR}$ (e.g. Blake et al. 1987, hereafter B87; Caselli et al. 1993; Beuther et al. 2005). $\mathrm{CH}_{3} \mathrm{OH}$ is an exception with pronounced emissions from the $\mathrm{HC}$ as well as from the CR. In addition, high levels of deuterium fractionation are found here. Since the HC region

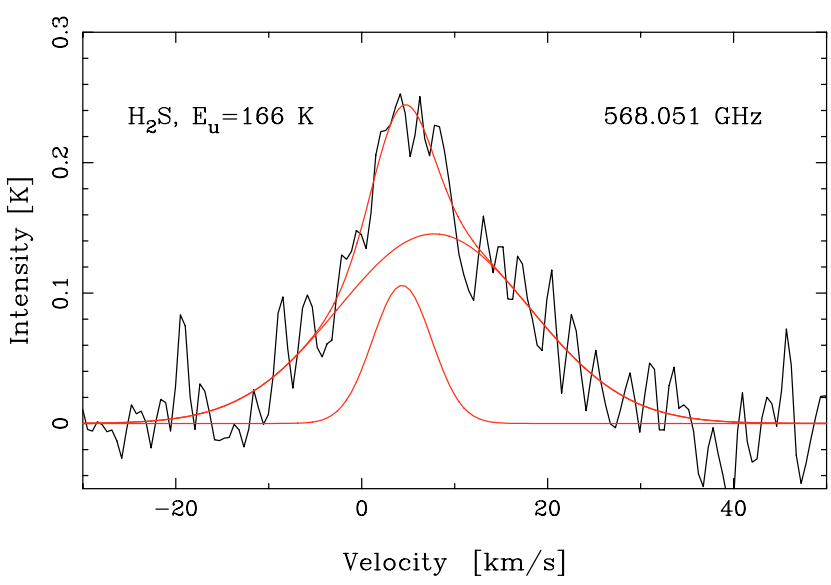

Fig. 6. The $\mathrm{H}_{2} \mathrm{~S} \quad 3_{3,1}-3_{2,2}$ transition with a two-component Gaussian fit shown together with the individual Gaussians. The line widths are $8 \mathrm{~km} \mathrm{~s}^{-1}$ and $24 \mathrm{~km} \mathrm{~s}^{-1}$ from the $\mathrm{HC}$ and outflow, respectively.

probably contains one or more massive protostars it presents an ideal opportunity to study active gas-phase chemistry. And due to the high temperatures in both the $\mathrm{HC}$ and $\mathrm{CR}$, the gas-phase chemistry will get a significant contribution of molecules from grain surface chemistry through evaporation of the icy mantles caused by the intense UV radiation from newly formed stars.

\subsubsection{Hydrogen sulphide $\left(\mathrm{H}_{2} \mathrm{~S}\right)$}

We observe only the $3_{3,1}-3_{2,2}$ transition of $\mathrm{H}_{2} \mathrm{~S}$, with emission from the $\mathrm{HC}$ and LVF, illustrated by a Gaussian decomposition in Fig. 6. The emission from the HC component has a width of $\sim 8 \mathrm{~km} \mathrm{~s}^{-1}$ at $v_{\mathrm{LSR}} \sim 5 \mathrm{~km} \mathrm{~s}^{-1}$ between velocities -5 to $+15 \mathrm{~km} \mathrm{~s}^{-1}$. The LVF emission has a width of $\sim 24 \mathrm{~km} \mathrm{~s}^{-1}$ at $v_{\text {LSR }} \sim 8 \mathrm{~km} \mathrm{~s}^{-1}$. The line is also shown in the bottom of Fig. 25 (online material) together with other comparison $\mathrm{HC}$ molecules.

The column densities are consistent with the comparison surveys assuming typical source sizes and temperatures.

\subsection{Hot Core molecules}

\subsubsection{Methyl cyanide $\left(\mathrm{CH}_{3} \mathrm{CN}\right)$}

Previous observations of the high density tracer $\mathrm{CH}_{3} \mathrm{CN}$ (e.g. Blake et al. 1986; Wilner et al. 1994) have shown that the low-J transitions in the vibrational ground state appears to be a mix of $\mathrm{CR}$ and $\mathrm{HC}$ emission, while the high- $J$ transitions and all the vibrationally excited lines originate in the $\mathrm{HC}$ only. This is also confirmed in our survey where we observe the $30_{K}-29_{K}$ transitions with $K=0-9$, and $31_{K}-30_{K}$ with $K=0-6$ and 9 . These lines suggest an origin in the HC at $v_{\mathrm{LSR}} \sim 5-6 \mathrm{~km} \mathrm{~s}^{-1}$ and widths of $\sim 8-9 \mathrm{~km} \mathrm{~s}^{-1}$, also consistent with W05 and C05. The $30_{4}-29_{4}$ ground state transition is shown in Fig. 25 (online material). In addition we see a number of weak vibrational lines from the $v_{8}=1$ bending mode with $30_{K}-29_{K}$ where $K=0-3$. In total we observe 17 line features from this molecule. Nine of these are free from blends and are used in the rotation diagram (Fig. 7). Due to the weak lines the rotation temperature of $137 \pm 25 \mathrm{~K}$ and the column density of $(5.0 \pm 3.6) \times 10^{15} \mathrm{~cm}^{-2}$ are comparatively uncertain. The temperature is rather low compared to W03 who estimate the temperature to $227 \mathrm{~K}$, and C05 to $250 \mathrm{~K}$. Still, the column density agrees well with B87, Sutton et al. (1995, hereafter S95), W03, and C05. 


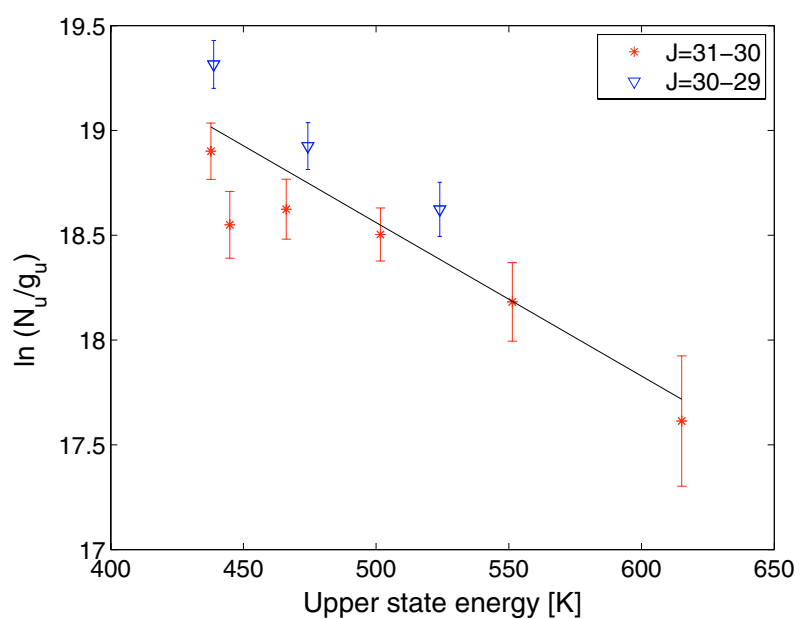

Fig. 7. Rotation diagram for $\mathrm{CH}_{3} \mathrm{CN}$ producing $T_{\mathrm{ROT}}=137 \mathrm{~K}$ (extended source).

Wilner et al. (1994) find an opacity of the HC emission of at most a few for the main lines. This could explain the rather low $\left[{ }^{13} \mathrm{C} /{ }^{12} \mathrm{C}\right]$ ratios in Blake et al. (1986) and Turner (1991). Sutton et al. (1986) suggests significant opacity from their statistical equilibrium calculations, if the $\mathrm{HC}$ is as small as $10^{\prime \prime}$. This would give even higher column densities in the $\mathrm{HC}$.

The partition function is calculated as recommended in Araya et al. (2005).

\subsubsection{Cyanoacetylene $\left(\mathrm{HC}_{3} \mathrm{~N}\right)$}

Two transitions of cyanoacetylene are seen, of which $J=54-53$ is a blend with $\mathrm{CH}_{3} \mathrm{OH}$. The transition $J=60-59$ is shown in Fig. 25 (online material). HC emission is here evident at $v_{\mathrm{LSR}} \sim$ $5-6 \mathrm{~km} \mathrm{~s}^{-1}$ and a line width of $\sim 10 \mathrm{~km} \mathrm{~s}^{-1}$. The column density is calculated with the simple LTE approximation and is in agreement with W03.

\subsubsection{Carbonyl sulphide (OCS)}

We have identified three transitions from carbonyl sulphide, $J=47-46, J=45-44$, and $J=46-45$ (shown in the online Fig. 25). The emission has its origin in the HC with $v_{\mathrm{LSR}} \sim$ $6 \mathrm{~km} \mathrm{~s}^{-1}$, and a width of $\sim 6 \mathrm{~km} \mathrm{~s}^{-1}$.

The estimated column density is about five times lower than found by both W03 and S95.

\subsubsection{Nitric oxide (NO)}

We observe three features with ${ }^{2} \Pi_{3 / 2}, J=11 / 2-9 / 2$, and ${ }^{2} \Pi_{1 / 2}$, $J=11 / 2-9 / 2$ from both e and $\mathrm{f}$ species, which are composed of twelve non-resolved hyperfine transitions. No separation into components is possible due to blends between the hyperfine transitions and other species. Our estimated rotation temperature from our transitions with upper state energies of $84 \mathrm{~K}$ and $232 \mathrm{~K}$ is found to be $75 \mathrm{~K}$. This is highly uncertain due to the severe blends in both low energy transitions. Since S01 and C05 observed $\mathrm{HC}$ emission we therefore use a typical $\mathrm{HC}$ temperature of $200 \mathrm{~K}$ and source size of $10^{\prime \prime}$. The resulting column density (using the high energy line) is in agreement with S01 and C05.

\subsection{Hot Core and Compact Ridge molecules}

The Compact Ridge is a more quiescent region as compared to the Hot Core. Here we find high abundances of oxygen-bearing species such as $\mathrm{CH}_{3} \mathrm{OH},\left(\mathrm{CH}_{3}\right)_{2} \mathrm{O}$ and $\mathrm{HDO}$ (B87; Caselli et al. 1993; Beuther et al. 2005). As in the HC, the evaporation of the icy mantles in the warm CR will release molecules produced by grain surface chemistry into the gas-phase.

\subsubsection{Ammonia $\left(\mathrm{NH}_{3} /{ }^{15} \mathrm{NH}_{3}\right)$}

The symmetric top ammonia molecule is a valuable diagnostic because its complex energy level structure covers a very broad range of critical densities and temperatures (see Ho \& Townes 1983, for energy level diagram and review).

Many observations have been made of the $\mathrm{NH}_{3}$ inversion lines at $\mathrm{cm}$ wavelengths since the first detection by Cheung et al. (1968). The upper state energy of the lowest metastable inversion lines are $24 \mathrm{~K}$ and $64 \mathrm{~K}$ comparable to $28 \mathrm{~K}$ for the rotational ground state transition $1_{0}-0_{0}$ at $572 \mathrm{GHz}$. The critical density is very different though, and is $3.6 \times 10^{7} \mathrm{~cm}^{-3}$ (calculated for $20 \mathrm{~K}$ ) for the rotational ground state transition, and about $10^{3} \mathrm{~cm}^{-3}$ for the inversion lines. The non-metastable inversion lines also trace higher excitation and density regions. Comparison of all these transitions could therefore give valuable information about both high- and low-density and temperature regions. The previous low quantity of observations of rotational transitions is due to the fact that they fall into the submillimetre and infrared regimes, which are generally not accessible from the ground and therefore has to be observed from space.

Observations of both metastable and non-metastable inversion lines (e.g. Batrla et al. 1983; Hermsen et al. 1988a,b; Migenes et al. 1989) have shown $\mathrm{NH}_{3}$ in the $\mathrm{HC}, \mathrm{CR}, \mathrm{ER}$ and LVF regions. The existence of an outflow component was however questioned by Genzel et al. (1982) since the hyperfine satellite lines could cause the broadness of the line if the opacity is large.

The rotational ground state transition was first and solely detected twenty-four years ago with the Kuiper Airborne Observatory (Keene et al. 1983). Note that the Kuiper Airborne Observatory had a similar beam size $\left(2^{\prime}\right)$ to that of Odin $\left(2{ }^{\prime} 1\right)$. Using Odin, sensitive observations have been made recently for example towards Orion KL and the Orion Bar (Larsson et al. 2003), the $\rho$ Oph A core (Liseau et al. 2003), Sgr B2 (Hjalmarson et al. 2005), as well as the molecular cloud S140. The resulting $\mathrm{NH}_{3}$ abundance in the Orion Bar is $5 \times 10^{-9}$ (Larsson et al. 2003).

In this spectral survey we have observed the rotational ground state $1_{0}-0_{0}$ transitions of $\mathrm{NH}_{3}$ and ${ }^{15} \mathrm{NH}_{3}$, which are shown in Fig. 25 (online material). We show the $\mathrm{NH}_{3}$ transition twice to emphasize the line wings. Our peak temperature agrees to within 5\% with Larsson et al. (2003) who used a rather different Odin observational setup, demonstrating the excellent calibration of the Odin data. The vibrational transition $v_{2}=1$ of this line at $466 \mathrm{GHz}$ has previously been observed by Schilke et al. (1992).

Figure 8 shows our two-component Gaussian fit to the $\mathrm{NH}_{3}$ line which has pronounced features of the $\mathrm{CR}$ and a broad component. The line widths are 5 and $16 \mathrm{~km} \mathrm{~s}^{-1}$ at LSR velocities 8 , and $9 \mathrm{~km} \mathrm{~s}^{-1}$ for the $\mathrm{CR}$ and broad components, respectively. The $\mathrm{CR}$ emission was also observed by Keene et al. (1983), while the broader component clearly seen in our Odin data, was only marginally present in their lower signalto-noise data. Our ${ }^{15} \mathrm{NH}_{3}$ spectrum shows only evidence of the 


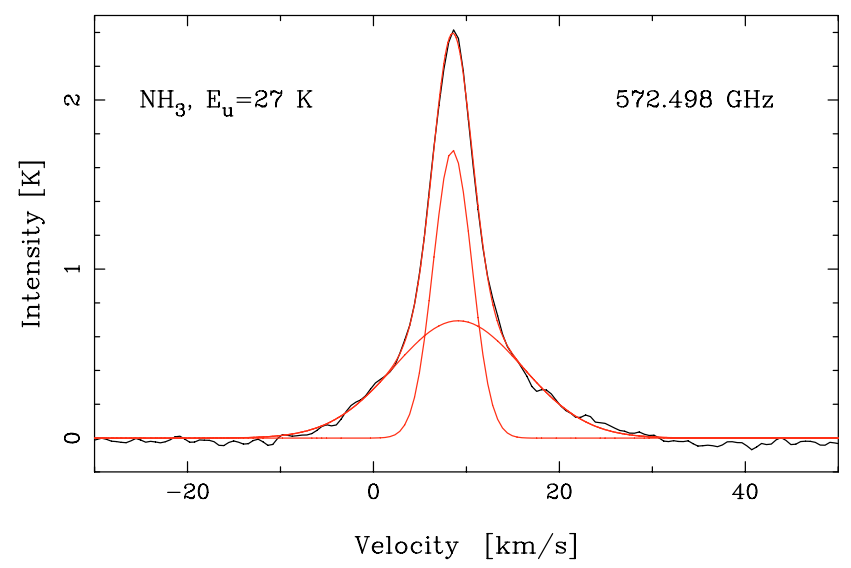

Fig. 8. The $\mathrm{NH}_{3}$ transition with a two-component Gaussian fit shown together with the individual Gaussians. The line widths are $5 \mathrm{~km} \mathrm{~s}^{-1}$ and $16 \mathrm{~km} \mathrm{~s}^{-1}$ from the CR and HC/outflow, respectively.

HC component (cf. Hermsen et al. 1985), with a width of $\sim 7 \mathrm{~km} \mathrm{~s}^{-1}$ at $v_{\text {LSR }} \approx 7 \mathrm{~km} \mathrm{~s}^{-1}$. The width of the broad $\mathrm{NH}_{3}$ component may seem too large to have an origin in the HC. However, the broadness of the line may be caused by opacity broadening (Eq. (21); cf. Phillips et al. 1979). From Eq. (16) combined with an assumed ${ }^{14} \mathrm{~N} /{ }^{15} \mathrm{~N}$ isotope ratio of 450 (Table 6), we estimate optical depths of $\sim 100$ and $\sim 0.3$ in the $\mathrm{NH}_{3}$ and ${ }^{15} \mathrm{NH}_{3} \mathrm{HC}$ lines, respectively. According to Eq. (21) this will broaden the optically thick $\mathrm{NH}_{3}$ emission line by approximately 2.6 times from a line width comparable to the optically thin ${ }^{15} \mathrm{NH}_{3} \mathrm{HC}$ emission to a resulting width of $\sim 17 \mathrm{~km} \mathrm{~s}^{-1}$. This is very close to the width of our Gaussian $\mathrm{HC}$ component, $16 \mathrm{~km} \mathrm{~s}^{-1}$. However, the high opacity in this component will cause the line profile to be flat topped with little or no line wings. Hence our broad Gaussian component not only contains the opacity broadened $\mathrm{HC}$ emission but also the outflow component seen by e.g. Wilson et al. (1979) and Pauls et al. (1983), in our spectrum visible as pronounced line wings. Alternatively it could be that the HC emission is hidden by optically thick $\mathrm{NH}_{3}$ LVF emission just as in case of water (cf. Sect. 6.2.2).

The $\mathrm{NH}_{3}$ source sizes of the $\mathrm{CR}$ and $\mathrm{HC}$ regions are found to be $17^{\prime \prime}$ and $8^{\prime \prime}$, respectively, and are used as beam-filling corrections. The rather large $\mathrm{CR}$ size as compared to the 6 " mean source size obtained for $\mathrm{CH}_{3} \mathrm{OH}$, might be due to the low upper state energy of $27 \mathrm{~K}$ for $\mathrm{NH}_{3}$. Figure 12 shows the decreasing methanol source size with upper state energy, where the lowest methanol transitions with upper state energies of 40-100 K reach a source size of $\sim 11^{\prime \prime}$. Hermsen et al. (1988b) find source sizes of $15^{\prime \prime}$ and 6 " for the CR and HC, respectively, in agreement with our calculations. VLA maps by Migenes et al. (1989) also show that the HC emission is clumped on 1 " scales.

Hermsen et al. (1988b) find a HC temperature of $160 \pm 25 \mathrm{~K}$ and a CR temperature above $100 \mathrm{~K}$. In addition Wilson et al. (2000) detect an even hotter HC component with a temperature of about $400 \mathrm{~K}$. Using HC and CR temperatures of $200 \mathrm{~K}$ and $115 \mathrm{~K}$, respectively, we find a $\mathrm{NH}_{3} \mathrm{HC}$ column density (calculated from the optically thin ${ }^{15} \mathrm{NH}_{3}$ line) of $1.6 \times 10^{18} \mathrm{~cm}^{-2}$. Our comparison surveys have no observations of this molecule, but our result agrees with Genzel et al. (1982), who report column densities of $\mathrm{NH}_{3}$ that reach $5 \times 10^{18} \mathrm{~cm}^{-2}$ from the $\mathrm{HC}$, with size $10^{\prime \prime}$ and temperatures about $200 \mathrm{~K}$. Their observations also confirmed increasing line width with increasing optical depth. Hermsen et al. (1988b) and Pauls et al. (1983) find values of $1 \times$ $10^{18} \mathrm{~cm}^{-2}$ for the HC.

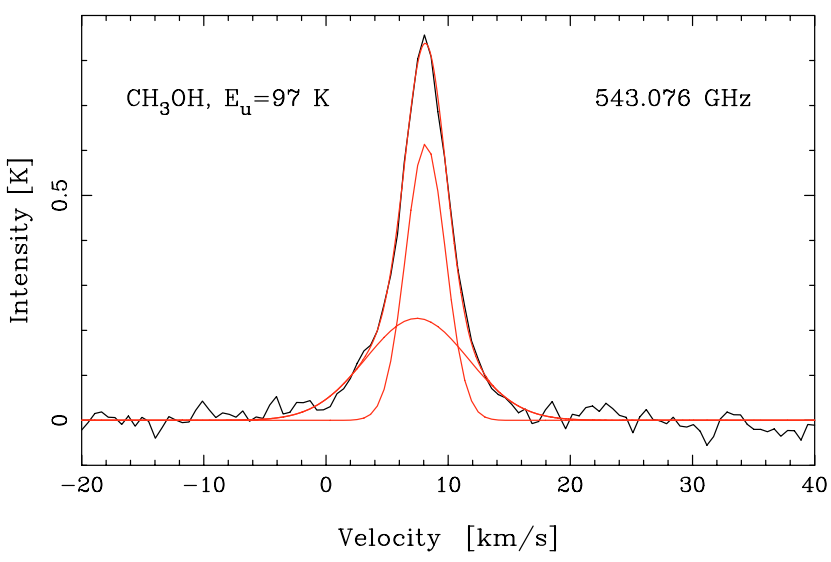

Fig. 9. Methanol line with a two-component fit shown together with the individual Gaussians. The line widths are $4 \mathrm{~km} \mathrm{~s}^{-1}$ and $10 \mathrm{~km} \mathrm{~s}^{-1}$ from the $\mathrm{CR}$ and $\mathrm{HC}$, respectively.

The optically thick $\mathrm{NH}_{3} \mathrm{CR}$ column density is found to be $3.4 \times 10^{15} \mathrm{~cm}^{-2}$. Optical depth broadening is used to estimate the opacity in this component. Batrla et al. (1983) found an intrinsic velocity width of $2.6 \mathrm{~km} \mathrm{~s}^{-1}$ by ammonia inversion lines observations. From a comparison with the observed line width, the opacity is estimated to be about 12 in the CR component. The opacity-corrected CR column density then becomes $4.0 \times 10^{16} \mathrm{~cm}^{-2}$. This is in agreement with the estimation of Hermsen et al. (1988b) who find a column density in the range $8 \times 10^{15}-8 \times 10^{16} \mathrm{~cm}^{-2}$ from the metastable $(6,6)$ inversion line.

\subsubsection{Methanol $\left(\mathrm{CH}_{3} \mathrm{OH} /{ }^{13} \mathrm{CH}_{3} \mathrm{OH}\right)$}

Methanol is an organic asymmetric top molecule with many energy levels (see energy level diagram in Nagai et al. 1979), and behaves like two different species labelled A and E for symmetry reasons.

We have observed 76 methanol lines of which 42 are from the $v_{t}=1$ state, which is the first excited vibrational state of the torsional motion of the $\mathrm{CH}_{3}$ group relative to the $\mathrm{OH}$ group. In the online Fig. 32 we have collected a number of examples of typical line profiles of $\mathrm{CH}_{3} \mathrm{OH}$, with different upper state energies and $A$-coefficients. The rarer isotopologue ${ }^{13} \mathrm{CH}_{3} \mathrm{OH}$ is seen with 23 lines, of which two are vibrationally excited. Three typical line profiles are shown in the online Fig. 30.

The $\mathrm{CH}_{3} \mathrm{OH}$ lines show evidence of two velocity components. One narrow, likely from the $\mathrm{CR}$, with a line width of $\sim 3-4 \mathrm{~km} \mathrm{~s}^{-1}$, and average velocity $\sim 8 \mathrm{~km} \mathrm{~s}^{-1}$. The other broader component with a probable origin in the $\mathrm{HC}$ has a line width of $\sim 6-10 \mathrm{~km} \mathrm{~s}^{-1}$, and average velocity $\sim 7 \mathrm{~km} \mathrm{~s}^{-1}$ (see an example of a two-component Gaussian fit in Fig. 9). This is consistent with the findings of Menten et al. (1988), S95, C05, and also of Beuther et al. (2005) who locate the methanol emission to the HC as well as the CR in their SMA aperture synthesis maps. According to recent CRYRING storage ring measurements (Geppert et al. 2005; Millar 2005) the dissociative recombination of a parent ion $\mathrm{CH}_{3} \mathrm{OH}_{2}^{+}+\mathrm{e}^{-} \rightarrow \mathrm{CH}_{3} \mathrm{OH}+\mathrm{H}$ is so slow that gas-phase formation of methanol is unable to explain the abundance of this molecule, even in dark clouds where it is rare. Instead we have to rely on efficient hydrogenation reactions on grain surfaces, and subsequent release of the methanol into gas-phase. In this scenario the presence of very large amounts of $\mathrm{CH}_{3} \mathrm{OH}$ in the compact, heated $\mathrm{CR}$ and $\mathrm{HC}$ sources is indeed expected. 


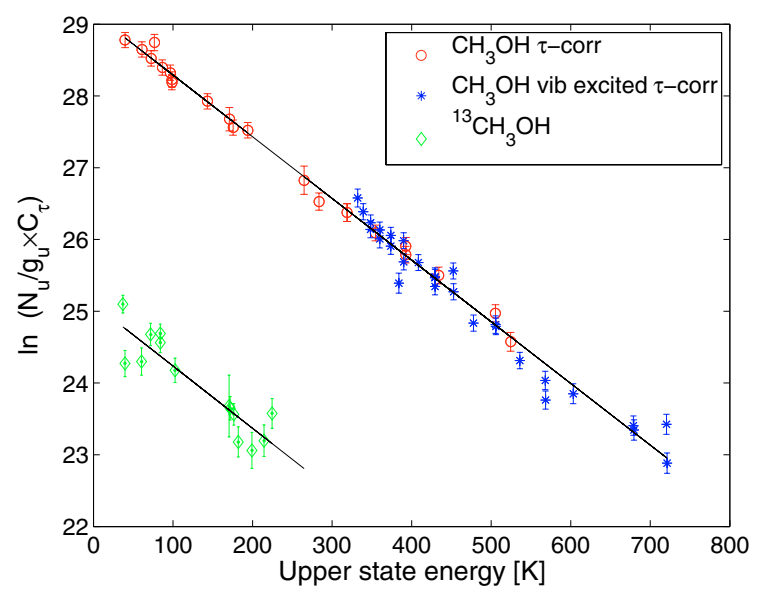

Fig. 10. $\mathrm{CH}_{3} \mathrm{OH}$ opacity corrected rotation diagram producing $T_{\mathrm{ROT}}=$ $116 \mathrm{~K}$ (extended source). The opacity is calculated with varying sourcesizes with energy. The ${ }^{13} \mathrm{CH}_{3} \mathrm{OH}$ rotation diagram gives a temperature of $115 \mathrm{~K}$.

The isotopologue ${ }^{13} \mathrm{CH}_{3} \mathrm{OH}$ show only evidence of the narrow component, which can be well fitted by a single Gaussian with $\Delta v \approx 3 \mathrm{~km} \mathrm{~s}^{-1}$ at $v_{\text {LSR }} \approx 8 \mathrm{~km} \mathrm{~s}^{-1}$. This is also consistent with Menten et al. (1988) and Beuther et al. (2005). The slight broadening of the $\mathrm{CH}_{3} \mathrm{OH}$ narrow components compared with that of ${ }^{13} \mathrm{CH}_{3} \mathrm{OH}$ might be caused by optical depth broadening. The ${ }^{13} \mathrm{CH}_{3} \mathrm{OH}$ from the $\mathrm{HC}$ is expected to be well below our detection limit. There are $14{ }^{13} \mathrm{CH}_{3} \mathrm{OH}$ lines free from blends with an upper state energy range between $37-225 \mathrm{~K}$, which are used in a rotation diagram (Fig. 10). No corrections for optical depths are needed since the ${ }^{13} \mathrm{CH}_{3} \mathrm{OH}$ transitions are optically thin. The rotation temperature is found to be $115 \pm 16 \mathrm{~K}$, and the column density $(5.9 \pm 1.5) \times 10^{16} \mathrm{~cm}^{-2}$.

If we exclude blended and very weak lines we have $50 \mathrm{CH}_{3} \mathrm{OH}$ lines with an upper state energy range from 40 to $721 \mathrm{~K}$. The large number of lines and the wide temperature range make methanol well suited to be used in a rotational diagram. However, one difficulty that may occur with this method is that the optical depths may vary considerably between the $\mathrm{CH}_{3} \mathrm{OH}$ transitions. In the rotation diagram seen in Fig. 44 (online material) the lines are plotted (using the total integrated intensity) without any attempt to correct for optical depth or beam-dilution. As can be seen there is a large scatter of the $\mathrm{CH}_{3} \mathrm{OH}$ lines. Three transitions with upper state energies of 77 , 171 and $265 \mathrm{~K}$ lie clearly very high above the others due to their low transition probability and low opacity. A separate fit of these three lines is made and the resulting beam-filling corrected column density becomes $(2.6 \pm 0.4) \times 10^{18} \mathrm{~cm}^{-2}$. This is about 3 times higher than the resulting column density from all the lines, $(9.3 \pm 1.1) \times 10^{17} \mathrm{~cm}^{-2}$. This indicates that opacity correction needs to be included in the rotation diagram.

Using the forward model, which includes opacity and beamfilling correction (see Fig. 45 in the online material), we find a column density of $(1.3 \pm 0.1) \times 10^{18} \mathrm{~cm}^{-2}$ in a source size of $6^{\prime \prime}$. (This size is used as beam-filling correction in all calculations of the column densities above.) The scatter in the rotation diagram is reduced and approaches the column density obtained from the three (assumed) optically thin lines. However, since this method has a tendency to underestimate the column density we proceed with opacity correction of the traditional rotation diagram. We note that most of the low energy lines seem to be optically thick (opacities between $\sim 1-6$ ) and most of the high energy lines seem to be optically thin (opacities between

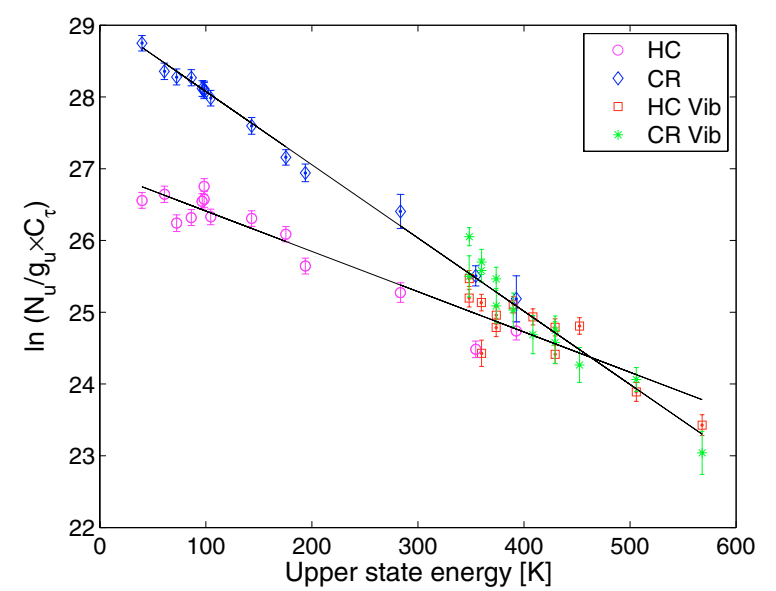

Fig. 11. Two component $\mathrm{CH}_{3} \mathrm{OH}$ opacity corrected rotation diagram producing $T_{\mathrm{ROT}}=178 \mathrm{~K}$ and $98 \mathrm{~K}$ for the $\mathrm{HC}$ and $\mathrm{CR}$, respectively (extended source). The opacity is calculated with the same parameters together with varying source-size with energy.

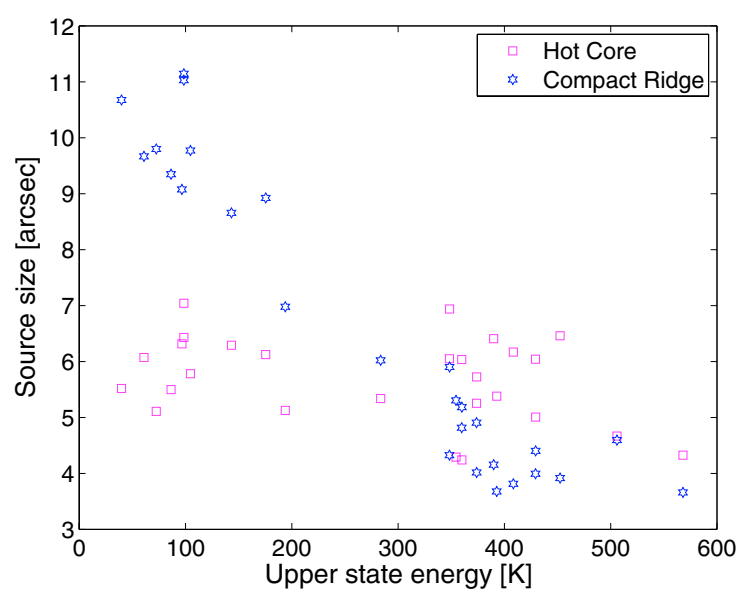

Fig. 12. Source size variation with energy for the $\mathrm{CR}$ and $\mathrm{HC}$ components of $\mathrm{CH}_{3} \mathrm{OH}$ (opacity-corrected with $N_{\mathrm{CR}}=1.7 \times 10^{18} \mathrm{~cm}^{-2}, T_{\mathrm{CR}}=$ $120 \mathrm{~K}$ and $\left.N_{\mathrm{HC}}=7.9 \times 10^{17} \mathrm{~cm}^{-2}, T_{\mathrm{HC}}=200 \mathrm{~K}\right)$.

$\sim 0.3-1.5)$. The rotation temperature would be too high if not opacity corrected.

An additional complication is that the extent of the emitting regions may be different for lines of different energy (cf. Menten et al. 1986). This is affecting our estimation of the opacity since we need a total column density (corrected for beam-filling) in the calculations. The online Fig. 46 shows that the source size of the low-energy lines varies between 5-12", whereas the size of the high-energy lines is almost constant (about $6^{\prime \prime}$ ), based on Eq. (14) at $T_{\mathrm{ROT}}=120 \mathrm{~K}$.

In Fig. 10 we show the opacity corrected rotation diagram. The opacity is calculated using the column density obtained from the three optically thin lines corrected for different beamfillings for each transition, and the same excitation temperature for all lines $(120 \mathrm{~K})$. The scatter in the plot is even more reduced than in the forward model and the resulting column density becomes $(3.4 \pm 0.2) \times 10^{18} \mathrm{~cm}^{-2}$. This is much higher than in our comparison surveys, but consistent with Johansson et al. (1984), Menten et al. (1986), and S01 using the ${ }^{13} \mathrm{CH}_{3} \mathrm{OH}$ column density (all corrected for our source size).

The rotation temperature is $116 \pm 2 \mathrm{~K}$ with opacity correction which is the same as produced by the ${ }^{13} \mathrm{CH}_{3} \mathrm{OH}$ rotation diagram $(115 \pm 16 \mathrm{~K})$ and the optically thin fit $(120 \pm 10 \mathrm{~K})$. 


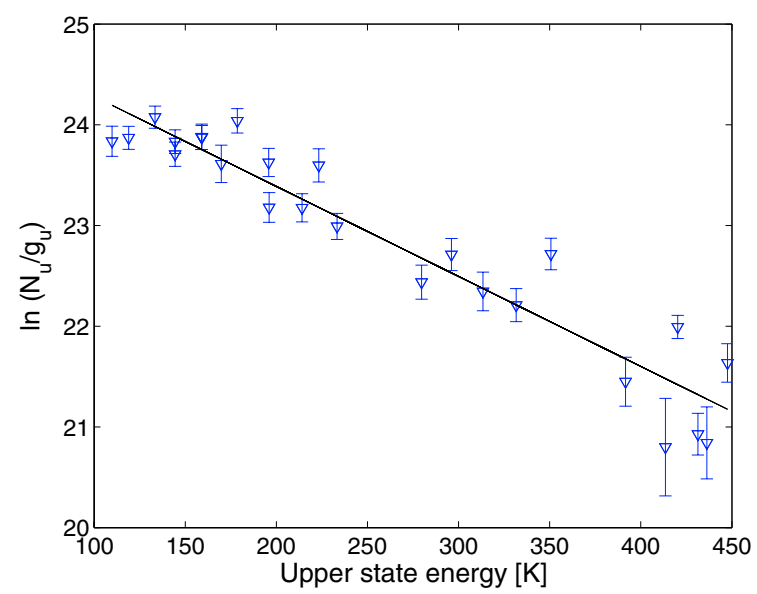

Fig. 13. Rotation diagram for $\left(\mathrm{CH}_{3}\right)_{2} \mathrm{O}$ producing $T_{\mathrm{ROT}}=112 \mathrm{~K}(\mathrm{ex}-$ tended source).

The forward model produces a slightly higher temperature $(136 \pm 4 \mathrm{~K})$, which suggests that the opacity correction is too low with this method.

There is also a possibility that the high- and low energy lines are emitted from different regions even though our rotation diagram does not indicate a change of rotation temperature. Using the Gaussian decomposition of the 27 strongest lines, we note that the integrated intensity of the low energy lines is dominated by the narrow CR component, and the high energy lines by the broad HC emission.

When calculating the opacity of the components we again take into account the varying source size with energy. However, Fig. 12 shows that the pronounced variation in size is only true for the narrow component. The broad component seems to have approximately the same size as the energy increases. This again supports the scenario in which the narrow component arises in the CR, which is denser and hotter in the central parts. Hence only the central parts have the ability to emit the high energy lines. The broad component keeps the small size across the transition energy range, supporting an origin in the HC. This source is small and hot and thus can emit all transitions throughout the whole region. The opacity of the $\mathrm{CR}$ component is found to be higher than in the HC component which is about 1 or less.

Plotting the components in a opacity corrected rotation diagram (Fig. 11), produces column densities and rotation temperatures for each region: $N_{\mathrm{ROT}}=(2.4 \pm 0.2) \times 10^{18} \mathrm{~cm}^{-2}, T_{\mathrm{ROT}}=$ $98 \pm 2 \mathrm{~K}$ and $(7.9 \pm 1.0) \times 10^{17} \mathrm{~cm}^{-2}, T_{\mathrm{ROT}}=178 \pm 11 \mathrm{~K}$ for the CR and HC, respectively. Both column densities are much higher than in our comparison surveys, but agrees well with S95 (corrected for our source size). The calculated temperatures are lower than in the comparison surveys, but the high apparent rotation temperatures may be caused by high opacity. Hollis et al. (1983) found that the ground-state transitions originate in a $90 \mathrm{~K}$ region, while the torsionally excited transitions come from a $200 \mathrm{~K}$ region.

The isotopic ratio of ${ }^{12} \mathrm{C} /{ }^{13} \mathrm{C}$ can be estimated from the ratio of the optically thin $\mathrm{CH}_{3} \mathrm{OH}$ and ${ }^{13} \mathrm{CH}_{3} \mathrm{OH}$ column densities, and is found to be $57 \pm 14$. This is consistent with previous estimates (Table 6).

\subsection{Compact Ridge molecules}

\subsubsection{Dimethyl ether $\left(\left(\mathrm{CH}_{3}\right)_{2} \mathrm{O}\right)$}

This molecule is affected by two internal rotors which are the origin of the fine structure lines of the AA, AE, EE and

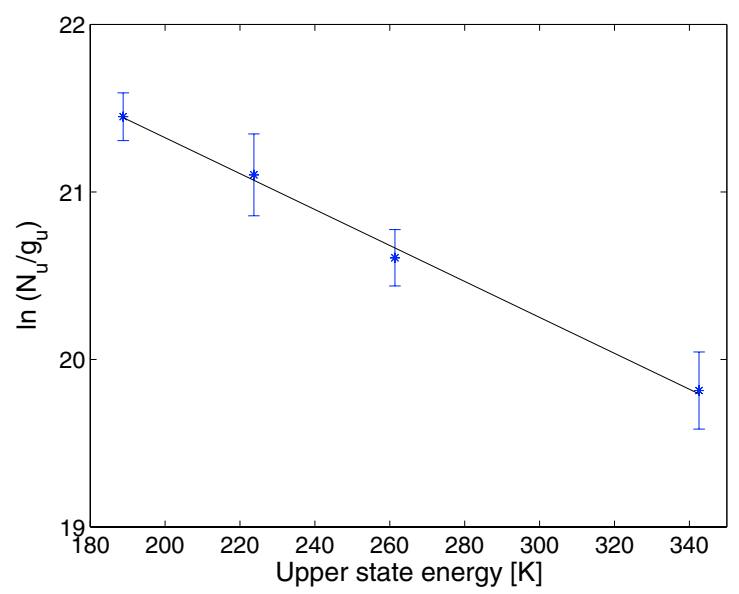

Fig. 14. Rotation diagram for $\mathrm{H}_{2} \mathrm{CS}$ producing $T_{\mathrm{ROT}}=93 \mathrm{~K}$ (extended source).

EA symmetries (Groner et al. 1998). The emission only shows characteristics of the CR with narrow widths of $3-4 \mathrm{~km} \mathrm{~s}^{-1}$ at $v_{\text {LSR }}$ velocities of $\sim 6-8 \mathrm{~km} \mathrm{~s}^{-1}$.

Since we cannot resolve these fine structure transitions, we treat them as one single line. The statistical weights and the partition function are changed accordingly. We observe 47 quartets out of which 37 are free from blends and hence can be used in the rotation diagram shown in Fig. 13. The resulting beamfilling corrected column density is $(1.3 \pm 0.3) \times 10^{17} \mathrm{~cm}^{-2}$ and the rotation temperature is $112 \pm 8 \mathrm{~K}$, which is higher than in the comparison line surveys (Table 1 ). The adopted source size is the same as obtained for $\mathrm{CH}_{3} \mathrm{OH}$, since these molecules most likely have a rather similar origin in the CR. This is also verified when calculating the source size with Eq. (14), assuming an opacity larger than unity. For a temperature of $112 \mathrm{~K}$ we find a CR size of 5-6". This is also indicating optically thick lines which could increase the column density even further.

\subsubsection{Thio-formaldehyde $\left(\mathrm{H}_{2} \mathrm{CS}\right)$}

Five transitions of the CR-emitting $\mathrm{H}_{2} \mathrm{CS}$ are observed, of which the $16_{3,13}-15_{3,12}$ transition is a blend with a U-line. The line profile of the $14_{1,13}-13_{1,12}$ transition is shown in Fig. 33 (online material). The four lines with no blends are used in the rotation diagram shown in Fig. 14, producing a rotation temperature, very similar to that of $\mathrm{CH}_{3} \mathrm{OH}, T_{\mathrm{ROT}}=(93 \pm 4) \mathrm{K}$. The resulting beam-filling corrected column density is $(1.3 \pm 0.2) \times$ $10^{15} \mathrm{~cm}^{-2}$, with a source size of $14^{\prime \prime}$ guided by our calculations for the $\mathrm{H}_{2} \mathrm{CO}$ optically thick CR emission (see Sect. 4.6.1).

A comparison of the $\mathrm{H}_{2} \mathrm{CS}$ and the optically thin $\mathrm{H}_{2}^{13} \mathrm{CO}$ results in a molecular abundance ratio of $\mathrm{H}_{2} \mathrm{CO} / \mathrm{H}_{2} \mathrm{CS} \sim 15$. This is lower than the quoted $[\mathrm{O} / \mathrm{S}]$ ratio of 35 (online Table 6) from Grevesse et al. (1996). From the comparison of $\mathrm{H}_{2} \mathrm{O}$ and $\mathrm{H}_{2} \mathrm{~S}$ in Sect. 6 we obtain a similar value of $\sim 20$.

\subsubsection{Thioformyl cation $\left(\mathrm{HCS}^{+}\right)$}

The thioformyl cation previously has not been seen either by W03 nor S01, and here we only observe the $J=13-12$ transition as a visible blend with ${ }^{33} \mathrm{SO}$. Due to the blend we cannot analyse this transition further, but this emission is most likely emitted in the same small hot and dense CR source as $\mathrm{CH}_{3} \mathrm{OH}$ and $\left(\mathrm{CH}_{3}\right)_{2} \mathrm{O}$. 


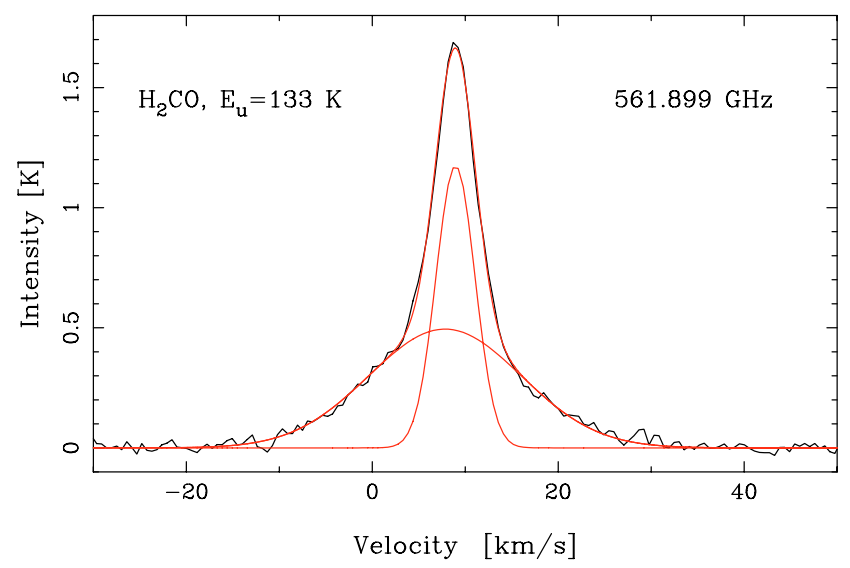

Fig. 15. The $\mathrm{H}_{2} \mathrm{CO} 8_{1,8}-7_{1,7}$ transition with a two-component Gaussian fit shown together with the individual Gaussians. The line widths are $5 \mathrm{~km} \mathrm{~s}^{-1}$ and $19 \mathrm{~km} \mathrm{~s}^{-1}$ from the CR and LVF, respectively.

\subsection{Outflow and Compact Ridge molecule}

\subsubsection{Formaldehyde $\left(\mathrm{H}_{2} \mathrm{CO} / \mathrm{H}_{2}^{13} \mathrm{CO} / \mathrm{HDCO}\right)$}

We detect three transitions from each of $\mathrm{H}_{2} \mathrm{CO}$ and $\mathrm{HDCO}$, and one transition from $\mathrm{H}_{2}^{13} \mathrm{CO}$. Since the energy range is small $(106-133 \mathrm{~K})$, no rotation diagram can be made. The $8_{1,8}-7_{1,7}$ transition of $\mathrm{H}_{2} \mathrm{CO}$ is shown in Fig. 33 (online material), together with the same transition of $\mathrm{H}_{2}^{13} \mathrm{CO}$ and the $9_{1,9}-8_{1,8}$ transition of HDCO. The $\mathrm{H}_{2} \mathrm{CO} 8_{0,8}-7_{0,7}$ transition shows a blend with Hot Core NS at $576.720 \mathrm{GHz}$. The $8_{1,7}-7_{1,6}$ transition of $\mathrm{H}_{2} \mathrm{C}^{18} \mathrm{O}$ is tentatively found at $571.477 \mathrm{GHz}$.

The $\mathrm{H}_{2} \mathrm{CO}$ lines show two velocity components. Figure 15 shows a two-component Gaussian fit. The narrow component from the CR has widths of $\sim 5 \mathrm{~km} \mathrm{~s}^{-1}$ at $v_{\mathrm{LSR}} \sim 8.5 \mathrm{~km} \mathrm{~s}^{-1}$, and the broader component from the LVF has widths of $\sim 19 \mathrm{~km} \mathrm{~s}^{-1}$ at $v_{\mathrm{LSR}} \sim 8 \mathrm{~km} \mathrm{~s}^{-1} . \mathrm{H}_{2}^{13} \mathrm{CO}$ and $\mathrm{HDCO}$ show only emission from the CR with similar widths and LSR velocities as for the narrow $\mathrm{H}_{2} \mathrm{CO}$ component. Comparison of the $\mathrm{CR}$ component of the $\mathrm{H}_{2} \mathrm{CO} 8_{1,8}-7_{1,7}$ transition with the same $\mathrm{H}_{2}^{13} \mathrm{CO}$ transition, results in optical depths of $\sim 6.6$ and $\sim 0.1$, respectively (using $\left.\left[{ }^{12} \mathrm{C} /{ }^{13} \mathrm{C}\right]=60\right)$.

Since the CR component is optically thick in $\mathrm{H}_{2} \mathrm{CO}$, this source size is calculated with Eq. (14) and is found to be as large as $14^{\prime \prime}$ for a temperature of $115 \mathrm{~K}$, in agreement with Mangum et al. (1990). The LVF source size becomes $10^{\prime \prime}$, which might be caused by a low opacity. Hence a LVF size of $15^{\prime \prime}$ is used for beam-filling correction. The resulting CR and LVF column densities are $3.0 \times 10^{15} \mathrm{~cm}^{-2}$ and $4.3 \times 10^{15} \mathrm{~cm}^{-2}$, respectively. With the use of the optically thin $\mathrm{H}_{2}^{13} \mathrm{CO}$ the $\mathrm{CR}$ column density increases to $2.0 \times 10^{16} \mathrm{~cm}^{-2}$, in agreement with Turner (1990), Mangum et al. (1990), and S95.

Since $\mathrm{H}_{2} \mathrm{CO}$ is optically thick we cannot calculate the $\left[{ }^{12} \mathrm{C} /{ }^{13} \mathrm{C}\right]$ elemental ratio. But with the use of the optically thin $\mathrm{H}_{2}^{13} \mathrm{CO}$ and $\mathrm{HDCO}$, the abundance ratio of $\mathrm{D} / \mathrm{H}$ is estimated to $\sim 0.01$, which implies a high deuterium fractionation in the CR. Turner (1990) derived a ratio of $\mathrm{HDCO} / \mathrm{H}_{2} \mathrm{CO}=0.14_{-0.07}^{+0.12}$ and $\mathrm{D}_{2} \mathrm{CO} / \mathrm{HDCO}=2.1_{-0.5}^{+1.2} \times 10^{-2}$ for the $\mathrm{CR}$. These large abundance ratios were interpreted as a result of active grain surface chemistry.

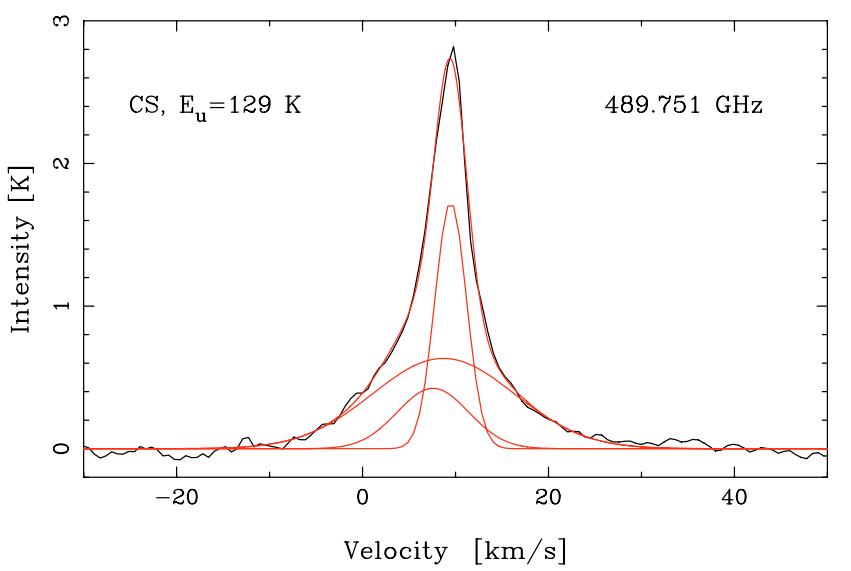

Fig. 16. The CS $J=10-9$ transition with a three-component Gaussian fit shown together with the individual Gaussians. The line widths are $4 \mathrm{~km} \mathrm{~s}^{-1}, 9 \mathrm{~km} \mathrm{~s}^{-1}$, and $18 \mathrm{~km} \mathrm{~s}^{-1}$ from the CR/ER, the HC and LVF, respectively.

\subsection{Outflow, Hot Core and Compact/Extended Ridge molecules}

\subsubsection{Carbon monosulfide $\left(\mathrm{CS} /{ }^{13} \mathrm{CS}\right)$}

Figure 16 shows a three-component Gaussian fit to the observed $J=10-9$ transition of CS. Emission is seen from a narrow component, the $\mathrm{HC}$ and the LVF at LSR velocities 9, 7 and $10 \mathrm{~km} \mathrm{~s}^{-1}$ with widths 4,9 and $18 \mathrm{~km} \mathrm{~s}^{-1}$, respectively. The narrow component may have an origin either from the ER or the CR, hence the column density is calculated with both alternatives. The CS line is also compared to $\mathrm{H}_{2} \mathrm{CS}$ and isotopologues of $\mathrm{H}_{2} \mathrm{CO}$ in Fig. 33 (online material).

The ${ }^{13} \mathrm{CS} J=12-11$ transition is observed with emission from a narrow (ER or CR) component, but is blended with a ${ }^{34} \mathrm{SO}_{2}$ transition. This makes the Gaussian fit with a width of $5 \mathrm{~km} \mathrm{~s}^{-1}$, at LSR velocity $7 \mathrm{~km} \mathrm{~s}^{-1}$ approximate. Comparison of peak antenna temperatures of the isotopologues (using a ${ }^{12} \mathrm{C} /{ }^{13} \mathrm{C}$ ratio of 60 ) suggests that the narrow $\mathrm{CS}$ component is optically thick $(\tau \sim 6-12)$. The source size of an ER component is calculated with Eq. (14) and is found to be $30^{\prime \prime}$ for at temperature of $60 \mathrm{~K}$. This suggests that either the emission of this component is rather extended and clumpy (see Sect. 8), or has an origin in the CR. For a typical CR temperature of $115 \mathrm{~K}$, we find a size of $20^{\prime \prime}$.

The resulting column densities are listed in Table 1. The column density of the LVF agrees well with B87, S95, S01 and $\mathrm{C} 05$, and the HC column also agrees with S95, but is lower than found in C05. The narrow component from either the CR och ER is more difficult to compare. Our ER column agrees rather well with B87, but is an order of magnitude lower than found by S95. As CR emission it agrees with S95. The differences may arise due to opacity, beam-sizes and energy levels.

\subsubsection{Hydrogen isocyanide (HNC)}

Figure 17 shows a four-component Gaussian fit of the HNC $J=6-5$ transition with an upper state energy of $91 \mathrm{~K}$, and a U-line seen in the red-ward LVF line wing at a velocity of $22 \mathrm{~km} \mathrm{~s}^{-1}$. As for CS, three velocity components, from the ER, $\mathrm{HC}$, and LVF, are clearly seen at $v_{\mathrm{LSR}}=9,6$ and 7 with widths of 4,9 and $27 \mathrm{~km} \mathrm{~s}^{-1}$, respectively. The sizes and temperatures for the subregions are taken to be representative of typical values 


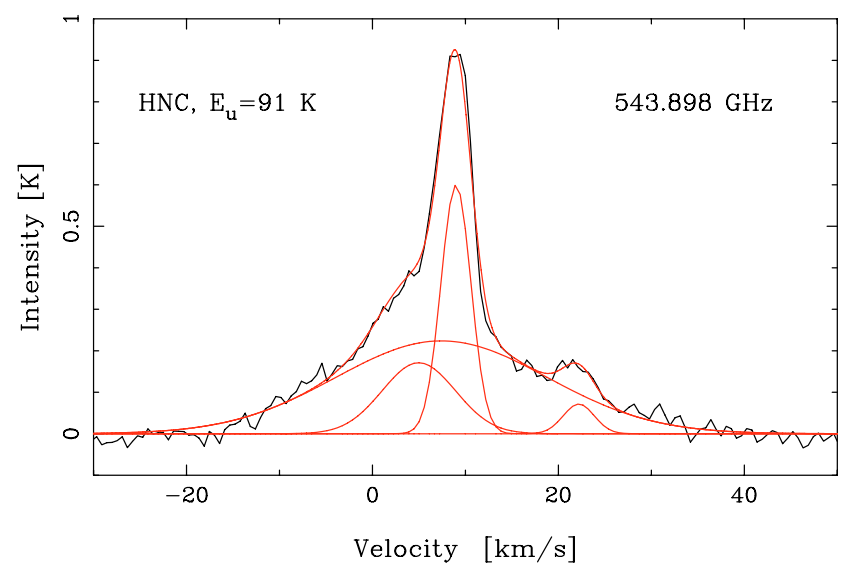

Fig. 17. The HNC $J=6-5$ transition and a U-line at $543.873 \mathrm{GHz}$ with a four-component Gaussian fit shown together with the individual Gaussians. The line widths are $4 \mathrm{~km} \mathrm{~s}^{-1}$ for the U-line, $4 \mathrm{~km} \mathrm{~s}^{-1}$, $9 \mathrm{~km} \mathrm{~s}^{-1}$, and $27 \mathrm{~km} \mathrm{~s}^{-1}$ for the HNC ER, HC and outflow components, respectively.

(see Table 1). The HNC line is also shown in Fig. 31 (online material).

\subsection{PDR/Extended Ridge and Hot Core molecule}

\subsubsection{The cyanide radical $(\mathrm{CN})$}

The main $\mathrm{CN}$ emission has its origin in the PDR/ER region and the HC (Rodríguez-Franco et al. 1998) at $v_{\mathrm{LSR}} \sim 9$ and $8.5 \mathrm{~km} \mathrm{~s}^{-1}$ with widths of $\sim 4$ and $\sim 10 \mathrm{~km} \mathrm{~s}^{-1}$, respectively. In total we have observed three lines with 8 non-resolved hyperfine structure features. Figure 31 (online material) shows one of the $N=5-4$ transitions, consisting of three non-resolved hyperfine structure lines, with two additional ones in the line wing at a velocity of $1 \mathrm{~km} \mathrm{~s}^{-1}$. The same transitions are shown in Fig. 18 with a three-Gaussian fit of the five transitions. No rotation diagram is made since the upper state energy of $54 \mathrm{~K}$ is the same for all transitions.

Using Gaussian fits, the LTE approximation and typical temperatures and source sizes, the column densities for the HC and PDR/ER regions are estimated to be $7.9 \times 10^{15} \mathrm{~cm}^{-2}$, and $4.9 \times$ $10^{13} \mathrm{~cm}^{-2}$ for the HC and PDR/ER, respectively. Our comparison surveys have no observations of $\mathrm{CN}$, but Rodríguez-Franco et al. (2001) obtained column densities by $\mathrm{CN}$ mapping, ranging from $10^{13} \mathrm{~cm}^{-2}$ in the Trapezium region to $10^{14}-10^{15} \mathrm{~cm}^{-2}$ in the Ridge region. S95 find $N=1 \times 10^{15} \mathrm{~cm}^{-2}$ with a $14^{\prime \prime}$ beam, and $\mathrm{B} 87$ also find the same $\mathrm{CN}$ column density with a $30^{\prime \prime}$ beam.

\subsection{Extended Ridge molecule}

\subsubsection{Diazenylium $\left(\mathrm{N}_{2} \mathrm{H}^{+}\right)$}

The diazenylium transition $J=6-5$ is shown in Fig. 31 (online material). The width of $\sim 5 \mathrm{~km} \mathrm{~s}^{-1}$ at $v_{\mathrm{LSR}} \approx 9 \mathrm{~km} \mathrm{~s}^{-1}$ indicates an ER origin of the emission, in agreement with mapping of the $J=1-0$ transitions by Womack et al. (1990) and Ungerechts et al. (1997). The column density of $1.0 \times 10^{12} \mathrm{~cm}^{-2}$, that we calculate using the simple LTE approximation, is much lower than that found by Ungerechts et al. (1997), $8.4 \times 10^{12} \mathrm{~cm}^{-2}$.

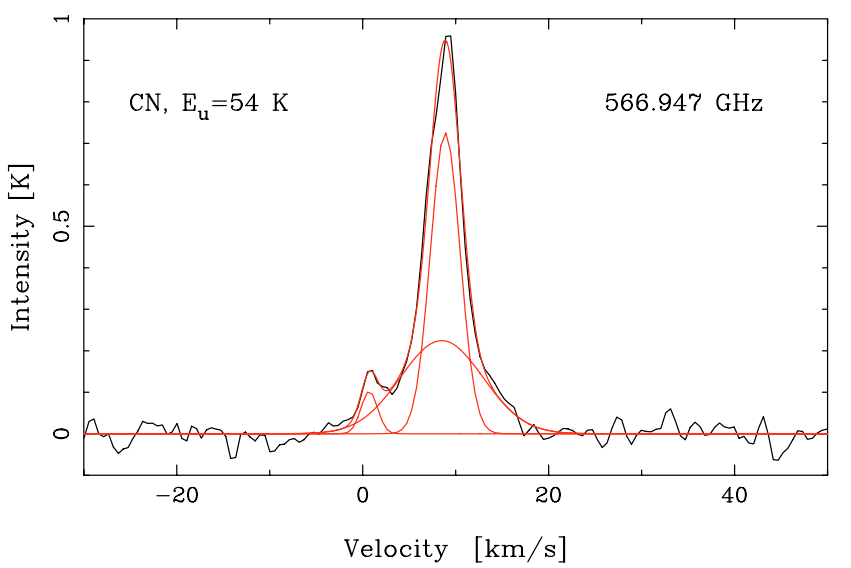

Fig. 18. $\mathrm{CN}$ with a three-component Gaussian fit of five unresolved hyperfine-structure lines shown together with the individual Gaussians. The widths are $4 \mathrm{~km} \mathrm{~s}^{-1}$ and $11 \mathrm{~km} \mathrm{~s}^{-1}$ for the PDR/ER and HC components of the three strong hyperfine-structure lines, respectively, and $2 \mathrm{~km} \mathrm{~s}^{-1}$ for the weak transitions at a velocity of $0 \mathrm{~km} \mathrm{~s}^{-1}$.

\subsection{Unidentified line features}

We observe 64 unidentified line features. Tentative assignments have been given to 26 lines, such as the first tentative detections of ND, and of the anion $\mathrm{SH}^{-}$(see Fig. 34, Tables 34, and 35 in the online material and Table 3 in Paper I). There are 28 U-lines, i.e. clearly detected lines, and 36 T-lines, which means that they are only marginally visible against the noise or in a blend. The tentative assignments also include the species $\mathrm{SO}^{+}, \mathrm{CH}_{3} \mathrm{CHO}$, $\mathrm{CH}_{3} \mathrm{OCHO}, \mathrm{SiS}, \mathrm{HNCO}, \mathrm{H}_{2} \mathrm{C}^{18} \mathrm{O}$, and a high energy $\mathrm{HDO}$ line. For details see Paper I.

The strongest U-line is found at $542.945 \mathrm{GHz}$ with a peak intensity of $140 \mathrm{mK}$. The line appears to show emission from two components, probably the CR and the HC (see Fig. 34 in the online material).

\section{Carbon monoxide $\left(\mathrm{CO} /{ }^{13} \mathrm{CO} / \mathrm{C}^{17} \mathrm{O} / \mathrm{C}^{18} \mathrm{O}\right)$, carbon (C) and $\mathrm{H}_{2}$ column densities}

We have observed the $J=5-4$ transition of $\mathrm{CO},{ }^{13} \mathrm{CO}, \mathrm{C}^{17} \mathrm{O}$, and $\mathrm{C}^{18} \mathrm{O}$ (Fig. 26). The $\mathrm{CO}$ line is the most intense single line in our $42 \mathrm{GHz}$ wide band. The FWZP (Full Width Zero Power) of CO is approximately $230 \mathrm{~km} \mathrm{~s}^{-1}$, as compared to $120 \mathrm{~km} \mathrm{~s}^{-1}$ reported in Wirström et al. (2006, hereafter W06), a result of our much lower noise level. Since W06 also used Odin but with another observation mode, we can again demonstrate the high accuracy of the Odin calibration with a comparison of the amplitudes, which agree within less than five percent.

As pointed out in W06 it is clear that CO $J=5-4$ has emission from at least three different components - LVF, HVF and a narrow component. The high brightness temperature of the last component suggests that this emission originates in the extended and warm PDR, whereas the narrow components from the optically thin isotopologues have approximately equal emission from the PDR and the colder ER gas behind it. We observe all three components in the $\mathrm{CO}$ and ${ }^{13} \mathrm{CO}$ emission, but only the narrow ER/PDR component and the LVF for the $\mathrm{C}^{17} \mathrm{O}$ and $\mathrm{C}^{18} \mathrm{O}$ isotopologues (W06). The Gaussian components are given in Tables 8 and 32 in the online material, and agree well with W06, especially when our higher signal-to-noise ratio is taken into account, which enables us to see line wings that were previously unobserved. 
A summary of the resulting column densities, estimated optical depths, used source sizes and temperatures is found in Table 2, and also in more detail in the online Table 8. Here also column densities calculated from all isotopologues are given together with the parameters of the Gaussian fits. Note that the column density for the $\mathrm{CO}$ narrow component (calculated from $\mathrm{C}^{17} \mathrm{O}$ ) is lowered by a factor of two, since this component only has emission from the PDR, while the isotopologues have approximately equal emission from both the PDR and ER. For detailed arguments see W06.

The only observed atomic species in this survey is the ${ }^{3} P_{1}-{ }^{3} P_{0}$ transition of $\mathrm{C}$ at $492.1607 \mathrm{GHz}$. It shows a narrow line profile from an extended emission with a width of $4.5 \mathrm{~km} \mathrm{~s}^{-1}$, at LSR velocity $\sim 9 \mathrm{~km} \mathrm{~s}^{-1}$. Due to the loss of orbits during this observation, the noise level here is $200 \mathrm{mK}$, as compared to our average level of $25 \mathrm{mK}$ in the rest of the spectral survey. This makes it impossible to distinguish a possible broad emission in this transition. Our beam-averaged column density of $\mathrm{C}$ is $5.6 \times 10^{17} \mathrm{~cm}^{-2}$. Tauber et al. (1995) find a lower limit for a beam-averaged $\mathrm{C}$ column density of $\sim 7 \times 10^{17} \mathrm{~cm}^{-2}$ (beam size 17") in the Orion bar. Ikeda et al. (1999) find a column density very similar to ours $\left(6.2 \times 10^{17} \mathrm{~cm}^{-2}\right)$ from observations of the $492.1607 \mathrm{GHz}$ transition with the Mount Fuji submillimetrewave telescope towards the Orion KL position, in a HPBW of 2 '2. The optical depth was estimated to be 0.2 . B87 find $N \gtrsim$ $7.5 \times 10^{17} \mathrm{~cm}^{-2}$ with a $30^{\prime \prime}$ beam towards the Orion KL region. Plume et al. (2000) presented maps of the same transition, obtained with the SWAS satellite, resulting in an average column density of $2 \times 10^{17} \mathrm{~cm}^{-2}$.

When estimating abundances we need comparison column densities of $\mathrm{H}_{2}$ for each subregion (results also given in Table 2). This is provided by $\mathrm{C}^{17} \mathrm{O}$ for the PDR/ER and LVF components, using $[\mathrm{CO}] /\left[\mathrm{H}_{2}\right]=8 \times 10^{-5}$ (e.g. Wilson \& Matteucci $1992)$, an isotope ratio $\left[{ }^{18} \mathrm{O}\right] /\left[{ }^{17} \mathrm{O}\right]=3.9$ (Table 6$)$, together with $\left[{ }^{16} \mathrm{O}\right] /\left[{ }^{18} \mathrm{O}\right]=330$ (Olofsson 2003). The latter value was found from high $\mathrm{S} / \mathrm{N} \mathrm{S}^{18} \mathrm{O}$ observations of molecular cloud cores. This is somewhat lower than the usually quoted value of 560 (Wilson \& Rood 1994), valid for the local ISM and estimated from $\mathrm{H}_{2} \mathrm{CO}$ surveys in 1981 and 1985. A likely explanation for the lower value is a local enrichment of ${ }^{18} \mathrm{O}$ relative to ${ }^{16} \mathrm{O}$ by the ejecta from massive stars. For the HVF component we use ${ }^{13} \mathrm{CO}$ since $\mathrm{C}^{17} \mathrm{O}$ has no HVF emission.

The resulting $\mathrm{H}_{2}$ column density from the LVF is $3.2 \times$ $10^{23} \mathrm{~cm}^{-2}$. This is close to the limits given by Masson et al. (1987) $(3-10) \times 10^{22} \mathrm{~cm}^{-2}$, as well as $1 \times 10^{23} \mathrm{~cm}^{-2}$ by Genzel \& Stutzki (1989). Wright et al. (2000) find a beam-averaged $\mathrm{H}_{2}$ column density of $2.8 \times 10^{23} \mathrm{~cm}^{-2}$ from observations of the $28.2 \mu \mathrm{m} \mathrm{H}_{2} 0-0 \mathrm{~S}(0)$ line for a temperature of $130 \mathrm{~K}$ (beam size $\left.20^{\prime \prime} \times 33^{\prime \prime}\right)$.

Our resulting $\mathrm{HVF} \mathrm{H}_{2}$ column density is $3.9 \times 10^{22} \mathrm{~cm}^{-2}$, in agreement with the Genzel \& Stutzki value of $5 \times 10^{22} \mathrm{~cm}^{-2}$. In contrast, Watson et al. (1985) found that the HVF column of warm shock heated $\mathrm{H}_{2}$ is only $3 \times 10^{21} \mathrm{~cm}^{-2}$, a result based upon their KAO observation of high- $J$ CO lines.

Tauber et al. (1995) reported an average $\mathrm{H}_{2}$ column density of $\sim 3 \times 10^{22} \mathrm{~cm}^{-2}$ from the Orion Bar (calculated from ${ }^{13} \mathrm{CO}$ mapping). This is in agreement with our total narrow component, which we find to be $4 \times 10^{22} \mathrm{~cm}^{-2}$. When we calculate the abundances in Sect. 7, we divide this value by two, since there are about equal contributions from the PDR and ER to the $\mathrm{C}^{17} \mathrm{O}$ emission (W06). Our value is also consistent with the results of Goldsmith et al. (1997) convolved with the 2!1 Odin beam.

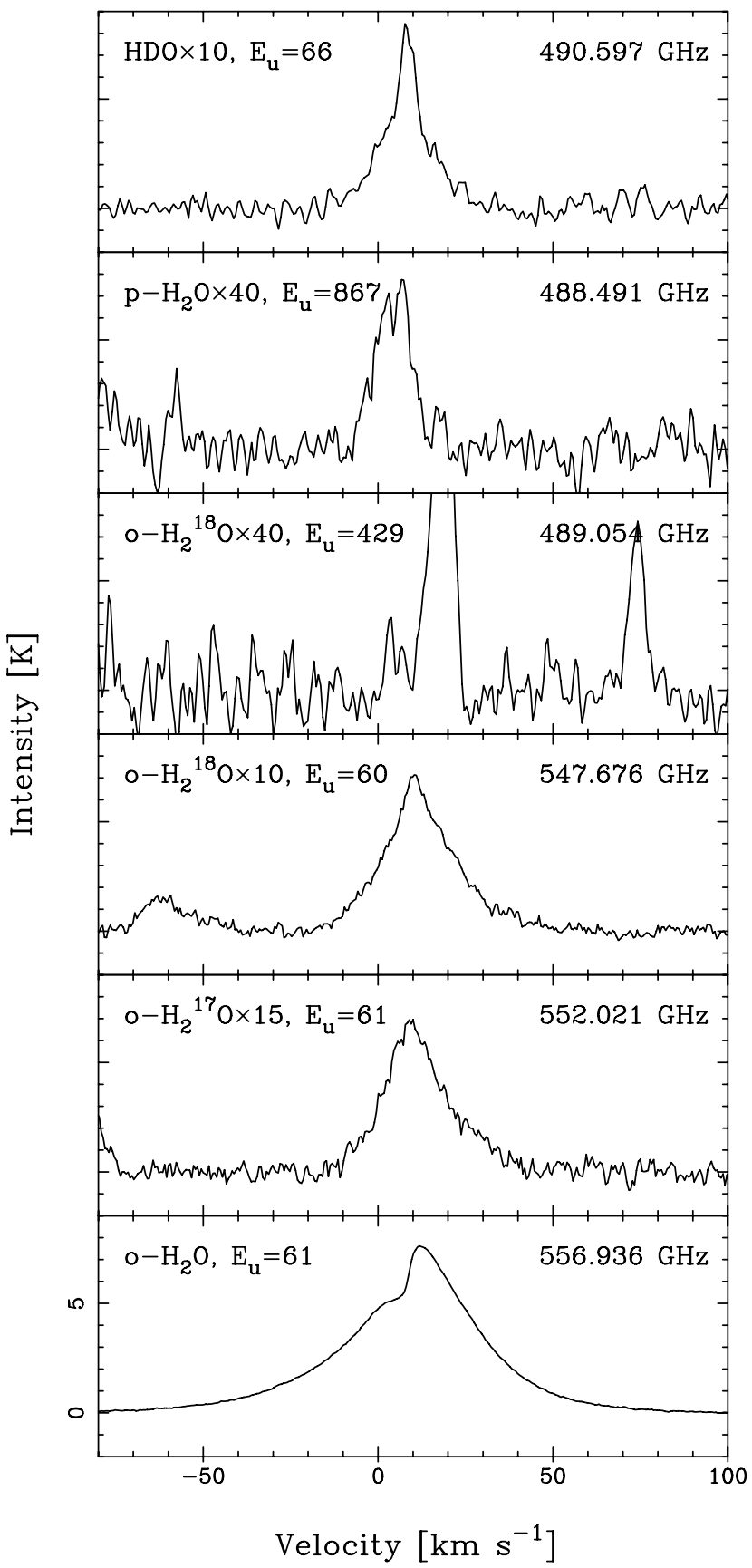

Fig. 19. Water and isotopologues. The $o-\mathrm{H}_{2}^{17} \mathrm{O}$ is reconstructed spectra with blending lines subtracted. An intensity scale factor is given after the molecular species.

\section{Water $\left(\mathrm{o}-\mathrm{H}_{2}^{16} \mathrm{O}, \mathrm{p}-\mathrm{H}_{2}^{16} \mathrm{O}, \mathrm{o}-\mathrm{H}_{2}^{17} \mathrm{O}, \mathrm{o}-\mathrm{H}_{2}^{18} \mathrm{O}, \mathrm{HDO}\right)$}

\subsection{Correcting the water emission lines for blends}

Because of the large number of methanol and sulphur dioxide lines observed, they cause the most common blends in all lines. Since we are particularly interested in water, we attempt to reconstruct the water isotopologues without blends. We use observed transitions in our survey with similar parameters $\left(E_{\mathrm{u}}\right.$, $A$-coefficient and $g_{\mathrm{u}}$ ), and scale them with the parameters of the blending lines before removal from the water isotopologue line of interest. The molecular line parameters of the blending transitions are found in the online Tables 9, 10 and 20. 
Two lines are blended with the $o-\mathrm{H}_{2}^{18} \mathrm{O} 1_{1,0}-1_{0,1}$ ground state rotational transition. The ${ }^{34} \mathrm{SO}_{2} 21_{3,19}-20_{2,18}$ transition is blended with the red wing, and in the blue wing there is an overlapping methanol line, $15_{1,15}-15_{2,14}, v_{t}=1$. However, since the simultaneous observations of $o-\mathrm{H}_{2}^{17} \mathrm{O}$ show that the $\mathrm{H}_{2}^{18} \mathrm{O}$ transition is optically thick even in the line wings (see next section), we do not attempt to remove these blending transitions.

The $o-\mathrm{H}_{2}^{17} \mathrm{O}$ ground state rotational transition is, however, optically thin in the line wings, and we therefore remove three blending lines. In Fig. 38 (online material) we show two of the blending lines together with the $o-\mathrm{H}_{2}^{17} \mathrm{O}$ line. In the blue $o-\mathrm{H}_{2}^{17} \mathrm{O}$ wing the blending $\mathrm{SO}_{2}$ transition $26_{6,20}-26_{5,21}$ is overlapping. In the red wing there are two blends. One from the $6_{6,1}-7_{5,3}$ methanol transition shown, and one from the very weak $\mathrm{SO}_{2}$ $34_{1,33}-34_{0,34}$ transition.

\subsection{Water analysis}

We have observed the $1_{1,0}-1_{0,1}$ ground state rotational transition of $o-\mathrm{H}_{2} \mathrm{O}$ and its isotopologues $o-\mathrm{H}_{2}^{18} \mathrm{O}$ and $o-\mathrm{H}_{2}^{17} \mathrm{O}$, which mainly show emission from the Plateau. A very weak feature at $489.054 \mathrm{GHz}$ is tentatively identified as the HC-tracing $4_{2,3}-3_{3,0}$ transition of $o-\mathrm{H}_{2}^{18} \mathrm{O}$ with an upper state energy of $429 \mathrm{~K}$. The HC-tracing $p-\mathrm{H}_{2} \mathrm{O}$ transition $6_{2,4}-7_{1,7}$ with an upper state energy of $867 \mathrm{~K}$, is also observed, as well as the $2_{0,2}-1_{1,1}$ HDO transition showing emission from the CR, HC and LVF. Figure 19 shows all detected water lines after removal of some blends in $\mathrm{H}_{2}^{17} \mathrm{O}$ as discussed in the previous section.

The optical depths, column densities, assumed source sizes and excitation temperatures are found in Table 2, and in more detail in Table 7 (online material), together with the parameters of the Gaussian fits.

Both the $o-\mathrm{H}_{2}^{18} \mathrm{O}$ and $o-\mathrm{H}_{2}^{17} \mathrm{O}$ ground state rotational transition show features of a weak, narrow component from the CR, a broad stronger component from the LVF, and with HVF emission mainly in the red wing. Figures 35 and 36 (online material) show three-component Gaussian fits to the water isotopologues. The emission from the ER and PDR is considered to be very low since the water mainly will be frozen onto the dust grains at the rather low temperatures in this region.

The $o-\mathrm{H}_{2} \mathrm{O}$ line is very optically thick at all velocities as seen in Fig. 39 (online material) which displays the ratio of $o-\mathrm{H}_{2} \mathrm{O}$ and $o-\mathrm{H}_{2}^{18} \mathrm{O}$. The excitation conditions for these two isotopologues are therefore very different. A similar figure of the ratio of $o-\mathrm{H}_{2}^{18} \mathrm{O}$ and $o-\mathrm{H}_{2}^{17} \mathrm{O}$ (Fig. 40 in the online material) shows an almost constant ratio of 1.5 for velocities between -10 and $+30 \mathrm{~km} \mathrm{~s}^{-1}$. This demonstrates that the two line profiles are almost identical, and that the $o-\mathrm{H}_{2}^{18} \mathrm{O}$ emission is rather optically thick at all velocities since $\left[{ }^{18} \mathrm{O} /{ }^{17} \mathrm{O}\right]=3.9$. By comparison of column densities from the total integrated intensities, the optical depths for $o-\mathrm{H}_{2}^{17} \mathrm{O}$ and $o-\mathrm{H}_{2}^{18} \mathrm{O}$, are 0.9 and 3.4, respectively. The small changes of the ratio with velocity as seen in Fig. 40 also are consistent with our decomposition into Gaussian components. The LVF is optically thick in both isotopologues, whereas the HVF and CR have lower optical depths causing increase of the ratio at their emission velocities.

\subsubsection{Ortho- $\mathrm{H}_{2} \mathrm{O}$ from the low- and high velocity flow and the Compact Ridge}

The similarity of the line profiles is also illustrated in Fig. 20 showing a comparison of $o-\mathrm{H}_{2}^{17} \mathrm{O}, o-\mathrm{H}_{2}^{18} \mathrm{O}$ and the $19_{3,17}-18_{2,16}$ $\mathrm{SO}_{2}$ transition, all normalised to their respective peak

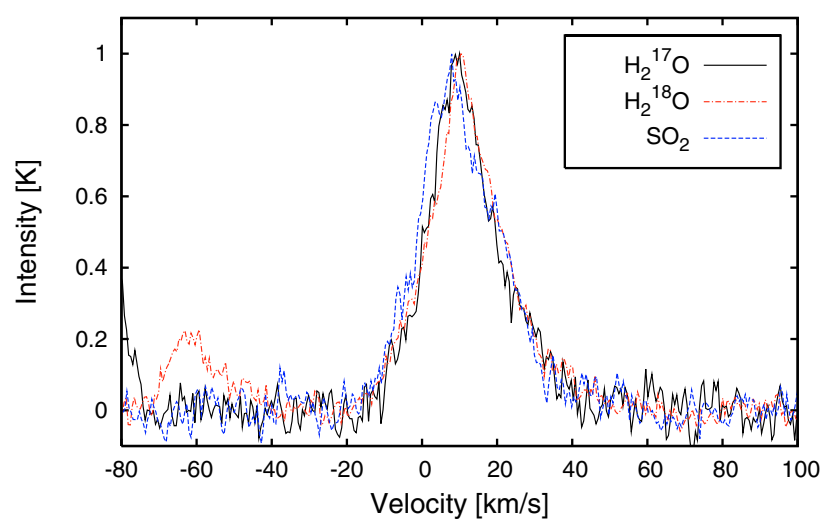

Fig. 20. Comparison of $\mathrm{H}_{2}^{18} \mathrm{O}$, with $\mathrm{H}_{2}^{17} \mathrm{O}$, and the $19_{3,17}-18_{2,16}$ $\mathrm{SO}_{2}$ transition, all normalised with respective peak temperature. The high degree of similarity of all three line profiles suggests an origin in the same gas and velocity fields, mainly from the LVF with additional emission from HVF in the red wings.

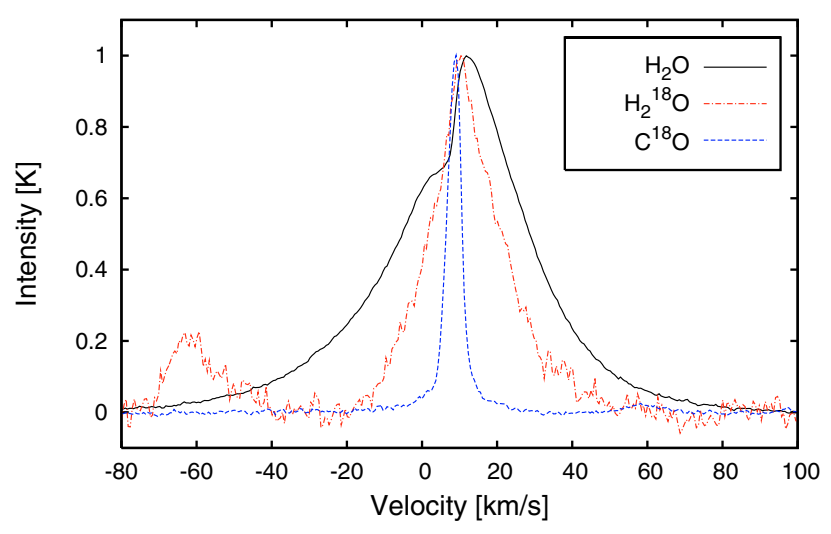

Fig. 21. Comparison of the optically thick self-absorbed $o-\mathrm{H}_{2} \mathrm{O}$ with $o-\mathrm{H}_{2}^{18} \mathrm{O}$ and $\mathrm{C}^{18} \mathrm{O} J=5-4$, all normalised with respective peak intensity. The LVF self-absorption of $o-\mathrm{H}_{2} \mathrm{O}$ in the blue wing is seen when compared to $o-\mathrm{H}_{2}^{18} \mathrm{O}$, which shows LVF emission in both wings and HVF emission mainly in the red wing.

temperature. The remarkable similarity of the line profiles suggests a very similar origin and chemistry of the water isotopologues and $\mathrm{SO}_{2}$ : the LVF and with additional HVF emission mainly in the red wings.

The resulting column densities (found in Table 2 and in the online Table 7) are calculated with the simple LTE approximation and for an ortho/para ratio of 3. As a first approximation of the column density we have used the full integrated intensity of the lines, assuming the Plateau to be the main emitting source (with $T_{\mathrm{ex}}=72 \mathrm{~K}$ and a source size of $15^{\prime \prime}$, see below). We have also calculated the column densities for the different subregions using the Gaussian components. In addition, the $o-\mathrm{H}_{2}^{17} \mathrm{O}$ and $o$ - $\mathrm{H}_{2}^{18} \mathrm{O}$ column densities are calculated with and without optical depth corrections. Since the $o-\mathrm{H}_{2} \mathrm{O}$ transition is highly optically thick, we calculate the column density from $o-\mathrm{H}_{2}^{17} \mathrm{O}$ and $o-\mathrm{H}_{2}^{18} \mathrm{O}$. With isotope ratios of $\left[{ }^{18} \mathrm{O}\right] /\left[{ }^{17} \mathrm{O}\right]=3.9$ and $\left[{ }^{16} \mathrm{O}\right] /\left[{ }^{18} \mathrm{O}\right]=330$ (Table 6), we determine the opacity-corrected column density of $\mathrm{H}_{2} \mathrm{O}$ to be $1.7 \times 10^{18} \mathrm{~cm}^{-2}$. The opacity-corrected LVF and HVF column densities, obtained from the Gaussian fits of the isotopologues, are $8.7 \times 10^{17} \mathrm{~cm}^{-2}$ and $8.8 \times 10^{17} \mathrm{~cm}^{-2}$, respectively. These calculations assume LVF and HVF source sizes for the isotopologues of $15^{\prime \prime}$ (cf. Olofsson et al. 2003), which is the same extent as the submillimetre HDO emission from the 


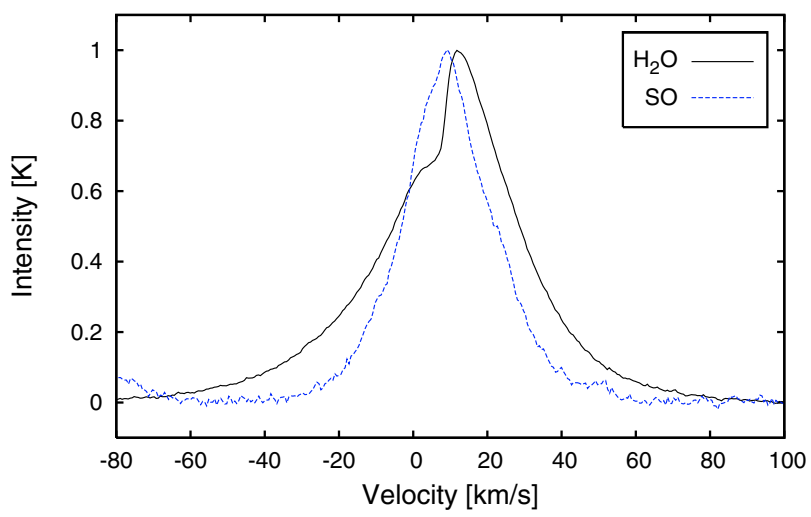

Fig. 22. Comparison of the $13_{13}-12_{12} \mathrm{SO}$ transition and $o-\mathrm{H}_{2} \mathrm{O}$, both normalised with respective peak intensity. Both species show emission from the LVF and the HVF, but the water LVF is self-absorbed in the blue-shifted emission.

LVF mapped by Pardo et al. (2001). As excitation temperature for both LVF and HVF we use $72 \mathrm{~K}$ as found by Wright et al. (2000). We also calculate the $\mathrm{H}_{2} \mathrm{O}$ HVF column density from the Gaussian fit to $\mathrm{H}_{2} \mathrm{O}$ itself, and with opacity-correction (calculated from the isotopologues) almost the same value is obtained as from the isotopologues. The size of the $\mathrm{H}_{2} \mathrm{O} \mathrm{HVF}$ is assumed to have an extent of 70" (Olofsson et al. 2003; Hjalmarson et al. 2005).

The opacity-corrected column density for the $\mathrm{H}_{2} \mathrm{O} \mathrm{CR}$ is $5.6 \times 10^{17} \mathrm{~cm}^{-2}$. For the CR we use the temperature and size obtained from our $\mathrm{CH}_{3} \mathrm{OH}$ rotation diagram of $115 \mathrm{~K}$ and $6 "$. This is also consistent with our calculation of the excitation temperature from the optically thick $\mathrm{H}_{2}^{18} \mathrm{O} \mathrm{CR}$ component, if a source size of $6^{\prime \prime}$ is assumed.

The $o-\mathrm{H}_{2} \mathrm{O}$ line has a central asymmetry that suggests strong self-absorption in the blue LVF by lower excitation foreground gas. The steep change in the self-absorption occurs in the velocity range of 2 to $12 \mathrm{~km} \mathrm{~s}^{-1}$. Figure 21 compares the selfabsorbed $o-\mathrm{H}_{2} \mathrm{O}$ transition both with $o-\mathrm{H}_{2}^{18} \mathrm{O}$, and with the narrow emission from the $\mathrm{C}^{18} \mathrm{O} J=5-4$ line, all normalised to their respective peak temperature. The LVF self-absorption of $o-\mathrm{H}_{2} \mathrm{O}$ in the blue wing is seen when compared to $o-\mathrm{H}_{2}^{18} \mathrm{O}$, which shows LVF emission in both wings, and HVF emission mainly in the red wing. Figure 22 shows a similar comparison between $o-\mathrm{H}_{2} \mathrm{O}$ and an optically thick $\mathrm{SO}$ transition at $559.320 \mathrm{GHz}$. Both species display emission from LVF and HVF, although the blue water LVF emission is self-absorbed.

In Fig. 23 we show the same SO $13_{13}-12_{12}$ transition again, but this time compared to $o-\mathrm{H}_{2}^{18} \mathrm{O}$. In the blue wing SO has excess emission as compared to the water emission, whereas the red wings of $\mathrm{SO}$ and $o-\mathrm{H}_{2}^{18} \mathrm{O}$ are almost identical. This might be caused by shock chemistry in the red HVF which is pushing into the ambient molecular cloud (Genzel \& Stutzki 1989), thereby producing a high water abundance. In the blue HVF, which is leaving the molecular cloud, no such shock chemistry seems to be present. The water abundance in this part of the HVF is likely due to evaporation from icy dust grains, which produces less water than shock chemistry. In contradiction to this, the SO emission is symmetric in both wings, suggesting that shock chemistry is not required to produce high $\mathrm{SO}$ abundances.

The similarity of the broad HVF emissions from $\mathrm{CO}$ and $\mathrm{H}_{2} \mathrm{O}$ is shown in Fig. 24. The FWZP of the broad component is $\sim 230 \mathrm{~km} \mathrm{~s}^{-1}$ for $o-\mathrm{H}_{2}^{16} \mathrm{O}, 50 \mathrm{~km} \mathrm{~s}^{-1}$ for the isotopologues, and $35 \mathrm{~km} \mathrm{~s}^{-1}$ for HDO.

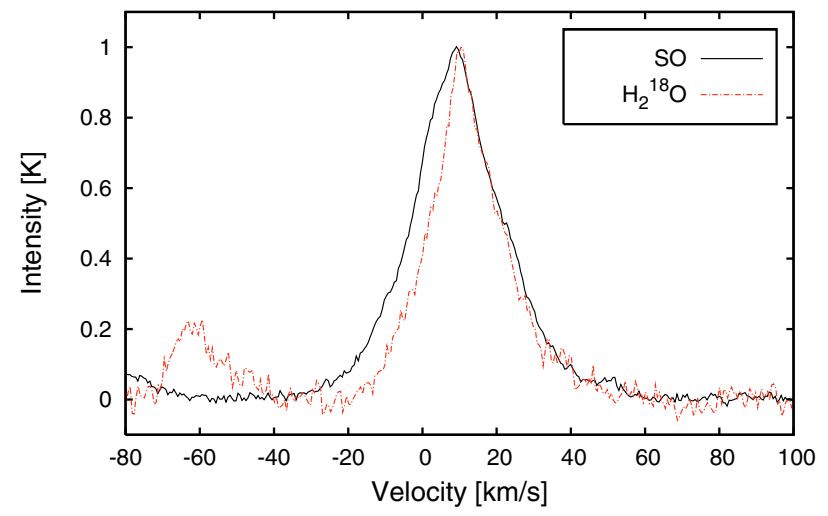

Fig. 23. Comparison of the $13_{13}-12_{12} \mathrm{SO}$ transition, and $o-\mathrm{H}_{2}^{18} \mathrm{O}$ normalised with respective peak intensity.

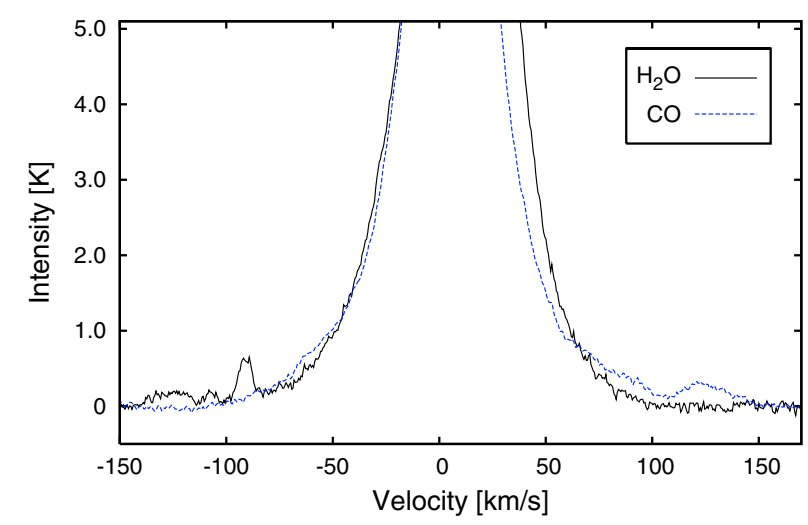

Fig. 24. Comparison of the broad HVF emission in the line wings of $\mathrm{CO}$ and $o-\mathrm{H}_{2} \mathrm{O}$ scaled 2.5 times. Note the large velocity scale.

\subsubsection{Para- $\mathrm{H}_{2} \mathrm{O}$ from the Hot Core}

In the main $o-\mathrm{H}_{2} \mathrm{O} \quad 1_{1,0}-1_{0,1}$ line spectrum (Fig. 19) possible emission from the $\mathrm{HC}$ and $\mathrm{CR}$ would be blended with the much stronger and broader component from the LVF. Melnick et al. (2000) concluded that the HC contributes negligibly to the water emission within the SWAS beam, and the CR would contribute less than 5-10\%. The highest energy levels in the ISO data presented by Lerate et al. (2006) and Cernicharo et al. (2006) may have a contribution from the HC, but those authors remark that the large far-IR line-plus-continuum opacity probably would hide most of this emission.

However, our detected optically thin $p-\mathrm{H}_{2} \mathrm{O} 6_{2,4}-7_{1,7}$ transition with upper state energy $867 \mathrm{~K}$, clearly reveals the emission from the HC. The width of the line is $12 \mathrm{~km} \mathrm{~s}^{-1}$ at $v_{\mathrm{LSR}} \sim$ $4.4 \mathrm{~km} \mathrm{~s}^{-1}$, between velocities -8 and $15 \mathrm{~km} \mathrm{~s}^{-1}$. When column densities are calculated using the simple LTE approximation, we find values in the range $(3.7-12) \times 10^{18} \mathrm{~cm}^{-2}$ for a temperature range of $200-500 \mathrm{~K}$ and a typical source size of $10^{\prime \prime}$. Since no clear $\mathrm{HC}$ emission is seen from the ground rotational state transition in $\mathrm{H}_{2}^{17} \mathrm{O}$, either the temperature in the $\mathrm{HC}$ is high enough to result in the negligible emission of this transition from the $\mathrm{HC}$, or the $\mathrm{H}_{2}^{17} \mathrm{O}$ transition has an optically thick LVF emission which is blocking possible $\mathrm{HC}$ emission. If the temperature is $500 \mathrm{~K}$, the emission from the $\mathrm{HC}$ would only be about $10 \%$ of the total (if no optical depths are taken into account), and therefore would be hidden in the stronger and broader LVF emission even if $\mathrm{H}_{2}^{17} \mathrm{O}$ is optically thin. However, if the temperature in the $\mathrm{HC}$ is about $200 \mathrm{~K}$, the $\mathrm{H}_{2}^{17} \mathrm{O}$ LVF emission has to have an optical depth larger than unity. Since our estimated value is about 
1.5 , this is consistent with a $\mathrm{HC}$ temperature of $200 \mathrm{~K}$ and a column density of $\mathrm{HC} \mathrm{H}_{2} \mathrm{O} 1.2 \times 10^{19} \mathrm{~cm}^{-2}$. This is in agreement with the only previous observation of $\mathrm{H}_{2} \mathrm{O}$ emission from the HC made by S01. They detected the vibrationally excited $1_{1,0}-1_{0,1} v_{2}=1$ transition and found a HC column density of $3 \times$ $10^{19} \mathrm{~cm}^{-2}$ with a temperature of $200 \mathrm{~K}$ and a water abundance of $1 \times 10^{-5}$. Gensheimer et al. (1996) estimated the $\mathrm{HC} \mathrm{H}_{2}^{18} \mathrm{O}$ column density to be $2.7 \times 10^{16} \mathrm{~cm}^{-2}$ from $\mathrm{H}_{2}^{18} \mathrm{O}$ mapping of the quasi-thermal $3_{1,3}-2_{2,0}$ transition with the IRAM telescope (12" beam). This column density translates to $1.3 \times 10^{19} \mathrm{~cm}^{-2}$ for $\mathrm{H}_{2} \mathrm{O}$ (corrected for source size and isotopologue ratio differences), in excellent agreement with our result, even though their observations suffered from severe blends. Their HC water mapping also showed that the emission from both $\mathrm{H}_{2}^{18} \mathrm{O}$ and HDO were unresolved by their beam, and the HDO mapping showed sizes of 6-8".

Our tentative detection of the optically thin $\mathrm{HC}$ emitting $o-\mathrm{H}_{2}^{18} \mathrm{O} 4_{2,3}-3_{3,0}$ transition, with an upper state energy of $430 \mathrm{~K}$, results in a $\mathrm{HC}_{2} \mathrm{O}$ column density of about $4 \times 10^{19} \mathrm{~cm}^{-2}$.

\subsubsection{Comparisons of outflow column densities}

Our column density results for the Plateau agrees excellently with those of Wright et al. (2000), who observed 19 pure rotational lines in absorption using the Short Wavelength Spectrometer (SWS) on board the Infrared Space Observatory (ISO), with a beam size of $14^{\prime \prime} \times 20^{\prime \prime}$ to $20^{\prime \prime} \times 30^{\prime \prime}$. Their rotation diagram, including a generalised curve-of-growth method, results in a rotation temperature of $72 \mathrm{~K}$, and a beam-averaged column density (from the total emission) of $1.5 \times 10^{18} \mathrm{~cm}^{-2}$. They also conclude that the observed water arises from an outflow centred near IRc2.

Lerate et al. (2006) observed more than 70 far-IR pure rotational $\mathrm{H}_{2}^{16} \mathrm{O}$ lines, and $5 \mathrm{H}_{2}^{18} \mathrm{O}$ lines, with the ISO LWS (Long Wavelength Spectrometer) between $\sim 43$ and $197 \mu$ m (beam size about $80^{\prime \prime}$ ). Their rotation diagram of the total emission from $\mathrm{H}_{2}^{18} \mathrm{O}$ results in a beam-averaged column density of $(2-5) \times$ $10^{14} \mathrm{~cm}^{-2}$, and a rotation temperature of $60 \mathrm{~K}$. For a $15^{\prime \prime}$ outflow source, their result translates to $(1.8-4.7) \times 10^{18} \mathrm{~cm}^{-2}$ for $\mathrm{H}_{2}^{16} \mathrm{O}$, also in good agreement with our value. In the analysis by Cernicharo et al. (2006) of this data set, they concluded that most of the water emission and absorption arises from an extended flow of gas with velocity $25 \pm 5 \mathrm{~km} \mathrm{~s}^{-1}$, with an inferred kinetic gas temperature of $80-100 \mathrm{~K}$.

\subsubsection{HDO from the Compact Ridge, low velocity flow and the Hot Core}

The deuterated species HDO is observed in the $2_{0,2}-1_{1,1}$ transition with $E_{\mathrm{u}}=66 \mathrm{~K}$, and shows evidence of CR, LVF, and also $\mathrm{HC}$ emission as is observed by W03. Figure 37 shows a threecomponent Gaussian fit. Pardo et al. (2001) reported detections of the $2_{1,2}-1_{1,1}$ and $1_{1,1}-1_{0,0}$ lines in the $850-900 \mathrm{GHz}$ spectral region, which seem to trace the Plateau gas and not the HC. Their conclusion is that the $\mathrm{HC}$ component is hidden behind the optically thick HDO LVF in their transitions, which is supporting our analysis of the non-detection of $\mathrm{HC}$ emission in the ground state rotational water transitions.

A T-line at $559.816 \mathrm{GHz}$ tentatively is identified as the high energy $(580 \mathrm{~K}) \mathrm{HDO}$ transition $6_{2,4}-6_{2,5}$.

Our estimated column density of HDO, assuming that the main emission originates in the outflows, is $9.1 \times 10^{15} \mathrm{~cm}^{-2}$, which is about the same value as reported by Lerate et al. (2006),
$8.5 \times 10^{15} \mathrm{~cm}^{-2}$ (corrected for source size). The column density reported by Pardo et al. (2001) is higher, $5 \times 10^{16} \mathrm{~cm}^{-2}$, calculated from an LVG model with a source size of $15^{\prime \prime}$, and opacities of 3.7 and 6.7 for their two lines.

We also calculate the column densities for the CR, LVF and $\mathrm{HC}$ separately, which are found to be $1.8 \times 10^{16} \mathrm{~cm}^{-2}, 4.5 \times$ $10^{15} \mathrm{~cm}^{-2}$, and $1.5 \times 10^{16} \mathrm{~cm}^{-2}$, respectively. With correction for source-size, this is 2-4 times lower than found in Olofsson (1984) by mapping the $1_{1,0}-1_{1,1}$ transition with a $47^{\prime \prime}$ beam (at Onsala Space Observatory); $3 \times 10^{16} \mathrm{~cm}^{-2}, 1 \times 10^{16} \mathrm{~cm}^{-2}$, and $7 \times 10^{16} \mathrm{~cm}^{-2}$, respectively.

\subsubsection{Molecular abundance ratios}

The $[\mathrm{D} / \mathrm{H}]$ ratio calculated from from $\mathrm{HDO} / \mathrm{H}_{2} \mathrm{O}$ is $0.005,0.001$ and 0.03 in the LVF, HC, and CR, respectively (Table 6). The $\mathrm{CR}$ ratio may be compared to the $\mathrm{HDCO} / \mathrm{H}_{2}^{13} \mathrm{CO}$ ratio from which we obtain a similar $[\mathrm{D} / \mathrm{H}]$ value of 0.01 (see Sect. 4.6.1). Lerate et al. (2006) found [D/H] values in the range 0.004-0.01.

The column densities for $\mathrm{H}_{2} \mathrm{O}$ and $\mathrm{H}_{2} \mathrm{~S}$ from the LVF are also used to estimate the molecular abundance ratio of $\mathrm{O} / \mathrm{S}$ to $\sim 20$ (Table 6). Using the $\mathrm{H}_{2} \mathrm{CS} / \mathrm{H}_{2}^{13} \mathrm{CO}$ ratio we obtain a similar value of $\sim 15$ (see Sect. 4.5.2).

\section{Molecular abundance estimates}

\subsection{Gas-phase abundances from the Odin spectral line survey}

Our estimated abundances for each subregion are summarised in Table 3, together with comparison abundances mostly from $\mathrm{B} 87$ and S95. We find very high gas-phase abundances of $\mathrm{H}_{2} \mathrm{O}$, $\mathrm{NH}_{3}, \mathrm{SO}_{2}, \mathrm{SO}, \mathrm{NO}$, and $\mathrm{CH}_{3} \mathrm{OH}$. Note that both our LVF and $\mathrm{HC}$ abundances are source averages. S95 use beam-averaged abundances (with a HPBW of $14^{\prime \prime}$ ), and B87 use a HC size of $10^{\prime \prime}$ and a Plateau size of $20^{\prime \prime}$, while we separate the LVF and HVF emissions with a slightly smaller size for the LVF (15"). The beam-averaged CR abundances in both B87 and S95 are corrected to our source-sizes to allow an easier comparison.

A large source of uncertainty in these calculations is the adopted $\mathrm{H}_{2}$ column densities. Whenever possible we have used our own calculated $\mathrm{H}_{2}$ column densities (for the ER, LVF, HVF, Table 2). For the HC and CR we have adopted $N\left(\mathrm{H}_{2}\right)=1 \times 10^{24} \mathrm{~cm}^{-2}$ (calculated for a HC size of $10^{\prime \prime}$ in B87), and $N\left(\mathrm{H}_{2}\right)=2 \times 10^{23} \mathrm{~cm}^{-2}$ (Wilson et al. 1986; B87; Goldsmith et al. 1997), respectively. In case of the HVF we also compare the (shocked) water column with the column density of the hot (shocked) $\mathrm{H}_{2}$, where $N_{\mathrm{HVF}}=3 \times 10^{21} \mathrm{~cm}^{-2}$ (Watson et al. 1985). When we calculate the abundances we assume that the derived $\mathrm{H}_{2}$ column density spatially coincides with the emission from the species of interest.

Most of our abundances, listed in Table 3, are in very good agreement with B87 and S95. However, there are a few exceptions - a 4-15 times higher abundance for $\mathrm{SO}_{2}$ in the LVF, and 2-5 times higher abundances in general in the CR than in B87 and S95. The differences may arise because our observed transitions probe higher density and more compact regions in the CR. Since we cannot discriminate between CR or ER emission for CS, the abundance is calculated with both alternatives. It turns out that the CS abundance is about the same for either source of emission. However, the high ER abundance of CS compared to that of B87 is to a large extent due to the very different $\mathrm{H}_{2}$ column densities used in our survey 
Table 3. Derived abundances and comparisons.

\begin{tabular}{|c|c|c|c|c|}
\hline Region & Species & $\begin{array}{l}\mathrm{X}^{g} \\
{\left[\times 10^{7}\right]}\end{array}$ & $\begin{array}{l}\text { B87 X }{ }^{h} \\
{\left[\times 10^{7}\right]}\end{array}$ & $\begin{array}{l}\mathrm{S} 95 \mathrm{X}^{i} \\
{\left[\times 10^{7}\right]}\end{array}$ \\
\hline \multirow[t]{9}{*}{$\mathrm{LVF}^{a}$} & $\mathrm{H}_{2} \mathrm{O}$ & 29 & & \\
\hline & HDO & 0.15 & 0.17 & \\
\hline & $\mathrm{SO}_{2}$ & 20 & 5.2 & 1.3 \\
\hline & $\mathrm{SO}$ & 3.1 & 5.2 & \\
\hline & $\mathrm{SiO}$ & 0.11 & 0.28 & 0.08 \\
\hline & $\mathrm{H}_{2} \mathrm{~S}$ & 1.5 & 0.98 & \\
\hline & $\mathrm{H}_{2} \mathrm{CO}$ & 0.14 & 0.31 & 1.1 \\
\hline & CS & 0.12 & 0.22 & 0.04 \\
\hline & $\mathrm{HNC}$ & 0.012 & & \\
\hline \multirow[t]{5}{*}{ HVF } & $\mathrm{H}_{2} \mathrm{O} /$ Total $\mathrm{H}_{2}^{b}$ & 220 & $200-300^{j}$ & \\
\hline & $\mathrm{H}_{2} \mathrm{O} / \mathrm{Hot} \mathrm{H}_{2}^{c^{2}}$ & 2900 & $2000-5000^{k}$ & \\
\hline & $\mathrm{SO}_{2}$ & 225 & & \\
\hline & $\mathrm{SO}$ & 21 & & \\
\hline & $\mathrm{SiO}$ & 0.45 & & \\
\hline \multirow[t]{12}{*}{$\mathrm{HC}^{d}$} & $\mathrm{H}_{2} \mathrm{O}$ & 120 & $140^{l}$ & \\
\hline & HDO & 0.15 & 0.5 & 0.14 \\
\hline & $\mathrm{H}_{2} \mathrm{~S}$ & 0.27 & $0.3^{m}$ & \\
\hline & $\mathrm{CH}_{3} \mathrm{CN}$ & 0.05 & 0.078 & 0.04 \\
\hline & $\mathrm{NH}_{3}$ & 16 & $10^{n}$ & \\
\hline & $\mathrm{HC}_{3} \mathrm{~N}$ & 0.018 & 0.016 & 0.018 \\
\hline & OCS & 0.17 & & 1.1 \\
\hline & $\mathrm{CH}_{3} \mathrm{OH}$ & $7.9^{\circ}$ & $1-10^{p}$ & 1.4 \\
\hline & HNC & 0.0044 & & \\
\hline & $\mathrm{CS}$ & 0.029 & & 0.06 \\
\hline & $\mathrm{CN}$ & 0.079 & & 0.008 \\
\hline & $\mathrm{NO}$ & 2.8 & $2.0^{m}$ & \\
\hline \multirow[t]{11}{*}{$\mathrm{CR}^{e}$} & $\mathrm{H}_{2} \mathrm{O}$ & 28 & & \\
\hline & HDO & 0.87 & & 0.93 \\
\hline & $\mathrm{NH}_{3}$ & 2.0 & & \\
\hline & $\mathrm{CH}_{3} \mathrm{OH}$ & $120^{\circ}$ & 30 & 22 \\
\hline & $\left(\mathrm{CH}_{3}\right)_{2} \mathrm{O}$ & 6.5 & 2.5 & 1.0 \\
\hline & $\mathrm{H}_{2} \mathrm{CO}$ & 1.0 & 0.6 & 0.46 \\
\hline & $\mathrm{HDCO}$ & 0.014 & & \\
\hline & $\mathrm{H}_{2} \mathrm{CS}$ & 0.065 & 0.06 & 0.014 \\
\hline & $\mathrm{SO}_{2}$ & 10 & & \\
\hline & SO & 0.85 & & \\
\hline & $\mathrm{CS}$ as CR & 0.40 & & 0.1 \\
\hline \multirow[t]{3}{*}{$\mathrm{ER}^{f}$} & $\mathrm{CS}$ as ER & 0.21 & 0.025 & 0.11 \\
\hline & $\mathrm{HNC}$ & 0.001 & 0.005 & \\
\hline & $\mathrm{N}_{2} \mathrm{H}^{+}$ & 0.0005 & & \\
\hline \multirow[t]{3}{*}{$\mathrm{PDR}^{f}$} & $\mathrm{H}_{2} \mathrm{O}$ & $\gtrsim 1.1^{q}$ & $0.33^{r}$ & \\
\hline & $\mathrm{CN}$ & 0.02 & 0.03 & \\
\hline & $\mathrm{NH}_{3}$ & $0.05^{s}$ & & \\
\hline
\end{tabular}

${ }^{a} \operatorname{LVF} N\left(\mathrm{H}_{2}\right)=3 \times 10^{23} \mathrm{~cm}^{-2}$ (this work). ${ }^{b} \mathrm{HVF}$ total $N\left(\mathrm{H}_{2}\right)=4 \times$ $10^{22} \mathrm{~cm}^{-2}$ (this work). ${ }^{c} \mathrm{HVF}$ hot $N\left(\mathrm{H}_{2}\right)=3 \times 10^{21} \mathrm{~cm}^{-2}$ (Watson et al. 1985). ${ }^{d} \mathrm{HC} N\left(\mathrm{H}_{2}\right)=1 \times 10^{24} \mathrm{~cm}^{-2}(\mathrm{~B} 87) .{ }^{e} \mathrm{CR} N\left(\mathrm{H}_{2}\right)=2 \times 10^{23} \mathrm{~cm}^{-2}$ (Wilson et al. 1986; Goldsmith et al. 1997). ${ }^{f}$ For both the ER and PDR: $N\left(\mathrm{H}_{2}\right)=2.0 \times 10^{22} \mathrm{~cm}^{-2}$ (this work, see Sect. 5). ${ }^{g}$ Source averages with sizes given in Tables 1 and $2 .{ }^{h}$ Source averages from Blake et al. (1987). ${ }^{i}$ Source averages from Sutton et al. (1995). ${ }^{j}$ Plateau abundance (both LVF and HVF), Cernicharo et al. (2006). ${ }^{k}$ Wright et al. (1996). ${ }^{l}$ Gensheimer et al. (1996). ${ }^{m}$ C05. ${ }^{n}$ Hermsen et al. (1988a). ${ }^{o}$ Estimated from the $\mathrm{CH}_{3} \mathrm{OH}$ two-component rotation diagram. ${ }^{p}$ Menten et al. (1988). ${ }^{q}$ W06. ${ }^{r}$ Melnick et al. (2000). ${ }^{s}$ Larsson et al. (2003) towards the Orion Bar.

and B87, $N\left(\mathrm{H}_{2}\right)=2 \times 10^{22} \mathrm{~cm}^{-2}$ and $N\left(\mathrm{H}_{2}\right)=3 \times 10^{23} \mathrm{~cm}^{-2}$, respectively.

Our $\mathrm{HVF} \mathrm{H}_{2} \mathrm{O}$ abundance, as compared to the total $\mathrm{H}_{2}$ density in the flow, is $3 \times 10^{-5}$, in agreement with the water abundance in the Plateau estimated by Cernicharo et al. (2006). If we compare the HVF water abundance to the hot shocked $\mathrm{H}_{2}$
Table 4. Relative abundances ratios and comparisons with ice abundances.

\begin{tabular}{lccccc}
\hline \hline Abundance ratio & \multicolumn{2}{c}{$\mathrm{LVF}$} & $\mathrm{HC}$ & $\mathrm{CR}$ & \multicolumn{2}{c}{ Ice abundances $^{a}$} \\
& \multicolumn{2}{c}{$N / N\left(\mathrm{H}_{2} \mathrm{O}\right) \times 100$} & Orion IRc2 & W33A \\
\hline $\mathrm{CH}_{3} \mathrm{OH} / \mathrm{H}_{2} \mathrm{O}$ & & 7 & 430 & 10 & $11-17$ \\
$\mathrm{HDO} / \mathrm{H}_{2} \mathrm{O}$ & 0.52 & 0.13 & 3.2 & & 0.3 \\
$\mathrm{HDCO} / \mathrm{H}_{2} \mathrm{CO}$ & & & 1.2 & & \\
$\mathrm{NH}_{3} / \mathrm{H}_{2} \mathrm{O}$ & & 13 & 7 & & 15 \\
$\mathrm{SO}_{2} / \mathrm{H}_{2} \mathrm{O}$ & 69 & & 36 & & $\sim 1.6$ \\
$\mathrm{H}_{2} \mathrm{CO} / \mathrm{H}_{2} \mathrm{O}$ & 0.5 & & 3.6 & & $\sim 3$ \\
$\mathrm{SO} / \mathrm{H}_{2} \mathrm{O}$ & 11 & & 3.0 & & \\
$\mathrm{OCS} / \mathrm{H}_{2} \mathrm{O}$ & & 0.14 & & $<0.2$ & 0.2 \\
$\mathrm{CS} / \mathrm{H}_{2} \mathrm{O}$ & 0.41 & 0.02 & 1.4 & & \\
$\mathrm{H}_{2} \mathrm{~S} / \mathrm{H}_{2} \mathrm{O}$ & 5.2 & 0.22 & & & \\
\hline
\end{tabular}

${ }^{a}$ Gibb et al. (2000) and (2004).

it is consistent with Wright et al. (2000) and Melnick et al. (2000), who estimate the shocked Plateau water abundance to be $(2-5) \times 10^{-4}$.

The $\mathrm{HC} \mathrm{H}_{2} \mathrm{O}$ abundance is in agreement with the mapping of $\mathrm{H}_{2}^{18} \mathrm{O}$ towards the Orion Hot Core with the IRAM telescope (12" beam) by Gensheimer et al. (1996). Their estimated abundance is $1.4 \times 10^{-5}$. S01 estimate the water abundance to be $\sim 1.0 \times 10^{-5}$ from their observation of the vibrationally excited $\mathrm{H}_{2} \mathrm{O} 1_{1,0}-1_{0,1} \quad v_{2}=1$ transition, also in accordance with our value.

High water abundances in high temperature regions, for example in outflows, PDRs, and hot cores are consistent with both water and deuterated water forming on grains at low temperatures, and subsequently evaporating from the grain surfaces at high temperatures above $\sim 90 \mathrm{~K}$. At temperatures above $\sim 400 \mathrm{~K}$, easily reached in shocks, neutral-neutral reactions produce even higher water abundances (cf. Neufeld et al. 1995). Hence, our high abundance in the $\mathrm{HC}$ of $\mathrm{H}_{2} \mathrm{O}$ can be the result of evaporation from grain surfaces, which also applies to $\mathrm{CH}_{3} \mathrm{OH}$ and $\mathrm{NH}_{3}$, as is discussed in more detail in Sect. 7.2. The water abundance in the CR and LVF is about the same, and lower than in the HC. This might be a natural consequence of a lower temperature in these regions with less evaporation from grain surfaces, which also applies to the PDR region. This is also the cause of the nondetection of water in the ER which has a temperature below the sublimation temperature. The highest water abundance is found in the HVF, which is suggestive of an even more efficient production in shocks.

\subsection{Gas-phase vs. grain surface abundances}

Ratios of our observed gas-phase column densities in the Orion LVF, HC and CR sources (as derived from Tables 1 and 2) and the water column density is found in Table 4 . These ratios are compared with the corresponding grain-surface abundance ratios towards two of the sources observed by ISO (Gibb et al. 2000, 2004), Orion IRc2 and the embedded high-mass protostar W33A.

Some suggestions from these comparisons are:

- Both $\mathrm{CH}_{3} \mathrm{OH}$ and $\mathrm{H}_{2} \mathrm{O}$ are very abundant in the dense and warm $\mathrm{HC}$, and their gas-phase abundance ratio is very similar to that in the grain-surface ice of Orion IRc2 and W33A. This strongly points at a dominant production via hydrogenation on cold grain surfaces and subsequent evaporation in the warm and hot cores (cf. Brown et al. 1988; Caselli et al. 1993; Stantcheva \& Herbst 2004; Garrod \& Herbst 2006; 
Chang et al. 2007), especially so since gas-phase production of $\mathrm{CH}_{3} \mathrm{OH}$ has been shown to be very inefficient (cf. Geppert et al. 2005; Millar 2005; Garrod et al. 2007). In the CR the $\mathrm{CH}_{3} \mathrm{OH} / \mathrm{H}_{2} \mathrm{O}$ ratio is about 60 times higher than in the $\mathrm{HC}$ and in ices, caused by the four times decrease of the water abundance, and the 15 times higher methanol abundance as compared to the $\mathrm{HC}$. This may suggest that $\mathrm{H}_{2} \mathrm{O}$ is consumed in the formation of $\mathrm{CH}_{3} \mathrm{OH}$ in accordance with the recent laboratory study of methanol formation from electronirradiated mixed $\mathrm{H}_{2} \mathrm{O} / \mathrm{CH}_{4}$ ice at $10 \mathrm{~K}$ by Wada et al. (2006).

- The rather similar gas-phase $\mathrm{HDO} / \mathrm{H}_{2} \mathrm{O}$ abundance ratios in the LVF and HC compared with the ice ratio in W33A most likely suggest efficient deuteration reactions on grain surfaces as the cause of the high water deuteration level. This is supported by our previous conclusions about the grain surface origin of the high water abundances. The much higher $\mathrm{HDO} / \mathrm{H}_{2} \mathrm{O}$ ratio found in the $\mathrm{CR}$, as well as the similar $\mathrm{HDCO} / \mathrm{H}_{2} \mathrm{CO}$ ratio, at least partly is caused by a decreasing $\mathrm{H}_{2} \mathrm{O}$ abundance - possibly a result of $\mathrm{H}_{2} \mathrm{O}$ consumption in the efficient grain-surface formation of $\mathrm{CH}_{3} \mathrm{OH}$ in this source.

- Likewise, the gas-phase abundance ratios of $\mathrm{NH}_{3}$ and $\mathrm{H}_{2} \mathrm{O}$ in the $\mathrm{CR}$ and $\mathrm{HC}$ are similar to the W33A ice abundance ratio, again strongly suggesting that both these abundant species originate primarily from hydrogenation on cold grain surfaces with subsequent evaporation (cf. Stantcheva \& Herbst 2004; Garrod et al. 2007).

- The high $\mathrm{SO}_{2} / \mathrm{H}_{2} \mathrm{O}$ abundance ratio observed in the LVF is contrasted with a low ice ratio in $\mathrm{W} 33 \mathrm{~A}$. The latter ratio is most likely explained by rather inefficient gas-phase formation of $\mathrm{SO}_{2}$ and subsequent adsorption onto already icy grain mantles formed by efficient hydrogenation on the cold grains. The high gas-phase $\mathrm{H}_{2} \mathrm{O}$ abundance in the LVF may directly result from evaporation caused by the strong radiation from the nearby LVF driving source. This heating also could release $\mathrm{S}$ and $\mathrm{Si}$ atoms from the grains. Subsequent gas-phase reactions, based upon undepleted elemental abundances, then could lead to the elevated abundances of $\mathrm{SO}_{2}$, $\mathrm{SO}, \mathrm{H}_{2} \mathrm{~S}$ and $\mathrm{SiO}$ observed in the LVF. These abundances are several orders of magnitude higher than those in quiescent clouds where the abundances of S and Si appear to be depleted (B87; Irvine et al. 1987). In this scenario the ISO observations of $\mathrm{OH}$ at high abundance in the LVF (Goicoechea et al. 2006) are important. Low velocity shocks also may play a role here (cf. Mitchell 1984; Pineau des Forêts et al. 1993).

- The very similar $\mathrm{CR} \mathrm{H}_{2} \mathrm{CO} / \mathrm{H}_{2} \mathrm{O}$ gas-phase and $\mathrm{W} 33 \mathrm{~A}$ ice abundances most likely just tells us that both abundance ratios have the same main origin.

- The similarity of the $\mathrm{HC}$ gas-phase $\mathrm{OCS} / \mathrm{H}_{2} \mathrm{O}$ abundance ratio and the corresponding ratio in the W33A ice, also might hint at a grain surface origin of OCS. However, the comparatively low OCS abundance is accommodated by current ion-molecule reaction models and the ice content then likely is a result of adsorption.

\section{Discussion - source sizes and source structure}

We have in our column density and molecular abundance calculations in all cases treated the various Orion KL subregions, probed by the large Odin antenna beam, as homogeneous sources having specified average temperatures, densities and equivalent circular sizes and beam-filling factors.
However, the High Velocity Outflow is known to be bi-polar with a FWHP size of 60-70", as estimated from simultaneous Odin mapping of the $\mathrm{H}_{2} \mathrm{O}$ and $\mathrm{CO} J=5-4$ brightness distributions (Olofsson et al. 2003; Hjalmarson et al. 2005). As seen from the radiative transfer equation, the $\mathrm{H}_{2} \mathrm{O}$ excitation temperature corresponding to a size of $70^{\prime \prime}$ is only $26 \mathrm{~K}$, while a temperature of $72 \mathrm{~K}$ as found by Wright et al. (2000) corresponds to a size of only $32^{\prime \prime}$. This indicates a very clumpy $\mathrm{H}_{2} \mathrm{O}$ brightness distribution, and that this source is filled with approximately one fourth of water emission. Similar results are obtained investigating the size-temperature relation of $\mathrm{CO}$. In fact, the appearance of the HVF may be similar to the clumpy, finger-like emission seen in shock-excited $\mathrm{H}_{2}$ (Salas et al. 1999) ${ }^{4}$.

The Low Velocity Outflow has a NE-SW elongated structure, roughly orthogonal to the HVF, which also must have small scale structure (Genzel et al. 1981; Greenhill et al. 1998). If we guide ourselves by the optically thick HDO lines observed by Pardo et al. (2001) and use a HPBW size of $15^{\prime \prime}$ for $\mathrm{H}_{2}^{18} \mathrm{O}$, the corresponding excitation temperature is only $40 \mathrm{~K}$. The size corresponding to $72 \mathrm{~K}$ is $10^{\prime \prime}$ which suggests that this source is filled with about one half of radiating gas-phase water. Similar results are found for all optically thick outflow species.

The Compact Ridge and Hot Core size-temperature relations are more consistent with the assumed values, although we know from Beuther et al. (2005) that both sources are very clumpy. This might be caused by their much smaller size as compared to the outflows, where the clumping affects larger scales. As seen from the $\mathrm{CH}_{3} \mathrm{OH}$ Fig. 46 (online material) and Fig. 12, the source size of the $\mathrm{CR}$ also varies with the upper state energies of the lines. This might indicate considerable temperature and density variations within the $\mathrm{CR}$.

Considering the uncertainties discussed above and in Sects. 3 and 10.2 (Appendix), the striking agreement with B87 and S95 strengthens our confidence of our results.

\section{Summary}

We present first results from a spectral line survey towards Orion $\mathrm{KL}$ in a frequency range inaccessible from the ground covering 487-492 and 542-577 GHz.

Some of the results from this survey:

1. We detect a total of 280 lines from 38 different molecular species.

2. In addition we detect 64 unidentified lines, which represents $19 \%$ of the total. Some tentative assignments of a few of them have been made such as the interstellar anion $\mathrm{SH}^{-}, \mathrm{ND}$, $\mathrm{SO}^{+}$, and $\mathrm{CH}_{3} \mathrm{OCHO}$.

3. The total beam-averaged emission in our survey is dominated by $\mathrm{CO}, o-\mathrm{H}_{2} \mathrm{O}, \mathrm{SO}_{2}, \mathrm{SO},{ }^{13} \mathrm{CO}$ and $\mathrm{CH}_{3} \mathrm{OH}$. Species with the largest number of lines are $\mathrm{CH}_{3} \mathrm{OH},\left(\mathrm{CH}_{3}\right)_{2} \mathrm{O}, \mathrm{SO}_{2}$, ${ }^{13} \mathrm{CH}_{3} \mathrm{OH}, \mathrm{CH}_{3} \mathrm{CN}$ and NO.

4. Six water lines are detected, including the ground state rotational transition $1_{1,0}-1_{0,1}$ of $o-\mathrm{H}_{2} \mathrm{O}$, and its isotopologues $o-\mathrm{H}_{2}^{18} \mathrm{O}$ and $o-\mathrm{H}_{2}^{17} \mathrm{O}$, which shows emission from the Lowand High Velocity Flow and the Compact Ridge. Hot Core emission from water is observed from the $p-\mathrm{H}_{2} \mathrm{O}$ transition $6_{2,4}-7_{1,7}$ with an upper state energy $867 \mathrm{~K}$, and from a weak line feature at $489.054 \mathrm{GHz}$ identified as the $4_{2,3}-3_{3,0}$ transition of $o-\mathrm{H}_{2}^{18} \mathrm{O}$ with an upper state energy of $430 \mathrm{~K}$. We have also observed the HDO $2_{0,2}-1_{1,1}$ transition from the Low

\footnotetext{
4 See also www: http://subarutelescope.org/Science/

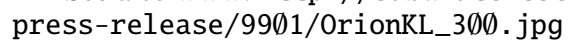


Velocity Flow, Compact Ridge and the Hot Core, and have a tentative detection of the high energy transition $(581 \mathrm{~K})$ $6_{2,4}-6_{2,5}$ of HDO.

5. We detect the $1_{0}-0_{0}$ transitions of $\mathrm{NH}_{3}$ and the isotopologue ${ }^{15} \mathrm{NH}_{3}$. The main isotopologue shows emission from both the Hot Core, LVF and Compact Ridge, while the rarer isotopologue only exhibits emission from the Hot Core.

6. Isotopologue abundance ratios of $\mathrm{D} / \mathrm{H},{ }^{12} \mathrm{C} /{ }^{13} \mathrm{C},{ }^{32} \mathrm{~S} /{ }^{34} \mathrm{~S}$, ${ }^{34} \mathrm{~S} /{ }^{33} \mathrm{~S}$ and ${ }^{18} \mathrm{O} /{ }^{17} \mathrm{O}$ are calculated, as well as the molecular abundance ratio of $\mathrm{O} / \mathrm{S}$, all in agreement with previous findings.

7. Different methods are used to obtain rotation temperatures and column densities. For eight different species with at least four lines and a sufficient energy range in the transitions, the rotation diagram method and the forward model are applied. The LTE approximation is used for all the other species.

8. Abundances are estimated for the observed species from the different subregions, and we find very high gas-phase abundances of $\mathrm{H}_{2} \mathrm{O}, \mathrm{NH}_{3}, \mathrm{SO}_{2}, \mathrm{SO}, \mathrm{NO}$, and $\mathrm{CH}_{3} \mathrm{OH}$. An important fact here is that all our abundance determinations, including those for water vapour, are based upon the same methodology.

9. A comparison of our estimated gas-phase abundances with the ice inventory of ISO is shedding new light on the chemical origins of $\mathrm{H}_{2} \mathrm{O}, \mathrm{CH}_{3} \mathrm{OH}, \mathrm{NH}_{3}$ and $\mathrm{SO}_{2}$ in the various Orion KL subregions.

10. The line density in our survey is 4-20 per $\mathrm{GHz}$, with a mean of 8 per $\mathrm{GHz}$. This is comparable with larger telescopes $\left(\sim 10 \mathrm{GHz}^{-1}\right)$, showing the excellent performance of the Odin satellite.

Acknowledgements. Generous financial support from the Research Councils and Space Agencies in Sweden, Canada, Finland and France is gratefully acknowledged. We sincerely thank Frank Lovas for a CD containing his molecular spectroscopy database SLAIM $\emptyset 3$, and are very grateful to the dedicated scientists supporting the molecular spectroscopy database the Cologne Database for Molecular Spectroscopy (CDMS) and the Jet Propulsion Laboratory (JPL) for making the difficult but absolutely necessary molecular spectroscopy available on the Internet. We also thank the referees whose constructive comments led to significant improvements of the paper.

\section{References}

Araya, E., Hofner, P., Kurtz, S., Bronfman, L., \& DeDeo, S. 2005, ApJS, 157, 279

Batrla, W., Wilson, T. L., Bastien, P., \& Ruf, K. 1983, A\&A, 128, 279

Bensch, F., Pak, I., Wouterloot, J. G. A., Klapper, G., \& Winnewisser, G. 2001, ApJ, 562, L185

Beuther, H., Zhang, Q., Greenhill, L. J., et al. 2005, ApJ, 632, 355

Bevington, P. R. 1969, Data Reduction and Error Analysis for the Physicas Sciences (McGraw-Hill book company)

Blake, G. A., Sutton, E. C., Masson, C. R., \& Phillips, T. G. 1986, ApJS, 60, 357

Blake, G. A., Sutton, E. C., Masson, C. R., \& Phillips, T. G. 1987, ApJ, 315, 621 (B87)

Brown, P. D., Charnley, S. B., \& Millar, T. J. 1988, MNRAS, 231, 409

Caselli, P., Hasegawa, T. I., \& Herbst, E. 1993, ApJ, 408, 548

Cernicharo, J., Goicoechea, J. R., Daniel, F., et al. 2006, ApJ, 649, 33

Chang, Q., Cuppen, H. M., \& Herbst, E. 2007, A\&A, 469, 973

Cheung, A. C., Rank, D. M., Townes, C. H., Thornton, D. D., \& Welch, W. J. 1968, Phys. Rev. Lett., 21, 1701

Chin, Y.-N., Henkel, C., Whiteoak, J. B., Langer, N., \& Churchwell, E. B. 1996, A\&A, 305, 960

Comito, C., Schilke, P., Phillips, T. G., et al. 2005, ApJS, 156, 127 (C05)

Friberg, P. 1984, A\&A, 132, 265

Garrod, R. T., \& Herbst, E. 2006, A\&A, 457, 927

Garrod, R. T., Wakelam, V., \& Herbst, E. 2007, A\&A, 467, 1103
Gensheimer, P. D., Mauersberger, R., \& Wilson, T. L. 1996, A\&A, 314, 281 Genzel, R., \& Stutzki, J. 1989, ARA\&A, 27, 41

Genzel, R., Reid, M. J., Moran, J. M., \& Downes, D. 1981, ApJ, 244, 884

Genzel, R., Downes, D., Ho, P. T. P., \& Bieging, J. 1982, ApJ, 259, L103

Geppert, W., Hellberg, F., Österdahl, et al. 2005, IAU Symp. 231, ed. D. C. Lis, G. A. Blake, \& E. Herbst (Cambridge University Press), 117

Gibb, E. L., Whittet, D. C. B., Schutte, W. A., et al. 2000, ApJ, 536, 347

Gibb, E. L., Whittet, D. C. B., Boogert, A. C. A., \& Tielens, A. G. G. M. 2004, ApJS, 151, 35

Goicoechea, J. R., Cernicharo, J., Lerate, M. R., et al. 2006, ApJ, 641, L49

Goldsmith, P. F., \& Langer, W. D. 1999, ApJ, 517, 209

Goldsmith, P. F., Bergin, E. A., \& Lis, D. C. 1997, ApJ, 491, 615

Greenhill, L. J., Gwinn, C. R., Schwartz, C., Moran, J. M., \& Diamond, P. J. 1998, Nature, 396, 650

Grevesse, N., Noels, A., \& Sauval, A. J. 1996, ASP Conf. Ser., 99, 117

Groner, P., Albert, S., Herbst, E., \& de Lucia, F. C. 1998, ApJ, 500, 1059

Hermsen, W., Wilson, T. L., Walmsley, C. M., \& Batrla, W. 1985, A\&A, 146, 134

Hermsen, W., Wilson, T. L., \& Bieging, J. H. 1988a, A\&A, 201, 276

Hermsen, W., Wilson, T. L., Walmsley, C. M., \& Henkel, C. 1988b, A\&A, 201, 285

Hjalmarson, Å., Bergman, P., Biver, N., et al. 2005, Adv. Space Res., 36, 1031

Ho, P. T. P., \& Townes, C. H. 1983, ARA\&A, 21, 239

Hollis, J. M., Lovas, F. J., Suenram, R. D., Jewell, P. R., \& Snyder, L. E. 1983, ApJ, 264, 543

Ikeda, M., Maezawa, H., Ito, T., et al. 1999, ApJ, 527, L59

Irvine, W. M., Schloerb, F. P., Hjalmarson, А., \& Herbst, E. 1985, in Protostars and Planets II, ed. D. C. Black, \& M. S. Matthews (University of Arizona Press), 579

Irvine, W. M., Goldsmith, P. F., \& Hjalmarson, Å. 1987, in Interstellar Processes, ed. D. J. Hollenbach, \& H. A. Thronson, Jr. (Reidel Publishing Co), 561

Johansson, L. E. B., Andersson, C., Elldér, J., et al. 1984, A\&A, 130, 227

Kahane, C., Gomez-Gonzalez, J., Cernicharo, J., \& Guélin, M. 1988, A\&A, $1988,190,167$

Keene, J., Blake, G. A., \& Phillips, T. G. 1983, ApJ, 271, L27

Lampton, M., Margon, B., \& Bowyer, S. 1976, ApJ, 208, 177

Larsson, B., Liseau, R., Bergman, P., et al. 2003, A\&A, 402, L69

Lerate, M. R., Barlow, M. J., Swinyard, B. M., et al. 2006, MNRAS, 370, 597

Liseau, R., Larsson, B., Brandeker, A., et al. 2003, A\&A, 402, L73

Lovas, F. J. 2003, Spectral Line Atlas for Interstellar Molecules (SLAIMø3) Ver.1, private communication of a CD

Mangum, J. G., Wootten, A., Loren, R. B., \& Wadiak, E. J. 1990, ApJ, 348, 542

Masson, C. R., Lo, K. Y., Phillips, T. G., et al. 1987, ApJ, 319, 446

Melnick, G. J., Stauffer, J. R., Ashby, M. L. N., et al. 2000, ApJ, 539, L77

Menten, K. M., Walmsley, C. M., Henkel, C., et al. 1986, A\&A, 169, 271

Menten, K. M., Walmsley, C. M., Henkel, C., \& Wilson, T. L. 1988, A\&A, 198, 253

Migenes, V., Johnston, K. J., Pauls, T. A., \& Wilson, T. L. 1989, ApJ, 347, 294

Millar, T. J. 2005, IAU Symp., 231, ed. D. C. Lis, G. A. Blake, \& E. Herbst (Cambridge University Press), 77

Mitchell, G. F. 1984, ApJ, 287, 665

Müller, H. S. P., Thorwirth, S., Roth, D. A., \& Winnewisser, G. 2001, A\&A, 370, L49

Nagai, T., Kaifu, N., Nagane, K., \& Akaba, K. 1979, PASJ, 31, 317

Neufeld, D. A., Lepp, S., \& Melnick, G. J. 1995, ApJS, 100, 132

Neufeld, D. A., Green, J. D., Hollenbach, et al. 2006, ApJ, 647, L33

Nordh, H. L., von Schéele, F., Frisk, U., et al. 2003, A\&A, 402, L21

Nummelin, A., Dickens, J. E., Bergman, P., et al. 1998, A\&A, 337, 275

Nummelin, A., Bergman, P., Hjalmarson, Å., et al. 2000, ApJS, 128, 213

Olofsson, H. 1984, A\&A, 134, 36 O

Olofsson, H., Hjalmarson, A., \& Rydbeck, O. E. H. 1981, A\&A, 100, L30

Olofsson, H., Elldér, J., Hjalmarson, Å., \& Rydbeck, O. E. H. 1982, A\&A, 113, L18

Olofsson, A. O. H. 2003, Thesis, Chalmers University of Techonology, ISBN 91-7291-341-X

Olofsson, A. O. H., Olofsson, G., Hjalmarson, A., et al. 2003, A\&A, 402, L47

Olofsson, A. O. H., Persson, C. M., Koning, N., et al. 2007, A\&A, 476, 791 (Paper I)

Pardo, J. R., Cernicharo, J., Herpin, F., et al. 2001, ApJ, 562, 799

Pauls, T. A., Wilson, T. L., Bieging, J. H., \& Martin, R. N. 1983, A\&A, 124, 23

Penzias, A. A. 1981a, ApJ, 249, 513

Penzias, A. A. 1981b, ApJ, 249, 518

Phillips, T. G., Wannier, P. G., Scoville, N. Z., \& Huggins, P. J. 1979, ApJ, 231, 720

Pickett, H. M., Poynter, R. L., Cohen, E. A., et al. 1998, J. Quant. Spectrosc. \& Rad. Transfer, 60, 883

Pineau des Forêts, G., Roueff, E., Schilke, P., \& Flower, D. R. 1993, MNRAS, 262,915 
Plume, R., Bensch, F., Howe, J. E., et al. 2000, ApJ, 539, L133

Rodríguez-Franco, A., Martín-Pintado, J., \& Fuente, A. 1998, A\&A, 329, 1097 Rodríguez-Franco, A., Wilson, T. L., Martín-Pintado, J., \& Fuente, A. 2001, ApJ, 559,985

Salas, L., Rosando., M., Cruz-González, I., et al. 1999, ApJ, 511, 822

Savage, C., Apponi, A. J., Ziurys, L. M., \& Wyckoff, S. 2002, ApJ, 578, 211

Schilke, P., Güsten, R., Schulz, A., Serabyn, E., \& Walmsley, C. M. 1992, A\&A, 261, L5

Schilke, P., Benford, D. J., Hunter, T. R., Lis, D. C., \& Phillips, T. G. 2001, ApJS, 132, 281 (S01)

Schöier, F. L., van der Tak, F. F. S., van Dishoeck, E. F., \& Black, J. H. 2005 A\&A, 432, 369

Serabyn, E., \& Weisstein, E. 1995, ApJ, 451, 238

Stantcheva, T., \& Herbst, E. 2004, A\&A, 423, 241

Sutton, E. C., Blake, G. A., Genzel, R., Masson, C. R., \& Phillips, T. G. 1986, ApJ, 311, 921

Sutton, E. C., Peng, R., Danchi, W. C., et al. 1995, ApJS, 97, 455 (S95)

Tauber, J. A., Lis, D. C., Keene, J., Schilke, P., \& Büttgenbach, T. H. 1995, A\&A, 297,567

Turner, B. E. 1990, ApJ, 362, L29
Turner, B. E. 1991, ApJS, 76, 617

Ungerechts, H., Bergin, E. A., Goldsmith, et al. 1997, ApJ, 482, 245

Wada, A., Mochizuki, N., \& Hiraoka, K. 2006, ApJ, 644, 300

Watson, D. M., Genzel, R., Townes, C. H., \& Storey, J. W. V. 1985, ApJ, 298, 316

White, G. J., Araki, A., Greaves, J. S., Ohishi, M., \& Higginbottom, N. S. 2003, A\&A, 407, 589 (W03)

Wilner, D. J., Wright, M. C. H., \& Plambeck, R. L. 1994, ApJ, 422, 642

Wilson, T. L., \& Matteucci, F. 1992, A\&ARv., 4, 1

Wilson, T. L., \& Rood, R. 1994, ARA\&A, 32, 191

Wilson, T. L., Downes, D., \& Bieging, J. 1979, A\&A, 71, 275

Wilson, T. L., Serabyn, E., Henkel, C., \& Walmsley, C. M. 1986, A\&A, 158, L1

Wilson, T. L., Gaume, R. A., Gensheimer, P., \& Johnston, K. J. 2000, ApJ, 538, 665

Wirström, E. S., Bergman, P., Olofsson, A. O. H., et al. 2006, A\&A, 453, 979 (W06)

Womack, M., Ziurys, L. M., Wyckoff, S., \& Sage, L. 1990, BAAS, 22, 1329

Wouterloot, J. G. A., Brand, J., \& Henkel, C. 2005, A\&A, 430, 549

Wright, M. C. H., Plambeck, R. L., \& Wilner, D. J. 1996, ApJ, 469, 216

Wright, C. M., van Dishoeck, E. F., Black, J. H., et al. 2000, A\&A, 358, 689 


\section{Online Material}




\section{Data analysis methods}

\subsection{Single line analysis}

With the assumption of optically thin emission, neglecting the background radiation, and assuming that the source fills the antenna main beam, the beam averaged upper state column density is calculated as

$N_{\mathrm{u}}^{\mathrm{thin}}=\frac{8 \pi k v_{\mathrm{u} l}^{2}}{h c^{3}} \frac{1}{A_{\mathrm{u} l}} \int T_{\mathrm{mb}} \mathrm{d} v$,

where $k$ is the Boltzmann constant, $v_{\mathrm{u} l}$ is the frequency of the transition, $h$ is the Planck constant, $c$ is the speed of light, $A_{\mathrm{u} l}$ is the Einstein $A$-coefficient for the transition, and $T_{\mathrm{mb}}$ is the main beam brightness temperature. As customary the frequency axis $v$ has been converted to a velocity axis $v$ using the speed of light.

The total column density of each species can then be found assuming LTE (Local Thermodynamic Equilibrium), where the excitation temperatures, $T_{\mathrm{ex}}$, for all the energy levels are the same. The molecular population of each level is then given by the Boltzmann equation, which also defines $T_{\mathrm{ex}}$

$N_{\mathrm{u}}=N_{\mathrm{tot}} \frac{g_{\mathrm{u}}}{Q(T)} \mathrm{e}^{-E_{\mathrm{u}} / k T_{\mathrm{ex}}}$,

where $g_{\mathrm{u}}$ is the statistical weight of the upper state, and $Q(T)$ is the partition function, which only depends on temperature and molecular constants and hence differs for different kinds of species. The $A$-coefficients, statistical weights, partition functions and upper state energy levels are available via the databases JPL, CDMS, Leiden ${ }^{5}$ (Schöier et al. 2005) or SLAIMø3. For a few molecules, e.g. $\left(\mathrm{CH}_{3}\right)_{2} \mathrm{O}$, we calculate the $A$-coefficients using line strengths found in SLAIM $\emptyset 3$ as

$A_{\mathrm{u} l}=\frac{16 \pi^{3} v_{\mathrm{u} l}^{3} \mu^{2}}{3 \epsilon_{0} h c^{3}} \frac{S_{\mathrm{u} l}}{g_{\mathrm{u}}}$

where $S_{\mathrm{u} l}$ is the rotational part of the line strength, and $\mu$ is the molecular dipole moment.

From Eqs. (9) and (1), we obtain the beam-averaged total column density

$N_{\text {tot }}^{\text {thin }}=\frac{8 \pi k v_{\mathrm{u} l}^{2}}{h c^{3}} \frac{1}{A_{\mathrm{u} l}} \frac{Q(T)}{g_{\mathrm{u}}} \mathrm{e}^{E_{\mathrm{u}} / k T_{\mathrm{ex}}} \int T_{\mathrm{mb}} \mathrm{d} v$

assuming optically thin emission.

The solution of the radiative transport equation, neglecting background radiation and with a constant source function, is

$T_{\mathrm{A}}^{*}=T_{\mathrm{b}} \eta_{\mathrm{mb}} \eta_{\mathrm{bf}}=J\left(T_{\mathrm{ex}}\right)\left(1-\mathrm{e}^{-\tau}\right) \eta_{\mathrm{mb}} \eta_{\mathrm{bf}}$,

where the beam-filling factor $\eta_{\mathrm{bf}}=\theta_{\mathrm{s}}^{2} /\left(\theta_{\mathrm{s}}^{2}+\theta_{\mathrm{mb}}^{2}\right)$, assuming that both the source brightness distribution and the antenna response are circularly symmetric and Gaussian. The radiation temperature, $J\left(T_{\text {ex }}\right)$ is

$J\left(T_{\mathrm{ex}}\right)=\frac{h v}{k} \frac{1}{\mathrm{e}^{h v / k T_{\mathrm{ex}}}-1} \approx T_{\mathrm{ex}}$,

where the approximation is valid only if $\mathrm{h} v \ll \mathrm{k} T_{\mathrm{ex}}$. For the appropriate temperatures in this region, $T \approx 100-200 \mathrm{~K}$, and frequencies $\sim 550 \mathrm{GHz}$, the radiation temperature will differ from $T_{\text {ex }}$ by approximately $10-15 \%$. Accordingly, we use $J\left(T_{\text {ex }}\right)$ and not $T_{\mathrm{ex}}$ in our calculations.

\footnotetext{
${ }^{5}$ http://www.strw. leidenuniv.nl/ moldata/
}

If the emission is optically thick $(\tau \gg 1)$ Eq. (12) simplifies to

$T_{\mathrm{A}}^{*}=J\left(T_{\mathrm{ex}}\right) \eta_{\mathrm{mb}} \eta_{\mathrm{bf}}=J\left(T_{\mathrm{ex}}\right) \eta_{\mathrm{mb}} \frac{\theta_{\mathrm{s}}^{2}}{\theta_{\mathrm{s}}^{2}+\theta_{\mathrm{mb}}^{2}}$.

Using this equation the beam-filling, and hence the approximate source size, can be determined without relying on correctly calculated optical depths. The variation in $T_{\mathrm{A}}^{*}$ that is seen mainly will be due to variations in the beam-filling factor, but there can also be variations in $T_{\mathrm{ex}}$, both along the path and between different states, which cannot be determined.

Since molecular clouds are known to be clumpy down to very small scales, it is indeed likely that the source does not fill the beam. This is especially true in case of the large Odin beam, and the total column density from Eq. (11) will be too low by a factor of $1 / \eta_{\mathrm{bf}}$. Variations in beam-filling between the different transitions of the same molecule also are probable. Hence, when we are comparing other observations (e.g. interferometry mapping) with ours to estimate the beam-filling, by necessity we have to compare transitions with similar parameters tracing the same gas.

The optical depth at the centre of the line can be calculated, assuming LTE and a Gaussian line profile, using

$\tau_{\max }=\sqrt{\frac{\ln 2}{16 \pi^{3}}} \frac{c^{3}}{v_{\mathrm{u} l}^{3} \Delta v} A_{\mathrm{u} l} N_{\text {tot }} \frac{g_{\mathrm{u}}}{Q(T)} \mathrm{e}^{-E_{\mathrm{u}} / k T_{\text {ex }}}\left(\mathrm{e}^{h v_{\mathrm{u} l} / k T_{\text {ex }}}-1\right)$

where $\Delta v$ is the width of the line, and $E_{\mathrm{u}}$ is the upper state energy. However, this approach demands knowledge of the total column density. If we have observations of isotopologues, and if the isotopologue abundance ratio $R$ is known, then the optical depths can be determined by means of Eq. (12). If the excitation temperatures are about the same for both isotopologues, and the optical depth of isotopologue one is larger than isotopologue two by a factor $R$, we then will have

$\frac{T_{\mathrm{A}, 1}}{T_{\mathrm{A}, 2}}=\frac{\left(1-\mathrm{e}^{-\tau_{1}}\right) \eta_{\mathrm{bf}, 1}}{\left(1-\mathrm{e}^{-\tau_{2}}\right) \eta_{\mathrm{bf}, 2}}=\frac{\left(1-\mathrm{e}^{-R \tau_{2}}\right) \eta_{\mathrm{bf}, 1}}{\left(1-\mathrm{e}^{-\tau_{2}}\right) \eta_{\mathrm{bf}, 2}}$.

This will give the mean optical depths of both species. If the emissions are co-spatial the beam-filling factors cancel.

Once a transition has become optically thick, the value of $N_{\mathrm{u}} / g_{\mathrm{u}}$ cannot increase any further. The derived total column density will then be too low and needs an optical depth correction factor $C_{\tau}$, which will be one or larger

$C_{\tau}=\frac{\tau}{1-\mathrm{e}^{-\tau}}$

With corrections for optical depth and beam-filling the true total source averaged column density will be

$N_{\text {tot }}=\frac{C_{\tau}}{\eta_{\mathrm{bf}}} \frac{8 \pi k v_{\mathrm{u} l}^{2}}{h c^{3}} \frac{1}{A_{\mathrm{u} l}} \frac{Q(T)}{g_{\mathrm{u}}} \mathrm{e}^{E_{\mathrm{u}} / k T_{\mathrm{ex}}} \int T_{\mathrm{mb}} \mathrm{d} v=\frac{C_{\tau}}{\eta_{\mathrm{bf}}} N_{\mathrm{tot}}^{\text {thin }}$.

If no information about optical depth is available this correction is not taken into account. For the excitation temperature in Eqs. (14) and (18), we use an adopted temperature that fits the species (Table 1), or the calculated rotation temperature $T_{\mathrm{ROT}}$ (see Sect. 3.2.1).

Note the importance of the partition function $Q(T)$, and the statistical weight $g_{\mathrm{u}}$ in Eq. (18). If the statistical weights include the ortho/para ratio whenever these molecular sub-divisions exist, the partition function must include them. It is also important to use the same statistical weights $g_{\mathrm{u}}$ in Eq. (18) when the partition function $Q(T)$ is calculated. 


\subsection{Additional limitations}

If there are deviations from the basic assumptions, errors will occur in the calculations for all models (cf. Goldsmith \& Langer 1999). These effects can to some extent be corrected for, like optical depth effects and beam-filling, as discussed above. In addition we have:

1. Several excitation temperatures/non-LTE. The population distribution may not be characterised by a single rotational temperature. The temperature can vary due to density, excitation gradients along the line-of-sight, IR flux, subthermal excitation etc. Since our beam is very large and encompasses a variety of different conditions, we may expect emission from several different sources, each with different temperature.

2. Adopted excitation temperature. Whenever we have too few lines to use the rotation diagram method or forward model we use the LTE approximation for a single line. The excitation temperature is then adopted from a rotation temperature of a similar species in our survey, or taken from the literature. This can create errors if the adopted temperature is not appropriate.

3. Source structure. The beam-filling correction are calculated assuming a homogenous source (see also Sect. 8). Clumping and substructures can introduce errors in the beam-filling corrections. Vastly different opacitites between the isotopologues (with $\mathrm{NH}_{3}$ and $\mathrm{H}_{2} \mathrm{O}$ as good examples) also complicate the analysis, as the beam-filling factors may be very different.

4. Gaussian decomposition. Errors in our Gaussian decompositions can introduce errors in the calculated optical depths and the column densities.

5. $\mathrm{H}_{2}$ column densities. The largest source of uncertainty in the abundances in Sect. 7 is the adopted $\mathrm{H}_{2}$ column densities and the assumption that the $\mathrm{H}_{2}$ emission and the molecule of interest spatially coincides. This can create errors by orders of magnitude.

6. Observational errors. Errors may exist in the measured line intensities due to misidentifications, unresolved blends, or pointing and calibration. However, the errors must be rather large to create significant errors in the column density obtained from the rotation diagram and forward model.

7. Background radiation. The background radiation, for example emission from warm dust, may be too large to be neglected. If the condition $T_{\mathrm{ex}} \gg T_{\mathrm{bg}}$ is violated, shifts along the ordinate in the rotation diagram with a factor of $\ln \left(1-T_{\mathrm{bg}} / T_{\mathrm{ex}}\right)$ will occur. The dust continuum radiation will for example affect the level populations of water, and must be included in accurate calculations for these transitions.

\subsection{Determination of relative chemical abundances}

The definition of molecular abundance of a species with respect to $\mathrm{H}_{2}$ is the ratio of the volume densities. This demands detailed knowledge of the geometry of the emitting region. If this is not known, column densities can be used as a substitute, with the assumption that the two species are well mixed and emitted from the same region, to obtain average abundances along the line of sight

$X_{\text {species }}=\frac{N_{\text {species }}}{N_{\mathrm{H}_{2}}}$.

The use of column densities will provide a higher degree of accuracy than the use of volume densities (Irvine et al. 1985). As long as the molecules are emitted from the same region with approximately the same source size, there is no dependence of beam-filling. In addition, since we have a uniformly calibrated set of data, uncertainties in calibration will not affect the result.

The relative isotopologue abundance $R$ can be determined in the same way as the molecular abundances,

$R=\frac{N_{1}}{N_{2}}$

when we have observations of optically thin isotopologues, or opacity-corrected column densities.

\subsection{Optical depth broadening}

If the intrinsic line shape is Gaussian, a high line opacity will increase the observed line width (cf. Phillips et al. 1979) as

$\Delta v \approx \Delta v_{i}\left(\frac{\ln \tau_{\mathrm{p}}}{\ln 2}\right)^{1 / 2}$

where $\Delta v_{i}$ is the intrinsic velocity width of the line and $\tau_{\mathrm{p}}(\gg 1)$ is the peak optical depth in the line. 
C. M. Persson et al.: A spectral line survey of Orion KL in the bands 486-492 and 541-577 GHz with the Odin satellite. II., Online Material p 4

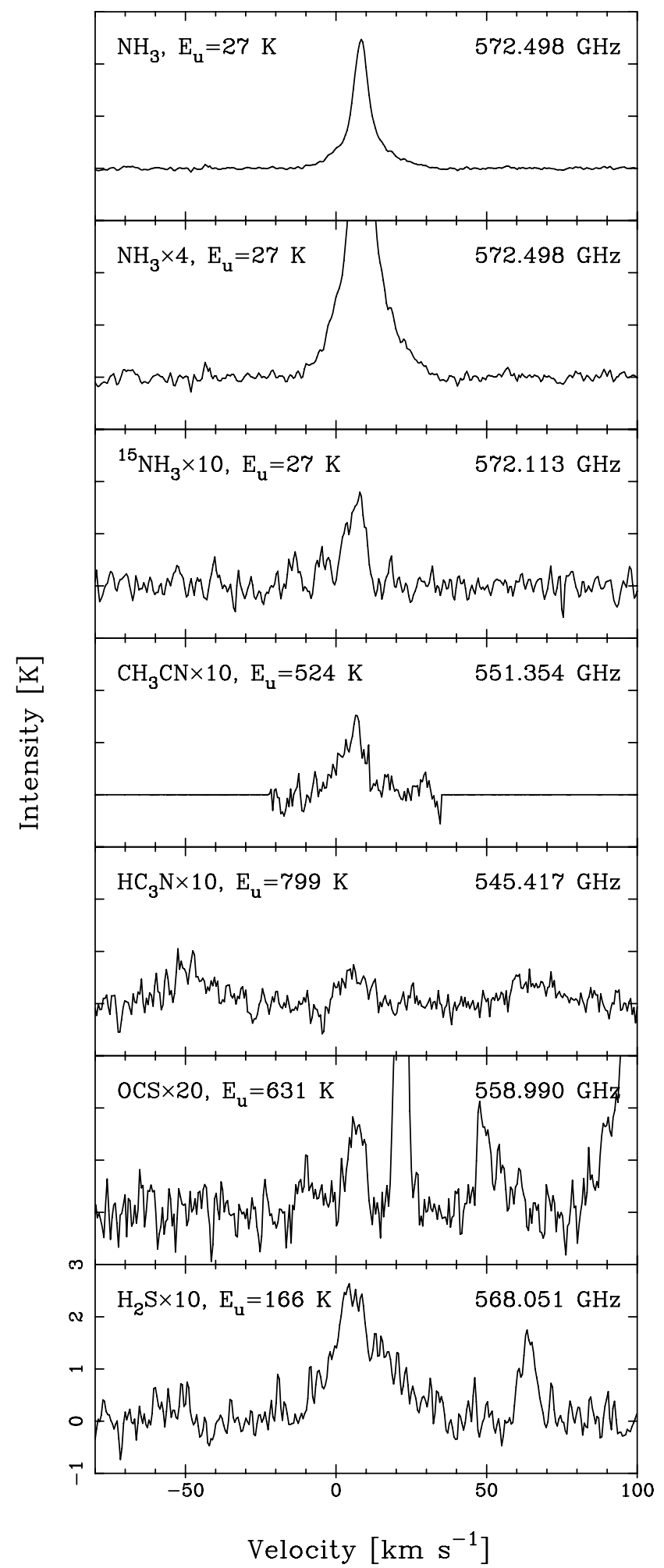

Fig. 25. Top figure shows the $\mathrm{NH}_{3}$ line, the second figure shows four times magnified $\mathrm{NH}_{3}$ line wings. The $\mathrm{NH}_{3}$ line profile shows emission from the $\mathrm{CR}$ and $\mathrm{HC}$. The ${ }^{15} \mathrm{NH}_{3}, \mathrm{CH}_{3} \mathrm{CN}, \mathrm{HC}_{3} \mathrm{~N}$ and $\mathrm{OCS}$ transitions suggest emission from the $\mathrm{HC}$, and $\mathrm{H}_{2} \mathrm{~S}$ from both the $\mathrm{HC}$ and LVF. An intensity scale factor is given after the molecular species.

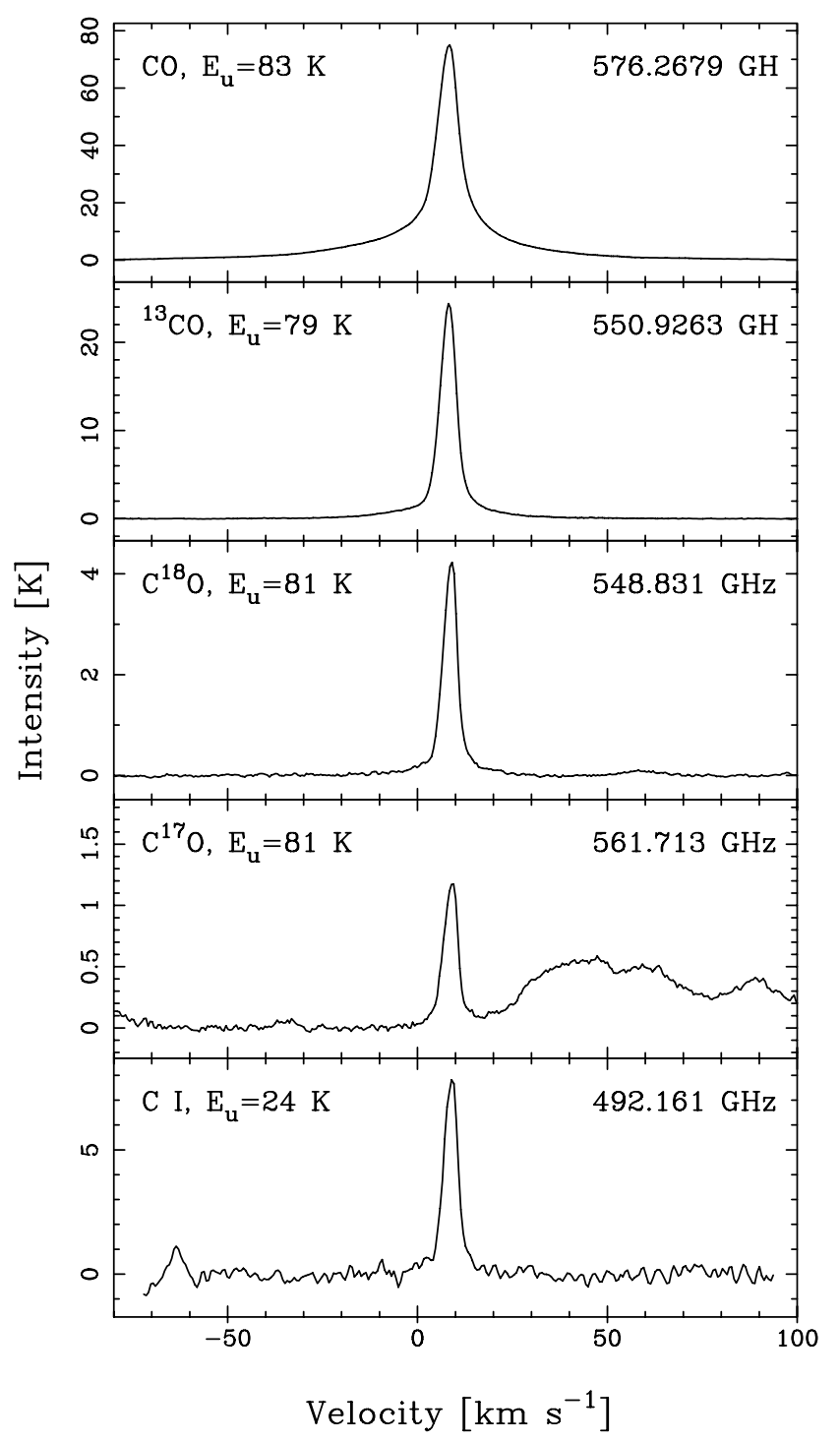

Fig. 26. CO, isotopologues and atomic C. Note the different intensity scales. 
C. M. Persson et al.: A spectral line survey of Orion KL in the bands 486-492 and 541-577 GHz with the Odin satellite. II., Online Material p 5

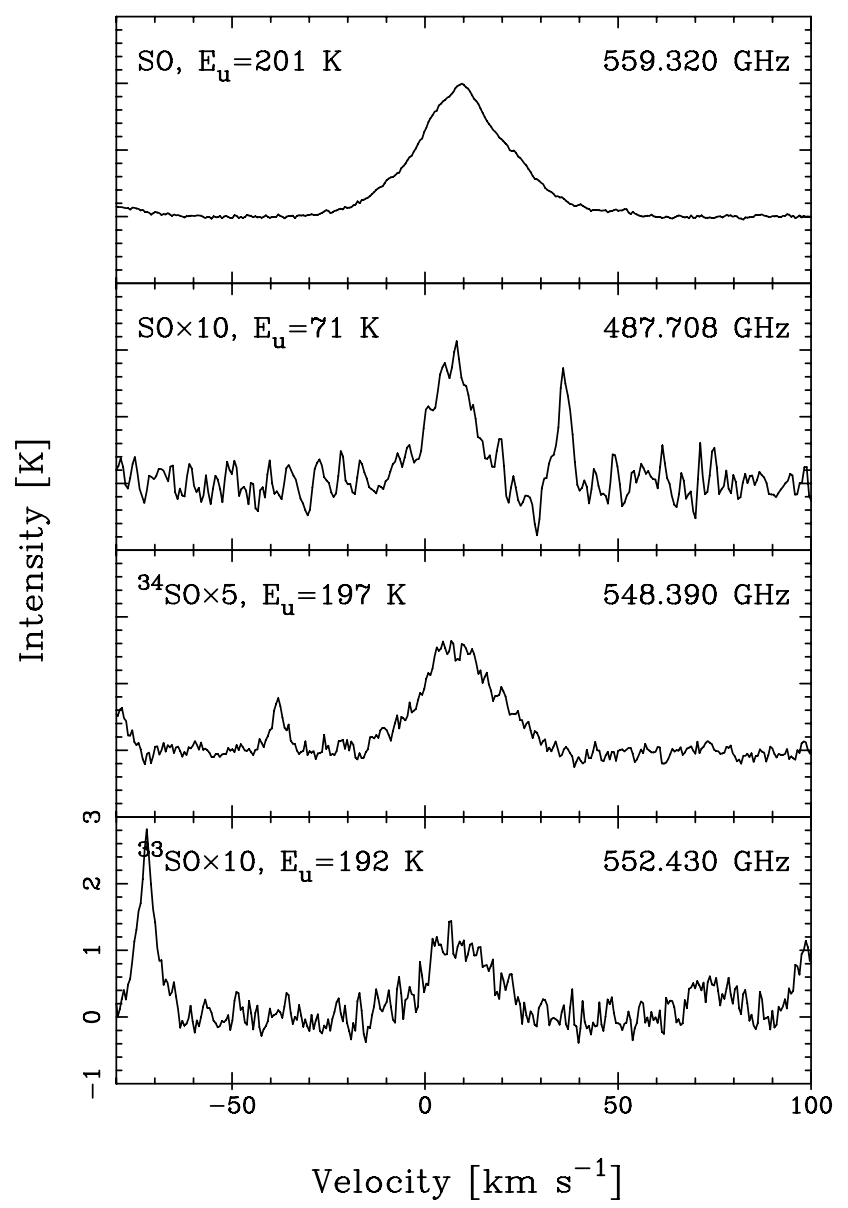

Fig. 27. SO and isotopologues. The SO line in the top panel is optically thick, and shows clear HVF line wings. The low-energy SO transition is optically thin. An intensity scale factor is given after the molecular species.

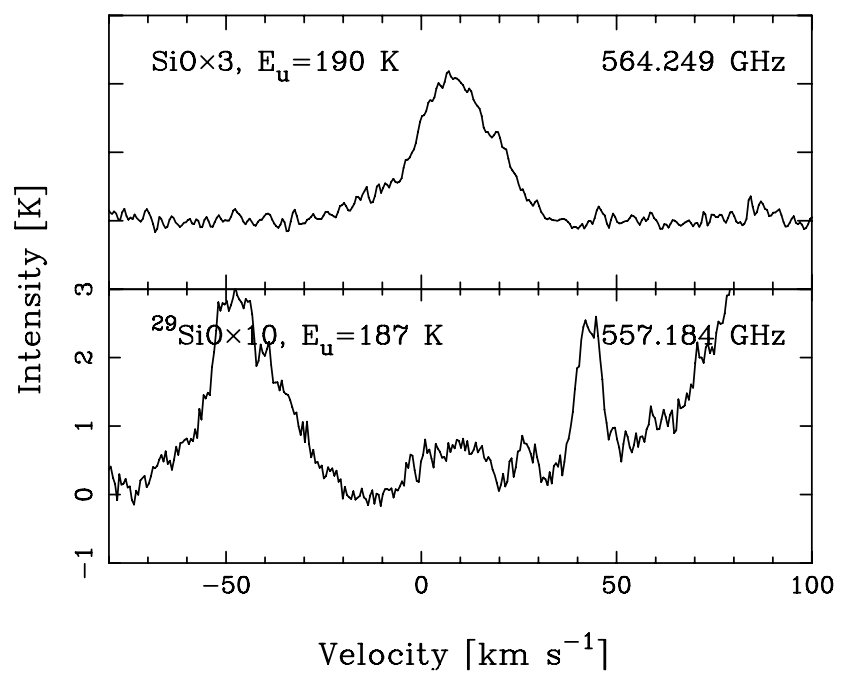

Fig. 28. The $J=13-12$ transition for both $\mathrm{SiO}$ and ${ }^{29} \mathrm{SiO}$. The $\mathrm{SiO}$ line is optically thick and also exhibits pronounced HVF line wings. A blend from $\mathrm{CH}_{3} \mathrm{OH}$ and ${ }^{13} \mathrm{CH}_{3} \mathrm{OH}$ is visible at $19.6 \mathrm{~km} \mathrm{~s}^{-1}$ in the $\mathrm{SiO}$ line. An intensity scale factor is given after the molecular species.

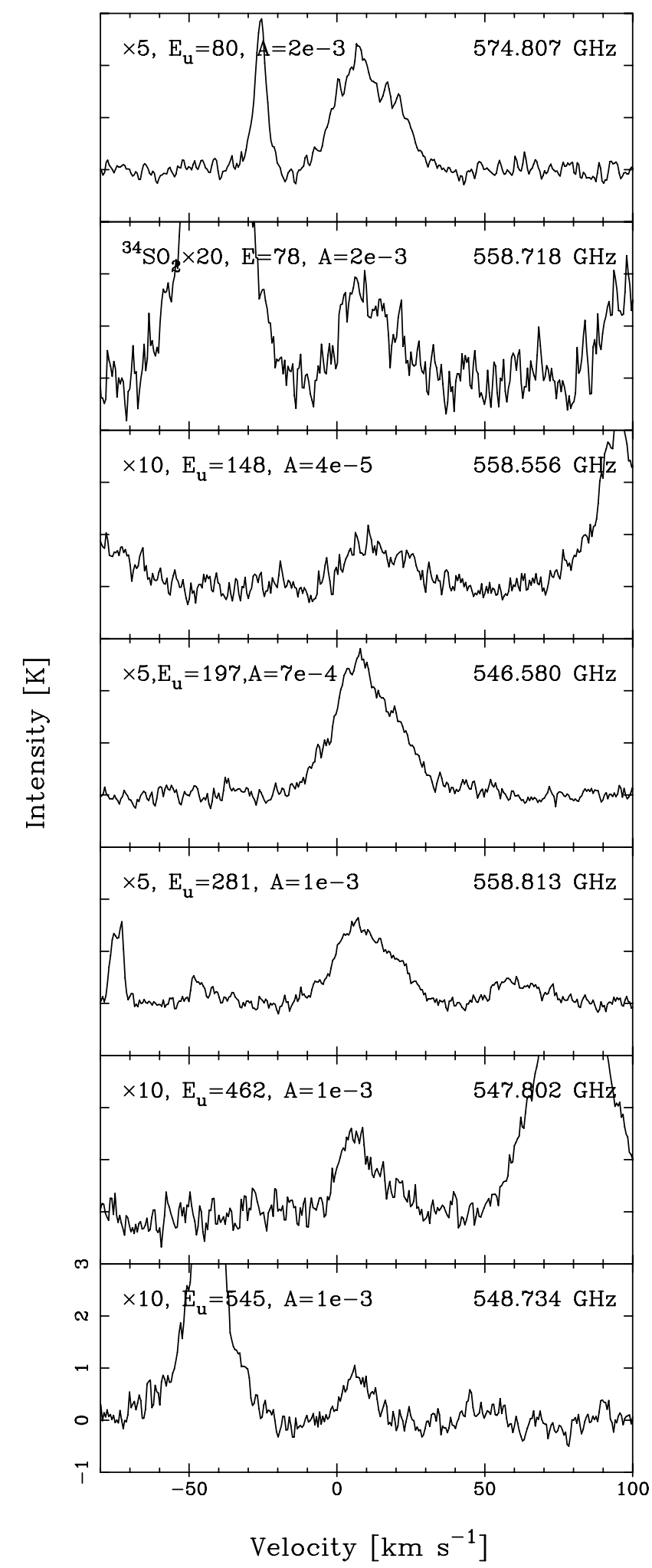

Fig. 29. $\mathrm{SO}_{2}$ with different upper state energy levels and $A$-coefficients. The ${ }^{34} \mathrm{SO}_{2}$ line is the same transition as the $\mathrm{SO}_{2}$ transition with $E_{\mathrm{u}}=$ $80 \mathrm{~K}$. An intensity scale factor is given in the top left corners. 
C. M. Persson et al.: A spectral line survey of Orion KL in the bands 486-492 and 541-577 GHz with the Odin satellite. II., Online Material p 6

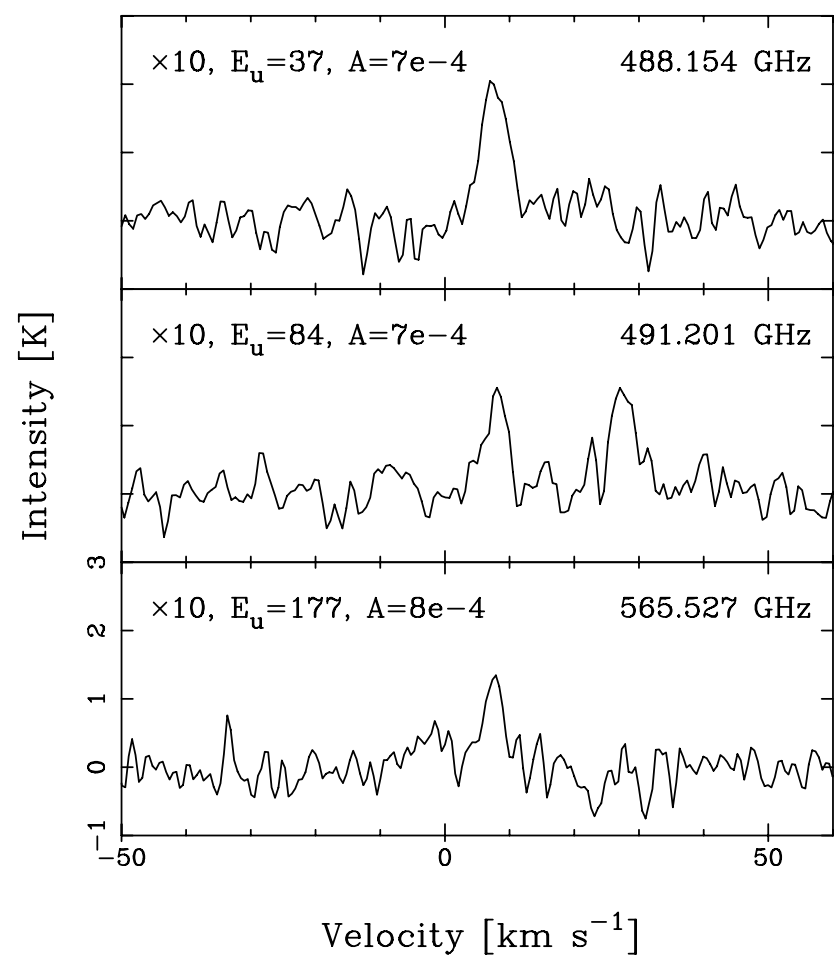

Fig. 30. ${ }^{13} \mathrm{CH}_{3} \mathrm{OH}$ with emission from the $\mathrm{CR}$. An intensity scale factor is given in the top left corners, upper state energies given in $\mathrm{K}$ and $A$-coefficients in $\mathrm{s}^{-1}$.

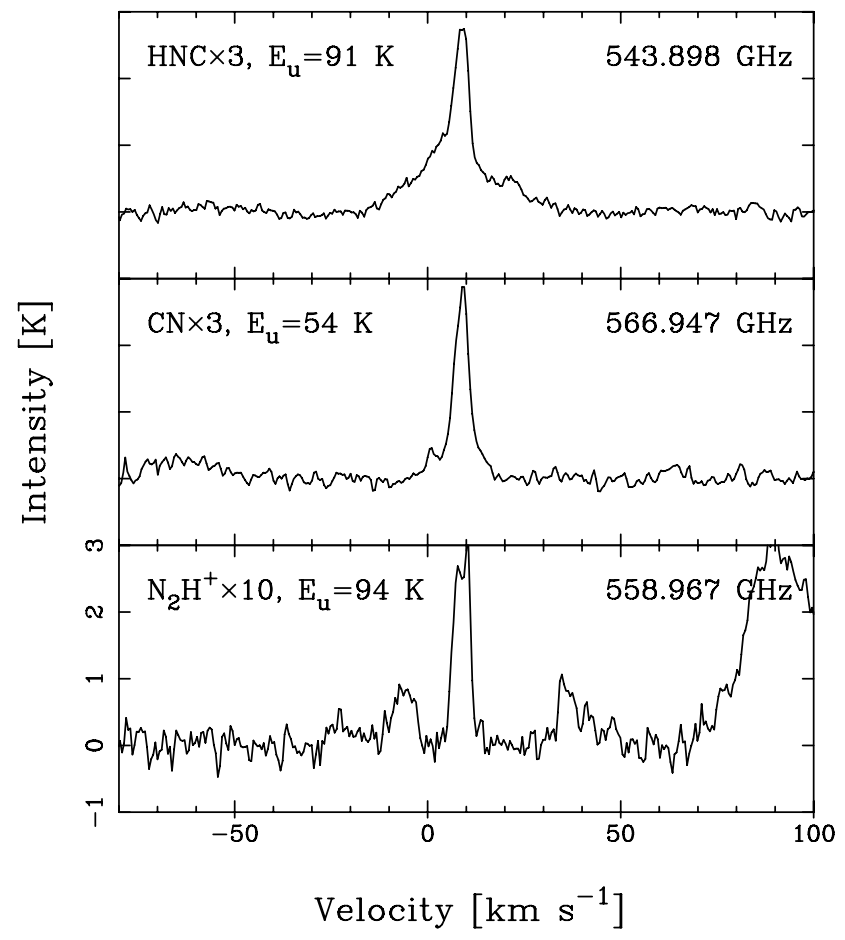

Fig. 31. The line profile of HNC shows emission from the ER, HC and LVF, $\mathrm{CN}$ from the PDR/ER and $\mathrm{HC}$, and $\mathrm{N}_{2} \mathrm{H}^{+}$from the ER. The line at $v \approx-8 \mathrm{~km} \mathrm{~s}^{-1}$ next to $\mathrm{N}_{2} \mathrm{H}^{+}$is OCS, which is also shown in Fig. 25. An intensity scale factor is given after the molecular species.

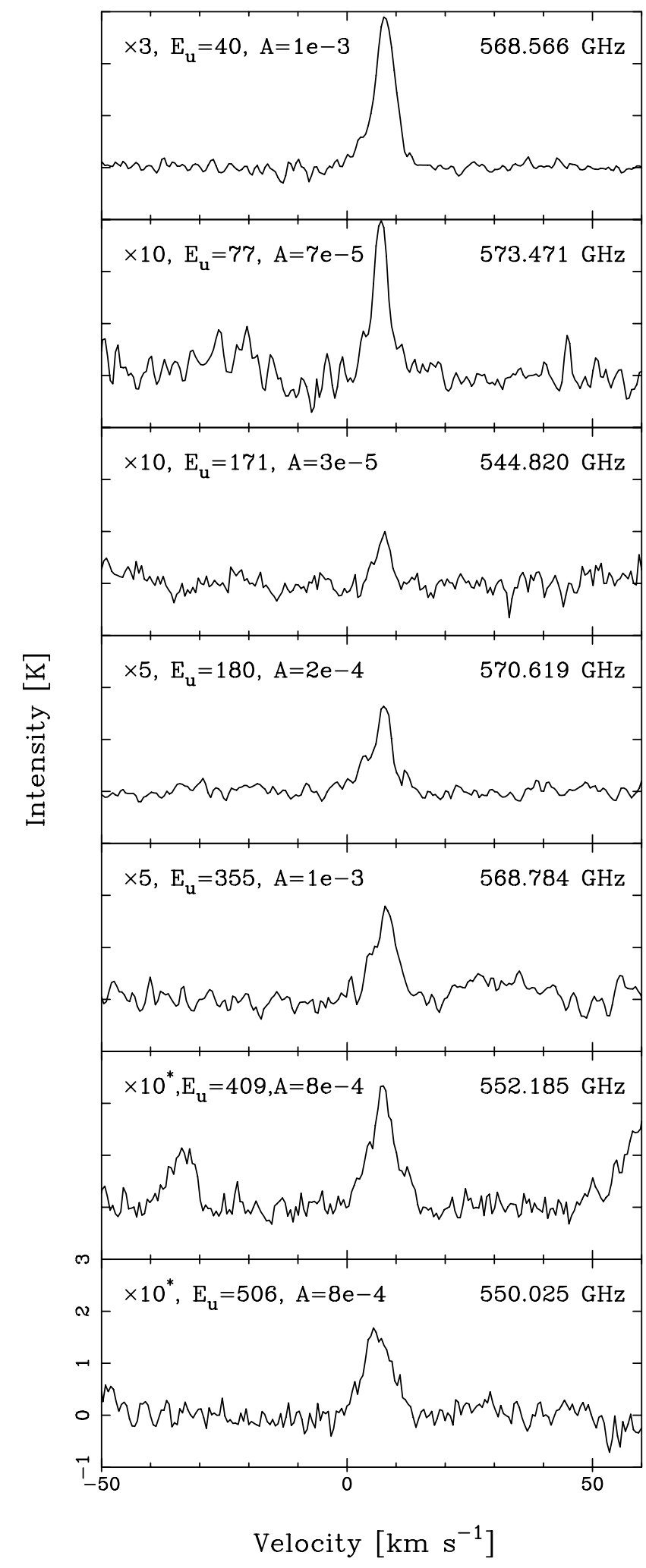

Fig. 32. $\mathrm{CH}_{3} \mathrm{OH}$ with emission from both the $\mathrm{CR}$ and $\mathrm{HC}$. Vibrationally excited transitions are marked by $*$ after the intensity scale factor given in the top left corners, with upper state energies given in $\mathrm{K}$ and $A$-coefficients in $\mathrm{s}^{-1}$. 
C. M. Persson et al.: A spectral line survey of Orion KL in the bands 486-492 and 541-577 GHz with the Odin satellite. II., Online Material p 7

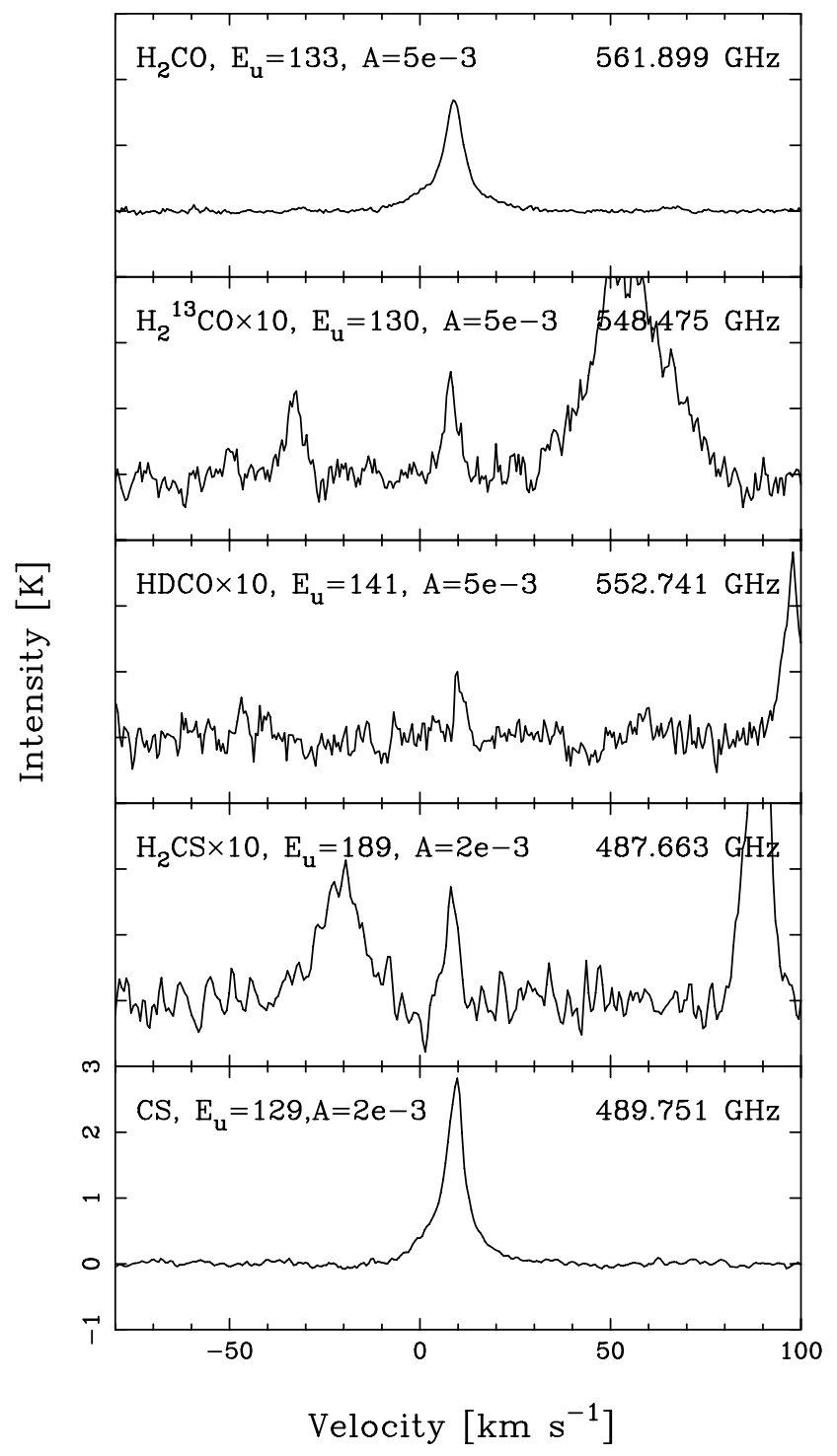

Fig. 33. The optically thick line profile of $\mathrm{H}_{2} \mathrm{CO}$ show emission from the CR and LVF. The optically thin transitions of $\mathrm{H}_{2}^{13} \mathrm{CO}, \mathrm{HDCO}$, and $\mathrm{H}_{2} \mathrm{CS}$ show only emission from the CR. The CS line profile shows emission from the HC, LVF and a narrow component from the CR or ER. An intensity scale factor is given after the molecular species, the upper state energies are given in $\mathrm{K}$ and the $A$-coefficients in $\mathrm{s}^{-1}$.

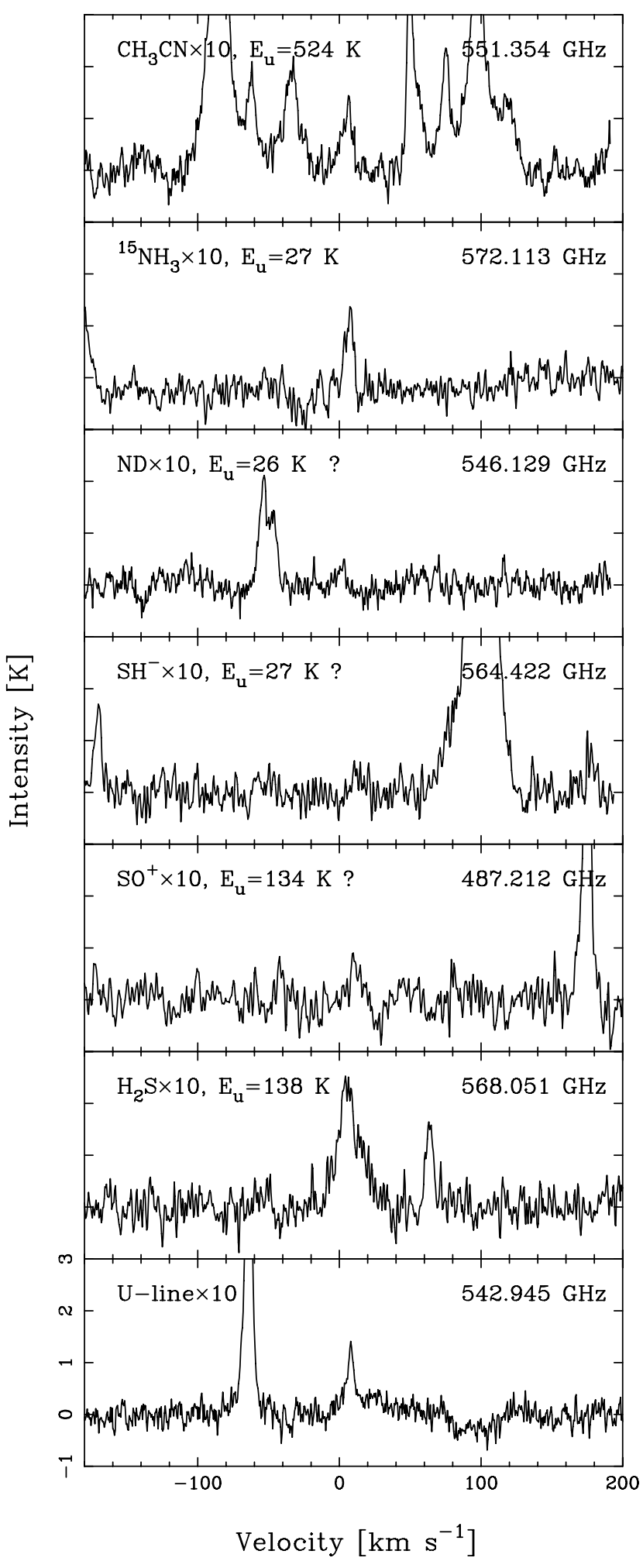

Fig. 34. Identification suggestions for a few U-lines together with ${ }^{15} \mathrm{NH}_{3}, \mathrm{H}_{2} \mathrm{~S}$ and $\mathrm{CH}_{3} \mathrm{CN}$ as comparison lines. The U-line at $542.945 \mathrm{GHz}$ is our strongest non-identified U-line. An intensity scale factor is given after the molecular species. 
C. M. Persson et al.: A spectral line survey of Orion KL in the bands 486-492 and 541-577 GHz with the Odin satellite. II., Online Material p 8

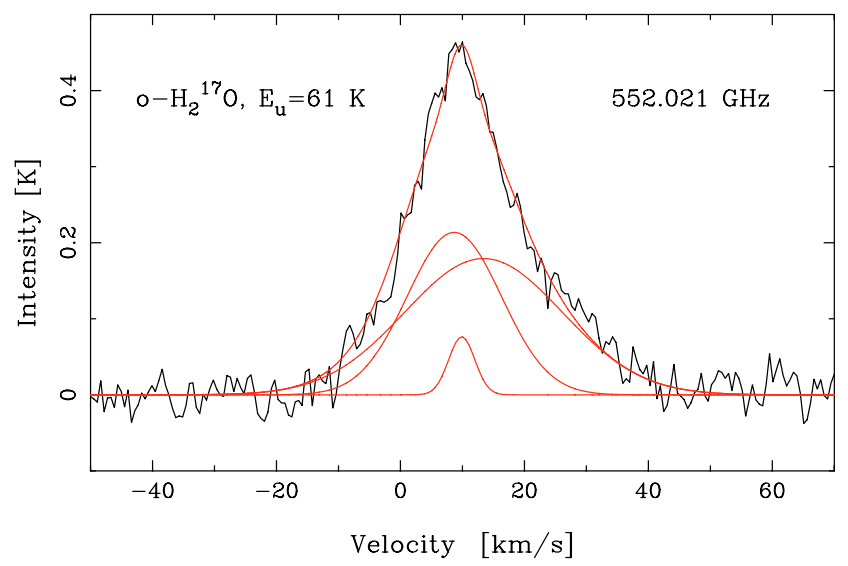

Fig. 35. A three-component Gaussian fit to $\mathrm{H}_{2}^{17} \mathrm{O}$ shown together with the individual Gaussians. The line widths are $5 \mathrm{~km} \mathrm{~s}^{-1}, 18 \mathrm{~km} \mathrm{~s}^{-1}$, and $30 \mathrm{~km} \mathrm{~s}^{-1}$ from the CR, LVF and HVF, respectively.

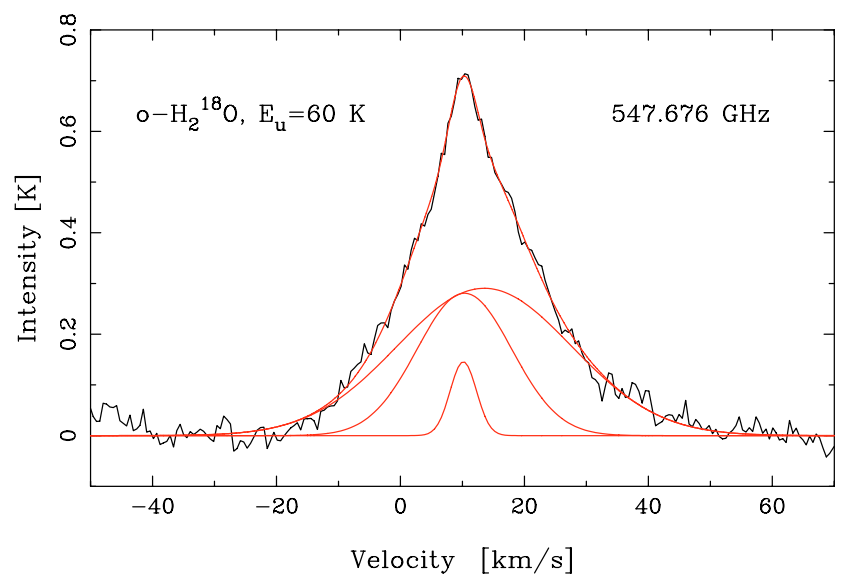

Fig. 36. A three-component Gaussian fit to $\mathrm{H}_{2}^{18} \mathrm{O}$ shown together with the individual Gaussians. The line widths are $5 \mathrm{~km} \mathrm{~s}^{-1}, 18 \mathrm{~km} \mathrm{~s}^{-1}$, and $33 \mathrm{~km} \mathrm{~s}^{-1}$ from the CR, LVF and HVF, respectively.

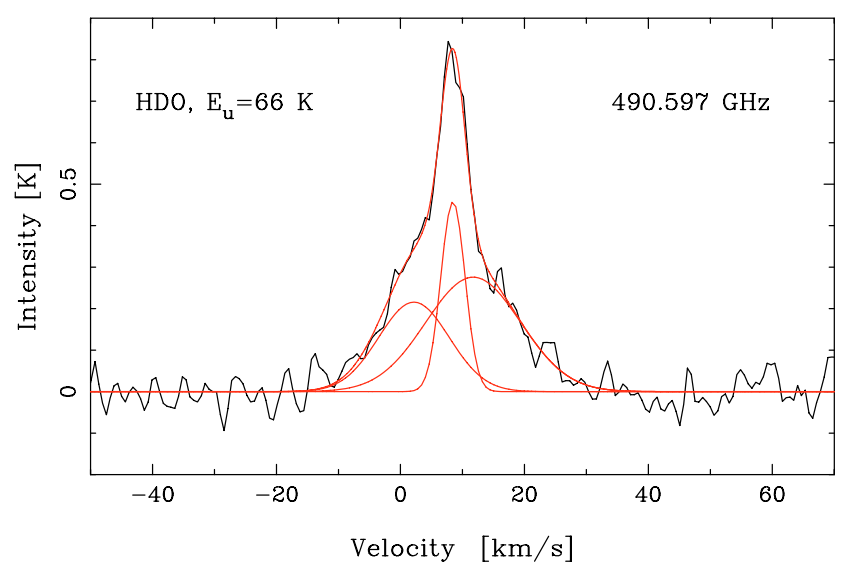

Fig. 37. A three-component Gaussian fit to HDO shown together with the individual Gaussians. The line widths are $5 \mathrm{~km} \mathrm{~s}^{-1}, 13 \mathrm{~km} \mathrm{~s}^{-1}$, and $18 \mathrm{~km} \mathrm{~s}^{-1}$ for the CR, HC, and LVF, respectively.

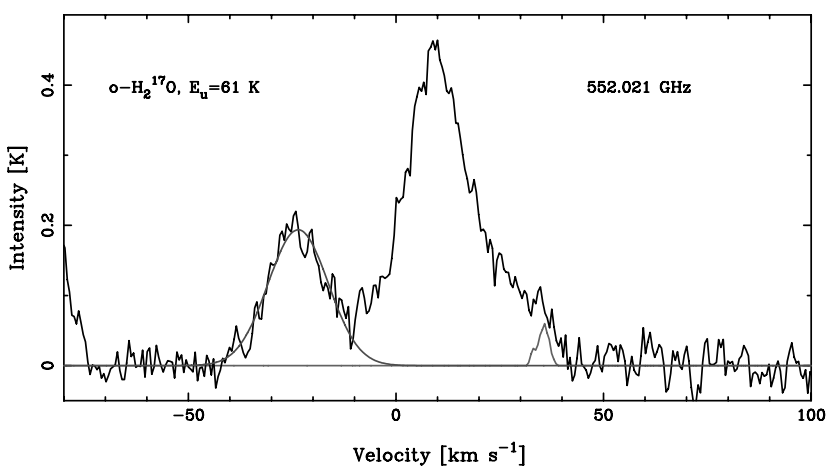

Fig. 38. $\mathrm{H}_{2}^{17} \mathrm{O}$ before removal of blends with reconstructed lines from $\mathrm{SO}_{2}$ and $\mathrm{CH}_{3} \mathrm{OH}$ shown.

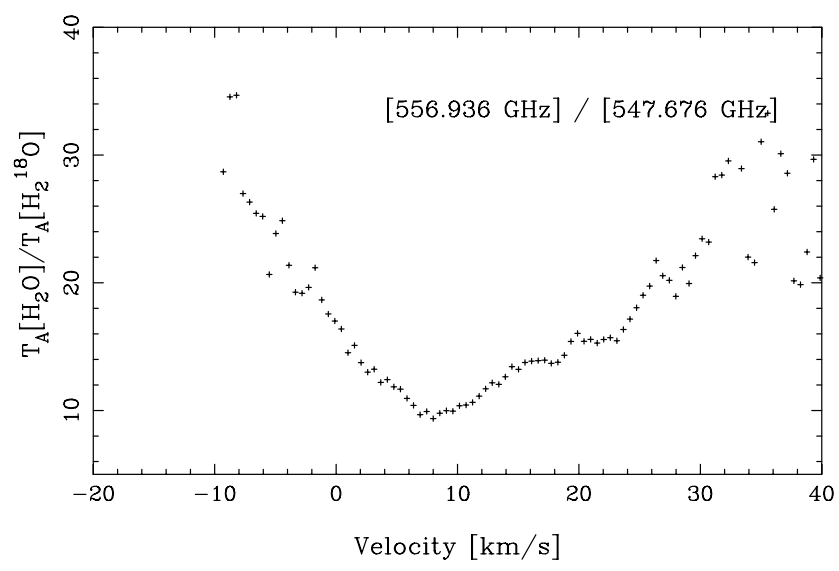

Fig. 39. Ratio of $o-\mathrm{H}_{2} \mathrm{O}$ over $o-\mathrm{H}_{2}^{18} \mathrm{O}$.

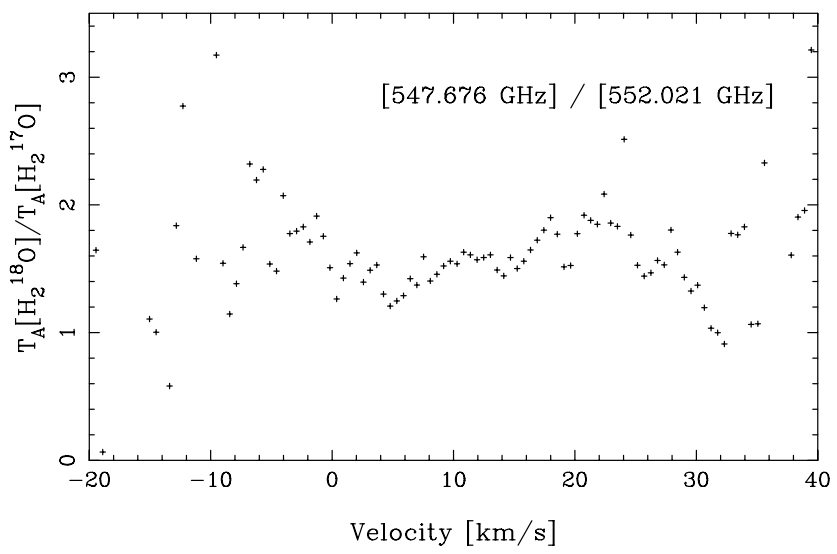

Fig. 40. Ratio of $o-\mathrm{H}_{2}^{18} \mathrm{O}$ over $o-\mathrm{H}_{2}^{17} \mathrm{O}$. 
C. M. Persson et al.: A spectral line survey of Orion KL in the bands 486-492 and 541-577 GHz with the Odin satellite. II., Online Material p 9

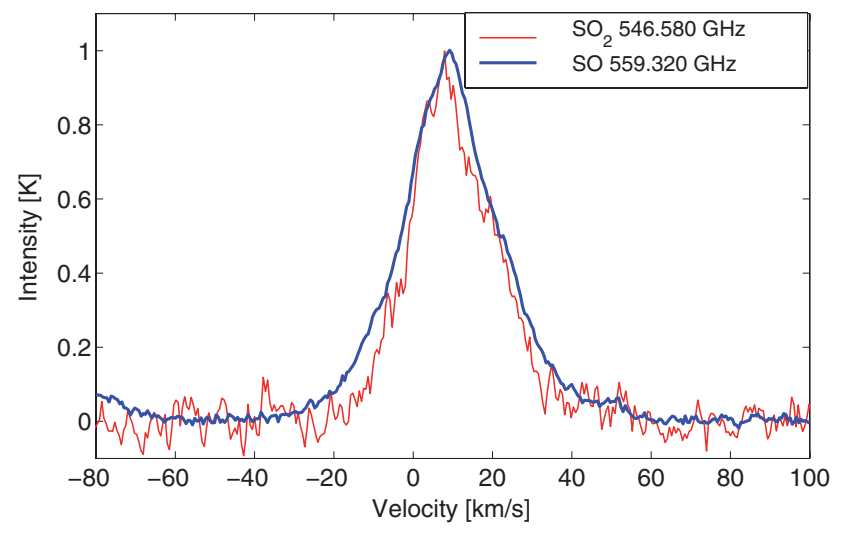

Fig. 41. Comparison of the $\mathrm{SO}$ and $\mathrm{SO}_{2}$ line profiles. Both lines are normalised to unity.

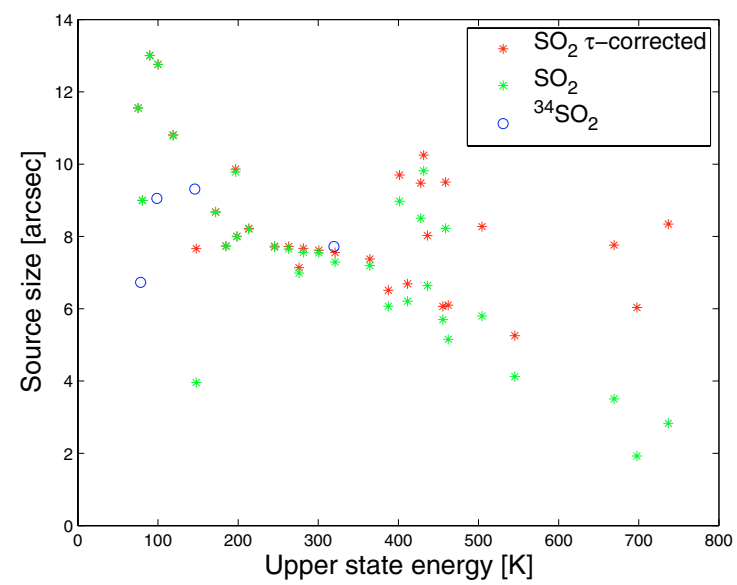

Fig. 42. Source sizes for opacity-corrected $\mathrm{SO}_{2}$ (calculated with $T_{\mathrm{ROT}}=$ $103 \mathrm{~K}$ and source size $=8^{\prime \prime}$ ) vs. non corrected $\mathrm{SO}_{2}$ together with ${ }^{34} \mathrm{SO}_{2}$ (calculated with $T_{\mathrm{ROT}}=125 \mathrm{~K}$ ).

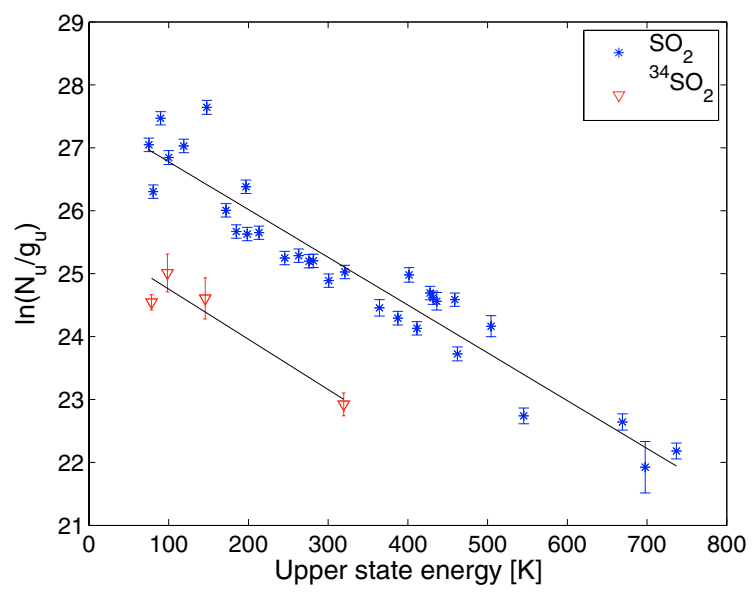

Fig. 43. Rotation diagram for $\mathrm{SO}_{2}$, not corrected for opacity, produces $T_{\text {ROT }}=132 \mathrm{~K}$ and $N_{\text {ROT }}=3.9 \times 10^{17} \mathrm{~cm}^{-2}$ (extended source). The ${ }^{34} \mathrm{SO}_{2}$ fit give $T_{\text {ROT }}=125 \mathrm{~K}$ and $N_{\mathrm{ROT}}=5.4 \times 10^{16} \mathrm{~cm}^{-2}$.

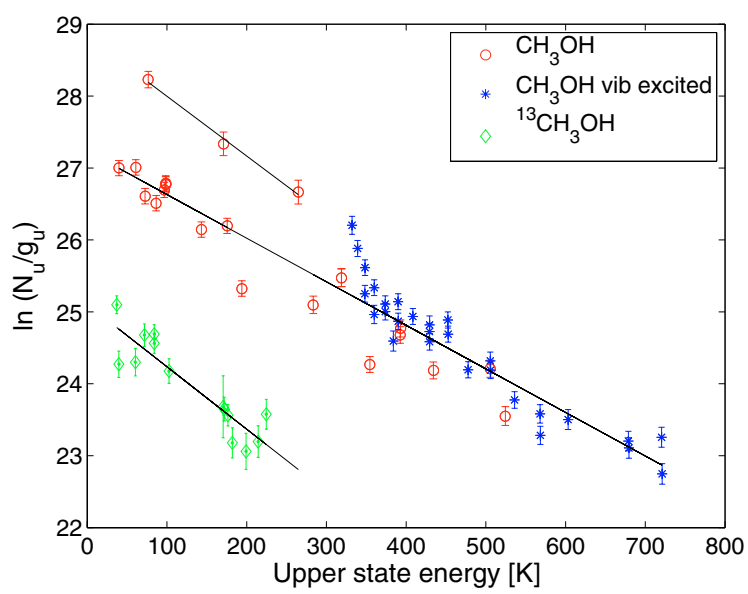

Fig. 44. Rotation diagrams: $\mathrm{CH}_{3} \mathrm{OH}$ producing $T_{\mathrm{ROT}}=165 \mathrm{~K}$ and $N_{\text {ROT }}=9.3 \times 10^{17} \mathrm{~cm}^{-2}$ (not opacity corrected); three optically thin $\mathrm{CH}_{3} \mathrm{OH}$ lines produces $T_{\text {ROT }}=120 \mathrm{~K}$ and $N_{\text {ROT }}=2.6 \times 10^{18} \mathrm{~cm}^{-2}$; ${ }^{13} \mathrm{CH}_{3} \mathrm{OH}$ producing $T_{\mathrm{ROT}}=115 \mathrm{~K}$ and $N_{\mathrm{ROT}}=5.9 \times 10^{17} \mathrm{~cm}^{-2}(\mathrm{ex}-$ tended source).

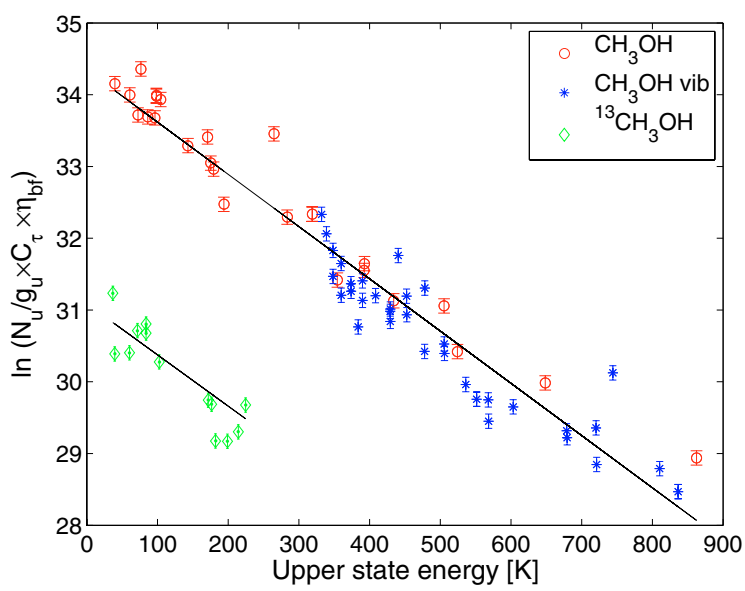

Fig. 45. $\mathrm{CH}_{3} \mathrm{OH}$ forward model producing $T_{\mathrm{ROT}}=136_{-4}^{+3} \mathrm{~K}, N=(1.3 \pm$ $0.1) \times 10^{18} \mathrm{~cm}^{-2}$ and a source size of $6^{\prime \prime+0.1}$. The ${ }^{13} \mathrm{CH}_{3} \mathrm{OH}$ forward model use the rotation temperature and source size obtained from $\mathrm{CH}_{3} \mathrm{OH}$. 
C. M. Persson et al.: A spectral line survey of Orion KL in the bands 486-492 and 541-577 GHz with the Odin satellite. II., Online Material p 10

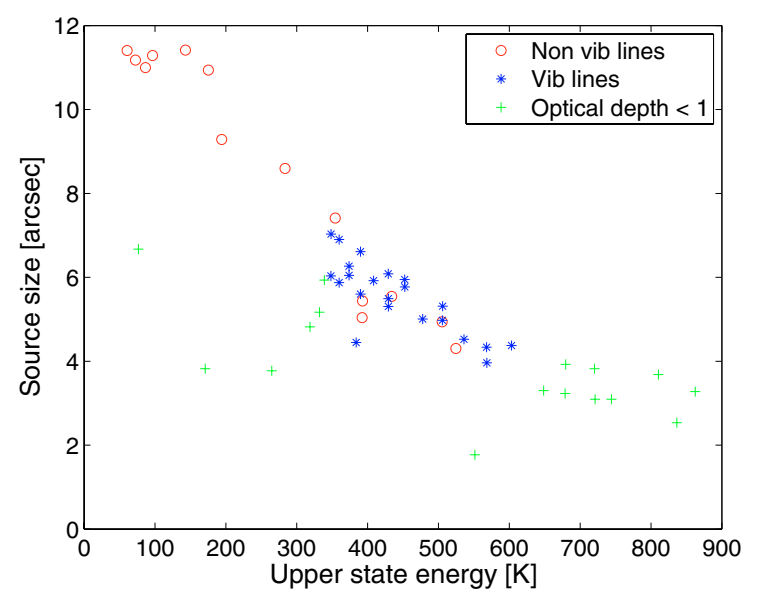

Fig. 46. Source size variation with energy for $\mathrm{CH}_{3} \mathrm{OH}$ (no opacity corrections). The low-energy transitions have larger source sizes than higher-energy transitions. Note that all lines with an optical depth less than one, fall below the general trend of decreasing source size with higher energy, since Eq. (14) is only valid for optically thick lines.

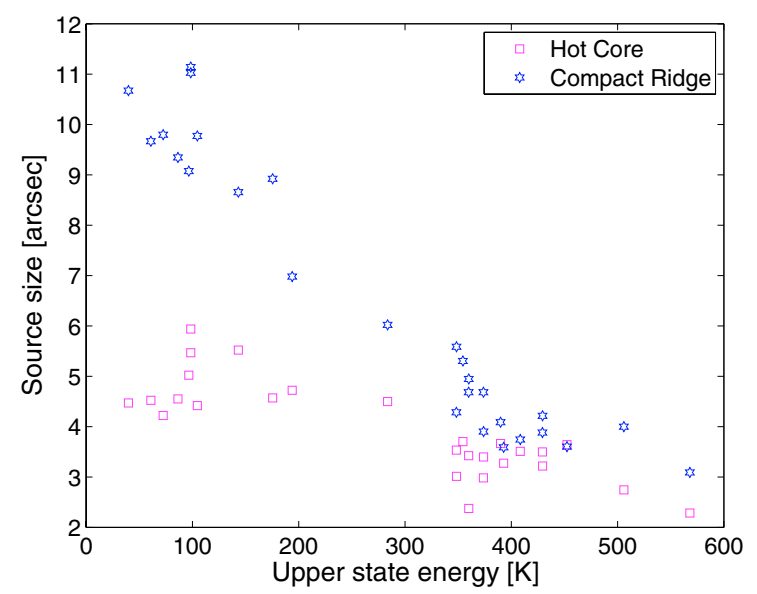

Fig. 47. Source size variation with energy for two components of $\mathrm{CH}_{3} \mathrm{OH}$ with no opacity correction.
Table 5. Summary of all detected species.

\begin{tabular}{|c|c|c|c|}
\hline Species & $\begin{array}{r}\text { Number } \\
\text { of lines }\end{array}$ & $\begin{array}{r}\text { Upper state } \\
\text { energy range } \\
{[\mathrm{K}]}\end{array}$ & $\begin{array}{r}\int T_{\mathrm{A}}^{*} \mathrm{~d} v \\
{\left[\mathrm{~K} \mathrm{~km} \mathrm{~s}^{-1}\right]}\end{array}$ \\
\hline $\mathrm{CH}_{3} \mathrm{OCH}_{3}$ & 47 & $106-448$ & 18.3 \\
\hline $\mathrm{SO}_{2}$ & 42 & $75-737$ & 239.9 \\
\hline${ }^{34} \mathrm{SO}_{2}$ & 5 & $79-457$ & 2.6 \\
\hline SO & 5 & 71-201 & 181.5 \\
\hline${ }^{33} \mathrm{SO}$ & 3 & 191-199 & 6.5 \\
\hline${ }^{34} \mathrm{SO}$ & 2 & 191-197 & 15.6 \\
\hline $\mathrm{CH}_{3} \mathrm{OH} v_{\mathrm{t}}=1$ & 42 & $332-836$ & \\
\hline $\mathrm{CH}_{3} \mathrm{OH}$ & 34 & $38-863$ & 108.6 \\
\hline${ }^{13} \mathrm{CH}_{3} \mathrm{OH}$ & 21 & $37-499$ & 6.8 \\
\hline${ }^{13} \mathrm{CH}_{3} \mathrm{OH} v_{\mathrm{t}}=1$ & 2 & $373-670$ & \\
\hline $\mathrm{CH}_{3} \mathrm{CN}$ & 17 & 410-1012 & 9.3 \\
\hline NO & 12 & 84-232 & 11.1 \\
\hline $\mathrm{CN}$ & 8 & 54 & 8.5 \\
\hline $\mathrm{H}_{2} \mathrm{CS}$ & 5 & $138-343$ & 1.7 \\
\hline $\mathrm{H}_{2} \mathrm{CO}$ & 3 & $106-133$ & 38.5 \\
\hline $\mathrm{H}_{2}^{13} \mathrm{CO}$ & 1 & 130 & 0.6 \\
\hline HDCO & 3 & 114-141 & 2.8 \\
\hline OCS & 3 & $604-658$ & 1.3 \\
\hline$o-\mathrm{H}_{2} \mathrm{O}$ & 1 & 61 & 320.3 \\
\hline$p-\mathrm{H}_{2} \mathrm{O}$ & 1 & 867 & 2.2 \\
\hline$o-\mathrm{H}_{2}^{17} \mathrm{O}$ & 1 & 61 & 9.4 \\
\hline$o-\mathrm{H}_{2}^{18} \mathrm{O}$ & 2 & $60-430$ & 16.2 \\
\hline HDŌ & 1 & 66 & 10.7 \\
\hline $\mathrm{HC}_{3} \mathrm{~N}$ & 2 & $648-799$ & 0.6 \\
\hline $\mathrm{CO}$ & 1 & 83 & 1100 \\
\hline${ }^{13} \mathrm{CO}$ & 1 & 79 & 174.3 \\
\hline $\mathrm{C}^{17} \mathrm{O}$ & 1 & 81 & 6.0 \\
\hline $\mathrm{C}^{18} \mathrm{O}$ & 1 & 79 & 24.3 \\
\hline $\mathrm{C}$ & 1 & 24 & 38.7 \\
\hline $\mathrm{NH}_{3}$ & 1 & 27 & 20.6 \\
\hline${ }^{15} \mathrm{NH}_{3}$ & 1 & 27 & 0.7 \\
\hline $\mathrm{HNC}$ & 1 & 91 & 10.7 \\
\hline $\mathrm{N}_{2} \mathrm{H}^{+}$ & 1 & 94 & 1.5 \\
\hline $\mathrm{H}_{2} \mathrm{~S}$ & 1 & 166 & 4.4 \\
\hline CS & 1 & 129 & 24 \\
\hline${ }^{13} \mathrm{CS}$ & 1 & 173 & $\mathrm{v}$ blend \\
\hline $\mathrm{SiO}$ & 1 & 190 & 17.6 \\
\hline${ }^{29} \mathrm{SiO}$ & 1 & 187 & 1.4 \\
\hline${ }^{30} \mathrm{SiO}$ & 1 & 185 & 0.5 \\
\hline $\mathrm{HCS}^{+}$ & 1 & 186 & $\mathrm{v}$ blend \\
\hline NS & 1 & 442 & $\mathrm{v}$ blend \\
\hline U-line & 28 & & 9.1 \\
\hline T-line & 36 & & 7.2 \\
\hline No. of species & 38 & & \\
\hline No. of lines & 344 & & \\
\hline Total $\int T_{\mathrm{A}}^{*} \mathrm{~d} v$ & & & 2455 \\
\hline
\end{tabular}


C. M. Persson et al.: A spectral line survey of Orion KL in the bands 486-492 and 541-577 GHz with the Odin satellite. II., Online Materialp 11

Table 6. Isotopologue abundance ratios from our survey, or from the literature, as compared to terrestrial values. The molecular abundance $\mathrm{O} / \mathrm{S}$ ratios are also included.

\begin{tabular}{|c|c|c|c|c|c|c|c|c|c|}
\hline & {$\left[{ }^{12} \mathrm{C} /{ }^{13} \mathrm{C}\right]$} & {$\left[{ }^{32} \mathrm{~S} /{ }^{\beta 4} \mathrm{~S}\right]$} & {$\left[{ }^{34} S /{ }^{33} S\right]$} & {$\left[{ }^{18} \mathrm{O} /{ }^{17} \mathrm{O}\right]$} & {$\left[{ }^{16} \mathrm{O} /{ }^{18} \mathrm{O}\right]$} & {$[\mathrm{D} / \mathrm{H}]$} & {$[\mathrm{O} / \mathrm{S}]$} & {$\left[{ }^{14} \mathrm{~N} /{ }^{15} \mathrm{~N}\right]$} & {$\left[{ }^{28} \mathrm{Si} /{ }^{29} \mathrm{Si}\right]$} \\
\hline This survey & $57 \pm 14^{a}$ & $21 \pm 6^{b}-23 \pm 7^{c}$ & $4.9^{d}$ & $3.6^{e}$ & & $0.001^{f}-0.03^{g}$ & $15^{h}-20^{i}$ & & \\
\hline Terrestrial & $89^{j}$ & $22.5^{j}$ & $5.5^{j}$ & $5.5^{k}$ & & & $35^{v}$ & $273^{l}$ & $19.6^{m}$ \\
\hline $\mathrm{K} 88^{j}$ & $47_{-5}^{+6}$ & $20.2_{-2.1}^{+2.6}$ & $5.7_{-0.6}^{+0.8}$ & & & & & & \\
\hline $\mathrm{W} \& \mathrm{R} 94^{n}$ & $77 \pm 7$ & $\sim 22$ & & $3.2 \pm 0.2$ & $560 \pm 25$ & & & $450 \pm 22$ & \\
\hline $\mathrm{C} 96^{\circ}$ & $75 \pm 21$ & $35 \pm 10$ & $7.53 \pm 0.45$ & & & & & & \\
\hline $\mathrm{B} 01^{p}$ & $65.0 \pm 9.2$ & & & $4.15 \pm 0.59$ & & & & & \\
\hline $\mathrm{P} 81 \mathrm{~b}^{q}$ & & & & $3.9 \pm 0.2$ & & & & & \\
\hline Various surveys & $43 \pm 7^{r}$ & & & $4.17 \pm 0.26^{s}$ & $330 \pm 69^{t}$ & $2 \times 10^{-5 u}$ & & & $16.9 \pm 2.0^{m}$ \\
\hline
\end{tabular}

${ }^{a}$ From ${ }^{12} \mathrm{CH}_{3} \mathrm{OH} /{ }^{13} \mathrm{CH}_{3} \mathrm{OH} .{ }^{b}$ From ${ }^{32} \mathrm{SO} /{ }^{34} \mathrm{SO} .{ }^{c}$ From ${ }^{32} \mathrm{SO}_{2} /{ }^{34} \mathrm{SO}_{2} \cdot{ }^{d}$ From ${ }^{34} \mathrm{SO} /{ }^{33} \mathrm{SO} .{ }^{e}$ From $\mathrm{C}^{18} \mathrm{O} / \mathrm{C}^{17} \mathrm{O} .{ }^{f}$ From HDO/H${ }_{2}^{17} \mathrm{O}$ Hot Core. ${ }^{g}$ From $\mathrm{HDO} / \mathrm{H}_{2}^{17} \mathrm{O}$ Compact Ridge. ${ }^{h}$ From $\mathrm{H}_{2}^{13} \mathrm{CO} / \mathrm{H}_{2}^{12} \mathrm{CS} \mathrm{CR} .{ }^{i}$ From $\mathrm{H}_{2}^{17} \mathrm{O} / \mathrm{H}_{2} \mathrm{~S}$ LVF. ${ }^{j}$ Kahane et al. (1988), the envelope of IRC+10216. ${ }^{k}$ Blake et al. (1987). ${ }^{l}$ Ho \& Townes (1983). ${ }^{m}$ Penzias (1981a). ${ }^{n}$ Wilson \& Rood (1994) and references therein, local ISM. ${ }^{o}$ Chin et al. (1996), towards Orion KL. ${ }^{p}$ Bensch et al. (2001), towards $\rho$ Ophiuchi Molecular Cloud. ${ }^{q}$ Penzias (1981b), towards Orion A. ${ }^{r}$ Savage et al. (2002), towards Orion A using CN and ${ }^{13} \mathrm{CN} .{ }^{s}$ Wouterloot et al. (2005), towards $\rho$ Ophiuchi Molecular Cloud, value from LTE column densities. ${ }^{t}$ Olofsson (2003), from $\mathrm{S}^{18} \mathrm{O}$ observations of molecular cloud cores. ${ }^{u}$ Neufeld et al. (2006). ${ }^{v}$ Standard abundances, Grevesse et al. (1996).

Table 7. $\mathrm{H}_{2} \mathrm{O}$ and isotopologue parameters and derived column densities.

\begin{tabular}{|c|c|c|c|c|c|c|c|c|c|c|}
\hline Species & Comp $^{a}$ & $\begin{array}{r}v_{\text {LSR }} \\
{\left[\mathrm{km} \mathrm{s}^{-1}\right]}\end{array}$ & $\begin{array}{r}\Delta v \\
{\left[\mathrm{~km} \mathrm{~s}^{-1}\right]}\end{array}$ & $\begin{array}{r}T_{\mathrm{A}}^{*} \\
{[\mathrm{~K}]}\end{array}$ & $\begin{array}{r}T_{\mathrm{k}} \\
{[\mathrm{K}]}\end{array}$ & $\begin{array}{r}\text { Size } \\
{\left[{ }^{\prime \prime}\right]}\end{array}$ & $N^{b}$ & $\begin{array}{r}\tau \\
\left.\mathrm{cm}^{-2}\right]\end{array}$ & $\begin{array}{l}N_{\tau \text { corr }}^{c} \\
\left.\mathrm{~cm}^{-2}\right]\end{array}$ & $\begin{array}{c}N_{\text {ISO }}^{d} \\
{\left[\mathrm{~cm}^{-2}\right]}\end{array}$ \\
\hline \multirow[t]{4}{*}{$o-\mathrm{H}_{2}^{16} \mathrm{O}$} & Total & & & & 72 & $(15)^{e}$ & & $\sim 1100^{f}$ & & $1.7 \times 10^{18}$ \\
\hline & $\mathrm{CR}$ & & & & 115 & $(6)^{e}$ & & $\sim 860^{f}$ & & $5.6 \times 10^{17}$ \\
\hline & LVF & & & & 72 & $(15)^{e}$ & & $\sim 1900^{f}$ & & $8.7 \times 10^{17}$ \\
\hline & HVF & 5.3 & 67.1 & 2.452 & 72 & 70 & $8.7 \times 10^{14}$ & $\sim 910^{f}$ & $8.0 \times 10^{17}$ & $8.8 \times 10^{17}$ \\
\hline$p-\mathrm{H}_{2}^{16} \mathrm{O}$ & $\mathrm{HC}$ & 4.4 & 12.0 & 0.181 & 200 & 10 & $1.2 \times 10^{19}$ & $0.3^{g}$ & & \\
\hline \multirow[t]{4}{*}{$o-\mathrm{H}_{2}^{17} \mathrm{O}$} & Total & & & & 72 & 15 & $8.6 \times 10^{14}$ & $0.9^{f}$ & $1.3 \times 10^{15}$ & \\
\hline & $\mathrm{CR}$ & 9.9 & 5.0 & 0.076 & 115 & 6 & $3.2 \times 10^{14}$ & $0.7^{f}$ & $4.4 \times 10^{14}$ & \\
\hline & LVF & 8.7 & 18.0 & 0.214 & 72 & 15 & $3.5 \times 10^{14}$ & $1.5^{f}$ & $6.7 \times 10^{14}$ & \\
\hline & HVF & 13.4 & 30.1 & 0.179 & 72 & 15 & $4.9 \times 10^{14}$ & $0.7^{f}$ & $6.8 \times 10^{14}$ & \\
\hline \multirow[t]{4}{*}{$o-\mathrm{H}_{2}^{18} \mathrm{O}$} & Total & & & & 72 & 15 & $1.4 \times 10^{15}$ & $3.4^{f}$ & $5.0 \times 10^{15}$ & $5.0 \times 10^{15}$ \\
\hline & $\mathrm{CR}$ & 10.1 & 5.0 & 0.145 & 115 & 6 & $6.2 \times 10^{14}$ & $2.6^{f}$ & $1.8 \times 10^{15}$ & $1.7 \times 10^{15}$ \\
\hline & LVF & 10.5 & 18.0 & 0.275 & 72 & 15 & $4.6 \times 10^{14}$ & $5.9^{f}$ & $2.7 \times 10^{15}$ & $2.6 \times 10^{15}$ \\
\hline & HVF & 13.4 & 33.4 & 0.298 & 72 & 15 & $9.3 \times 10^{14}$ & $2.8^{f}$ & $2.8 \times 10^{15}$ & $2.7 \times 10^{15}$ \\
\hline \multirow[t]{4}{*}{ HDO } & Total & & & & 72 & 15 & $9.1 \times 10^{15}$ & $\sim 1.5^{g}$ & & \\
\hline & $\mathrm{CR}$ & 8.5 & 4.6 & 0.459 & 115 & 6 & $1.8 \times 10^{16}$ & $\sim 3^{g}$ & & \\
\hline & LVF & 11.8 & 18.0 & 0.273 & 72 & 15 & $4.5 \times 10^{15}$ & $\sim 0.3^{g}$ & & \\
\hline & $\mathrm{HC}$ & 2.2 & 13.4 & 0.216 & 200 & 10 & $1.5 \times 10^{16}$ & $\sim 0.5^{g}$ & & \\
\hline
\end{tabular}

${ }^{a}$ Total $=$ the total integrated intensity is used, $\mathrm{CR}=$ Compact Ridge, $\mathrm{LVF}=$ Low Velocity Flow, HVF $=$ High Velocity Flow, HC $=$ Hot Core.

${ }^{b}$ Corrected for beam-filling.

${ }^{c}$ Corrected for beam-filling, and for optical depth with factor $\tau /\left(1-\mathrm{e}^{-\tau}\right)$.

${ }^{d}$ Column calculated from isotopologue $o-\mathrm{H}_{2}^{17} \mathrm{O}$, beam-filling and optical depth corrected.

${ }^{e}$ Size from isotopologues. The full $\mathrm{LVF} o-\mathrm{H}_{2}^{16} \mathrm{O}$ emission may have a larger extent.

${ }^{f}$ Calculated from the ratio of $\mathrm{H}_{2}^{18} \mathrm{O}$ and $\mathrm{H}_{2}^{17} \mathrm{O}$ column densities.

${ }^{g}$ Calculated with Eq. (15). 
C. M. Persson et al.: A spectral line survey of Orion KL in the bands 486-492 and 541-577 GHz with the Odin satellite. II., Online Material p 12

Table 8. CO and isotopologue parameters and derived column densities.

\begin{tabular}{|c|c|c|c|c|c|c|c|c|c|c|c|c|}
\hline Species & Comp $^{a}$ & $v_{\mathrm{LSR}}$ & $\Delta v$ & $\begin{array}{r}T_{\mathrm{A}}^{*} \\
{[\mathrm{~K}]}\end{array}$ & $\underset{\left[\mathrm{K} \mathrm{km} \mathrm{s}^{-1}\right]}{\int T_{\mathrm{A}}^{*} \mathrm{~d} v}$ & $\begin{array}{r}T_{\mathrm{k}} \\
{[\mathrm{K}]}\end{array}$ & $\begin{array}{r}\text { Size } \\
{\left[{ }^{\prime \prime}\right]}\end{array}$ & $\begin{array}{r}N \\
{\left[\mathrm{~cm}^{-2}\right]}\end{array}$ & $\tau$ & $\begin{array}{r}N_{\mathrm{ISO}}\left(\mathrm{C}^{17} \mathrm{O}\right) \\
{\left[\mathrm{cm}^{-2}\right]}\end{array}$ & $N_{\text {ISO }}\left(\mathrm{C}^{18} \mathrm{O}\right)$ & $N_{\text {ISO }}\left({ }^{13} \mathrm{CO}\right)$ \\
\hline \multirow[t]{3}{*}{$\mathrm{CO}$} & $\mathrm{PDR}^{b}$ & & & & & 100 & & & & $1.6 \times 10^{18}$ & $1.5 \times 10^{18}$ & $1.2 \times 10^{18}$ \\
\hline & LVF & & & & & 100 & $(30)^{d}$ & & & $2.5 \times 10^{19}$ & $2.2 \times 10^{19}$ & $2.3 \times 10^{19}$ \\
\hline & HVF & & & & & 100 & $(70)^{d}$ & & & & & $2.2 \times 10^{18}$ \\
\hline \multirow[t]{3}{*}{${ }^{13} \mathrm{CO}$} & $\mathrm{N}^{c}$ & 8.1 & 4.8 & 21.6 & 109.9 & 100 & $\ldots$ & $5.7 \times 10^{16}$ & & $5.4 \times 10^{16}$ & $4.9 \times 10^{16}$ & \\
\hline & LVF & 7.8 & 18.0 & 2.18 & 41.6 & 100 & 30 & $3.9 \times 10^{17}$ & & $4.2 \times 10^{17}$ & $3.7 \times 10^{17}$ & \\
\hline & HVF & 6.7 & 48.7 & 0.470 & 24.2 & 100 & 70 & $5.2 \times 10^{16}$ & & & & \\
\hline \multirow[t]{2}{*}{$\mathrm{C}^{17} \mathrm{O}$} & $\mathrm{N}^{c}$ & 8.8 & 4.2 & 1.11 & 4.95 & 100 & $\ldots$ & $2.5 \times 10^{15}$ & 0.07 & & & \\
\hline & LVF & 9.9 & 18.0 & 0.116 & 2.21 & 100 & 30 & $2.0 \times 10^{16}$ & 0.1 & & & \\
\hline \multirow[t]{2}{*}{$\mathrm{C}^{18} \mathrm{O}$} & $\mathrm{N}^{c}$ & 8.7 & 4.2 & 3.81 & 17.0 & 100 & $\ldots$ & $8.9 \times 10^{15}$ & 0.3 & $9.8 \times 10^{15}$ & & \\
\hline & LVF & 7.8 & 18.0 & 0.367 & 7.00 & 100 & 30 & $6.7 \times 10^{16}$ & 0.3 & $7.7 \times 10^{16}$ & & \\
\hline \multirow[t]{4}{*}{$\mathrm{H}_{2}$} & $\mathrm{PDR}^{b}$ & & & & & & $\cdots$ & & & $2.0 \times 10^{22}$ & $1.8 \times 10^{22}$ & $1.5 \times 10^{22}$ \\
\hline & $\mathrm{ER}^{b}$ & & & & & & & & & $2.0 \times 10^{22}$ & $1.8 \times 10^{22}$ & $1.5 \times 10^{22}$ \\
\hline & LVF & & & & & & $(30)^{d}$ & & & $3.2 \times 10^{23}$ & $2.8 \times 10^{23}$ & $2.3 \times 10^{23}$ \\
\hline & HVF & & & & & & $(70)^{d}$ & & & & & $3.9 \times 10^{22}$ \\
\hline
\end{tabular}

${ }^{a} \mathrm{~N}=$ Narrow, $\mathrm{LVF}=$ Low Velocity Flow, HVF $=$ High Velocity Flow.

${ }^{b}$ This is half of the column density obtained from the narrow components of the isotopolouges, since CO narrow component only has emission from the PDR, while the isotopologues have equal emission from PDR and ER (as discussed in W06).

${ }^{c}$ Consists of approximately equal emission from PDR and ER.

${ }^{d}$ Size from CO isotopologues. The size of the full LVF CO emission is larger than the isotopologues and calculated to be $45^{\prime \prime}$. 
Table 9. $\mathrm{SO}_{2}$ parameters ${ }^{a}$.

\begin{tabular}{|c|c|c|c|c|c|c|c|c|c|c|}
\hline $\begin{array}{l}v_{u l} \\
{[\mathrm{MHz}]}\end{array}$ & $\begin{array}{r}\Delta v_{\mathrm{p}} \\
{[\mathrm{MHz}]}\end{array}$ & $\begin{array}{r}\Delta v_{\mathrm{g}} \\
{[\mathrm{MHz}]}\end{array}$ & $\begin{array}{l}\text { Transition } \\
J_{K_{a}, K_{c}}\end{array}$ & $\begin{array}{r}E_{u} \\
{[\mathrm{~K}]}\end{array}$ & $\begin{array}{l}A_{u l} \\
{\left[\mathrm{~s}^{-1}\right]}\end{array}$ & $\begin{array}{r}T_{\mathrm{A}}^{*}(\text { peak }) \\
{[\mathrm{mK}]}\end{array}$ & $\begin{array}{r}\text { Ampl. } \\
{[\mathrm{mK}]}\end{array}$ & $\begin{array}{r}\text { Width } \\
{\left[\mathrm{km} \mathrm{s}^{-1}\right]}\end{array}$ & $\begin{array}{r}\int T_{\mathrm{A}}^{*} \mathrm{~d} v \\
{\left[\mathrm{~km} \mathrm{~s}^{-1}\right]}\end{array}$ & Note \\
\hline 491934.7 & & & $7_{4,4}-6_{3,3}$ & 65.0 & $9.49 \mathrm{e}-4$ & & & & & blend $\mathrm{HDCO}$ \\
\hline 541750.9 & 0.9 & & $14_{3,11}-13_{2,12}$ & 119.0 & $6.31 \mathrm{e}-4$ & 695 & & & 15.80 & \\
\hline & & 0.0 & & & & & 143 & 5.0 & & 3G: CR \\
\hline & & -0.1 & & & & & 266 & 18.0 & & 3G: LVF \\
\hline & & 3.2 & & & & & 301 & 34.9 & & 3G: HVF \\
\hline 541810.6 & & & $30_{6,24}-30_{5,25}$ & 516.7 & $1.34 \mathrm{e}-3$ & & & & & weak \\
\hline 543413.5 & -2.5 & -0.5 & $29_{2,28}-28_{1,27}$ & 401.5 & $1.64 \mathrm{e}-3$ & 457 & 411 & 25.5 & 10.70 & blend $\mathrm{CH}_{3} \mathrm{OH} \& \mathrm{SO}_{2}$ \\
\hline 543467.7 & & & $37_{3,35}-37_{2,36}$ & 664.0 & $7.77 \mathrm{e}-4$ & & & & & v blend $\mathrm{CH}_{3} \mathrm{OH} \& \mathrm{SO}_{2}$ \\
\hline 545318.5 & 3.5 & 5.5 & $37_{6,32}-37_{5,33}$ & 736.9 & $1.43 e-3$ & 66 & 41 & 17.5 & 0.72 & \\
\hline 545517.3 & -0.7 & -2.7 & $35_{6,30}-35_{5,31}$ & 669.3 & $1.42 \mathrm{e}-3$ & 99 & 63 & 16.5 & 1.07 & \\
\hline 546579.8 & -1.2 & 2.8 & $19_{3,17}-18_{2,16}$ & 197.0 & $7.40 \mathrm{e}-4$ & 546 & 488 & 25.1 & 12.90 & \\
\hline 547802.2 & 1.2 & -1.8 & $28_{6,22}-28_{5,23}$ & 462.2 & $1.36 \mathrm{e}-3$ & 160 & 136 & 16.8 & 2.41 & \\
\hline 548734.3 & -3.7 & -2.7 & $31_{6,26}-31_{5,27}$ & 545.3 & $1.40 \mathrm{e}-3$ & 102 & 87 & 11.3 & 1.02 & \\
\hline 548838.9 & & & $40_{4,36}-39_{5,35}$ & 808.3 & $5.52 \mathrm{e}-4$ & & & & & blend $\mathrm{C}^{18} \mathrm{O}$ \\
\hline 549303.3 & 3.3 & 11.3 & $10_{4,6}-9_{3,7}$ & 89.8 & $1.07 \mathrm{e}-3$ & 890 & 857 & 32.8 & 29.20 & $\begin{array}{l}\text { blend } \mathrm{CH}_{3} \mathrm{OH}, \\
{ }^{13} \mathrm{CH}_{3} \mathrm{OH} \&{ }^{34} \mathrm{SO}\end{array}$ \\
\hline 549566.4 & 15.4 & 5.4 & $30_{1,29}-29_{2,28}$ & 427.9 & $1.73 e-3$ & 455 & 369 & 24.7 & 9.38 & blend $\mathrm{CH}_{3} \mathrm{OCH}_{3}$ \\
\hline 550946.7 & & & $29_{6,24}-29_{5,25}$ & 488.9 & $1.40 \mathrm{e}-3$ & & & & & blend ${ }^{13} \mathrm{CO}$ \\
\hline 551622.9 & -3.1 & & $38_{2,36}-38_{1,37}$ & 697.7 & $7.94 \mathrm{e}-4$ & 43 & & & 0.31 & weak \\
\hline 552069.4 & -11.6 & & $34_{1,33}-34_{0,34}$ & 542.8 & $4.43 e-4$ & & & & & blend $\mathrm{H}_{2}^{17} \mathrm{O}, \mathrm{SO}_{2}$ \\
\hline 552078.9 & -2.1 & 0.0 & $26_{6,20}-26_{5,21}$ & 411.4 & $1.37 \mathrm{e}-3$ & 223 & 197 & 17.1 & 3.33 & blend $\mathrm{H}_{2}^{17} \mathrm{O}, \mathrm{SO}_{2}$ \\
\hline 553164.9 & 2.9 & 2.9 & $27_{6,22}-27_{5,23}$ & 436.3 & $1.39 \mathrm{e}-3$ & 224 & 225 & 22.5 & & v blend \& $3 \mathrm{G} \mathrm{CH}_{3} \mathrm{OH}$ \\
\hline 554212.8 & 7.8 & 1.8 & $31_{1,31}-30_{0,30}$ & 431.5 & $2.34 \mathrm{e}-3$ & 545 & 490 & 21.4 & 10.90 & blend $\mathrm{CH}_{3} \mathrm{OH}$ \\
\hline 555121.5 & -2.5 & & $24_{6,18}-24_{5,19}$ & 364.4 & $1.37 \mathrm{e}-3$ & 264 & & & 4.20 & blend $\left(\mathrm{CH}_{3}\right)_{2} \mathrm{O}$ \\
\hline 555204.1 & -6.9 & & $25_{6,20}-25_{5,21}$ & 387.4 & $1-38 e-3$ & 223 & 188 & 19.9 & 3.75 & \\
\hline 555666.3 & 0.7 & -0.7 & $5_{5,1}-4_{4,0}$ & 75.1 & $2.18 \mathrm{e}-3$ & 742 & 677 & 28.1 & 20.00 & blend $\mathrm{CH}_{3} \mathrm{OCH}_{3}$ \\
\hline 556959.9 & & & $23_{6,18}-23_{5,19}$ & 342.2 & $1.37 \mathrm{e}-3$ & & & & & blend $\mathrm{H}_{2} \mathrm{O}$ \\
\hline 557283.2 & -3.8 & 0.2 & $22_{6,16}-22_{5,17}$ & 321.0 & $1.36 \mathrm{e}-3$ & 303 & 271 & 22.9 & 6.72 & \\
\hline 558101.2 & & & $15_{9,7}-16_{8,8}$ & 308.6 & $1.54 \mathrm{e}-3$ & & & & & blend SO \\
\hline 558390.9 & -1.1 & -1.1 & $21_{6,16}-21_{5,17}$ & 300.8 & $1.35 \mathrm{e}-3$ & 335 & 290 & 20.0 & 5.55 & blend \& $3 \mathrm{G} \mathrm{CH}_{3} \mathrm{OH}$ \\
\hline 558555.8 & 4.8 & 9.2 & $16_{3,13}-16_{0,16}$ & 147.8 & $3.90 \mathrm{e}-5$ & 115 & 80 & 23.8 & 1.93 & \\
\hline 558812.5 & -2.5 & 2.5 & $20_{6,14}-20_{5,15}$ & 281.4 & $1.34 \mathrm{e}-3$ & 327 & 291 & 23.7 & 7.17 & \\
\hline 559500.4 & -0.6 & -0.6 & $19_{6,14}-19_{5,15}$ & 263.0 & $1.32 \mathrm{e}-3$ & 352 & 298 & 23.1 & 7.31 & \\
\hline 559882.1 & -1.9 & 0.1 & $18_{6,12}-18_{5,13}$ & 245.5 & $1.31 \mathrm{e}-3$ & 331 & 302 & 21.7 & 6.59 & \\
\hline 560318.9 & -1.1 & -1.1 & $17_{6,12}-17_{5,13}$ & 229.0 & $1.29 \mathrm{e}-3$ & 393 & 376 & 18.1 & & v blend \& $2 \mathrm{G} \mathrm{CH}_{3} \mathrm{OH}$ \\
\hline 560613.5 & -1.5 & 1.5 & $16_{6,10}-16_{5,11}$ & 213.3 & $1.27 \mathrm{e}-3$ & 354 & 342 & 23.4 & 8.52 & blend ${ }^{34} \mathrm{SO}_{2}$ \\
\hline 560891.0 & -3.0 & & $15_{6,10}-15_{5,11}$ & 198.6 & $1.25 \mathrm{e}-3$ & 378 & 325 & 22.6 & 7.68 & \\
\hline 561094.8 & -1.2 & -1.2 & $14_{6,8}-14_{5,9}$ & 184.8 & $1.22 \mathrm{e}-3$ & 326 & 304 & 23.0 & 7.30 & \\
\hline 561265.6 & -0.4 & 1.4 & $13_{6,8}-13_{5,9}$ & 171.9 & $1.19 \mathrm{e}-3$ & 467 & 382 & 23.2 & 9.26 & blend $\mathrm{CH}_{3} \mathrm{OH}$ \\
\hline 561361.4 & & & $21_{3,19}-20_{2,18}$ & 234.7 & $8.31 \mathrm{e}-4$ & 522 & & & & blend $\mathrm{SO}_{2}$ \\
\hline 561392.9 & 0.9 & & $12_{6,6}-12_{5,7}$ & 160.0 & $1.14 \mathrm{e}-3$ & 436 & & & & blend $\mathrm{CH}_{3} \mathrm{OH} \& \mathrm{SO}_{2}$ \\
\hline 561490.5 & 0.5 & & $11_{6,6}-11_{5,7}$ & 149.0 & $1.09 \mathrm{e}-3$ & 383 & & & & blend $\mathrm{SO}_{2}$ \\
\hline 561560.3 & -1.7 & & $10_{6,4}-10_{5,5}$ & 138.8 & $1.02 \mathrm{e}-3$ & 402 & & & & $\mathrm{v}$ blend $\mathrm{SO}_{2}$ \\
\hline 561608.6 & -0.4 & & $9_{6,4}-9_{5,5}$ & 129.7 & $9.37 \mathrm{e}-4$ & 502 & & & & $\mathrm{v}$ blend $\mathrm{SO}_{2}$ \\
\hline 561639.3 & -0.7 & & $8_{6,2}-8_{5,3}$ & 121.4 & $8.18 \mathrm{e}-3$ & 564 & & & & $\mathrm{v}$ blend $\mathrm{SO}_{2}$ \\
\hline 561656.7 & 16.7 & & $7_{6,2}-7_{5,3}$ & 114.0 & $6.50 \mathrm{e}-4$ & 547 & & & & $\mathrm{v}$ blend $\mathrm{SO}_{2}$ \\
\hline 561664.2 & 24.2 & & $6_{6,0}-6_{5,1}$ & 107.6 & $3.99 \mathrm{e}-4$ & 547 & & & & $\mathrm{v}$ blend $\mathrm{SO}_{2}$ \\
\hline 567592.7 & -1.3 & & $11_{4,8}-10_{3,37}$ & 100.0 & $1.12 \mathrm{e}-3$ & 822 & & & 16.80 & \\
\hline 571532.6 & -7.4 & -1.4 & $32_{2,30}-31_{3,29}$ & 504.3 & $1.34 \mathrm{e}-3$ & 465 & 171 & 21.3 & & blend \& $2 \mathrm{G} \mathrm{SO}_{2}$ \\
\hline 571553.3 & -2.7 & 0.3 & $32_{0,32}-31_{1,31}$ & 459.0 & $2.58 \mathrm{e}-3$ & 465 & 343 & 21.2 & 11.30 & blend \& $2 \mathrm{G} \mathrm{SO}_{2}$ \\
\hline 574587.8 & -7.2 & -3.2 & $23_{3,21}-22_{2,20}$ & 276.0 & $9.46 \mathrm{e}-4$ & 276 & 248 & 21.4 & 5.47 & \\
\hline 574807.3 & -2.7 & 3.3 & $6_{5,1}-5_{4,2}$ & 80.7 & $2.07 \mathrm{e}-3$ & 478 & 410 & 23.4 & 9.97 & blend ${ }^{34} \mathrm{SO}_{2}$ \\
\hline 576042.1 & -5.9 & -4.9 & $31_{2,30}-30_{1,29}$ & 455.6 & $2.03 e-3$ & 200 & 165 & 16.0 & 2.72 & \\
\hline
\end{tabular}

${ }^{a} v_{\mathrm{u} l}=$ rest frequency of the transition $u \rightarrow l ; \Delta v_{\mathrm{p}}=$ the difference between freq and the observed frequency at the peak temperature; $\Delta v_{\mathrm{g}}=$ the difference between freq and the frequency of the Gaussian fit; Transition = the quantum numbers for the transition; $E_{\mathrm{u}}=$ the upper state energy; $A_{\mathrm{u} l}=$ the Einstein $A$-coefficient; $T_{\mathrm{A}}^{*}$ (peak) = the observed peak temperature of the transition; Ampl. = the peak temperature of the Gaussian fit; Width $=$ the width of the transition from the Gaussian fit; $\int T_{\mathrm{A}}^{*} \mathrm{~d} v=$ the integrated intensity from the observed spectra; Note: $2 \mathrm{G}$ or $3 \mathrm{G}$ denotes a two- or three-component Gaussian fit, $\mathrm{v}$ blend denotes a visible blend, Total No. = the total number of transitions of the molecule in the table. All these lines are also marked in the spectra shown in Paper I Appendix A, and listed in the online Table of Paper I. These total numbers of lines include not visible blends, which are not counted in Table 5. 
C. M. Persson et al.: A spectral line survey of Orion KL in the bands 486-492 and 541-577 GHz with the Odin satellite. II., Online Material p 14

Table 10. ${ }^{34} \mathrm{SO}_{2}$ parameters ${ }^{a}$.

\begin{tabular}{|c|c|c|c|c|c|c|c|c|c|c|}
\hline $\begin{array}{l}v_{u l} \\
{[\mathrm{MHz}]}\end{array}$ & $\begin{array}{r}\Delta v_{\mathrm{p}} \\
{[\mathrm{MHz}]}\end{array}$ & $\begin{array}{r}\Delta v_{\mathrm{g}} \\
{[\mathrm{MHz}]}\end{array}$ & $\begin{array}{l}\text { Transition } \\
J_{K_{a}, K_{c}}\end{array}$ & $\begin{array}{r}E_{u} \\
{[\mathrm{~K}]}\end{array}$ & $\begin{array}{l}A_{u l} \\
{\left[\mathrm{~s}^{-1}\right]}\end{array}$ & $\begin{array}{r}T_{\mathrm{A}}^{*}(\text { peak }) \\
{[\mathrm{mK}]}\end{array}$ & $\begin{array}{r}\text { Ampl. } \\
{[\mathrm{mK}]}\end{array}$ & $\begin{array}{r}\text { Width } \\
{\left[\mathrm{km} \mathrm{s}^{-1}\right]}\end{array}$ & $\begin{array}{r}\int T_{\mathrm{A}}^{*} \mathrm{~d} v \\
{\left[\mathrm{~K} \mathrm{~km} \mathrm{~s}^{-1}\right]}\end{array}$ & Note \\
\hline 542097.7 & -0.3 & 4.7 & $11_{6,6}-11_{5,7}$ & 145.8 & $9.83 \mathrm{e}-4$ & & 102 & 16.0 & & from $3 \mathrm{G} \mathrm{CH}_{3} \mathrm{OH}$ \\
\hline 542177.4 & & & $10_{6,4}-10_{5,5}$ & 135.7 & $9.23 \mathrm{e}-4$ & & & & & \\
\hline 542233.5 & & & $9_{6,4}-9_{5,5}$ & 126.5 & $8.44 \mathrm{e}-4$ & & & & & weak \\
\hline 542270.1 & & & $8_{6,2}-8_{5,3}$ & 118.3 & $7.37 \mathrm{e}-4$ & & & & & weak \\
\hline 542291.7 & & & $7_{6,2}-7_{5,3}$ & 110.9 & $5.86 \mathrm{e}-4$ & & & & & weak \\
\hline 542302.3 & & & $6_{6,0}-6_{5,1}$ & 104.5 & $3.60 \mathrm{e}-4$ & & & & & weak \\
\hline 547613.5 & & & $21_{3,19}-20_{2,18}$ & 233.5 & $7.87 \mathrm{e}-4$ & & & & & blend $\mathrm{H}_{2}^{18} \mathrm{O}$ \\
\hline 551767.4 & & & $31_{1,31}-30_{0,30}$ & 429.7 & $2.32 \mathrm{e}-3$ & & & & & blend $\mathrm{CH}_{3} \mathrm{OH}$, weak \\
\hline 554708.2 & & -6.8 & $11_{4,8}-10_{3,7}$ & 98.5 & $1.04 \mathrm{e}-3$ & 141 & 123 & 20.1 & & $\begin{array}{l}\text { v blend }{ }^{13} \mathrm{CS} \\
\text { from } 2 \mathrm{G}{ }^{13} \mathrm{CS}\end{array}$ \\
\hline 558717.5 & 2.5 & 3.5 & $6_{5,1}-5_{4,2}$ & 78.5 & $1.90 \mathrm{e}-3$ & 98 & 83 & 19.5 & 1.67 & \\
\hline 560590.2 & & & $23_{3,21}-22_{2,20}$ & 274.7 & $9.02 \mathrm{e}-4$ & & & & & blend $\mathrm{SO}_{2}$ \\
\hline 569091.6 & -3.4 & & $32_{0,32}-31_{1,31}$ & 457.0 & $2.55 \mathrm{e}-3$ & 74 & & & 0.33 & weak \\
\hline 573527.3 & 2.3 & & $25_{3,23}-24_{2,22}$ & 319.5 & $1.05 \mathrm{e}-3$ & 92 & & & 0.68 & weak \\
\hline 574797.9 & & & $12_{4,8}-11_{3,9}$ & 109.5 & $1.10 \mathrm{e}-3$ & & & & & blend $\mathrm{SO}_{2}$ \\
\hline Total No. & 14 & & & & & & & & & \\
\hline
\end{tabular}

${ }^{a}$ Notation as in Table 9 .

Table 11. SO parameters ${ }^{a}$.

\begin{tabular}{|c|c|c|c|c|c|c|c|c|c|c|}
\hline $\begin{array}{l}v_{u l} \\
{[\mathrm{MHz}]}\end{array}$ & $\begin{array}{r}\Delta v_{\mathrm{p}} \\
{[\mathrm{MHz}]}\end{array}$ & $\begin{array}{r}\Delta v_{\mathrm{g}} \\
{[\mathrm{MHz}]}\end{array}$ & $\begin{array}{l}\text { Transition } \\
N_{J}\end{array}$ & $\begin{array}{r}E_{u} \\
{[\mathrm{~K}]}\end{array}$ & $\begin{array}{l}A_{u l} \\
{\left[\mathrm{~s}^{-1}\right]} \\
\end{array}$ & $\begin{array}{r}T_{\mathrm{A}}^{*} \text { (peak) } \\
{[\mathrm{mK}]} \\
\end{array}$ & $\begin{array}{r}\text { Ampl. } \\
{[\mathrm{mK}]}\end{array}$ & $\begin{array}{r}\text { Width } \\
{\left[\mathrm{km} \mathrm{s}^{-1}\right]}\end{array}$ & $\begin{array}{r}\int T_{\mathrm{A}}^{*} \mathrm{~d} v \\
{\left[\mathrm{~K} \mathrm{~km} \mathrm{~s}^{-1}\right]}\end{array}$ & Note \\
\hline 487708.5 & 0.5 & -1.5 & $7_{7}-6_{7}$ & 71.0 & $1.70 \mathrm{e}-5$ & 206 & 178 & 13.8 & 2.67 & \\
\hline 558087.7 & 2.7 & $\begin{array}{l}2.7 \\
0.7 \\
2.7\end{array}$ & $13_{12}-12_{11}$ & 194.4 & $2.28 \mathrm{e}-3$ & 2094 & $\begin{array}{r}160 \\
759 \\
1178\end{array}$ & $\begin{array}{r}4.7 \\
18.0 \\
35.5\end{array}$ & 59.00 & $\begin{array}{l}\text { blend } \mathrm{SO}_{2} \\
3 \mathrm{G} ; \mathrm{CR} \\
3 \mathrm{G} ; \mathrm{LVF} \\
3 \mathrm{G} ; \mathrm{HVF}\end{array}$ \\
\hline 559319.8 & 3.8 & $\begin{array}{r}3.8 \\
-0.2 \\
4.8\end{array}$ & $13_{13}-12_{12}$ & 201.1 & $2.30 \mathrm{e}-3$ & 1996 & $\begin{array}{r}165 \\
674 \\
1163\end{array}$ & $\begin{array}{r}5.0 \\
18.0 \\
35.3\end{array}$ & 56.90 & $\begin{array}{l}\text { 3G; CR } \\
\text { 3G; LVF } \\
\text { 3G; HVF }\end{array}$ \\
\hline 560178.7 & 2.7 & $\begin{array}{l}2.7 \\
0.7 \\
1.7\end{array}$ & $13_{14}-12_{13}$ & 192.7 & $2.32 \mathrm{e}-3$ & 2168 & $\begin{array}{r}213 \\
666 \\
1285\end{array}$ & $\begin{array}{r}5.0 \\
18.0 \\
35.6\end{array}$ & 61.70 & $\begin{array}{l}\text { 3G; CR } \\
\text { 3G; LVF } \\
\text { 3G; HVF }\end{array}$ \\
\hline 568741.6 & 9.6 & 1.6 & $9_{9}-89$ & 106.1 & $1.90 \mathrm{e}-5$ & 105 & 78 & 15.9 & 1.24 & \\
\hline
\end{tabular}

${ }^{a}$ Notation as in Table 9.

Table 12. ${ }^{33} \mathrm{SO}$ parameters ${ }^{a}$.

\begin{tabular}{|c|c|c|c|c|c|c|c|c|c|c|}
\hline $\begin{array}{l}v_{u l} \\
{[\mathrm{MHz}]}\end{array}$ & $\begin{array}{r}\Delta v_{\mathrm{p}} \\
{[\mathrm{MHz}]}\end{array}$ & $\begin{array}{r}\Delta v_{\mathrm{g}} \\
{[\mathrm{MHz}]}\end{array}$ & $\begin{array}{l}\text { Transition } \\
N_{J}\end{array}$ & $\begin{array}{r}E_{u} \\
{[\mathrm{~K}]} \\
\end{array}$ & $\begin{array}{l}A_{u l} \\
{\left[\mathrm{~s}^{-1}\right]} \\
\end{array}$ & $\begin{array}{r}T_{\mathrm{A}}^{*}(\text { peak }) \\
{[\mathrm{mK}]} \\
\end{array}$ & $\begin{array}{r}\text { Ampl. } \\
{[\mathrm{mK}]}\end{array}$ & $\begin{array}{r}\text { Width } \\
{\left[\mathrm{km} \mathrm{s}^{-1}\right]}\end{array}$ & $\begin{array}{r}\int T_{\mathrm{A}}^{*} \mathrm{~d} v \\
{\left[\mathrm{~K} \mathrm{~km} \mathrm{~s}^{-1}\right]}\end{array}$ & Note \\
\hline 552429.8 & -2.2 & 1.8 & $12_{13}-11_{12}$ & 192.5 & $2.18 \mathrm{e}-3$ & 138 & 112 & 20.3 & 2.41 & \multirow{3}{*}{$\begin{array}{l}\text { Blend } 2 \mathrm{U} \text {-lines } \\
\& \mathrm{CH}_{3} \mathrm{CN}\end{array}$} \\
\hline 553681.3 & -6.7 & -2.7 & $13_{13}-12_{12}$ & 199.2 & $2.20 \mathrm{e}-3$ & 113 & 85 & 17.0 & & \\
\hline 554555.6 & -3.4 & -3.4 & $14_{13}-13_{12}$ & 190.8 & $2.24 \mathrm{e}-3$ & 110 & 100 & 20.5 & 2.06 & \\
\hline
\end{tabular}

${ }^{a}$ Notation as in Table 9. 
C. M. Persson et al.: A spectral line survey of Orion KL in the bands 486-492 and 541-577 GHz with the Odin satellite. II., Online Materialp 15

Table 13. ${ }^{34} \mathrm{SO}$ parameters ${ }^{a}$.

\begin{tabular}{|c|c|c|c|c|c|c|c|c|c|c|}
\hline $\begin{array}{l}v_{u l} \\
{[\mathrm{MHz}]}\end{array}$ & $\begin{array}{r}\Delta v_{\mathrm{p}} \\
{[\mathrm{MHz}]}\end{array}$ & $\begin{array}{r}\Delta v_{\mathrm{g}} \\
{[\mathrm{MHz}]}\end{array}$ & $\begin{array}{l}\text { Transition } \\
N_{J}\end{array}$ & $\begin{array}{r}E_{u} \\
{[\mathrm{~K}]}\end{array}$ & $\begin{array}{l}A_{u l} \\
{\left[\mathrm{~s}^{-1}\right]}\end{array}$ & $\begin{array}{r}T_{\mathrm{A}}^{*}(\text { peak }) \\
{[\mathrm{mK}]}\end{array}$ & $\begin{array}{r}\text { Ampl. } \\
{[\mathrm{mK}]}\end{array}$ & $\begin{array}{r}\text { Width } \\
{\left[\mathrm{km} \mathrm{s}^{-1}\right]}\end{array}$ & $\underset{\left[\mathrm{K}^{2} \mathrm{~km} \mathrm{~s}^{-1}\right]}{\int T_{\mathrm{A}}^{*} \mathrm{~d} v}$ & Note \\
\hline 547119.6 & -5.4 & -2.4 & $12_{13}-11_{12}$ & 190.7 & $2.15 \mathrm{e}-3$ & 380 & 326 & 27.6 & 9.35 & \\
\hline 548389.8 & -2.2 & 0.8 & $13_{13}-12_{12}$ & 197.4 & $2.17 \mathrm{e}-3$ & 324 & 304 & 22.8 & 7.31 & \\
\hline 549278.7 & & & $14_{13}-13_{12}$ & 189.0 & $2.19 \mathrm{e}-3$ & & & & & $\begin{array}{l}\text { blend } \mathrm{CH}_{3} \mathrm{OH}, \\
\mathrm{SO}_{2} \&{ }^{13} \mathrm{CH}_{3} \mathrm{OH}\end{array}$ \\
\hline 561700.4 & & & $9_{9}-9_{8}$ & 104.3 & $1.83 e-5$ & & & & & blend $\mathrm{SO}_{2} \& \mathrm{C}^{17} \mathrm{O}$ \\
\hline Total No. & 4 & & & & & & & & & \\
\hline
\end{tabular}

${ }^{a}$ Notation as in Table 9.

Table 14. $\mathrm{SiO}$ and isotopologue parameters ${ }^{a}$.

\begin{tabular}{|c|c|c|c|c|c|c|c|c|c|c|c|}
\hline Species & $\begin{array}{l}v_{u l} \\
{[\mathrm{MHz}]}\end{array}$ & $\begin{array}{r}\Delta v_{\mathrm{p}} \\
{[\mathrm{MHz}]}\end{array}$ & $\begin{array}{r}\Delta v_{\mathrm{g}} \\
{[\mathrm{MHz}]}\end{array}$ & $\begin{array}{l}\text { Transition } \\
J\end{array}$ & $\begin{array}{r}E_{u} \\
{[\mathrm{~K}]}\end{array}$ & $\begin{array}{l}A_{u l} \\
{\left[\mathrm{~s}^{-1}\right]}\end{array}$ & $\begin{array}{r}T_{\mathrm{A}}^{*}(\text { peak }) \\
{[\mathrm{mK}]}\end{array}$ & $\begin{array}{l}\text { Ampl. } \\
{[\mathrm{mK}]}\end{array}$ & $\begin{array}{r}\text { Width } \\
{\left[\mathrm{km} \mathrm{s}^{-1}\right]}\end{array}$ & $\underset{\left[\mathrm{K} \mathrm{km} \mathrm{s}^{-1}\right]}{\int T_{\mathrm{A}}^{*} \mathrm{~d} v}$ & Note \\
\hline \multirow[t]{3}{*}{$\mathrm{SiO}$} & 564249.2 & -2.8 & & $13-12$ & 189.6 & $9.66 \mathrm{e}-3$ & 729 & & & 17.60 & \\
\hline & & & 2.2 & & & & & 391 & 18.0 & & 2G; LVF \\
\hline & & & -1.8 & & & & & 315 & 31.5 & & 2G; HVF \\
\hline${ }^{29} \mathrm{SiO}$ & 557184.4 & 2.4 & 1.4 & $13-12$ & 187.2 & $9.31 \mathrm{e}-3$ & 82 & 72 & 21.2 & 1.39 & blend $\mathrm{H}_{2} \mathrm{O}$ \\
\hline${ }^{30} \mathrm{SiO}$ & 550605.2 & -9.8 & -5.8 & $13-12$ & 185.0 & $8.98 \mathrm{e}-3$ & 71 & 59 & 7.5 & 0.45 & $?$ \\
\hline
\end{tabular}

${ }^{a}$ Notation as in Table 9.

Table 15. $\mathrm{H}_{2} \mathrm{~S}$ parameters ${ }^{a}$.

\begin{tabular}{|c|c|c|c|c|c|c|c|c|c|c|}
\hline $\begin{array}{l}v_{u l} \\
{[\mathrm{MHz}]}\end{array}$ & $\begin{array}{r}\Delta v_{\mathrm{p}} \\
{[\mathrm{MHz}]}\end{array}$ & $\begin{array}{r}\Delta v_{\mathrm{g}} \\
{[\mathrm{MHz}]}\end{array}$ & $\begin{array}{l}\text { Transition } \\
J_{K_{a}, K_{c}}\end{array}$ & $\begin{array}{r}E_{u} \\
{[\mathrm{~K}]} \\
\end{array}$ & $\begin{array}{l}A_{u l} \\
{\left[\mathrm{~s}^{-1}\right]}\end{array}$ & $\begin{array}{r}T_{\mathrm{A}}^{*}(\text { peak }) \\
{[\mathrm{mK}]}\end{array}$ & $\begin{array}{r}\text { Ampl. } \\
{[\mathrm{mK}]}\end{array}$ & $\begin{array}{r}\text { Width } \\
{\left[\mathrm{km} \mathrm{s}^{-1}\right]}\end{array}$ & $\begin{array}{r}\int T_{\mathrm{A}}^{*} \mathrm{~d} v \\
{\left[\mathrm{~km} \mathrm{~s}^{-1}\right]}\end{array}$ & Note \\
\hline 567079.6 & & & $6_{4,2}-6_{3,3}$ & 540.2 & $6.52 \mathrm{e}-4$ & & & & & blend NO \\
\hline \multirow[t]{3}{*}{568050.7} & -7.3 & & $3_{3,1}-3_{2,2}$ & 165.9 & $3.32 \mathrm{e}-4$ & 247 & & & 4.41 & \\
\hline & & -7.3 & & & & & 106 & 7.5 & & 2G; HC \\
\hline & & -0.3 & & & & & 145 & 24.4 & & 2G; Plateau \\
\hline
\end{tabular}

\footnotetext{
${ }^{a}$ Notation as in Table 9.
} 
Table 16. $\mathrm{CH}_{3} \mathrm{CN}$ parameters ${ }^{a}$.

\begin{tabular}{|c|c|c|c|c|c|c|c|c|c|c|}
\hline $\begin{array}{l}v_{u l} \\
{[\mathrm{MHz}]}\end{array}$ & $\begin{array}{r}\Delta v_{\mathrm{p}} \\
{[\mathrm{MHz}]}\end{array}$ & $\begin{array}{r}\Delta v_{\mathrm{g}} \\
{[\mathrm{MHz}]}\end{array}$ & $\begin{array}{l}\text { Transition } \\
J_{K}\end{array}$ & $\begin{array}{r}E_{u} \\
{[\mathrm{~K}]}\end{array}$ & $\begin{array}{l}A_{u l} \\
{\left[\mathrm{~s}^{-1}\right]}\end{array}$ & $\begin{array}{r}T_{\mathrm{A}}^{*}(\text { peak }) \\
{[\mathrm{mK}]}\end{array}$ & $\begin{array}{l}\text { Ampl. } \\
{[\mathrm{mK}]}\end{array}$ & $\begin{array}{r}\text { Width } \\
{\left[\mathrm{km} \mathrm{s}^{-1}\right]}\end{array}$ & $\begin{array}{r}\int T_{\mathrm{A}}^{*} \mathrm{~d} v \\
{\left[\mathrm{~K} \mathrm{~km} \mathrm{~s}^{-1}\right]}\end{array}$ & Note \\
\hline$\frac{550671.7}{50711}$ & & & $30_{9}-29_{9}$ & 984.6 & $1.34 \mathrm{e}-2$ & & & & & blend $\mathrm{CH}_{3} \mathrm{OH}$ \\
\hline 550850.0 & -6.0 & & $30_{8}-29_{8}$ & 864.2 & $1.37 \mathrm{e}-2$ & & & & & v blend ${ }^{13} \mathrm{CO}$ \\
\hline 551007.4 & 0.4 & & $30_{7}-29_{7}$ & 758.0 & $1.39 \mathrm{e}-2$ & & & & & v blend ${ }^{13} \mathrm{CO}$ \\
\hline 551143.9 & -5.1 & -5.1 & $30_{6}-29_{6}$ & 665.8 & $1.41 \mathrm{e}-2$ & 145 & 125 & 13.2 & & $\begin{array}{l}\mathrm{v} \text { blend } \mathrm{NO} \text {; from } \\
5 \mathrm{G} \mathrm{CH} \mathrm{CH}_{3} \mathrm{CN}, \mathrm{NO}\end{array}$ \\
\hline 551259.6 & & -8.4 & $30_{5}-29_{5}$ & 587.8 & $1.43 \mathrm{e}-2$ & 159 & 160 & 10.6 & & $\begin{array}{l}\& \mathrm{CH}_{3} \mathrm{OH} \\
\text { v blend } \mathrm{CH}_{3} \mathrm{OCH}_{3} ; \\
\text { from } 2 \mathrm{G} \mathrm{CH}_{3} \mathrm{OCH}_{3}\end{array}$ \\
\hline 551354.2 & -1.8 & -4.8 & $30_{4}-29_{4}$ & 524.0 & $1.45 \mathrm{e}-2$ & 144 & 112 & 9.4 & 1.09 & \\
\hline 551427.9 & -1.1 & -4.1 & $30_{3}-29_{3}$ & 474.3 & $1.46 \mathrm{e}-2$ & 221 & 198 & 9.9 & 1.80 & \\
\hline 551480.6 & -2.4 & -4.4 & $30_{2}-29_{2}$ & 438.8 & $1.47 \mathrm{e}-2$ & 210 & 173 & 9.0 & 1.43 & \\
\hline 551512.2 & & & $30_{1}-29_{1}$ & 417.5 & $1.47 \mathrm{e}-2$ & & & & & $\mathrm{v}$ blend $\mathrm{NO}$ \\
\hline 551522.7 & & & $30_{0}-29_{0}$ & 410.4 & $1.48 \mathrm{e}-2$ & & & & & $\mathrm{v}$ blend NO \\
\hline $552646.6^{*}$ & -1.4 & & $30_{1}-29_{1} \ell=+1$ & 930.2 & $1.48 \mathrm{e}-2$ & & & & & weak \\
\hline $552970.8^{*}$ & -3.2 & & $30_{0}-29_{0} \ell= \pm 1$ & 936.7 & $1.49 \mathrm{e}-2$ & & & & & weak \\
\hline $553007.8^{*}$ & -6.2 & & $30_{2}-29_{2} \ell=-1$ & 991.9 & $1.48 \mathrm{e}-2$ & & & & & weak \\
\hline $553029.1^{*}$ & -0.9 & & $30_{1}-29_{1} \ell=-1$ & 957.2 & $1.49 \mathrm{e}-2$ & & & & & weak \\
\hline $553240.3^{*}$ & -2.7 & & $30_{3}-29_{3} \ell=+1$ & 961.1 & $1.48 \mathrm{e}-2$ & & & & & weak \\
\hline $553362.2^{*}$ & & & $30_{2}-29_{2} \ell=+1$ & 938.9 & $1.48 \mathrm{e}-2$ & & & & & weak \& narrow \\
\hline 553707.6 & & & & 931.8 & & & & & & weak \\
\hline 568999.3 & -1.7 & & $31_{9}-30_{9}$ & 1011.9 & $1.49 \mathrm{e}-2$ & 81 & & & & weak \\
\hline 569486.9 & -3.1 & -5.1 & $31_{6}-30_{6}$ & 693.2 & $1.57 \mathrm{e}-2$ & 144 & 98 & 7.8 & 0.77 & strange shape \\
\hline 569606.3 & -1.7 & -3.7 & $31_{5}-30_{5}$ & 615.2 & $1.58 \mathrm{e}-2$ & 91 & 77 & 3.3 & 0.25 & \\
\hline 569704.0 & -6.0 & -5.0 & $31_{4}-30_{4}$ & 551.3 & $1.60 \mathrm{e}-2$ & 130 & 124 & 3.6 & 0.45 & \\
\hline 569780.1 & -6.9 & -6.9 & $31_{3}-30_{3}$ & 501.6 & $1.61 \mathrm{e}-2$ & 241 & 165 & 8.4 & 1.26 & \\
\hline 569834.5 & -1.5 & -3.5 & $31_{2}-30_{2}$ & 466.2 & $1.62 \mathrm{e}-2$ & 126 & 126 & 5.8 & 0.71 & \\
\hline 569867.1 & -4.9 & -2.9 & $31_{1}-30_{1}$ & 444.9 & $1.63 \mathrm{e}-2$ & 159 & 151 & 5.1 & 0.66 & blend $\mathrm{CH}_{3} \mathrm{CN}$ \\
\hline 569878.0 & -3.0 & -2.0 & $31_{0}-30_{0}$ & 437.8 & $1.63 \mathrm{e}-2$ & 220 & 208 & 5.5 & 0.95 & blend $\mathrm{CH}_{3} \mathrm{CN}$ \\
\hline Total No. & 25 & & & & & & & & & \\
\hline
\end{tabular}

${ }^{a}$ Notation as in Table 9. ${ }^{*}$ Vibrationally excited transition, $v_{8}=1$.

Table 17. $\mathrm{NH}_{3}$ and ${ }^{15} \mathrm{NH}_{3}$ parameters ${ }^{a}$.

\begin{tabular}{|c|c|c|c|c|c|c|c|c|c|c|c|}
\hline Species & $\begin{array}{l}v_{u l} \\
{[\mathrm{MHz}]}\end{array}$ & $\begin{array}{r}\Delta v_{\mathrm{p}} \\
{[\mathrm{MHz}]}\end{array}$ & $\begin{array}{r}\Delta v_{\mathrm{g}} \\
{[\mathrm{MHz}]}\end{array}$ & $\begin{array}{l}\text { Transition } \\
J_{K}\end{array}$ & $\begin{array}{r}E_{u} \\
{[\mathrm{~K}]}\end{array}$ & $\begin{array}{l}A_{u l} \\
{\left[\mathrm{~s}^{-1}\right]}\end{array}$ & $\begin{array}{r}T_{\mathrm{A}}^{*}(\text { peak }) \\
{[\mathrm{mK}]}\end{array}$ & $\begin{array}{l}\text { Ampl. } \\
{[\mathrm{mK}]}\end{array}$ & $\begin{array}{r}\text { Width } \\
{\left[\mathrm{km} \mathrm{s}^{-1}\right]}\end{array}$ & $\begin{array}{r}\int T_{\mathrm{A}}^{*} \mathrm{~d} v \\
{\left[\mathrm{Km} \mathrm{s}^{-1}\right]}\end{array}$ & Note \\
\hline \multirow[t]{3}{*}{$\mathrm{NH}_{3}$} & 572498.2 & 1.2 & & $1_{0}-0_{0}$ & 27.5 & $1.61 \mathrm{e}-3$ & 2409 & & & 20.60 & \\
\hline & & & 1.2 & & & & & 1704 & 4.9 & & $2 \mathrm{G}$ fit; $\mathrm{CR}$ \\
\hline & & & 2.2 & & & & & 694 & 16.2 & & $2 \mathrm{G}$ fit; $\mathrm{HC}$ \\
\hline${ }^{15} \mathrm{NH}_{3}$ & 572112.8 & -0.2 & & $1_{0}-0_{0}$ & 27.5 & $1.57 \mathrm{e}-3$ & 167 & 150 & 6.7 & 1.02 & \\
\hline Total No. & 2 & & & & & & & & & & \\
\hline
\end{tabular}

${ }^{a}$ Notation as in Table 9.

Table 18. $\mathrm{HC}_{3} \mathrm{~N}$ parameters ${ }^{a}$.

\begin{tabular}{lrrlrlrrrrr}
\hline \hline $\begin{array}{l}v_{u l} \\
{[\mathrm{MHz}]}\end{array}$ & $\begin{array}{r}\Delta v_{\mathrm{p}} \\
{[\mathrm{MHz}]}\end{array}$ & $\begin{array}{r}\Delta v_{\mathrm{g}} \\
{[\mathrm{MHz}]}\end{array}$ & $\begin{array}{l}\text { Transition } \\
J\end{array}$ & $\begin{array}{r}E_{u} \\
{[\mathrm{~K}]}\end{array}$ & $\begin{array}{l}A_{u l} \\
{\left[\mathrm{~s}^{-1}\right]}\end{array}$ & $\begin{array}{r}T_{\mathrm{A}}^{*}(\text { peak) } \\
{[\mathrm{mK}]}\end{array}$ & $\begin{array}{r}\text { Ampl. } \\
{[\mathrm{mK}]}\end{array}$ & $\begin{array}{r}\text { Width } \\
{\left[\mathrm{km} \mathrm{s}^{-1}\right]}\end{array}$ & $\begin{array}{r}\int T_{\mathrm{A}}^{*} \mathrm{~d} v \\
{\left[\mathrm{~K} \mathrm{~km} \mathrm{~s}^{-1}\right]}\end{array}$ & Note \\
\hline 490955.7 & -6.3 & -5.3 & $54-53$ & 648.2 & $9.50 \mathrm{e}-3$ & 91 & 86 & 6.4 & 0.53 & blend $\mathrm{CH}_{3} \mathrm{OH}$ \\
545417.1 & -3.9 & & $60-59$ & 798.7 & $1.30 \mathrm{e}-2$ & 70 & 57 & 10.3 & 0.60 & \\
\hline Total No. & 2 & & & & & & & & & \\
\hline
\end{tabular}

${ }^{a}$ Notation as in Table 9. 
C. M. Persson et al.: A spectral line survey of Orion KL in the bands 486-492 and 541-577 GHz with the Odin satellite. II., Online Materialp 17

Table 19. OCS parameters ${ }^{a}$.

\begin{tabular}{|c|c|c|c|c|c|c|c|c|c|c|}
\hline $\begin{array}{l}v_{u l} \\
{[\mathrm{MHz}]}\end{array}$ & $\begin{array}{r}\Delta v_{\mathrm{p}} \\
{[\mathrm{MHz}]}\end{array}$ & $\begin{array}{r}\Delta v_{\mathrm{g}} \\
{[\mathrm{MHz}]}\end{array}$ & $\begin{array}{l}\text { Transition } \\
J\end{array}$ & $\begin{array}{r}E_{u} \\
{[\mathrm{~K}]}\end{array}$ & $\begin{array}{l}A_{u l} \\
{\left[\mathrm{~s}^{-1}\right]}\end{array}$ & $\begin{array}{r}T_{\mathrm{A}}^{*}(\text { peak }) \\
{[\mathrm{mK}]} \\
\end{array}$ & $\begin{array}{r}\text { Ampl. } \\
{[\mathrm{mK}]}\end{array}$ & $\begin{array}{r}\text { Width } \\
{\left[\mathrm{km} \mathrm{s}^{-1}\right]} \\
\end{array}$ & $\begin{array}{r}\int T_{\mathrm{A}}^{*} \mathrm{~d} v \\
{\left[\mathrm{~K} \mathrm{~km} \mathrm{~s}^{-1}\right]}\end{array}$ & Note \\
\hline 546859.8 & -3.2 & & $45-44$ & 603.9 & $4.81 \mathrm{e}-4$ & 67 & & & 0.31 & blend $\mathrm{SO}_{2},{ }^{13} \mathrm{CH}_{3} \mathrm{OH}$ \\
\hline 558990.5 & -4.5 & -2.5 & $46-45$ & 630.7 & $5.14 \mathrm{e}-4$ & 88 & 88 & 6.5 & 0.58 & \\
\hline 571119.7 & -2.3 & & $47-46$ & 658.1 & $5.49 \mathrm{e}-4$ & 68 & & & 0.41 & $?$ \\
\hline Total No. & 3 & & & & & & & & & \\
\hline
\end{tabular}

${ }^{a}$ Notation as in Table 9.

Table 20. $\mathrm{CH}_{3} \mathrm{OH}$ parameters ${ }^{a}$.

\begin{tabular}{|c|c|c|c|c|c|c|c|c|c|c|}
\hline $\begin{array}{l}v_{u l} \\
{[\mathrm{MHz}]}\end{array}$ & $\begin{array}{r}\Delta v_{\mathrm{p}} \\
{[\mathrm{MHz}]}\end{array}$ & $\begin{array}{r}\Delta v_{\mathrm{g}} \\
{[\mathrm{MHz}]}\end{array}$ & $\begin{array}{l}\text { Transition } \\
J_{K_{a}, K_{c}}\end{array}$ & $\begin{array}{r}E_{u} \\
{[\mathrm{~K}]}\end{array}$ & $\begin{array}{l}A_{u l} \\
{\left[\mathrm{~s}^{-1}\right]}\end{array}$ & $\begin{array}{r}T_{\mathrm{A}}^{*}(\text { peak }) \\
{[\mathrm{mK}]}\end{array}$ & $\begin{array}{l}\text { Ampl. } \\
{[\mathrm{mK}]}\end{array}$ & $\begin{array}{r}\text { Width } \\
{\left[\mathrm{km} \mathrm{s}^{-1}\right]}\end{array}$ & $\begin{array}{r}\int T_{\mathrm{A}}^{*} \mathrm{~d} v \\
{\left[\mathrm{~K} \mathrm{~km} \mathrm{~s}^{-1}\right]}\end{array}$ & Note \\
\hline \multirow[t]{3}{*}{486940.9} & 0.9 & & $4_{2,3}-4_{1,4} \mathrm{~A}$ & 60.9 & $5.45 \mathrm{e}-4$ & 884 & & & 5.13 & \\
\hline & & 0.9 & & & & & 635 & 3.8 & & 2G; CR \\
\hline & & -0.1 & & & & & 241 & 10.1 & & 2G; HC \\
\hline \multirow[t]{3}{*}{487531.9} & 0.9 & & $10_{1,9}-9_{1,8} \mathrm{~A}$ & 143.3 & $5.15 \mathrm{e}-4$ & 855 & & & 4.85 & \\
\hline & & 0.9 & & & & & 509 & 3.3 & & $2 \mathrm{G} ; \mathrm{CR}$ \\
\hline & & -0.1 & & & & & 359 & 8.1 & & $2 \mathrm{G} ; \mathrm{HC}$ \\
\hline $488945.5^{*}$ & -0.5 & -1.0 & $7_{2,5}-8_{3,5} \mathrm{E}$ & 429.4 & $5.79 \mathrm{e}-4$ & 191 & 188 & 5.0 & 1.01 & \\
\hline \multirow[t]{3}{*}{489037.0} & 0.0 & & $5_{2,4}-5_{1,5} \mathrm{~A}$ & 72.5 & $5.70 \mathrm{e}-4$ & 849 & & & 4.36 & \\
\hline & & 0.0 & & & & & 652 & 3.7 & & 2G; CR \\
\hline & & -2.0 & & & & & 210 & 8.5 & & $2 \mathrm{G} ; \mathrm{HC}$ \\
\hline 489224.3 & 0.3 & 0.3 & $23_{1,23}-22_{2,20} \mathrm{~A}$ & 648.5 & $1.92 \mathrm{e}-4$ & 74 & 69 & 2.9 & 0.21 & \\
\hline 490960.0 & -2.0 & & $21_{3,19}-20_{4,17} \mathrm{E}$ & 598.5 & $2.27 \mathrm{e}-4$ & & & & & blend $\mathrm{HC}_{3} \mathrm{~N}$ \\
\hline \multirow[t]{3}{*}{491550.9} & 0.1 & & $6_{2,5}-6_{1,6} \mathrm{~A}$ & 86.4 & $5.87 \mathrm{e}-4$ & 821 & & & 4.76 & \\
\hline & & -0.1 & & & & & 593 & 3.8 & & 2G; CR \\
\hline & & -1.1 & & & & & 244 & 9.5 & & 2G; HC \\
\hline 492278.6 & 0.0 & & $4_{1,4}-3_{0,3} E$ & 37.6 & $7.65 e-4$ & 927 & 920 & 4.4 & 2.58 & \\
\hline \multirow[t]{3}{*}{542000.9} & 0.9 & & $6_{3,4}-5_{2,3} \mathrm{~A}$ & 98.5 & $7.93 \mathrm{e}-4$ & 1261 & & & 6.89 & \\
\hline & & 0.9 & & & & & 817 & 3.2 & & 2G; CR \\
\hline & & 0.9 & & & & & 413 & 9.3 & & $2 \mathrm{G} ; \mathrm{HC}$ \\
\hline \multirow[t]{3}{*}{542081.9} & -0.1 & & $6_{3,3}-5_{2,4} \mathrm{~A}$ & 98.5 & $7.94 \mathrm{e}-4$ & 1230 & & & & \\
\hline & & -0.1 & & & & & 834 & 3.5 & & from $3 \mathrm{G}^{34} \mathrm{SO}_{2}$; CR \\
\hline & & 1.9 & & & & & 350 & 9.0 & & from $3 \mathrm{G}^{34} \mathrm{SO}_{2}$; $\mathrm{HC}$ \\
\hline $542163.0^{*}$ & -2.0 & -4.0 & $20_{1,20}-20_{2,19}$ & 810.4 & $7.35 \mathrm{e}-4$ & 91 & 68 & 6.0 & 0.35 & \\
\hline \multirow{3}{*}{543076.1} & 0.1 & & $8_{0,8}-7_{1,7} \mathrm{E}$ & 96.6 & $4.54 \mathrm{e}-4$ & 856 & & & 4.75 & \\
\hline & & 0.1 & & & & & 614 & 3.8 & & 2G; CR \\
\hline & & -0.9 & & & & & 227 & 9.9 & & 2G; HC \\
\hline $543457.3^{*}$ & -2.7 & & $19_{1,19}-19_{2,18} \mathrm{~A}$ & 764.3 & $7.49 \mathrm{e}-4$ & & & & & $\mathrm{v}$ blend $\mathrm{SO}_{2}$ \\
\hline $544653.1^{*}$ & -4.9 & & $18_{1,18}-18_{2,17} \mathrm{~A}$ & 720.4 & $7.62 \mathrm{e}-4$ & 98 & & & 0.55 & $?$ \\
\hline 544820.5 & -0.5 & -1.5 & $5_{5,1}-6_{4,2} \mathrm{E}$ & 170.9 & $2.60 e-5$ & 98 & 91 & 3.4 & 0.32 & \\
\hline 545034.8 & 0.8 & & $26_{3,23} 26_{2,24} \mathrm{E}$ & 862.5 & $9.00 \mathrm{e}-4$ & 72 & & & 0.31 & \\
\hline $545755.6^{*}$ & -6.4 & -4.4 & $17_{1,17}-17_{2,16} \mathrm{~A}$ & 678.8 & $7.75 e-4$ & 70 & 70 & 5.6 & 0.50 & \\
\hline $546226.8^{*}$ & -1.2 & & $11_{3,9}-12_{4,9} \mathrm{E}$ & 570.1 & $8.26 \mathrm{e}-4$ & & & & & v blend $\mathrm{CH}_{3} \mathrm{OH}$ \\
\hline 546239.0 & -1.0 & & $17_{2,16}-17_{1,17} \mathrm{~A}$ & 392.5 & $7.38 \mathrm{e}-4$ & 212 & & & 2.13 & blend $\mathrm{CH}_{3} \mathrm{OH}$ \\
\hline $547698.9^{*}$ & & & $15_{1,15}-15_{2,14} \mathrm{~A}$ & 602.6 & $7.97 \mathrm{e}-4$ & & & & & blend $\mathrm{H}_{2}^{18} \mathrm{O}$ \\
\hline \multirow[t]{3}{*}{$548548.7^{*}$} & -1.3 & & $14_{1,14}-14_{2,13} \mathrm{~A}$ & 568.0 & $8.07 \mathrm{e}-4$ & 126 & & & 0.63 & \\
\hline & & -2.3 & & & & & 64 & 2.7 & & $2 \mathrm{G} ; \mathrm{CR}$ \\
\hline & & -2.3 & & & & & 61 & 7.5 & & 2G; HC \\
\hline $549322.8^{*}$ & & & $13_{1,13}-13_{2,12} \mathrm{~A}$ & 535.6 & $8.16 \mathrm{e}-4$ & & & & & $\begin{array}{l}\text { blend } \mathrm{SO}_{2}, \\
\&{ }^{13} \mathrm{CH}_{3} \mathrm{OH}\end{array}$ \\
\hline $550025.2^{*}$ & -4.8 & -2.8 & $12_{1,12}-12_{2,11} \mathrm{~A}$ & 505.6 & $8.24 \mathrm{e}-4$ & 166 & 157 & 6.9 & 1.15 & \\
\hline $550659.3^{*}$ & -2.7 & -3.7 & $11_{1,11}-11_{1,11} \mathrm{~A}$ & 477.9 & $8.31 \mathrm{e}-4$ & 168 & 153 & 5.9 & 0.94 & blend $\mathrm{CH}_{3} \mathrm{CN}$ \\
\hline
\end{tabular}

${ }^{a}$ Notation as in Table 9. ${ }^{*}$ Vibrationally excited transition, $v_{t}=1$. 
Table 20. continued.

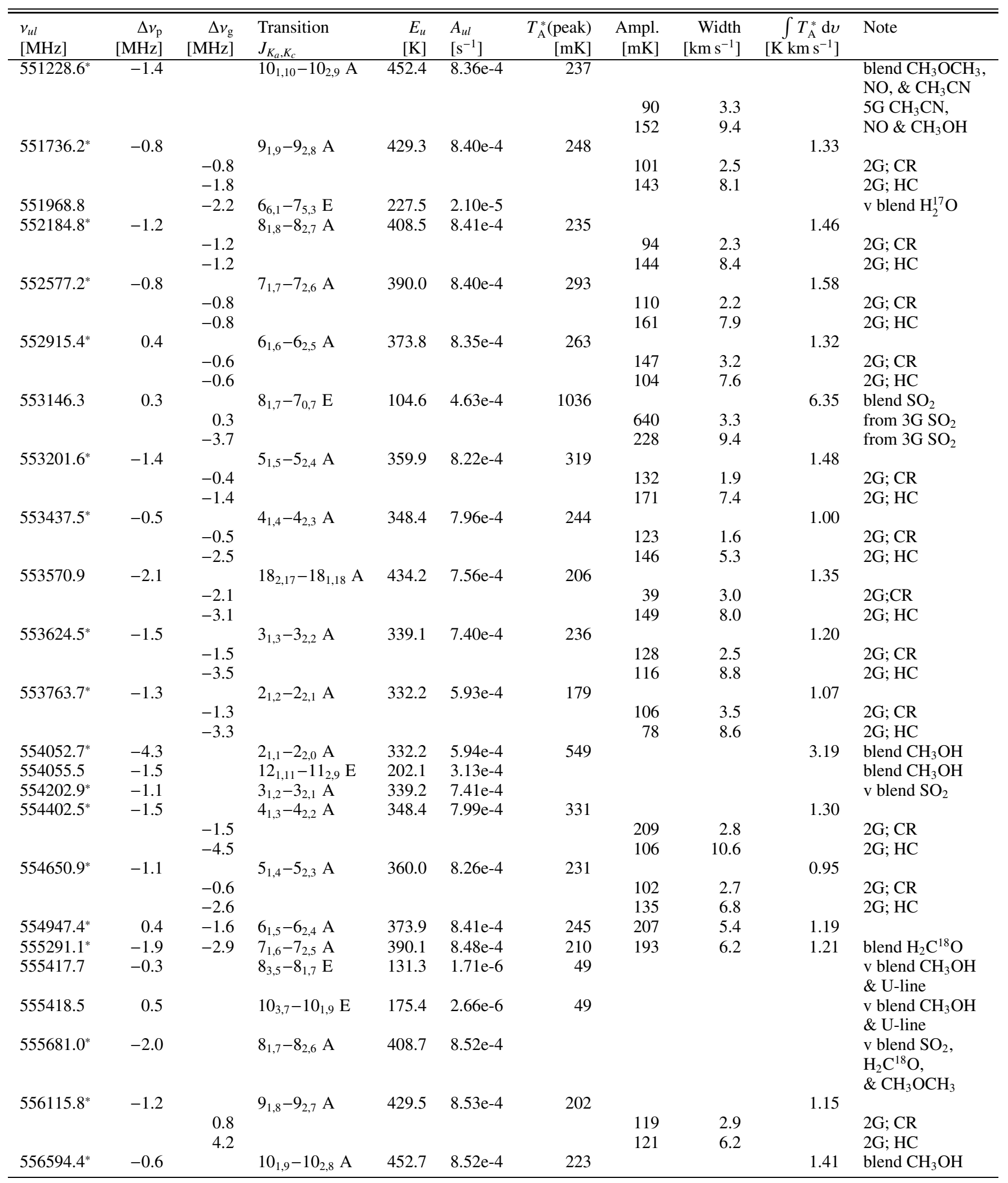


Table 20. continued.

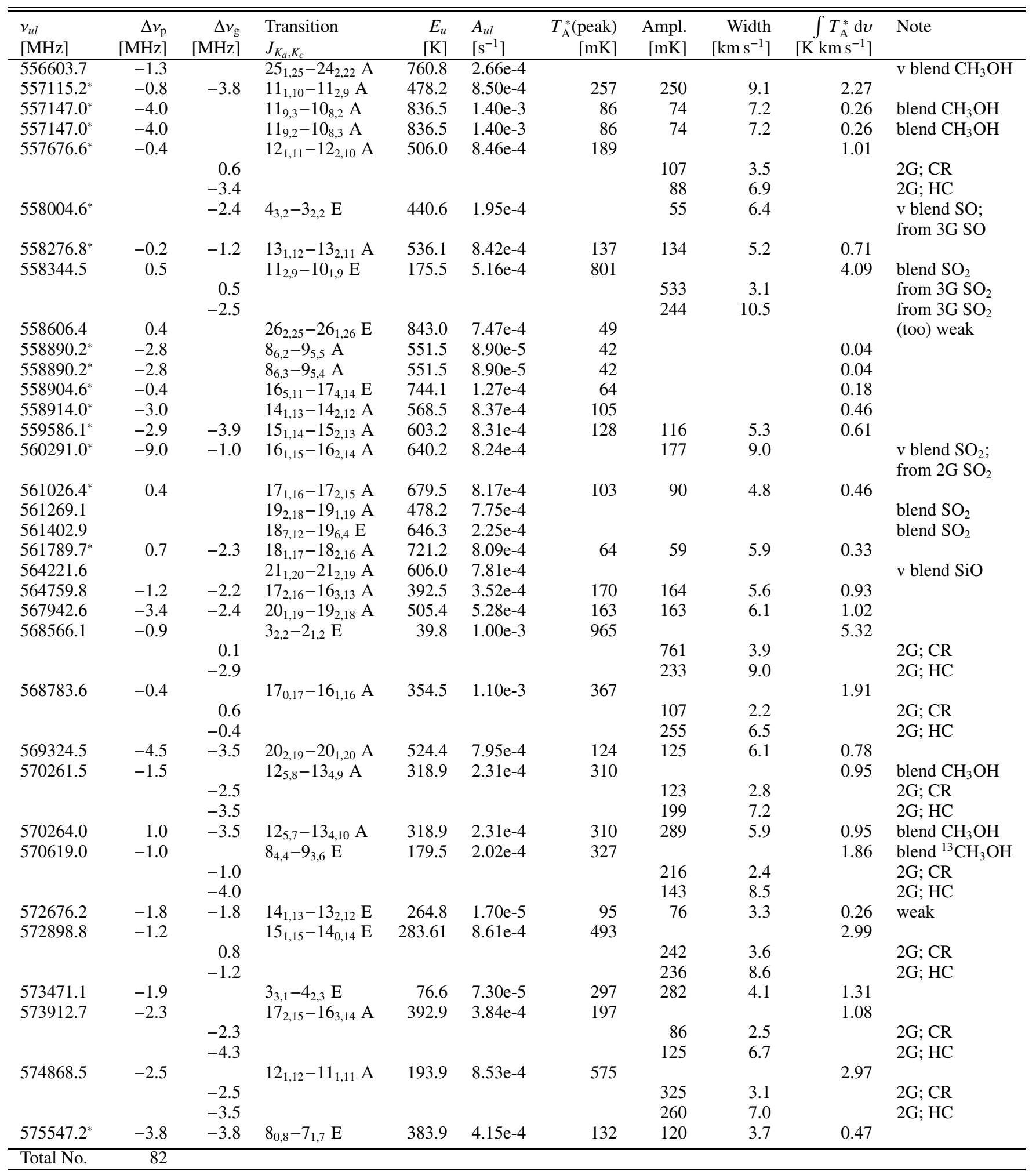


Table 21. ${ }^{13} \mathrm{CH}_{3} \mathrm{OH}$ parameters ${ }^{a}$.

\begin{tabular}{|c|c|c|c|c|c|c|c|c|c|c|}
\hline $\begin{array}{l}v_{u l} \\
{[\mathrm{MHz}]}\end{array}$ & $\begin{array}{r}\Delta v_{\mathrm{p}} \\
{[\mathrm{MHz}]}\end{array}$ & $\begin{array}{r}\Delta v_{\mathrm{g}} \\
{[\mathrm{MHz}]}\end{array}$ & $\begin{array}{l}\text { Transition } \\
J_{K_{a}, K_{c}}\end{array}$ & $\begin{array}{r}E_{u} \\
{[\mathrm{~K}]}\end{array}$ & $\begin{array}{l}A_{u l} \\
{\left[\mathrm{~s}^{-1}\right]}\end{array}$ & $\begin{array}{r}T_{\mathrm{A}}^{*}(\text { peak }) \\
{[\mathrm{mK}]}\end{array}$ & $\begin{array}{l}\text { Ampl. } \\
{[\mathrm{mK}]}\end{array}$ & $\begin{array}{r}\text { Width } \\
{\left[\mathrm{km} \mathrm{s}^{-1}\right]}\end{array}$ & $\begin{array}{r}\int T_{\mathrm{A}}^{*} \mathrm{~d} v \\
{\left[\mathrm{~K} \mathrm{~km} \mathrm{~s}^{-1}\right]}\end{array}$ & Note \\
\hline 488153.5 & -1.5 & -0.5 & $4_{1,4}-3_{03} \mathrm{~A}$ & 37.0 & $7.46 \mathrm{e}-4$ & 204 & 205 & 4.9 & 1.04 & \\
\hline 488302.6 & 0.6 & -0.4 & $4_{2,3}-4_{2,3} \mathrm{~A}$ & 60.5 & $5.50 \mathrm{e}-4$ & 154 & 151 & 2.3 & 0.34 & \\
\hline 490299.4 & 0.4 & & $5_{2,4}-5_{1,5} \mathrm{~A}$ & 71.8 & $5.75 \mathrm{e}-4$ & 168 & & & 0.59 & \\
\hline 491170.0 & 0.0 & 1.0 & $5,{ }_{3,3}-4_{2,2} \mathrm{~A}$ & 84.0 & $6.52 \mathrm{e}-4$ & 155 & 155 & 4.4 & 0.73 & \\
\hline 491201.3 & 0.3 & 0.3 & $5,2-4_{2,3} \mathrm{~A}$ & 84.0 & $6.53 \mathrm{e}-4$ & 156 & 145 & 4.2 & 0.64 & \\
\hline 491310.1 & & & $11_{1,10}-10_{2,8}$ & 170.6 & $2.15 \mathrm{e}-4$ & 73 & & & 0.34 & weak \\
\hline $544140.5^{*}$ & & & $17_{1,17}-17_{2,16} \mathrm{~A}$ & 670.5 & $7.71 \mathrm{e}-4$ & 63 & & & 0.12 & \\
\hline 544206.7 & -1.3 & -0.3 & $8_{1,7}-7_{07}$ & 102.6 & $4.41 \mathrm{e}-4$ & 93 & 76 & 4.9 & 0.37 & \\
\hline 547457.8 & -1.2 & -2.2 & $11_{2,9}-10_{1,9}$ & 171.9 & $4.90 \mathrm{e}-4$ & 90 & 82 & 3.9 & 0.32 & \\
\hline $549297.1^{*}$ & & & $10_{1,10}-10_{2,9} \mathrm{~A}$ & 449.5 & $8.29 \mathrm{e}-4$ & & & & & $\begin{array}{l}\text { blend } \mathrm{SO}_{2} \\
\& \mathrm{CH}_{3} \mathrm{OH}\end{array}$ \\
\hline $552835.1^{*}$ & & & $6_{1,5}-6_{2,4} \mathrm{~A}$ & 372.9 & $8.32 \mathrm{e}-4$ & 48 & & & 0.10 & weak \\
\hline 555700.1 & & & $15_{1,15}-14_{0,14} \mathrm{E}$ & 277.0 & $7.72 \mathrm{e}-4$ & & & & & $\begin{array}{l}\text { blend } \mathrm{SO}_{2} \\
\& \mathrm{CH}_{3} \mathrm{OH}\end{array}$ \\
\hline 561138.5 & -0.5 & & $12_{1,12}-11_{1,11} \mathrm{~A}$ & 189.7 & $7.93 e-4$ & & & & & $\mathrm{v}$ blend $\mathrm{SO}_{2}$ \\
\hline 564223.7 & -4.3 & & $12_{0,12}-11_{0,11}$ & 189.4 & $8.10 \mathrm{e}-4$ & & & & & $\mathrm{v}$ blend $\mathrm{SiO}$ \\
\hline 565245.2 & -1.8 & -0.8 & $12_{1,12}-11_{1,11} E$ & 182.1 & $8.10 \mathrm{e}-4$ & 89 & 72 & 4.2 & 0.30 & \\
\hline 565527.8 & -0.2 & -1.2 & $12_{0,12}-11_{0,11} \mathrm{~A}$ & 176.6 & $8.17 \mathrm{e}-4$ & 133 & 135 & 3.5 & 0.51 & \\
\hline 565737.4 & 1.4 & 1.4 & $12_{8,4}-11_{8,3} \mathrm{~A}$ & 499.3 & $4.53 \mathrm{e}-4$ & 68 & 65 & 2.0 & 0.07 & too weak? \\
\hline 565737.4 & 1.4 & 1.4 & $12_{8,5}-11_{8,4} \mathrm{~A}$ & 499.3 & $4.53 \mathrm{e}-4$ & 68 & 65 & 2.0 & 0.07 & too weak? \\
\hline 565895.0 & & & $12_{2,11}-11_{2,10} \mathrm{~A}$ & 214.4 & $8.01 \mathrm{e}-4$ & 85 & & & 0.34 & $?$ \\
\hline 565914.4 & 4.4 & 3.4 & $12_{6,7}-11_{6,6}$ & 356.4 & $6.11 \mathrm{e}-4$ & 108 & 103 & 3.2 & 0.32 & \\
\hline 565946.2 & -1.8 & 0.2 & $12_{6,6}-11_{6,5} \mathrm{~A}$ & 371.3 & $6.13 e-4$ & 68 & 51 & 4.7 & 0.23 & \\
\hline 566411.9 & -0.1 & & $12_{3,9}-11_{3,8}$ & 224.7 & $7.70 \mathrm{e}-4$ & 110 & & & 0.48 & blend U-line? \\
\hline 566662.8 & -0.2 & -1.2 & $3_{2,2}-2_{1,2} \mathrm{E}$ & 39.6 & $9.96 \mathrm{e}-4$ & 115 & 108 & 3.2 & 0.35 & \\
\hline 566840.7 & 1.7 & & $12_{2,10}-11_{2,9}$ & 199.1 & $7.92 \mathrm{e}-4$ & 69 & & & 0.30 & \\
\hline 570624.2 & -2.8 & & $12_{1,11}-11_{1,10} \mathrm{~A}$ & 192.7 & $8.35 \mathrm{e}-4$ & 140 & & & & $\mathrm{v}$ blend $\mathrm{CH}_{3} \mathrm{OH}$ \\
\hline Total No. & 25 & & & & & & & & & \\
\hline
\end{tabular}

${ }^{a}$ Notation as in Table 9. ${ }^{*}$ Vibrationally excited transition, $v_{t}=1$.

Table 22. $\left(\mathrm{CH}_{3}\right)_{2} \mathrm{O}$ parameters ${ }^{a}$.

\begin{tabular}{|c|c|c|c|c|c|c|c|c|c|c|}
\hline $\begin{array}{l}v_{u l} \\
{[\mathrm{MHz}]}\end{array}$ & $\begin{array}{r}\Delta v_{\mathrm{p}} \\
{[\mathrm{MHz}]}\end{array}$ & $\begin{array}{r}\Delta v_{\mathrm{g}} \\
{[\mathrm{MHz}]}\end{array}$ & $\begin{array}{l}\text { Transition } \\
J_{K_{a}, K_{c}}\end{array}$ & $\begin{array}{r}E_{u} \\
{[\mathrm{~K}]}\end{array}$ & $\begin{array}{l}A_{u l} \\
{\left[\mathrm{~s}^{-1}\right]}\end{array}$ & $\begin{array}{r}T_{\mathrm{A}}^{*}(\text { peak }) \\
{[\mathrm{mK}]}\end{array}$ & $\begin{array}{r}\text { Ampl. } \\
{[\mathrm{mK}]}\end{array}$ & $\begin{array}{r}\text { Width } \\
{\left[\mathrm{km} \mathrm{s}^{-1}\right]}\end{array}$ & $\begin{array}{r}\int T_{\mathrm{A}}^{*} \mathrm{~d} v \\
{\left[\mathrm{~K} \mathrm{~km} \mathrm{~s}^{-1}\right]}\end{array}$ & Note \\
\hline 490795.3 & -4.7 & & $15_{4,11}-14_{3,12} \mathrm{AE}$ & 131.9 & $3.56 \mathrm{e}-4$ & 194 & & & 2.05 & blend 3 groups \\
\hline 490795.3 & & & $15_{4,11}-14_{3,12}$ EA & 131.9 & $3.56 \mathrm{e}-4$ & & & & & \\
\hline 490797.5 & & & $12_{5,8}-11_{4,7}$ EA & 106.2 & $2.26 \mathrm{e}-4$ & & & & & \\
\hline 490798.3 & & & $15_{4,11}-14_{3,12} \mathrm{EE}$ & 131.9 & $3.56 \mathrm{e}-4$ & & & & & \\
\hline 490801.3 & & & $15_{4,11}-14_{3,12}$ AA & 131.9 & $3.56 \mathrm{e}-4$ & & & & & \\
\hline 490804.3 & & & $12_{5,8}-11_{4,7} \mathrm{AE}$ & 106.2 & $4.84 \mathrm{e}-4$ & & & & & \\
\hline 490804.7 & & & $12_{5,8}-11_{4,7} \mathrm{EE}$ & 106.2 & $3.01 \mathrm{e}-4$ & & & & & \\
\hline 490810.3 & & & $12_{5,8}-11_{4,7}$ AA & 106.2 & $4.84 \mathrm{e}-4$ & & & & & \\
\hline 490811.4 & & & $12_{5,7}-11_{4,7}$ EA & 106.2 & $2.58 \mathrm{e}-4$ & & & & & \\
\hline 490812.1 & & & $12_{5,7}-11_{4,7} \mathrm{EE}$ & 106.2 & $1.82 \mathrm{e}-4$ & & & & & \\
\hline 490864.4 & & & $12_{5,8}-11_{4,8}$ EA & 106.2 & $2.58 \mathrm{e}-4$ & & & & & \\
\hline 490869.8 & & & $12_{5,8}-11_{4,8} \mathrm{EE}$ & 106.2 & $1.82 \mathrm{e}-4$ & & & & 0.88 & blend 2 groups \\
\hline 490871.5 & & & $12_{5,7}-11_{4,8} \mathrm{AE}$ & 106.2 & $4.84 \mathrm{e}-4$ & & & & & \\
\hline 490877.2 & & & $12_{5,7}-11_{4,8} \mathrm{EE}$ & 106.2 & $3.01 \mathrm{e}-4$ & & & & & \\
\hline 490877.6 & & & $12_{5,7}-11_{4,8}$ AA & 106.2 & $4.84 \mathrm{e}-4$ & & & & & \\
\hline 490878.3 & & & $12_{5,7}-11_{4,8}$ EA & 106.2 & $2.26 \mathrm{e}-4$ & & & & & \\
\hline 542257.7 & -1.3 & -3.3 & $19_{4,16}-18_{3,15} \mathrm{AE}$ & 195.8 & $4.30 \mathrm{e}-4$ & 112 & 111 & 4.8 & 0.48 & entire group \\
\hline 542257.7 & -1.3 & -3.3 & $19_{4,16}-18_{3,15}$ EA & & & & & & & \\
\hline 542260.1 & 1.1 & -0.9 & $19_{4,16}-18_{3,15} \mathrm{EE}$ & & & & & & & \\
\hline 542262.4 & 3.4 & 1.4 & $19_{4,16}-18_{3,15}$ AA & & & & & & & \\
\hline
\end{tabular}

${ }^{a}$ Notation as in Table 9. 
C. M. Persson et al.: A spectral line survey of Orion KL in the bands 486-492 and 541-577 GHz with the Odin satellite. II., Online Material p 21

Table 22. continued.

\begin{tabular}{|c|c|c|c|c|c|c|c|c|c|c|}
\hline $\begin{array}{l}v_{u l} \\
{[\mathrm{MHz}]}\end{array}$ & $\begin{array}{r}\Delta v_{\mathrm{p}} \\
{[\mathrm{MHz}]}\end{array}$ & $\begin{array}{r}\Delta v_{\mathrm{g}} \\
{[\mathrm{MHz}]}\end{array}$ & $\begin{array}{l}\text { Transition } \\
J_{K_{a}, K_{c}}\end{array}$ & $\begin{array}{r}E_{u} \\
{[\mathrm{~K}]}\end{array}$ & $\begin{array}{l}A_{u l} \\
{\left[\mathrm{~s}^{-1}\right]}\end{array}$ & $\begin{array}{r}T_{\mathrm{A}}^{*}(\text { peak }) \\
{[\mathrm{mK}]}\end{array}$ & $\begin{array}{l}\text { Ampl. } \\
{[\mathrm{mK}]}\end{array}$ & $\begin{array}{r}\text { Width } \\
{\left[\mathrm{km} \mathrm{s}^{-1}\right]}\end{array}$ & $\begin{array}{r}\int T_{\mathrm{A}}^{*} \mathrm{~d} v \\
{\left[\mathrm{~K} \mathrm{~km} \mathrm{~s}^{-1}\right]}\end{array}$ & Note \\
\hline 543753.9 & -5.1 & & $18_{3,15}-17_{2,16} \mathrm{AE}$ & 169.8 & $1.94 \mathrm{e}-4$ & 45 & & & 0.20 & entire group \\
\hline 543753.9 & -5.1 & & $18_{3,15}-17_{2,16}$ EA & & & & & & & \\
\hline 543756.9 & -2.1 & & $18_{3,15}-17_{2,16} \mathrm{EE}$ & & & & & & & \\
\hline 543759.8 & 0.8 & & $18_{3,15}-17_{2,16}$ AA & & & & & & & \\
\hline 546827.8 & -4.2 & -3.2 & $15_{5,11}-14_{4,10}$ EA & 144.4 & $5.50 \mathrm{e}-4$ & 116 & 119 & 3.5 & 0.60 & entire group \\
\hline 546829.2 & -2.8 & -1.8 & $15_{5,11}-14_{4,10} \mathrm{AE}$ & & & & & & & \\
\hline 546831.5 & -0.5 & 0.5 & $15_{5,11}-14_{4,10} \mathrm{EE}$ & & & & & & & \\
\hline 546834.5 & 2.5 & 3.5 & $15_{5,11}-14_{4,10}$ AA & & & & & & & \\
\hline 547284.8 & -2.2 & -3.2 & $15_{5,10}-14_{4,11} \mathrm{AE}$ & 144.4 & $5.90 \mathrm{e}-4$ & 187 & 170 & 3.1 & 0.56 & entire group \\
\hline 547286.2 & -0.8 & -1.8 & $15_{5,10}-14_{4,11}$ EA & & $5.59 \mathrm{e}-4$ & & & & & \\
\hline 547287.8 & 0.8 & -0.2 & $15_{5,10}-14_{4,11} \mathrm{EE}$ & & $5.82 \mathrm{e}-4$ & & & & & \\
\hline 547290.1 & 3.1 & 2.1 & $15_{5,10}-14_{4,11}$ AA & & $5.90 \mathrm{e}-4$ & & & & & \\
\hline 549504.7 & -3.3 & & $30_{1,29}-29_{2,28}$ EA & 420.3 & $1.16 \mathrm{e}-4$ & 82 & & & 0.39 & entire group \\
\hline 549504.7 & -3.3 & & $30_{1,29}-29_{2,28} \mathrm{AE}$ & & & & & & & \\
\hline 549504.9 & -3.1 & & $30_{1,29}-29_{2,28} \mathrm{EE}$ & & & & & & & \\
\hline 549505.2 & -2.8 & & $30_{1,29}-29_{2,28}$ AA & & & & & & & \\
\hline 549543.8 & & & $12_{66}-11_{56} \mathrm{EA}$ & 121.6 & $7.76 \mathrm{e}-4$ & & & & & $\begin{array}{l}2 \text { groups } \\
\text { bl } \mathrm{SO}_{2}\end{array}$ \\
\hline 549546.5 & & & $12_{67}-11_{56} \mathrm{AE}$ & & & & & & & \\
\hline 549547.4 & & & $12_{66}-11_{56} \mathrm{EE}$ & & & & & & & \\
\hline 549547.7 & & & $12_{66}-11_{57} \mathrm{AE}$ & & & & & & & \\
\hline 549550.4 & & & $12_{67}-11_{57}$ EA & & & & & & & \\
\hline 549550.6 & & & $12_{67}-11_{56}$ AA & & & & & & & \\
\hline 549550.8 & & & $12_{67}-11_{57} \mathrm{EE}$ & & & & & & & \\
\hline 549551.7 & 0.7 & & $12_{66}-11_{57} \mathrm{AA}$ & & & & & & & \\
\hline 551270.8 & -6.2 & -6.2 & $9_{7,3}-8_{6,2}$ EA & 109.8 & $1.09 \mathrm{e}-4$ & 383 & 312 & 4.3 & & $\begin{array}{l}\text { blend } \mathrm{CH}_{3} \mathrm{CN} \text {; } \\
2 \mathrm{G} \mathrm{CH}_{3} \mathrm{CN}\end{array}$ \\
\hline 551273.6 & -3.4 & -3.4 & $9_{7,3}-8_{6,2} \mathrm{EE}$ & & & & & & & \\
\hline 551275.1 & -1.9 & -1.9 & $9_{7,2}-8_{6,3} \mathrm{AE}$ & & & & & & & \\
\hline 551275.1 & -1.9 & -1.9 & $9_{7,3}-8_{6,2} \mathrm{AE}$ & & & & & & & \\
\hline 551276.5 & -0.5 & -0.5 & $9,7,3-8_{6,2}$ AA & & & & & & & \\
\hline 551276.5 & -0.5 & -0.5 & $9_{7,2}-8_{6,3}$ AA & & & & & & & \\
\hline 551277.9 & 0.9 & 0.9 & $9_{7,2}-8_{6,3} \mathrm{EE}$ & & & & & & & \\
\hline 551279.4 & 2.4 & 2.4 & $9_{7,2}-8_{6,3}$ EA & & & & & & & \\
\hline 552258.9 & -3.1 & & $18_{4,14}-17_{3,15}$ EA & 178.6 & $4.35 \mathrm{e}-4$ & 112 & & & 0.67 & entire group \\
\hline 552258.9 & -3.1 & & $18_{4,14}-17_{3,15} \mathrm{AE}$ & & & & & & & \\
\hline 552261.4 & -0.6 & & $18_{4,14}-17_{3,15} \mathrm{EE}$ & & & & & & & \\
\hline 552264.0 & 2.0 & & $18_{4,14}-17_{3,15} \mathrm{AA}$ & & & & & & & \\
\hline 554619.8 & -5.2 & & $25_{10,15}-25_{9,16}$ AA & 436.3 & $7.47 \mathrm{e}-4$ & 64 & & & 0.13 & entire group \\
\hline 554619.8 & -5.2 & & $25_{10,16}-25_{9,17} \mathrm{AA}$ & & & & & & & \\
\hline 554621.0 & -4.0 & & $25_{10,16}-25_{9,17} \mathrm{EE}$ & & & & & & & \\
\hline 554621.5 & -3.5 & & $25_{10,15}-25_{9,16} \mathrm{EE}$ & & & & & & & \\
\hline 554622.1 & -2.9 & & $25_{10,16}-25_{9,17}$ EA & & & & & & & \\
\hline 554622.6 & -2.4 & & $25_{10,15}-25_{9,16} \mathrm{AE}$ & & & & & & & \\
\hline 554622.6 & -2.4 & & $25_{10,16}-25_{9,17} \mathrm{AE}$ & & & & & & & \\
\hline 554623.2 & -1.7 & & $25_{10,15}-25_{9,16}$ EA & & & & & & & \\
\hline 554811.5 & -2.5 & & $24_{10,14}-24_{9,15} \mathrm{AA}$ & 413.5 & $7.36 \mathrm{e}-4$ & 60 & & 2.2 & 0.12 & entire group \\
\hline 554811.5 & -2.5 & & $24_{10,15}-24_{9,16}$ AA & & & & & & & \\
\hline 554812.7 & -1.3 & & $24_{10,15}-24_{9,16} \mathrm{EE}$ & & & & & & & \\
\hline 554813.4 & -0.6 & & $24_{10,14}-24_{9,15} \mathrm{EE}$ & & & & & & & \\
\hline 554813.9 & -0.1 & & $24_{10,15}-24_{9,16}$ EA & & & & & & & \\
\hline 554814.6 & 0.6 & & $24_{10,14}-24_{9,15} \mathrm{AE}$ & & & & & & & \\
\hline 554814.6 & 0.6 & & $24_{10,15}-24_{9,16} \mathrm{AE}$ & & & & & & & \\
\hline 554815.3 & 1.3 & & $24_{10,14}-24_{9,15}$ EA & & & & & & & \\
\hline 554888.3 & -2.7 & & $20_{4,17}-19_{3,16}$ EA & 214.1 & $4.50 \mathrm{e}-4$ & 118 & & & 0.32 & entire group \\
\hline 554888.3 & -2.7 & & $20_{4,17}-19_{3,16} \mathrm{AE}$ & & & & & & & \\
\hline 554890.4 & -0.6 & & $200_{4,17}-19_{3,16} \mathrm{EE}$ & & & & & & & \\
\hline 554892.5 & 1.5 & & $20_{4,17}-19_{3,16}$ AA & & & & & & & \\
\hline
\end{tabular}


Table 22. continued.

\begin{tabular}{|c|c|c|c|c|c|c|c|c|c|c|}
\hline $\begin{array}{l}v_{u l} \\
{[\mathrm{MHz}]}\end{array}$ & $\begin{array}{r}\Delta v_{\mathrm{p}} \\
{[\mathrm{MHz}]}\end{array}$ & $\begin{array}{r}\Delta v_{\mathrm{g}} \\
{[\mathrm{MHz}]}\end{array}$ & $\begin{array}{l}\text { Transition } \\
J_{K_{a}, K_{c}}\end{array}$ & $\begin{array}{r}E_{u} \\
{[\mathrm{~K}]}\end{array}$ & $\begin{array}{l}A_{u l} \\
{\left[\mathrm{~s}^{-1}\right]}\end{array}$ & $\begin{array}{r}T_{\mathrm{A}}^{*}(\text { peak }) \\
{[\mathrm{mK}]}\end{array}$ & $\begin{array}{l}\text { Ampl. } \\
{[\mathrm{mK}]}\end{array}$ & $\begin{array}{r}\text { Width } \\
{\left[\mathrm{km} \mathrm{s}^{-1}\right]}\end{array}$ & $\underset{\left[\mathrm{K} \mathrm{km} \mathrm{s}^{-1}\right]}{\int T_{\mathrm{A}}^{*} \mathrm{~d} v}$ & Note \\
\hline 554979.1 & -4.9 & & $23_{10,13}-23_{9,14}$ AA & 391.7 & $7.23 \mathrm{e}-4$ & 90 & & & 0.21 & entire group \\
\hline 554979.1 & -4.9 & & $23_{10,14}-23_{9,15}$ AA & & & & & & & \\
\hline 554980.4 & -3.6 & & $23_{10,14}-23_{9,15} \mathrm{EE}$ & & & & & & & \\
\hline 554981.2 & -2.8 & & $23_{10,13}-23_{9,14} \mathrm{EE}$ & & & & & & & \\
\hline 554981.7 & -2.3 & & $23_{10,14}-23_{9,15}$ EA & & & & & & & \\
\hline 554982.5 & -1.5 & & $23_{10,13}-23_{9,14} \mathrm{AE}$ & & & & & & & \\
\hline 554982.5 & -1.5 & & $23_{10,14}-23_{9,15} \mathrm{AE}$ & & & & & & & \\
\hline 554983.3 & -0.7 & & $23_{10,13}-23_{9,14}$ EA & & & & & & & \\
\hline 555124.5 & & & $22_{10,12}-22_{9,13}$ AA & 370.7 & $7.08 \mathrm{e}-4$ & & & & & entire group \\
\hline 555124.5 & & & $22_{10,13}-22_{9,14}$ AA & & & & & & & $\mathrm{bl} \mathrm{SO}$ \\
\hline 555125.9 & & & $22_{10,13}-22_{9,14} \mathrm{EE}$ & & & & & & & \\
\hline 555126.8 & & & $22_{10,12}-22_{9,13} \mathrm{EE}$ & & & & & & & \\
\hline 555127.3 & & & $22_{10,13}-22_{9,14} \mathrm{EA}$ & & & & & & & \\
\hline 555128.2 & & & $22_{10,12}-22,9,13 \mathrm{AE}$ & & & & & & & \\
\hline 555128.2 & & & $22_{10,13}-22_{9,14} \mathrm{AE}$ & & & & & & & \\
\hline 555129.1 & & & $22_{10,12}-22_{9,13}$ EA & & & & & & & \\
\hline 555249.8 & -11.2 & -9.2 & $21_{10,11}-21_{9,12} \mathrm{AA}$ & 350.7 & $6.92 \mathrm{e}-4$ & 129 & 104 & 8.2 & 0.82 & entire group \\
\hline 555249.8 & -11.2 & -9.2 & $21_{10,12}-21_{9,13} \mathrm{AA}$ & & & & & & & \\
\hline 555251.3 & -9.7 & -7.7 & $21_{10,12}-21_{9,13} \mathrm{EE}$ & & & & & & & \\
\hline 555252.3 & -8.7 & -6.7 & $21_{10,11}-21_{9,12} \mathrm{EE}$ & & & & & & & \\
\hline 555252.7 & -8.3 & -6.3 & $21_{10,12}-21_{9,13}$ EA & & & & & & & \\
\hline 555253.8 & -7.2 & -5.2 & $21_{10,12}-21_{9,13} \mathrm{AE}$ & & & & & & & \\
\hline 555253.8 & -7.2 & -5.2 & $21_{10,11}-21_{9,12} \mathrm{AE}$ & & & & & & & \\
\hline 555254.9 & -6.1 & -4.1 & $21_{10,11}-21_{9,12}$ EA & & & & & & & \\
\hline 555356.8 & -6.2 & -6.2 & $20_{10,10}-20_{9,11}$ AA & 331.6 & $6.73 e-4$ & 75 & 71 & 4.9 & 0.37 & entire group \\
\hline 555356.8 & -6.2 & -6.2 & $20_{10,11}-20_{9,12}$ AA & & & & & & & \\
\hline 555358.3 & -4.7 & -4.7 & $20_{10,11}-20_{9,12} \mathrm{EE}$ & & & & & & & \\
\hline 555359.5 & -3.5 & -3.5 & $20_{10,10}-20_{9,11} \mathrm{EE}$ & & & & & & & \\
\hline 555359.9 & -3.1 & -3.1 & $20_{10,11}-20_{9,12}$ EA & & & & & & & \\
\hline 555361.1 & -1.9 & -1.9 & $20_{10,10}-20_{9,11}$ AE & & & & & & & \\
\hline 555361.1 & -1.9 & -1.9 & $20_{10,11}-20_{9,12} \mathrm{AE}$ & & & & & & & \\
\hline 555362.3 & -0.7 & -0.7 & $20_{10,10}-20_{9,11}$ EA & & & & & & & \\
\hline 555447.3 & -3.7 & -5.7 & $19_{10,9}-19_{9,10}$ AA & 313.4 & $6.52 \mathrm{e}-4$ & 104 & & 5.1 & 0.39 & entire group \\
\hline 555447.3 & -3.7 & -5.7 & $19_{10,10}-19_{9,11}$ AA & & & & & & & \\
\hline 555448.9 & -2.1 & -4.1 & $19_{10,10}-19_{9,11} \mathrm{EE}$ & & & & & & & \\
\hline 555450.2 & -0.8 & -2.8 & $19_{10,9}-19_{9,10} \mathrm{EE}$ & & & & & & & \\
\hline 555450.6 & -0.4 & -2.4 & $19_{10,10}-19_{9,11}$ EA & & & & & & & \\
\hline 555451.9 & 0.9 & -1.1 & $19_{10,9}-19_{9,10} \mathrm{AE}$ & & & & & & & \\
\hline 555451.9 & 0.9 & -1.1 & $19_{10,10}-19_{9,11} \mathrm{AE}$ & & & & & & & \\
\hline 555453.1 & 2.1 & 0.1 & $19_{10,9}-19_{9,10}$ EA & & & & & & & \\
\hline 555522.9 & -4.1 & -6.1 & $18_{10,8}-18_{9,9}$ AA & 296.1 & $6.28 \mathrm{e}-4$ & 110 & & & 0.51 & entire group \\
\hline 555522.9 & -4.1 & -6.1 & $18_{10,9}-18_{9,10} \mathrm{AA}$ & & & & & & & \\
\hline 555524.6 & -2.6 & -4.6 & $18_{10,9}-18_{9,10} \mathrm{EE}$ & & & & & & & \\
\hline 555526.0 & -1.0 & -3.0 & $18_{10,8}-18_{9,9} \mathrm{EE}$ & & & & & & & \\
\hline 555526.4 & -0.6 & -2.6 & $18_{10,9}-18_{9,10}$ EA & & & & & & & \\
\hline 555527.8 & 0.8 & 1.2 & $18_{10,8}-18_{9,9} \mathrm{AE}$ & & & & & & & \\
\hline 555527.8 & 0.8 & 1.2 & $18_{10,9}-18_{9,10} \mathrm{AE}$ & & & & & & & \\
\hline 555529.2 & 2.2 & 0.2 & $18_{10,8}-18_{9,9}$ EA & & & & & & & \\
\hline 555585.3 & -5.7 & -5.7 & $17_{10,7}-17_{9,8}$ AA & 279.7 & $5.99 \mathrm{e}-4$ & 83 & & 4.2 & 0.35 & entire group \\
\hline 555585.3 & -5.7 & -5.7 & $17_{10,8}-17_{9.9}$ AA & & & & & & & \\
\hline 555587.1 & -3.9 & -3.9 & $17_{10,8}-7_{9,9} \mathrm{EE}$ & & & & & & & \\
\hline 555588.6 & -2.4 & -2.4 & $17_{10,7}-17_{9,8} \mathrm{EE}$ & & & & & & & \\
\hline 555589.0 & -2.0 & -2.0 & $17_{10,8}-17_{9,9}$ EA & & & & & & & \\
\hline 555590.4 & -0.6 & -0.6 & $17_{10,7}-17_{9,8} \mathrm{AE}$ & & & & & & & \\
\hline 555590.4 & -0.6 & -0.6 & $17_{10,8}-17_{9,9} \mathrm{AE}$ & & & & & & & \\
\hline 555591.9 & 0.9 & 0.9 & $17_{10,7}-17_{9,8}$ EA & & & & & & & \\
\hline
\end{tabular}


C. M. Persson et al.: A spectral line survey of Orion KL in the bands 486-492 and 541-577 GHz with the Odin satellite. II., Online Material p 23

Table 22. continued.

\begin{tabular}{|c|c|c|c|c|c|c|c|c|c|c|}
\hline $\begin{array}{l}v_{u l} \\
{[\mathrm{MHz}]}\end{array}$ & $\begin{array}{r}\Delta v_{\mathrm{p}} \\
{[\mathrm{MHz}]}\end{array}$ & $\begin{array}{r}\Delta v_{\mathrm{g}} \\
{[\mathrm{MHz}]}\end{array}$ & $\begin{array}{l}\text { Transition } \\
J_{K_{a}, K_{c}}\end{array}$ & $\begin{array}{r}E_{u} \\
{[\mathrm{~K}]}\end{array}$ & $\begin{array}{l}A_{u l} \\
{\left[\mathrm{~s}^{-1}\right]}\end{array}$ & $\begin{array}{r}T_{\mathrm{A}}^{*}(\text { peak }) \\
{[\mathrm{mK}]}\end{array}$ & $\begin{array}{l}\text { Ampl. } \\
{[\mathrm{mK}]}\end{array}$ & $\begin{array}{r}\text { Width } \\
{\left[\mathrm{km} \mathrm{s}^{-1}\right]}\end{array}$ & $\begin{array}{r}\int T_{\mathrm{A}}^{*} \mathrm{~d} v \\
{\left[\mathrm{~K} \mathrm{~km} \mathrm{~s}^{-1}\right]}\end{array}$ & Note \\
\hline 555635.9 & & & $16_{10,6}-16_{9,7}$ AA & 264.2 & $5.66 \mathrm{e}-4$ & & & & & blend $\mathrm{SO}_{2}$ \\
\hline 555635.9 & & & $16_{10,7}-16_{9,8}$ AA & & & & & & & \\
\hline 555637.9 & & & $16_{10,7}-16_{9,8} \mathrm{EE}$ & & & & & & & \\
\hline 555639.4 & & & $16_{10,6}-16_{9,7} \mathrm{EE}$ & & & & & & & \\
\hline 555639.8 & & & $16_{10,7}-16_{9,8}$ EA & & & & & & & \\
\hline 555641.4 & & & $16_{10,6}-16_{9,7} \mathrm{AE}$ & & & & & & & \\
\hline 555641.4 & & & $16_{10,7}-16_{9,8} \mathrm{AE}$ & & & & & & & \\
\hline 555642.9 & & & $16_{10,6}-16_{9,7}$ EA & & & & & & & \\
\hline 555676.3 & & & $15_{10,5}-15_{9,6}$ AA & 249.7 & $5.27 \mathrm{e}-4$ & & & & & $\begin{array}{l}\text { blend } \mathrm{SO}_{2} \text {, } \\
\mathrm{CH}_{3} \mathrm{OH}\end{array}$ \\
\hline 555676.3 & & & $15_{10,6}-15_{9,7}$ AA & & & & & & & \\
\hline 555678.3 & & & $15_{10,6}-15_{9,7} \mathrm{EE}$ & & & & & & & \\
\hline 555679.9 & & & $15_{10,5}-15_{9,6} \mathrm{EE}$ & & & & & & & \\
\hline 555680.3 & & & $15_{10,6}-15_{9,7}$ EA & & & & & & & \\
\hline 555681.9 & & & $15_{10,5}-15_{9,6} \mathrm{AE}$ & & & & & & & \\
\hline 555681.9 & & & $15_{10,6}-15_{9,7} \mathrm{AE}$ & & & & & & & \\
\hline 555683.6 & & & $15_{10,5}-15_{9,6}$ EA & & & & & & & \\
\hline 555707.6 & & & $14_{10,4}-14_{9,5}$ AA & 236.0 & $4.80 \mathrm{e}-4$ & & & & & blend $\mathrm{SO}_{2}$ \\
\hline 555707.6 & & & $14_{10,5}-14_{9,6}$ AA & & & & & & & \\
\hline 555709.7 & & & $14_{10,5}-14_{9,6} \mathrm{EE}$ & & & & & & & \\
\hline 555711.4 & & & $14_{10,4}-14_{9,5} \mathrm{EE}$ & & & & & & & \\
\hline 555711.8 & & & $14_{10,5}-14_{9,6}$ EA & & & & & & & \\
\hline 555713.5 & & & $14_{10,4}-14_{9,5} \mathrm{AE}$ & & & & & & & \\
\hline 555713.5 & & & $14_{10,5}-14_{9,6} \mathrm{AE}$ & & & & & & & \\
\hline 555715.2 & & & $14_{10,4}-14_{9,5}$ EA & & & & & & & \\
\hline 555731.2 & -4.8 & -6.8 & $13_{10,3}-13_{9,4}$ AA & 223.3 & $4.23 \mathrm{e}-4$ & 96 & & 6.2 & 0.61 & entire group \\
\hline 555731.2 & -4.8 & -6.8 & $13_{10,4}-13_{9,5}$ AA & & & & & & & \\
\hline 555733.4 & -2.6 & -4.6 & $13_{10,4}-13_{9,5} \mathrm{EE}$ & & & & & & & \\
\hline 555735.2 & -0.8 & -2.8 & $13_{10,3}-13_{9,4} \mathrm{EE}$ & & & & & & & \\
\hline 555735.5 & -0.5 & -2.5 & $13_{10,4}-13_{9,5}$ EA & & & & & & & \\
\hline 555737.3 & 1.3 & -0.7 & $13_{10,3}-13_{9,4} \mathrm{AE}$ & & & & & & & \\
\hline 555737.3 & 1.3 & -0.7 & $13_{10,4}-13_{9,5} \mathrm{AE}$ & & & & & & & \\
\hline 555739.1 & 3.1 & 1.1 & $13_{10,3}-13_{9,4}$ EA & & & & & & & \\
\hline 555748.2 & & & $12_{10,2}-12_{9,3}$ AA & 211.5 & $3.53 \mathrm{e}-4$ & & & & & blend 3 groups \\
\hline 555748.2 & & & $12_{10,3}-12_{9,4}$ AA & & & & & & & \\
\hline 555750.5 & & & $12_{10,3}-12_{9,4} \mathrm{EE}$ & & & & & & & \\
\hline 555752.3 & & & $12_{10,2}-12_{9,3} \mathrm{EE}$ & & & & & & & \\
\hline 555752.7 & & & $12_{10,3}-12_{9,4}$ EA & & & & & & & \\
\hline 555754.6 & & & $12_{10,2}-12_{9,3} \mathrm{AE}$ & & & & & & & \\
\hline 555754.6 & & & $12_{10,3}-12_{9,4} \mathrm{AE}$ & & & & & & & \\
\hline 555756.4 & & & $12_{10,2}-12_{9,3}$ EA & & & & & & & \\
\hline 555759.7 & & & $11_{10,1}-11_{9,2}$ AA & 200.6 & $2.64 \mathrm{e}-4$ & & & & & blend 3 groups \\
\hline 555759.7 & & & $11_{10,2}-11_{9,3}$ AA & & & & & & & \\
\hline 555762.1 & & & $11_{10,2}-11_{9,3} \mathrm{EE}$ & & & & & & & \\
\hline 555764.0 & & & $11_{10,1}-11_{9,2} \mathrm{EE}$ & & & & & & & \\
\hline 555764.4 & & & $11_{10,2}-11_{9,3}$ EA & & & & & & & \\
\hline 555766.3 & & & $11_{10,1}-11_{9,2} \mathrm{AE}$ & & & & & & & \\
\hline 555766.3 & & & $11_{10,2}-11_{9,3} \mathrm{AE}$ & & & & & & & \\
\hline 555766.8 & & & $10_{10,0}-10_{9,1}$ AA & 190.5 & $1.50 \mathrm{e}-4$ & & & & & blend 3 groups \\
\hline 555766.8 & & & $10_{10,1}-10_{9,2}$ AA & & & & & & & \\
\hline 555768.2 & & & $11_{10,1}-11_{9,2}$ EA & 200.6 & $2.64 \mathrm{e}-4$ & & & & & \\
\hline 555769.2 & & & $10_{10,1}-10_{9,2} \mathrm{EE}$ & 190.5 & $1.50 \mathrm{e}-4$ & & & & & blend 3 groups \\
\hline 555771.2 & & & $10_{10,0}-10_{9,1} \mathrm{EE}$ & & & & & & & \\
\hline 555771.6 & & & $10_{10,1}-10_{9,2}$ EA & & & & & & & \\
\hline 555773.5 & & & $10_{10,0}-10_{9,1} \mathrm{AE}$ & & & & & & & \\
\hline 555773.5 & & & $10_{10,1}-10_{9,2} \mathrm{AE}$ & & & & & & & \\
\hline 555775.5 & & & $10_{10,0}-10_{9,1}$ EA & & & & & & & \\
\hline
\end{tabular}


Table 22. continued.

\begin{tabular}{|c|c|c|c|c|c|c|c|c|c|c|}
\hline $\begin{array}{l}v_{u l} \\
{[\mathrm{MHz}]}\end{array}$ & $\begin{array}{r}\Delta v_{\mathrm{p}} \\
{[\mathrm{MHz}]}\end{array}$ & $\begin{array}{r}\Delta v_{\mathrm{g}} \\
{[\mathrm{MHz}]}\end{array}$ & $\begin{array}{l}\text { Transition } \\
J_{K_{a}, K_{c}}\end{array}$ & $\begin{array}{r}E_{u} \\
{[\mathrm{~K}]}\end{array}$ & $\begin{array}{l}A_{u l} \\
{\left[\mathrm{~s}^{-1}\right]}\end{array}$ & $\begin{array}{r}T_{\mathrm{A}}^{*}(\text { peak }) \\
{[\mathrm{mK}]}\end{array}$ & $\begin{array}{r}\text { Ampl. } \\
{[\mathrm{mK}]}\end{array}$ & $\begin{array}{r}\text { Width } \\
{\left[\mathrm{km} \mathrm{s}^{-1}\right]}\end{array}$ & $\underset{\left[\mathrm{K} \mathrm{km} \mathrm{s}^{-1}\right]}{\int T_{\mathrm{A}}^{*} \mathrm{~d} v}$ & Note \\
\hline 556179.4 & -1.6 & -0.6 & $31_{0,31}-30_{1,30}$ EA & 431.3 & $1.50 \mathrm{e}-4$ & 65 & 60 & 3.5 & 0.17 & entire group \\
\hline 556179.4 & -1.6 & -0.6 & $31_{0,31}-30_{1,30} \mathrm{AE}$ & & & & & & & \\
\hline 556179.4 & -1.6 & -0.6 & $31_{0,31}-30_{1,30} \mathrm{EE}$ & & & & & & & \\
\hline 556179.5 & -1.5 & -0.5 & $31_{0,31}-30_{1,30} \mathrm{AA}$ & & & & & & & \\
\hline 556212.0 & & & $31_{1,31}-30_{0,30}$ EA & & & & & & & (Too) weak \\
\hline 556212.0 & & & $31_{1,31}-30_{0,30} \mathrm{AE}$ & & & & & & & (Too) weak \\
\hline 556212.1 & & & $31_{1,31}-30_{0,30} \mathrm{EE}$ & & & & & & & (Too) weak \\
\hline 556212.2 & & & $31_{1,31}-30_{0,30} \mathrm{AA}$ & & & & & & & (Too) weak \\
\hline 560648.9 & & & $29_{3,27}-28_{2,26} \mathrm{AA}$ & 407.3 & $8.54 \mathrm{e}-4$ & & & & & $\mathrm{v}$ blend $\mathrm{SO}_{2}$ \\
\hline 560648.9 & & & $29_{3,27}-28_{2,26} \mathrm{EE}$ & & & & & & & \\
\hline 560649.0 & & & $29_{3,27}-28_{2,26}$ EA & & & & & & & \\
\hline 560649.0 & & & $29_{3,27}-28_{2,26} \mathrm{AE}$ & & & & & & & \\
\hline 565262.1 & -3.9 & -3.9 & $16_{5,12}-15_{4,11}$ EA & 159.0 & $6.18 \mathrm{e}-4$ & 154 & 120 & 5.7 & 0.69 & entire group \\
\hline 565262.8 & -3.2 & & $16_{5,12}-15_{4,11} \mathrm{AE}$ & & & & & & & \\
\hline 565265.2 & -0.8 & & $16_{5,12}-15_{4,11} \mathrm{EE}$ & & & & & & & \\
\hline 565267.9 & 1.9 & & $16_{5,12}-15_{4,11}$ AA & & & & & & & \\
\hline 566046.6 & -3.4 & -4.4 & $16_{5,11}-15_{4,12} \mathrm{AE}$ & 159.0 & $6.29 \mathrm{e}-4$ & 204 & 198 & 3.4 & 0.71 & entire group \\
\hline 566047.3 & -2.7 & -3.7 & $16_{5,11}-15_{4,12}$ EA & & & & & & & \\
\hline 566049.3 & -0.7 & -1.7 & $16_{5,11}-15_{4,12} \mathrm{EE}$ & & & & & & & \\
\hline 566051.7 & 1.7 & 0.7 & $16_{5,11}-15_{4,12}$ AA & & & & & & & \\
\hline 566606.7 & -2.3 & -2.3 & $21_{4,18}-20_{3,17} \mathrm{AE}$ & 233.3 & $4.71 \mathrm{e}-4$ & 90 & 73 & 3.9 & 0.28 & entire group \\
\hline 566606.7 & -2.3 & -2.3 & $21_{4,18}-20_{3,17}$ EA & & & & & & & \\
\hline 566608.5 & -0.5 & -0.5 & $21_{4,18}-20_{3,17} \mathrm{EE}$ & & & & & & & \\
\hline 566610.4 & 1.4 & 1.4 & $21_{4,18}-20_{3,17}$ AA & & & & & & & \\
\hline 568430.6 & -7.4 & & $13_{6,7}-12_{5,7}$ EA & 133.4 & $8.10 \mathrm{e}-4$ & 331 & 330 & 5.1 & 1.79 & entire group \\
\hline 568432.6 & -5.4 & & $13_{6,8}-12_{5,7} \mathrm{AE}$ & & & & & & & \\
\hline 568433.9 & -4.1 & & $13_{6,7}-12_{5,7} \mathrm{EE}$ & & $7.85 \mathrm{e}-4$ & & & & & \\
\hline 568435.3 & -2.7 & & $13_{6,7}-12_{5,8} \mathrm{AE}$ & & $8.19 \mathrm{e}-4$ & & & & & \\
\hline 568436.3 & -1.7 & & $13_{6,8}-12_{5,7}$ AA & & & & & & & \\
\hline 568437.2 & -0.8 & & $13_{6,8}-12_{5,8}$ EA & & $8.10 \mathrm{e}-4$ & & & & & \\
\hline 568437.7 & -0.3 & & $13_{6,8}-12_{5,8} \mathrm{EE}$ & & $7.85 \mathrm{e}-4$ & & & & & \\
\hline 568439.2 & 1.2 & & $13_{6,7}-12_{5,8}$ AA & & $8.19 \mathrm{e}-4$ & & & & & \\
\hline 568690.1 & -2.9 & & $31_{2,30}-30_{1,29} \mathrm{AE}$ & 447.6 & $1.30 \mathrm{e}-4$ & 92 & & & 0.29 & entire group \\
\hline 568690.1 & & & $31_{2,30}-30_{1,29}$ EA & & & & & & & \\
\hline 568690.3 & -2.7 & & $31_{2,30}-30_{1,29} \mathrm{EE}$ & & & & & & & \\
\hline 568690.4 & -2.6 & & $31_{2,30}-30_{1,29} \mathrm{AA}$ & & & & & & & \\
\hline 570219.1 & -5.9 & & $10_{7,4}-9_{6,3}$ EA & 118.9 & $1.12 \mathrm{e}-4$ & 351 & 342 & 4.3 & 1.55 & entire group \\
\hline 570221.9 & -2.9 & & $10_{7,4}-9_{6,3} \mathrm{EE}$ & & & & & & & \\
\hline 570223.3 & -1.7 & & $10_{7,3}-96,4 \mathrm{AE}$ & & & & & & & \\
\hline 570223.3 & -1.7 & & $10_{7,4}-9_{6,3} \mathrm{AE}$ & & & & & & & \\
\hline 570224.7 & -0.3 & & $10_{7,4}-9_{6,3}$ AA & & & & & & & \\
\hline 570224.7 & -0.3 & & $10_{7,3}-9_{6,4} \mathrm{AA}$ & & & & & & & \\
\hline 570226.1 & 1.1 & & $10_{7,3}-9_{6,4} \mathrm{EE}$ & & & & & & & \\
\hline 570227.5 & 2.5 & & $10_{7,3}-9_{6,4}$ EA & & & & & & & \\
\hline 574090.9 & -7.1 & -6.1 & $19_{4,15}-18_{3,16}$ EA & 196.0 & $4.59 \mathrm{e}-4$ & 92 & 89 & 2.8 & 0.29 & entire group \\
\hline 574090.9 & -7.1 & -6.1 & $19_{4,15}-18_{3,16} \mathrm{AE}$ & & & & & & & \\
\hline 574093.3 & -4.7 & -3.7 & $19_{4,15}-18_{3,16} \mathrm{EE}$ & & & & & & & \\
\hline 574095.7 & -2.3 & -1.3 & $19_{4,15}-18_{3,16}$ AA & & & & & & & \\
\hline Total No. & 236 & & & & & & & & & \\
\hline
\end{tabular}


C. M. Persson et al.: A spectral line survey of Orion KL in the bands 486-492 and 541-577 GHz with the Odin satellite. II., Online Material p 25

Table 23. $\mathrm{H}_{2} \mathrm{CO}$ and isotopologue parameters ${ }^{a}$.

\begin{tabular}{|c|c|c|c|c|c|c|c|c|c|c|c|}
\hline Species & $\begin{array}{l}v_{u l} \\
{[\mathrm{MHz}]}\end{array}$ & $\begin{array}{r}\Delta v_{\mathrm{p}} \\
{[\mathrm{MHz}]}\end{array}$ & $\begin{array}{r}\Delta v_{\mathrm{g}} \\
{[\mathrm{MHz}]}\end{array}$ & $\begin{array}{l}\text { Transition } \\
J_{K_{a}, K_{c}}\end{array}$ & $\begin{array}{r}E_{u} \\
{[\mathrm{~K}]}\end{array}$ & $\begin{array}{l}A_{u l} \\
{\left[\mathrm{~s}^{-1}\right]}\end{array}$ & $\begin{array}{r}T_{\mathrm{A}}^{*}(\text { peak }) \\
{[\mathrm{mK}]}\end{array}$ & $\begin{array}{l}\text { Ampl. } \\
{[\mathrm{mK}]}\end{array}$ & $\begin{array}{r}\text { Width } \\
{\left[\mathrm{km} \mathrm{s}^{-1}\right]}\end{array}$ & $\begin{array}{r}\int T_{\mathrm{A}}^{*} \mathrm{~d} v \\
{\left[\mathrm{Km} \mathrm{s}^{-1}\right]}\end{array}$ & Note \\
\hline \multirow[t]{7}{*}{$\mathrm{H}_{2} \mathrm{CO}$} & 491968.4 & 2.4 & 1.4 & $7_{1,7}-6_{1,6}$ & 106.3 & $3.44 \mathrm{e}-3$ & 2040 & 1954 & 5.2 & 11.30 & \\
\hline & 561899.3 & 1.3 & & $8_{1,8}-7_{1,7}$ & 133.3 & $5.20 \mathrm{e}-3$ & 1705 & & & 16.3 & \\
\hline & & & 1.3 & & & & & 1167 & 4.9 & & 2G; CR \\
\hline & & & -0.7 & & & & & 504 & 19.0 & & 2G; LVF \\
\hline & 576708.3 & -0.7 & & $8_{0,8}-7_{0,7}$ & 125.1 & $5.70 \mathrm{e}-3$ & 1116 & & & 11.30 & blend NS \\
\hline & & & 0.3 & & & & & 742 & 4.8 & & 2G; CR \\
\hline & & & -6.7 & & & & & 392 & 18.7 & & 2G; LVF \\
\hline $\mathrm{H}_{2}^{13} \mathrm{CO}$ & 548475.2 & 0.2 & 0.2 & $8_{1,8}-7_{1,7}$ & 130.4 & $4.84 \mathrm{e}-3$ & 155 & 135 & 4.3 & 0.62 & \\
\hline \multirow[t]{3}{*}{ HDCO } & 491937.0 & 2.0 & 3.0 & $8_{1,8}-7_{1,7}$ & 114.4 & $3.48 \mathrm{e}-3$ & 370 & 360 & 6.1 & 2.41 & blend U-line? \\
\hline & 552740.9 & -0.1 & 0.9 & $9_{1,9}-8_{1,8}$ & 141.0 & $4.99 \mathrm{e}-3$ & 101 & 88 & 3.0 & 0.27 & \\
\hline & 565857.5 & 2.5 & & $9_{0,9}-8_{0,8}$ & 137.3 & $5.40 \mathrm{e}-3$ & 60 & & & 0.19 & weak \\
\hline
\end{tabular}

${ }^{a}$ Notation as in Table 9 .

Table 24. $\mathrm{H}_{2} \mathrm{CS}$ parameters ${ }^{a}$.

\begin{tabular}{lrrlrlrrrrl}
\hline \hline$v_{u l}$ & $\begin{array}{r}\Delta v_{\mathrm{p}} \\
{[\mathrm{MHz}]}\end{array}$ & $\begin{array}{r}\Delta v_{\mathrm{g}} \\
{[\mathrm{MHz}]}\end{array}$ & $\begin{array}{l}\text { Transition } \\
{[\mathrm{MHz}]}\end{array}$ & $\begin{array}{l}J_{K_{a}, K_{c}} \\
{[\mathrm{~K}]}\end{array}$ & $\begin{array}{l}A_{u l} \\
{\left[\mathrm{~s}^{-1}\right]}\end{array}$ & $\begin{array}{r}T_{\mathrm{A}}^{*}(\text { peak) } \\
{[\mathrm{mK}]}\end{array}$ & $\begin{array}{r}\text { Ampl. } \\
{[\mathrm{mK}]}\end{array}$ & $\begin{array}{r}\text { Width } \\
{\left[\mathrm{km} \mathrm{s}^{-1}\right]}\end{array}$ & $\begin{array}{c}\int T_{\mathrm{A}}^{*} \mathrm{~d} v \\
{\left[\mathrm{~K} \mathrm{~km} \mathrm{~s}^{-1}\right]}\end{array}$ & Note \\
\hline 487663.4 & 0.4 & 0.4 & $14_{1,13}-13_{1,12}$ & 188.8 & $1.76 \mathrm{e}-3$ & 172 & 161 & 3.7 & 0.62 \\
547308.2 & -3.8 & -2.8 & $16_{0,16}-15_{0,15}$ & 223.7 & $2.51 \mathrm{e}-3$ & 77 & 63 & 3 & 0.19 \\
549402.4 & 0.4 & 0.4 & $16_{3,14}-15_{3,13}$ & 342.6 & $2.45 \mathrm{e}-3$ & 62 & 55 & 1.8 & 0.15 & blend U-line \\
549447.5 & -1.5 & & $16_{3,13}-15_{3,12}$ & 342.6 & $2.45 \mathrm{e}-3$ & 98 & & & & $\begin{array}{l}\text { blend } \mathrm{CH}_{3} \mathrm{OH} ; \\
\text { in } \mathrm{H}_{2} \mathrm{O} \text { wing }\end{array}$ \\
557123.2 & 2.2 & & $16_{1,15}-15_{1,14}$ & 240.6 & $2.64 \mathrm{e}-3$ & & & & & 0.38 \\
574140.0 & -2.0 & -2.0 & $17_{1,17}-16_{1,16}$ & 261.4 & $2.90 \mathrm{e}-3$ & 130 & 125 & 2.9 & & 0.38 \\
\hline Total No. & 6 & & & & & & & & & \\
\hline
\end{tabular}

${ }^{a}$ Notation as in Table 9.

Table 25. CS and ${ }^{13} \mathrm{CS}$ parameters ${ }^{a}$.

\begin{tabular}{|c|c|c|c|c|c|c|c|c|c|c|c|}
\hline Species & $\begin{array}{l}v_{u l} \\
{[\mathrm{MHz}]}\end{array}$ & $\begin{array}{r}\Delta v_{\mathrm{p}} \\
{[\mathrm{MHz}]}\end{array}$ & $\begin{array}{r}\Delta v_{\mathrm{g}} \\
{[\mathrm{MHz}]}\end{array}$ & $\begin{array}{l}\text { Transition } \\
J\end{array}$ & $\begin{array}{r}E_{u} \\
{[\mathrm{~K}]}\end{array}$ & $\begin{array}{l}A_{u l} \\
{\left[\mathrm{~s}^{-1}\right]}\end{array}$ & $\begin{array}{r}T_{\mathrm{A}}^{*}(\text { peak }) \\
{[\mathrm{mK}]}\end{array}$ & $\begin{array}{l}\text { Ampl. } \\
{[\mathrm{mK}]}\end{array}$ & $\begin{array}{r}\text { Width } \\
{\left[\mathrm{km} \mathrm{s}^{-1}\right]}\end{array}$ & $\underset{\left[\mathrm{K}^{2} \mathrm{~km} \mathrm{~s}^{-1}\right]}{\int T_{\mathrm{A}}^{*} \mathrm{~d} v}$ & Note \\
\hline \multirow[t]{4}{*}{$\overline{\mathrm{CS}}$} & 489751.1 & 3.1 & & $10-9$ & 129.3 & 0.00250 & 2814 & & & 23.4 & \\
\hline & & & -0.9 & & & & & 424 & 9.0 & & $\mathrm{HC}, 3 \mathrm{G}$ fit \\
\hline & & & 2.1 & & & & & 1730 & 4.0 & & $\mathrm{ER} / \mathrm{CR}, 3 \mathrm{G}$ fit \\
\hline & & & 1.1 & & & & & 633 & 18.0 & & LVF, 3G fit \\
\hline${ }^{13} \mathrm{CS}$ & 554726.0 & & -2.0 & $12-11$ & 173.1 & 0.00366 & & 88 & 4.8 & & $\begin{array}{l}\text { v blend, } \\
2 \mathrm{G}^{34} \mathrm{SO}_{2}\end{array}$ \\
\hline
\end{tabular}

${ }^{a}$ Notation as in Table 9. 
Table 26. NO parameters ${ }^{a}$.

\begin{tabular}{|c|c|c|c|c|c|c|c|c|c|}
\hline $\begin{array}{l}v_{u l} \\
{[\mathrm{MHz}]}\end{array}$ & $\begin{array}{r}\Delta v_{\mathrm{p}} \\
{[\mathrm{MHz}]}\end{array}$ & $\begin{array}{l}\text { Transition } \\
J(F)\end{array}$ & $\begin{array}{r}E_{u} \\
{[\mathrm{~K}]}\end{array}$ & $\begin{array}{l}A_{u l} \\
{\left[\mathrm{~s}^{-1}\right]}\end{array}$ & $\begin{array}{r}T_{\mathrm{A}}^{*}(\text { peak }) \\
{[\mathrm{mK}]} \\
\end{array}$ & $\begin{array}{r}\text { Ampl. } \\
{[\mathrm{mK}]}\end{array}$ & $\begin{array}{r}\text { Width } \\
{\left[\mathrm{km} \mathrm{s}^{-1}\right]} \\
\end{array}$ & $\begin{array}{r}\int T_{\mathrm{A}}^{*} \mathrm{~d} v \\
{\left[\mathrm{~K} \mathrm{~km} \mathrm{~s}^{-1}\right]}\end{array}$ & Note \\
\hline 551187.3 & -0.7 & ${ }^{2} \Pi_{1 / 2} 5.5(5.5)-4.5(4.5) \mathrm{e}$ & 84.2 & $2.16 \mathrm{e}-5$ & 540 & $\begin{array}{l}265 \\
284\end{array}$ & $\begin{array}{r}5.4 \\
18.6\end{array}$ & & $\begin{array}{l}\text { entire group; } \\
5 \mathrm{G} \text { from } \mathrm{CH}_{3} \mathrm{CN} \text {, } \\
\mathrm{NO} \& \mathrm{CH}_{3} \mathrm{OH}\end{array}$ \\
\hline $\begin{array}{l}551187.5 \\
551188.8\end{array}$ & & $\begin{array}{l}{ }^{2} \Pi_{1 / 2} 5.5(6.5)-4.5(5.5) \mathrm{e} \\
{ }^{2} \Pi_{1 / 2} 5.5(4.5)-4.5(3.5) \mathrm{e}\end{array}$ & $\begin{array}{l}84.1 \\
84.2\end{array}$ & $\begin{array}{l}2.23 e-5 \\
2.14 e-5\end{array}$ & & & & & \\
\hline 551531.5 & 0.5 & ${ }^{2} \Pi_{1 / 2} 5.5(6.5)-4.5(5.5) \mathrm{f}$ & 84.3 & $2.24 \mathrm{e}-5$ & 644 & & & 9.331 & $\begin{array}{l}\text { entire group; } \\
\text { blend } \mathrm{CH}_{3} \mathrm{CN}\end{array}$ \\
\hline 551534.0 & 3.0 & ${ }^{2} \Pi_{1 / 2} 5.5(4.5)-4.5(3.5) \mathrm{f}$ & 84.2 & $2.15 e-5$ & & & & & blend $\mathrm{CH}_{3} \mathrm{CN}$, $\mathrm{NO}$ \\
\hline 551534.1 & 3.1 & ${ }^{2} \Pi_{1 / 2} 5.5(5.5)-4.5(4.5) f$ & 84.3 & $2.16 e-5$ & & & & & blend $\mathrm{CH}_{3} \mathrm{CN}$, NO \\
\hline 567064.2 & -11.8 & ${ }^{2} \Pi_{3 / 2} 5.5(6.5)-4.5(5.5) \mathrm{e}$ & 231.7 & $2.27 e-5$ & 122 & 97 & 19.1 & 1.805 & entire group; \\
\hline 567069.6 & & ${ }^{2} \Pi_{3 / 2} 5.5(5.5)-4.5(4.5) \mathrm{e}$ & 231.7 & $2.63 e-5$ & & & & & blend $\mathrm{H}_{2} \mathrm{~S}$ \\
\hline 567073.4 & & ${ }^{2} \Pi_{3 / 2} 5.5(4.5)-4.5(3.5) \mathrm{e}$ & 231.7 & $1.82 \mathrm{e}-5$ & & & & & blend $\mathrm{H}_{2} \mathrm{~S}$ \\
\hline 567077.9 & & ${ }^{2} \Pi_{3 / 2} 5.5(6.5)-4.5(5.5) \mathrm{f}$ & 231.7 & $2.27 e-5$ & & & & & blend $\mathrm{H}_{2} \mathrm{~S}$ \\
\hline 567082.7 & & ${ }^{2} \Pi_{3 / 2} 5.5(5.5)-4.5(4.5) \mathrm{f}$ & 231.7 & $2.19 \mathrm{e}-5$ & & & & & blend $\mathrm{H}_{2} \mathrm{~S}$ \\
\hline 567086.6 & & ${ }^{2} \Pi_{3 / 2} 5.5(4.5)-4.5(3.5) f$ & 231.7 & $2.18 \mathrm{e}-5$ & & & & & blend $\mathrm{H}_{2} \mathrm{~S}$ \\
\hline Total No. & 12 & & & & & & & & \\
\hline
\end{tabular}

${ }^{a}$ Notation as in Table 9.

Table 27. HNC parameters ${ }^{a}$.

\begin{tabular}{|c|c|c|c|c|c|c|c|c|c|c|}
\hline $\begin{array}{l}v_{u l} \\
{[\mathrm{MHz}]}\end{array}$ & $\begin{array}{r}\Delta v_{\mathrm{p}} \\
{[\mathrm{MHz}]}\end{array}$ & $\begin{array}{r}\Delta v_{\mathrm{g}} \\
{[\mathrm{MHz}]}\end{array}$ & $\begin{array}{l}\text { Transition } \\
J\end{array}$ & $\begin{array}{r}E_{u} \\
{[\mathrm{~K}]}\end{array}$ & $\begin{array}{l}A_{u l} \\
{\left[\mathrm{~s}^{-1}\right]}\end{array}$ & $\begin{array}{r}T_{\mathrm{A}}^{*}(\text { peak }) \\
{[\mathrm{mK}]}\end{array}$ & $\begin{array}{l}\text { Ampl. } \\
{[\mathrm{mK}]}\end{array}$ & $\begin{array}{r}\text { Width } \\
{\left[\mathrm{km} \mathrm{s}^{-1}\right]}\end{array}$ & $\begin{array}{r}\left.\int \mathrm{K} \mathrm{km} \mathrm{s}^{-1}\right] \\
T^{*} \mathrm{~d} v\end{array}$ & Note \\
\hline 543897.6 & 1.6 & & $6-5$ & 91.4 & $8.04 \mathrm{e}-3$ & 913 & & & 10.70 & $\mathrm{v}$ blend U-line \\
\hline & & 1.6 & & & & & 600 & 3.8 & & ER; from 4G U-line \\
\hline & & -4.4 & & & & & 171 & 9.3 & & $\mathrm{HC}$; from 4G U-line \\
\hline & & -1.4 & & & & & 224 & 26.8 & & Plateau; from 4G U-line \\
\hline
\end{tabular}

${ }^{a}$ Notation as in Table 9.

Table 28. CN parameters ${ }^{a}$.

\begin{tabular}{|c|c|c|c|c|c|c|c|c|c|c|}
\hline $\begin{array}{l}v_{u l} \\
{[\mathrm{MHz}]}\end{array}$ & $\begin{array}{r}\Delta v_{\mathrm{p}} \\
{[\mathrm{MHz}]}\end{array}$ & $\begin{array}{r}\Delta v_{\mathrm{g}} \\
{[\mathrm{MHz}]}\end{array}$ & $\begin{array}{l}\text { Transition } \\
N(J, F)\end{array}$ & $\begin{array}{r}E_{u} \\
{[\mathrm{~K}]}\end{array}$ & $\begin{array}{l}A_{u l} \\
{\left[\mathrm{~s}^{-1}\right]}\end{array}$ & $\begin{array}{r}T_{\mathrm{A}}^{*}(\text { peak }) \\
{[\mathrm{mK}]}\end{array}$ & $\begin{array}{l}\text { Ampl. } \\
{[\mathrm{mK}]}\end{array}$ & $\begin{array}{r}\text { Width } \\
{\left[\mathrm{km} \mathrm{s}^{-1}\right]}\end{array}$ & $\begin{array}{r}\int T_{\mathrm{A}}^{*} \mathrm{~d} v \\
{\left[\mathrm{~K} \mathrm{~km} \mathrm{~s}^{-1}\right]}\end{array}$ & Note \\
\hline \multirow[t]{3}{*}{566729.9} & 1.9 & 0.9 & $5(4.5,5.5)-4(3.5,4.5)$ & 54.4 & $1.98 \mathrm{e}-3$ & 690 & & & 3.345 & entire group; \\
\hline & & & & & & & 570 & 3.5 & & 2G; PDR/ER \\
\hline & & & & & & & 122 & 10.0 & & 2G; HC \\
\hline 566730.7 & & & $5(4.5,3.5)-4(3.5,2.5)$ & 54.4 & $1.86 \mathrm{e}-3$ & & & & & blend $\mathrm{CN}$ \\
\hline 566730.8 & & & $5(4.5,4.5)-4(3.5,3.5)$ & 54.4 & $1.88 \mathrm{e}-3$ & & & & & blend $\mathrm{CN}$ \\
\hline \multirow[t]{3}{*}{566946.8} & 1.8 & & $5(5.5,5.5)-4(4.5,4.5)$ & 54.4 & $1.96 \mathrm{e}-3$ & 965 & & & 5.15 & $\begin{array}{r}\text { entire group; } \\
\text { blend CN }\end{array}$ \\
\hline & & 1.8 & $5(5.5,5.5)-4(4.5,4.5)$ & 54.4 & $1.96 \mathrm{e}-3$ & & 736 & 3.8 & & 3G CN; PDR/ER \\
\hline & & 0.8 & $5(5.5,5.5)-4(4.5,4.5)$ & 54.4 & $1.96 \mathrm{e}-3$ & & 214 & 10.8 & & v blends; HC \\
\hline 566946.9 & & & $5(5.5,6.5)-4(4.5,5.5)$ & 54.4 & $2.03 e-3$ & & & & & blend $\mathrm{CN}$ \\
\hline 566947.2 & & & $5(5.5,4.5)-4(4.5,3.5)$ & 54.4 & $1.95 \mathrm{e}-3$ & & & & & blend $\mathrm{CN}$ \\
\hline 566962.0 & 1.0 & 0.0 & $5(5.5,4.5)-4(4.5,4.5)$ & 54.4 & $8.00 \mathrm{e}-5$ & & 100 & 2 & & $\begin{array}{r}\text { entire group; } \\
3 \mathrm{G} \mathrm{CN}\end{array}$ \\
\hline 566963.7 & & & $5(5.5,5.5)-4(4.5,5.5)$ & 54.4 & $6.7 e-5$ & & & & & \\
\hline Total No. & 8 & & & & & & & & & \\
\hline
\end{tabular}

${ }^{a}$ Notation as in Table 9.

Table 29. $\mathrm{N}_{2} \mathrm{H}^{+}$parameters ${ }^{a}$.

\begin{tabular}{lrrlrlrrrr}
\hline \hline$v_{u l}$ & $\begin{array}{r}\Delta v_{\mathrm{p}} \\
{[\mathrm{MHz}]}\end{array}$ & $\begin{array}{r}\Delta v_{\mathrm{g}} \\
{[\mathrm{MHz}]}\end{array}$ & $\begin{array}{l}\text { Transition } \\
J\end{array}$ & $\begin{array}{r}E_{u} \\
{[\mathrm{~K}]}\end{array}$ & $\begin{array}{l}A_{u l} \\
{\left[\mathrm{~s}^{-1}\right]}\end{array}$ & $\begin{array}{r}T_{\mathrm{A}}^{*}(\text { peak }) \\
{[\mathrm{mK}]}\end{array}$ & $\begin{array}{r}\text { Ampl. } \\
{[\mathrm{mK}]}\end{array}$ & $\begin{array}{r}\text { Width } \\
{\left[\mathrm{km} \mathrm{s}^{-1}\right]}\end{array}$ & $\begin{array}{r}\int T_{\mathrm{A}}^{*} \mathrm{~d} v \\
{\left[\mathrm{~K} \mathrm{~km} \mathrm{~s}^{-1}\right]}\end{array}$ \\
\hline 558966.6 & 4.6 & 1.6 & $6-5$ & 93.9 & $1.08 \mathrm{e}-2$ & 315 & 300 & 4.8 & 1.46 \\
\hline Total No. & 1 & & & & & & & & \\
\hline
\end{tabular}

${ }^{a}$ Notation as in Table 9. 
C. M. Persson et al.: A spectral line survey of Orion KL in the bands 486-492 and 541-577 GHz with the Odin satellite. II., Online Material p 27

Table 30. $\mathrm{HCS}^{+}$parameters ${ }^{a}$.

\begin{tabular}{|c|c|c|c|c|c|c|c|c|c|c|}
\hline $\begin{array}{l}v_{u l} \\
{[\mathrm{MHz}]}\end{array}$ & $\begin{array}{r}\Delta v_{\mathrm{p}} \\
{[\mathrm{MHz}]}\end{array}$ & $\begin{array}{r}\Delta v_{\mathrm{g}} \\
{[\mathrm{MHz}]}\end{array}$ & $\begin{array}{l}\text { Transition } \\
J\end{array}$ & $\begin{array}{r}E_{u} \\
{[\mathrm{~K}]}\end{array}$ & $\begin{array}{l}A_{u l} \\
{\left[\mathrm{~s}^{-1}\right]}\end{array}$ & $\begin{array}{r}T_{\mathrm{A}}^{*}(\text { peak }) \\
{[\mathrm{mK}]}\end{array}$ & $\begin{array}{l}\text { Ampl. } \\
{[\mathrm{mK}]}\end{array}$ & $\begin{array}{r}\text { Width } \\
{\left[\mathrm{km} \mathrm{s}^{-1}\right]}\end{array}$ & $\begin{array}{r}\int T_{\mathrm{A}}^{*} \mathrm{~d} v \\
{\left[\mathrm{~K} \mathrm{~km} \mathrm{~s}^{-1}\right]}\end{array}$ & Note \\
\hline 554576.6 & & & $13-12$ & 186.3 & $3.66 \mathrm{e}-3$ & & 57 & 3.4 & & $\begin{array}{l}\mathrm{v} \text { blend }{ }^{33} \mathrm{SO} \\
2 \mathrm{G}^{33} \mathrm{SO}\end{array}$ \\
\hline
\end{tabular}

${ }^{a}$ Notation as in Table 9.

Table 31. NS parameters ${ }^{a}$.

\begin{tabular}{lrrlrlrrrrr}
\hline \hline$v_{u l}$ & $\Delta v_{\mathrm{p}}$ & $\Delta v_{\mathrm{g}}$ & Transition & $E_{u}$ & $A_{u l}$ & $T_{\mathrm{A}}^{*}($ peak) & Ampl. & Width & $\int T_{\mathrm{A}}^{*} \mathrm{~d} v$ & Note \\
{$[\mathrm{MHz}]$} & {$[\mathrm{MHz}]$} & {$[\mathrm{MHz}]$} & $J$ & {$[\mathrm{~K}]$} & {$\left[\mathrm{s}^{-1}\right]$} & {$[\mathrm{mK}]$} & {$\left[\mathrm{km} \mathrm{s}^{-1}\right]$} & {$\left[\mathrm{K} \mathrm{km} \mathrm{s}^{-1}\right]$} & \\
\hline 576720.2 & & & ${ }^{2} \Pi_{1 / 2} 12.5-11.5$ & 187.36 & & & & & & \\
\hline Total No. & 1 & & & & & & \\
\hline
\end{tabular}

${ }^{a}$ Notation as in Table 9.

Table 32. $\mathrm{CO}$ and $\mathrm{C}$ parameters ${ }^{a}$.

\begin{tabular}{|c|c|c|c|c|c|c|c|c|c|c|c|}
\hline Species & $\begin{array}{l}v_{u l} \\
{[\mathrm{MHz}]}\end{array}$ & $\begin{array}{r}\Delta v_{\mathrm{p}} \\
{[\mathrm{MHz}]}\end{array}$ & $\begin{array}{r}\Delta v_{\mathrm{g}} \\
{[\mathrm{MHz}]}\end{array}$ & $\begin{array}{l}\text { Transition } \\
J\end{array}$ & $\begin{array}{r}E_{u} \\
{[\mathrm{~K}]}\end{array}$ & $\begin{array}{l}A_{u l} \\
{\left[\mathrm{~s}^{-1}\right]}\end{array}$ & $\begin{array}{r}T_{\mathrm{A}}^{*}(\text { peak }) \\
{[\mathrm{mK}]}\end{array}$ & $\begin{array}{l}\text { Ampl. } \\
{[\mathrm{mK}]}\end{array}$ & $\begin{array}{r}\text { Width } \\
{\left[\mathrm{km} \mathrm{s}^{-1}\right]}\end{array}$ & $\begin{array}{r}\int \mathrm{K} \mathrm{km} \mathrm{s}_{\mathrm{A}}^{*} \mathrm{~d} v \\
\mathrm{~d} v\end{array}$ & Note \\
\hline $\mathrm{CO}$ & 576267.9 & -0.1 & & $5-4$ & 83.0 & $1.22 \mathrm{e}-5$ & 62200 & & & 785.50 & \\
\hline \multirow{4}{*}{${ }^{13} \mathrm{CO}$} & 550926.3 & 0.3 & & $5-4$ & 79.3 & $1.10 \mathrm{e}-5$ & 24300 & & & 174.30 & \\
\hline & & & 0.3 & & & & & 21600 & 4.8 & & $3 \mathrm{G} ; \mathrm{N}$ \\
\hline & & & -0.7 & & & & & 2180 & 18.0 & & 3G; LVF \\
\hline & & & -0.7 & & & & & 470 & 48.7 & & 3G;HVF \\
\hline \multirow[t]{3}{*}{$\mathrm{C}^{17} \mathrm{O}$} & 561712.8 & 1.8 & 1.8 & $5-4$ & 80.9 & $1.14 \mathrm{e}-5$ & 1169 & & & 6.03 & blend \\
\hline & & & 1.8 & & & & & 1070 & 4.2 & & $\begin{array}{l}{ }^{34} \mathrm{SO}, \mathrm{SO}_{2} \\
3 \mathrm{G} \cdot \mathrm{N}\end{array}$ \\
\hline & & & 3.8 & & & & & 116 & 18.0 & & 3G; LVF \\
\hline \multirow[t]{3}{*}{$\mathrm{C}^{18} \mathrm{O}$} & 548831.0 & 2.0 & & $5-4$ & 79.0 & $1.06 e-5$ & 4219 & & & 24.30 & \\
\hline & & & 1.0 & & & & & 3810 & 4.2 & & $3 \mathrm{G} ; \mathrm{N}$ \\
\hline & & & 0.0 & & & & & 367 & 18.0 & & 3G; LVF \\
\hline $\mathrm{C}$ & 492160.7 & & & $1-0$ & 23.6 & $7.99 \mathrm{e}-8$ & 7800 & 7794 & 4.5 & 38.7 & \\
\hline
\end{tabular}

${ }^{a}$ Notation as in Table 9.

Table 33. Water parameters ${ }^{a}$.

\begin{tabular}{|c|c|c|c|c|c|c|c|c|c|c|c|}
\hline Species & $\begin{array}{l}v_{u l} \\
{[\mathrm{MHz}]}\end{array}$ & $\begin{array}{r}\Delta v_{\mathrm{p}} \\
{[\mathrm{MHz}]}\end{array}$ & $\begin{array}{r}\Delta v_{\mathrm{g}} \\
{[\mathrm{MHz}]}\end{array}$ & $\begin{array}{l}\text { Transition } \\
J_{K_{a}, K_{c}}\end{array}$ & $\begin{array}{r}E_{u} \\
{[\mathrm{~K}]}\end{array}$ & $\begin{array}{l}A_{u l} \\
{\left[\mathrm{~s}^{-1}\right]}\end{array}$ & $\begin{array}{r}T_{\mathrm{A}}^{*}(\text { peak }) \\
{[\mathrm{mK}]}\end{array}$ & $\begin{array}{r}\text { Ampl. } \\
{[\mathrm{mK}]}\end{array}$ & $\begin{array}{r}\text { Width } \\
{\left[\mathrm{km} \mathrm{s}^{-1}\right]} \\
\end{array}$ & $\begin{array}{r}\int T_{\mathrm{A}}^{*} \mathrm{~d} v \\
{\left[\mathrm{~K} \mathrm{~km} \mathrm{~s}^{-1}\right]}\end{array}$ & Note \\
\hline$o-\mathrm{H}_{2} \mathrm{O}$ & 556936.0 & -7.0 & & $1_{1,0}-1_{0,1}$ & 61.0 & $3.46 \mathrm{e}-3$ & 7600 & & & 320.30 & \\
\hline$p-\mathrm{H}_{2} \mathrm{O}$ & 488491.1 & -0.9 & -5.9 & $6_{2,4}-7_{1,7}$ & 867.3 & $1.22 \mathrm{e}-5$ & 196 & 181 & 12.0 & 2.24 & \\
\hline \multirow[t]{4}{*}{$o-\mathrm{H}_{2}^{17} \mathrm{O}$} & 552021.0 & 2.0 & & $1_{1,0}-1_{0,1}$ & 60.7 & $3.37 \mathrm{e}-3$ & 464 & & & 9.44 & $\begin{array}{l}\text { blend } \mathrm{SO}_{2} \\
\& \mathrm{CH}_{3} \mathrm{OH}\end{array}$ \\
\hline & & & 4.0 & & & & & 76 & 5.0 & & $3 \mathrm{G} ; \mathrm{CR}$ \\
\hline & & & 1.0 & & & & & 214 & 18.0 & & 3G; LVF \\
\hline & & & 10.0 & & & & & 179 & 30.1 & & 3G; HVF \\
\hline \multirow{5}{*}{$o-\mathrm{H}_{2}^{18} \mathrm{O}$} & 489054.3 & -6.7 & -7.7 & $4_{2,3}-3_{3,0}$ & 429 & $8.84 \mathrm{e}-6$ & 83 & 58 & 5.7 & 0.33 & $?$ \\
\hline & 547676.4 & 3.4 & & $1_{1,0}-1_{0,1}$ & 60.5 & $3.29 \mathrm{e}-3$ & 715 & & & 15.90 & $\begin{array}{l}\text { blend }{ }^{34} \mathrm{SO}_{2} \\
\& \mathrm{CH}_{3} \mathrm{OH}\end{array}$ \\
\hline & & & 4.4 & & & & & 145 & 5.0 & & $3 \mathrm{G} ; \mathrm{CR}$ \\
\hline & & & 4.4 & & & & & 275 & 18.0 & & 3G; LVF \\
\hline & & & 11.4 & & & & & 298 & 33.4 & & 3G; HVF \\
\hline \multirow[t]{4}{*}{ HDO } & 490596.7 & -0.3 & & $2_{0,2}-1_{1,1}$ & 66.4 & $5.25 \mathrm{e}-4$ & 841 & & & 10.70 & \\
\hline & & & 0.7 & & & & & 459 & 4.6 & & 3G; CR \\
\hline & & & 6.7 & & & & & 273 & 18.0 & & 3G; LVF \\
\hline & & & -11.3 & & & & & 216 & 13.4 & & 3G; LVF \\
\hline
\end{tabular}

${ }^{a}$ Notation as in Table 9. 
C. M. Persson et al.: A spectral line survey of Orion KL in the bands 486-492 and 541-577 GHz with the Odin satellite. II., Online Material p 28

Table 34. U-line parameters ${ }^{a}$.

\begin{tabular}{|c|c|c|c|c|c|}
\hline $\begin{array}{l}v_{u l} \\
{[\mathrm{MHz}]}\end{array}$ & $\begin{array}{r}T_{\mathrm{A}}^{*}(\text { peak }) \\
{[\mathrm{mK}]}\end{array}$ & $\begin{array}{l}\text { Ampl. } \\
{[\mathrm{mK}]}\end{array}$ & $\begin{array}{r}\text { Width } \\
{\left[\mathrm{km} \mathrm{s}^{-1}\right]}\end{array}$ & $\begin{array}{r}\left.\int \mathrm{K} \mathrm{km} \mathrm{s}^{-1}\right] \\
T_{\mathrm{A}}^{*} \mathrm{~d} v\end{array}$ & Note \\
\hline 487209 & 91 & & & 0.673 & $\mathrm{SO}^{+} ?$ \\
\hline 488598 & 94 & 73 & 3.4 & 0.256 & $\mathrm{CH}_{3} \mathrm{OCHO}$ ? \\
\hline 488633 & 83 & 76 & 4.3 & 0.313 & $\mathrm{CH}_{3} \mathrm{CHO}$ ? \\
\hline 491496 & 104 & & & 1.438 & $\mathrm{CH}_{3} \mathrm{OCHO} ?$ \\
\hline 491892 & 157 & & & 0.64 & tripple peaked \\
\hline 541981 & 109 & 87 & 4.5 & 0.38 & $\mathrm{CH}_{3} \mathrm{OCHO} ?$ \\
\hline 542945 & 140 & 122 & 6.7 & 0.813 & \\
\hline 543873 & & 72 & 3.9 & & $\mathrm{v}$ blend $\mathrm{HNC}$; from $4 \mathrm{G} \mathrm{HNC}$ \\
\hline 546138 & 50 & & & 0.368 & ND? \\
\hline 549449 & & & & & blend with $\mathrm{H}_{2} \mathrm{CS}$ \\
\hline 552308 & 64 & 50 & 13 & 0.663 & \\
\hline 553667 & & 62 & 3.4 & & blend ${ }^{33} \mathrm{SO}, 3 \mathrm{G}$ fit with ${ }^{33} \mathrm{SO}, \mathrm{CH}_{3} \mathrm{OCHO}$ ? \\
\hline 553716 & & 80 & 2.4 & & blend ${ }^{33} \mathrm{SO}, 3 \mathrm{G}$ fit with ${ }^{33} \mathrm{SO}$ \\
\hline 559239 & & & & & $\mathrm{v}$ blend $\mathrm{SO} ; \mathrm{CH}_{3} \mathrm{OCHO}$ ? \\
\hline 559861 & & & & & $\mathrm{v}$ blend $\mathrm{SO}_{2}, \mathrm{CH}_{3} \mathrm{OCHO}$ ? \\
\hline 559913 & & & & & $\mathrm{v}$ blend $\mathrm{SO}_{2}$ \\
\hline 561971 & 57 & & & 0.187 & \\
\hline 562960 & 106 & 107 & 5.4 & 0.593 & \\
\hline 563033 & 94 & 79 & 5.1 & 0.395 & \\
\hline 564105 & 111 & 75 & 6.2 & 0.495 & \\
\hline 566066 & 117 & 108 & 2.7 & 0.306 & \\
\hline 567485 & 143 & 133 & 2 & 0.278 & \\
\hline 569138 & 148 & 135 & 3.1 & 0.41 & HNCO? \\
\hline 570303 & 68 & 85 & 2.6 & 0.158 & \\
\hline 572596 & 90 & 84 & 2.4 & 0.202 & \\
\hline 572678 & 95 & 74 & 3.1 & 0.268 & \\
\hline 574184 & 80 & 81 & 2 & 0.155 & \\
\hline 576446 & & & & & $\mathrm{v}$ blend $\mathrm{CO}$ wing \\
\hline Total No. & 28 & & & & \\
\hline
\end{tabular}

${ }^{a}$ Notation as in Table 9. 
C. M. Persson et al.: A spectral line survey of Orion KL in the bands 486-492 and 541-577 GHz with the Odin satellite. II., Online Materialp 29

Table 35. T-line parameters ${ }^{a}$.

\begin{tabular}{|c|c|c|c|c|c|}
\hline $\begin{array}{l}v_{u l} \\
{[\mathrm{MHz}]}\end{array}$ & $\begin{array}{r}T_{\mathrm{A}}^{*}(\text { peak }) \\
{[\mathrm{mK}]}\end{array}$ & $\begin{array}{l}\text { Ampl. } \\
{[\mathrm{mK}]}\end{array}$ & $\begin{array}{r}\text { Width } \\
{\left[\mathrm{km} \mathrm{s}^{-1}\right]}\end{array}$ & $\begin{array}{r}\int T_{\mathrm{A}}^{*} \mathrm{~d} v \\
{\left[\mathrm{~K} \mathrm{~km} \mathrm{~s}^{-1}\right]}\end{array}$ & Note \\
\hline 486845 & 80 & 83 & 3.3 & 0.275 & $\mathrm{SO}^{+} ?$ \\
\hline 487507 & 70 & 77 & 2.7 & 0.213 & $\mathrm{CH}_{3} \mathrm{CHO} ?$ \\
\hline 488477 & 49 & 47 & 3.2 & 0.147 & \\
\hline 489193 & 107 & 114 & 1.7 & 0.412 & \\
\hline 489709 & & & & & SiS?; v blend CS \\
\hline 541926 & 104 & 93 & 2.7 & 0.292 & \\
\hline 544016 & 51 & & & 0.396 & SiS? \\
\hline 546176 & 50 & & & 0.060 & ND? \\
\hline 546662 & 67 & & & 0.141 & \\
\hline 546805 & 79 & 68 & 2.3 & 0.213 & \\
\hline 547080 & & & & & $\mathrm{v}$ blend ${ }^{34} \mathrm{SO}$ \\
\hline 547162 & & & & & $\mathrm{v}$ blend ${ }^{34} \mathrm{SO}$ \\
\hline 547262 & 69 & & & 0.115 & HNCO? \\
\hline 549142 & 53 & & & 0.217 & HNCO? \\
\hline 549199 & 43 & & & 0.199 & $\mathrm{HNCO} ?$ or $\mathrm{H}_{2} \mathrm{CS} ?$ \\
\hline 549719 & 68 & 62 & 3.6 & 0.278 & $\mathrm{CH}_{3} \mathrm{OCHO}$ ? or $\mathrm{SO}_{2}$ ? \\
\hline 550132 & 64 & & & 0.375 & $\mathrm{SO}_{2} ?$ \\
\hline 552846 & 62 & & & 0.131 & \\
\hline 555312 & 52 & 46 & 2.5 & 0.117 & \\
\hline 555914 & 63 & & & 0.194 & \\
\hline 555933 & 49 & & & 0.124 & \\
\hline 556267 & 40 & & & 0.193 & \\
\hline 556633 & 52 & 51 & 1.9 & 0.1 & \\
\hline 559816 & 45 & & & 0.060 & weak, HDO? \\
\hline 560753 & 43 & & & 0.212 & \\
\hline 562118 & 70 & 60 & 3.6 & 0.219 & \\
\hline 563481 & 96 & & & 0.278 & weak, HNCO? \\
\hline 564418 & 61 & 36 & 9.3 & 0.336 & $\mathrm{SH}^{-} ?$ \\
\hline 570335 & 79 & 81 & 1.6 & 0.112 & \\
\hline 570790 & 76 & 69 & 2.1 & 0.141 & \\
\hline 570814 & 72 & 71 & 1.7 & 0.124 & \\
\hline 571151 & 49 & & & 0.138 & HNCO? \\
\hline 571217 & 59 & & & 0.168 & HNCO? \\
\hline 571477 & 58 & & & 0.118 & $\mathrm{H}_{2} \mathrm{C}^{18} \mathrm{O} ?$ \\
\hline 575397 & 69 & 62 & 1.8 & 0.104 & \\
\hline 577160 & 144 & 93 & 6.0 & 0.503 & \\
\hline Total No. & 36 & & & & \\
\hline
\end{tabular}

${ }^{a}$ Notation as in Table 9. 